Bente Jacobsen

\title{
PRAGMATIC MEANING
}

IN

\section{COURT INTERPRETING:}

An empirical study of additions in

consecutively interpreted

question-answer dialogues

PhD thesis

Submitted to the Faculty of Modern Languages

the Aarhus School of Business

August 2002 


\section{Acknowledgements}

I would like to thank everyone whose encouragement, inspiration and contributions made this thesis possible. In particular, I would like to thank my two doctoral supervisors, Associate Professor Anne Schjoldager of the Aarhus School of Business and Professor Ian Mason of Heriot-Watt University for all their valuable support, comments and advice. I would also like to thank Associate Professor Sandro Nielsen of the Aarhus School of Business for his many comments on Chapter 3. I also wish to express my sincere gratitude to the participants in the two trials who facilitated the recording of question-answer dialogues. I am especially indebted to the three court interpreters who generously allowed me to record and analyse their performance.

Aarhus, 14 August 2002.

Bente Jacobsen 



\section{Contents}

List of Figures and Tables

ix

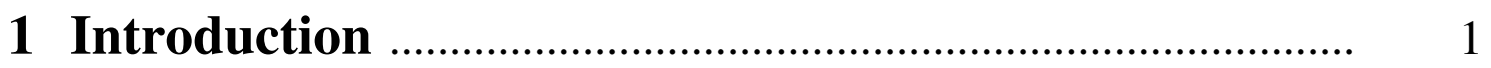

1.1 Defining court interpreting ................................................... 3

1.2 Hypotheses and research questions ......................................... 7

1.3 The investigation ............................................................. 9

1.4 Overview of chapters ........................................................ 10

2 Court interpreting research ................................................ 13

2.1 The state of the art of dialogue interpreting research .............. 13

2.1.1 'Translating machine' or active participant ................... 14

2.1.2 Participation framework .............................................. 15

2.1.3 'Ownership' of meaning ................................................. 16

2.1.4 The interpreter as a cross-cultural mediator .................. 17

2.1.5 The 'natural' interpreter............................................. 18

2.1.6 The negotiation of face ................................................. 19

2.1.7 Conclusion and discussion ........................................... 20

2.2 Court interpreting research .................................................... 21

2.2.1. Ruth Morris' study ....................................................... 22

2.2.2 Miriam Shlesinger's study .......................................... 25

2.2.3 Susan Berk-Seligson's study ........................................ 26

2.2.4 Peter Jansen's study .................................................... 29

2.2.5 Conclusion and discussion............................................. 31

2.3 Establishing the hypotheses ................................................. 33

3 Court interpreting in Denmark ...................................... 36

3.1 The background of the investigation in this thesis .................. 36

3.1.1 Principles of criminal justice ...................................... 38

3.1.2 General aspects of criminal proceedings ...................... 39

3.1.3 Trial procedure in the setting ......................................... 41

3.1.3.1 The participants and their role .......................... 42

3.1.3.2 The discourse ............................................... 44

3.1.3.3 Power relationship ........................................ 46

3.2 The interpreting situation ................................................... 49 
3.3 Legal provisions for the use of court interpreters ................... 52

3.4 The authorization process ............................................... 56

3.5 Official guidelines on the performance of court interpreters ... 58

3.5.1 The general scheme for the recruitment of interpreters and the administration of their services ........................ 59

3.5.2 Ethical guidelines ....................................................... 61

3.5.2.1 The principle of Accuracy and Completeness .. 64

3.6 Conclusion ................................................................... 65

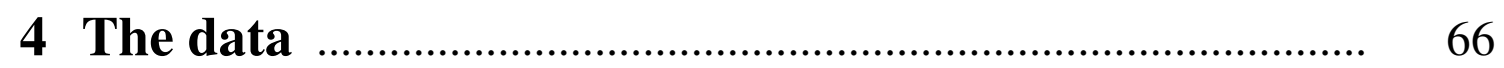

4.1 The mock trial .................................................................. 66

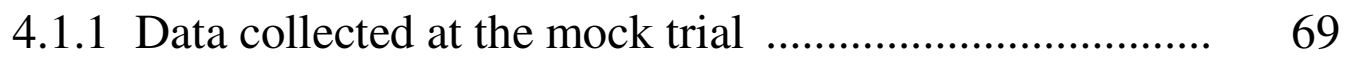

4.2 The authentic trial ......................................................... $\quad 70$

4.2.1 Data collected at the authentic trial ................................ 71

4.3 The data collection process ............................................... $\quad 72$

4.3.1 Practical issues .......................................................... 74

4.3.1.1 Deciding on the method of recording and acquiring the right recording equipment .......... $\quad 76$

4.3.1.2 Preparing a project description ......................... 77

4.3.1.3 Getting the co-operation of the legal system .... 78

4.3.1.4 Getting the co-operation of authorized court interpreters ................................................. 80

4.3.1.5 Getting the co-operation of prosecutors ........... 81

4.3.1.6 Getting the co-operation of defence counsels .. $\quad 83$

4.3.1.7 Getting the co-operation of defendants and witnesses (.............................................. 83

4.3.1.8 Locating suitable trials .................................... 83

4.3.1.9 Final comments ............................................. 83

4.4 The transcription process …............................................. 85

4.4.1 Transcription conventions ........................................... 86

4.4.1.1 Transcription symbols .................................... 86

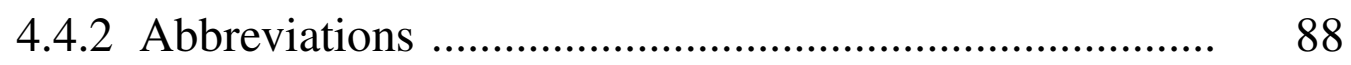

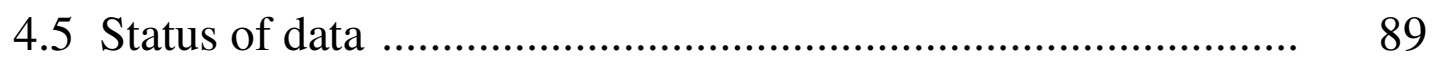

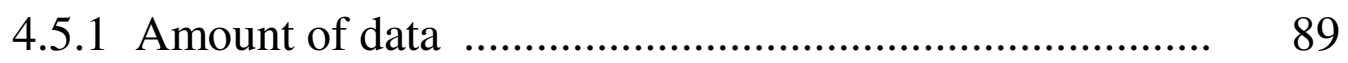

4.5.2 Lack of authenticity ..................................................... 90

4.5.3 Awareness of the recording process .............................. 91

4.6 Four kinds of interpreter behaviour ........................................ 93 
4.6.1 Change of footing ........................................................... 94

4.6.2 Completion of fragmented source texts ......................... 95

4.6.3 Correcting errors of grammar ...................................... 97

4.6.4 Engaging in dialogue with participants ………............. 97

4.7 Conclusion .................................................................. 99

5 Conversational implicature ........................................... 100

5.1 Defining pragmatics ........................................................ 100

5.2 The theory of conversational implicature .............................. 101

5.2.1 Semantic meaning and the theory of meaning-nn ......... 103

5.2.2 The Co-operative principle (CP) and the maxims ......... 105

5.2.3 Non-observance of the maxims ................................. 109

5.2.3.1 Flouting a maxim ........................................ 110

5.2.3.1.1 Flouting necessitated by a clash between maxims .............................. 111

5.2.3.1.2 Flouting the maxim of Quantity ....... 111

5.2.3.1.3 Flouting the maxim of Quality ......... 113

5.2.3.1.4 Flouting the maxim of Relation ....... 115

5.2.3.1.5 Flouting the maxim of Manner ........ 116

5.2.3.2 Other categories of non-observance ................ 118

5.2.3.2.1 Violating a maxim ........................... 118

5.2.3.2.2 Infringing a maxim ........................ 119

5.2.3.2.3 Opting out of observing a maxim .... 119

5.2.3.2.4 Suspending a maxim ....................... 120

5.2.4 Testing for implicature ............................................... 121

5.2.4.1 Defeasibility ................................................. 122

5.2.4.2 Non-detachability .......................................... 123

5.2.4.3 Non-conventionality ....................................... 124

5.2.4.4 Indeterminacy .............................................. 125

5.2.5 Problems associated with the theory of implicature ...... 125

5.2.5.1 Determining and distinguishing between types of non-observance ................................. 126

5.2.5.2 Distinguishing between implicatures .............. 127

5.2.5.3 Different and overlapping maxims ................. 128

5.2.5.4 Calculability ................................................... 128

5.2.5.5 Speaker motives …....................................... 128

5.3 Implicature in court interpreting ......................................... 129 
5.3.1 The role of the $\mathrm{CP}$ and the maxims .............................. 130

5.3.1.1 Defendants and non-observance ..................... 130

5.3.1.2 Witnesses and non-observance ...................... 132

5.3.2 Strategies for conveying implicature ............................ 134

5.3.2.1 Interpret the semantic content only ................. 135

5.3.2.2 Interpret part of the semantic content only ...... 136

5.3.2.3 Interpret the semantic content and explicate the implicature ............................................. 137

5.3.2.4 Interpret part of the semantic content and explicate the implicature ................................. 137

5.3.2.5 Interpret the semantic content and explicate part of the implicature .................................... 138

5.3.2.6 Interpret part of the semantic content and explicate part of the implicature ...................... 139

5.3.2.7 Explicate the implicature only ......................... 139

5.3.2.8 Explicate only one implicature ....................... 140

5.3.2.9 Conclusion and discussion .............................. 141

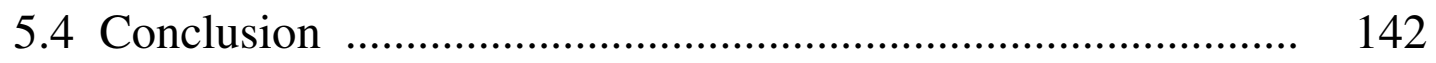

6 Addition categories ............................................................ 143

6.1 The methodology ............................................................... 143

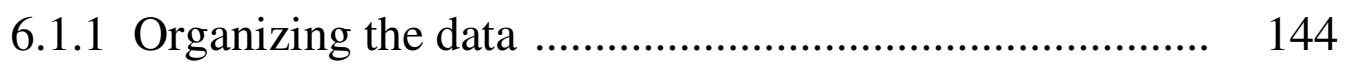

6.1.2 A formal translation ................................................. 145

6.1.2.1 Examples illustrating formal translations ........ 147

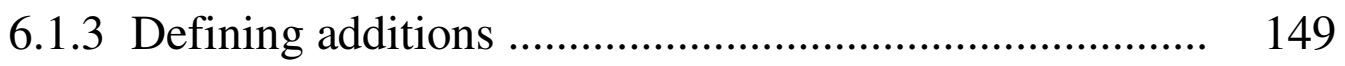

6.1.4 Given versus new information ................................... 154

6.2 Source-text/target-text comparison of the data from the

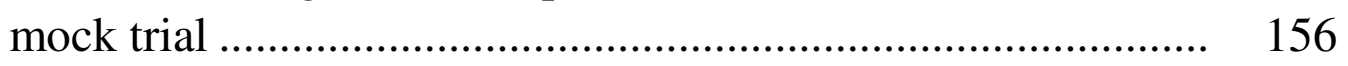

6.2.1 Additions with no impact on the semantic and/or pragmatic content of the source text ............................ 159

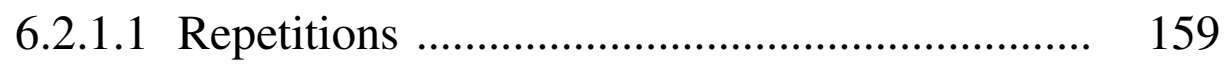

6.2.1.2 Silent pauses ................................................... 160

6.2.1.3 Voice-filled pauses ........................................... 161

6.2.1.4 False starts .................................................. 161

6.2.2 Additions with minimal impact on the semantic and/or pragmatic content of the source text .................. 162

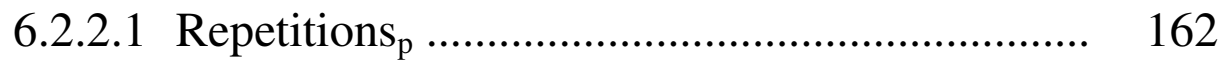




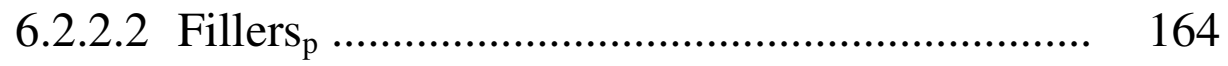

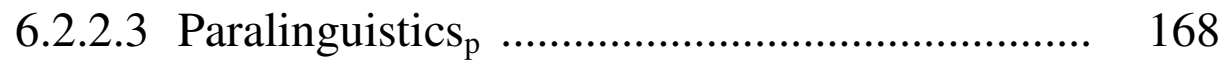

6.2.2.4 Explicating additions ................................... 170

6.2.2.4.1 Obvious-information additions ........ 171

6.2.2.4.2 Connective additions ....................... 179

6.2.2.4.3 Additions explicating non-verbal information .................................... 182

6.2.2.5 Elaborating additions .................................... 183

6.2.3 Additions with significant impact on the semantic and/or pragmatic content of the source text ................. 185

6.2.3.1 Emphasizing additions ................................... 186

6.2.3.2 Down-toning additions .................................. 189

6.2.3.3 New-information additions .............................. 191

6.3 Source-text/target-text comparison of the data from the authentic trial

6.3.1 Additions with no impact on the semantic and/or pragmatic content of the source text ............................. 196

6.3.1.1 Repetitions ...................................................... 196

6.3.1.2 Silent pauses .................................................. 196

6.3.1.3 Voice-filled pauses ........................................ 197

6.3.1.4 False starts ...................................................... 197

6.3.2 Additions with minimal impact on the semantic and/or pragmatic content of the source text ................. 197

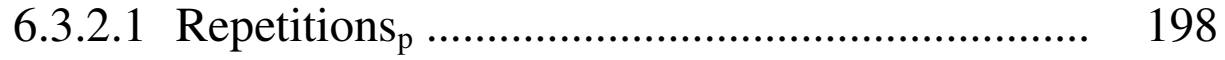

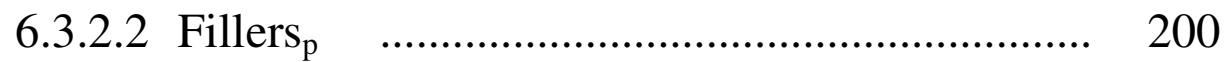

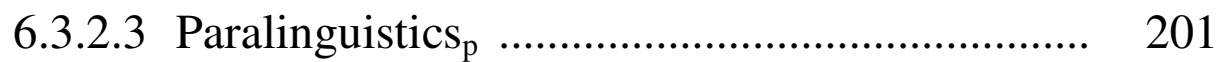

6.3.2.4 Explicating additions ..................................... 202

6.3.2.4.1 Obvious-information additions ........ 203

6.3.2.4.2 Connective additions ....................... 211

6.3.2.4.3 Additions explicating culturebound information .......................... 215

6.3.2.5 Elaborating additions .................................... 216

6.3.3 Additions with significant impact on the semantic and/or pragmatic content of the source text ................. 217

6.3.3.1 Emphasizing additions ................................... 217

6.3.3.2 Down-toning additions ................................... 220

6.3.3.3 New-information additions ............................ 222

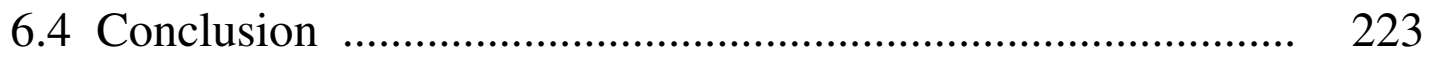


7 Interpreter motives

7.1 The caveat concerning access to the motivations of text producers

7.1.1 The inference process: interpreting the motivations of text producers

7.1.1.1 The theory of relevance

7.1.2 Implications for the court interpreter

7.2 Interpreter motives for including additions with minimal impact

7.2.1 Repetitions p $_{\mathrm{p}}$

236

7.2.2 Fillers $_{\mathrm{p}}$

7.2.3 Paralinguistics p $_{\mathrm{p}}$

7.2.4 Explicating additions

240

7.2.4.1 Obvious-information additions

7.2.4.1.1 Additions explicating textually evoked information

7.2.4.1.2 Additions explicating situationally evoked information

7.2.4.1.3 Additions explicating inferrable information

7.2.4.1.4 Additions taking up parts of questions

7.2.4.1.5 Additions expressing negation or confirmation

7.2.4.1.6 Additions completing fragmented source texts

7.2.4.2 Connective additions

7.2.4.3 Additions explicating non-verbal information . 260

7.2.4.4 Additions explicating culture-bound information

7.2.5 Elaborating additions

7.3 Interpreter motives for including additions with significant impact

7.3.1 Emphasizing additions

7.3.2 Down-toning additions

7.3.3 New-information additions 


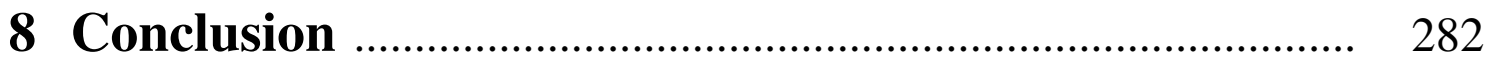

8.1 Research summary and discussion ..................................... 282

8.2 Research perspectives ...................................................... 287

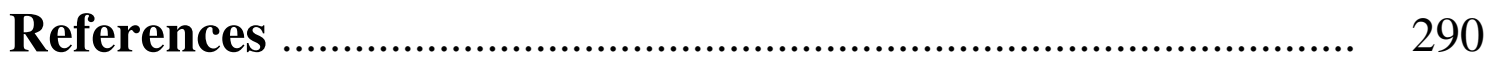

\section{Figures}

Figure 3.1: The seating of participants in a criminal trial in a Danish district court sitting with lay judges

Figure 3.2: Power relationship in a criminal trial in a Danish district court sitting with lay judges

\section{Tables}

Table 1.1: The essential features of dialogue interpreting and conference interpreting

Table 4.1: Transcription symbols

Table 4.2: Abbreviations in examples

Table 5.1: The role of the $\mathrm{CP}$ and the maxims in question-answer dialogues in criminal proceedings in a Danish district court

Table 6.1: Additions identified in the data from the mock trial 158

Table 6.2: Additions identified in the data from the authentic trial 


\section{Introduction}

This thesis investigates consecutively interpreted question-answer dialogues in a courtroom setting, an activity commonly referred to as court interpreting.

In Denmark, court interpreting has been undergoing a number of developments over the past 20 years. This is mainly due to the large influx of refugees during the 1980s and 1990s, which, together with the growth in the immigrant population, has brought focus on the need for properly trained interpreters, in the courtroom as well as in other settings, and also an awareness of the role of interpreters in different settings.

As a result of this awareness of interpreter roles, guidelines for interpreter behaviour were laid down for the first time in 1994. The guidelines, Instructions for Interpreters (cf. Chapter 3, Section 3.5.2), were laid down by the National Commissioner of the Danish Police (Rigspolitichefen) and are directed at police interpreters, but they are generally regarded as applying also to interpreters working in courts of law. The guidelines deal with four principles: Accuracy and Completeness, Impartiality, Confidentiality, Conflict of Interest. The last three of these principles refer to an interpreter's role, but the first principle, the principle of Accuracy and Completeness, refers to her linguistic performance and outlines a requirement for verbatim translations of source texts. In other words, the interpreter is perceived as a kind of 'translating machine', simply transferring language products from one language into another.

Various studies of court interpreting (e.g. Berk-Seligson 1988, 1990a, 1990b; Hale 1996, 1997a, 2001; Jacobsen 2000, 2001, 2002a, 2002b; Jansen 1995; Morris 1989a, 1989b, 1993a, 1993b, 1995; Shlesinger 1991) have demonstrated that this perception of the court interpreter is common in most legal systems (or among users of interpreting services in general), but that it often clashes with the reality of the interpreting situation in the courtroom (and in other settings, as shown by e.g. Roy 1993, 1996, 2000; Wadensjö 1992, 1995, 1997 1998;), in which meaning is subject to constant negotiation and verbatim translations may lead to misunderstandings. Morris (1995) observes that the conflict is illustrated by 
the terminology: legal systems prefer the term 'translation' to the term 'rendition’ or 'interpretation’. Morris (1995:26) observes:

"When it comes to court interpreting, then, the law distinguishes between the prescribed activity of what it calls translation defined as an objective, mechanistic, transparent process in which the interpreter acts as a mere conduit of words - and the proscribed activity of interpretation, which involves interpreters decoding and attempting to convey their understanding of speaker meanings and intentions".

The activity of interpretation, the law holds, is "desirable and acceptable for jurists, but utterly inappropriate and prohibited for court interpreters" (1995:26).

Mason (2000b:218) observes that this perception of the court interpreter as a 'translating machine', able to produce exact replicas of original utterances, may be explained by reference to the 'conduit metaphor'. It was Reddy (1979) who coined this term to describe commonly held assumptions about language communication, noting that when we talk about language we use metaphors which suggest that communication consists of transporting a definable entity from producer to receiver via a process of de-coding and re-encoding: 'get the message across', 'convey the content', 'bring out the truth', 'put the thought into words', etc. (Mason 2000b:218, cf. Green 1996:10). The conduit model of communication greatly influences the ordinary image of the interpreter, which explains why the layperson expects her to produce verbatim translations of original utterances (cf. Wadensjö 1998:7). As Mason (2000b:218) observes, users of interpreting services cannot be expected to be familiar with "recent trends in linguistics and language study", and thus they cannot be expected to be aware of the need, long recognized in linguistics, "for a pragmatic dimension to account for the relation between language, its context of use and the multiple meanings which can be exchanged beyond the literal, propositional sense of the words uttered".

The conflict between, on the one hand, the Danish legal system's perception, reflected in the guidelines, of the court interpreter as a mere translating device, and, on the other, the reality of the interpreting situation 
in the courtroom has been the point of departure for the investigation in this thesis. Before presenting the investigation in more detail, however, I shall attempt in Section 1.1 to clear up some confusion connected with the term court interpreting.

\subsection{Defining court interpreting}

The activity referred to here as court interpreting is sometimes referred to as legal interpreting, judiciary interpreting or forensic interpreting. However, judging from the literature, court interpreting is the most widely used term (e.g. Berk-Seligson 1988, 1990a, 1990b; de Jongh 1992; Hale 1997a, 1997b; Mikkelson 1998, 2000; Morris 1995; Roberts 1997). Strictly speaking, the term limits interpreting to a given setting, namely a court of law, but interpreting conducted in various other institutions associated with the judiciary, for example law offices, law enforcement agencies, and prisons, also tend to come under the heading of court interpreting (Mikkelson 2000:1).

Court interpreting is sometimes regarded as belonging within the broader concept of what is usually termed community interpreting (Roberts 1997). Sometimes, ad hoc interpreting, cultural interpreting, liaison interpreting, or public service interpreting, are used as synonymous terms for this activity (Roberts 1997:8), but, judging from the Critical Link conference series (Toronto 1995, Vancouver 1998, Montreal 2001, Stockholm 2004), community interpreting has now become the most widely accepted label (Carr et al. 1997; Roberts et al. 2000).

However, when giving an overview of the development of community interpreting since the 1960s, Pöchhacker (1999:127) observes that, more often than not, court interpreting "is viewed as a separate specialty", one that is distinct from the activity of community interpreting. According to Pöchhacker (1999:127), this may be explained by the great diversity of community interpreting which refers, in the most general sense, to interpreting in all kinds of institutional settings, involving all kinds of languages and cultural groups. Pöchhacker (1999:127) observes that this diversity "makes for the tremendous complexity of community interpreting as a concept and renders it very difficult to describe". Consequently, attempts at accounting for the actual practice are most often "specified for 
particular settings and their specific institutional (e.g. legal) constraints" (1999:127).

The term community interpreting may be used for making a situational distinction between community and conference interpreting, the latter referring to interpreting at conferences and in conference-like situations (cf. Mason 1999b:148). Within the boundaries of this distinction, various user variables may be involved, such as mode: typically simultaneous, in booths (conference) or typically consecutive dialogue (community), or power and distance: typically equal-to-equal relations (conference) or typically a power differential (community).

Likewise, the term may be used for making a professional distinction between community and conference interpreting (cf. Mason 2000b:216). This distinction, which reflects differences in interpreters' professional status, areas of specialization and conditions of work, is encountered more frequently than the situational distinction (cf. Mason 2000b:216).

Both distinctions, situational and professional, are perfectly adequate in many contexts. However, discussing methodological issues in dialogue interpreting research, Mason (2000b:216) convincingly argues that "from a research point of view", a more appropriate distinction is one which is "specific about the object of study and the way in which the latter influences the research agenda and the models and methods most appropriate to its investigation". The term "dialogue interpreting', Mason (2000b:216) argues, "seems most suited to what we see as an identifiable and distinctive field of study". The essential characteristic of dialogue interpreting is face-to-face interaction, and studies carried out since the late 1970s demonstrate that it is this single feature, face-to-face interaction, which determines most of the issues in dialogue interpreting research, e.g. turn management, role conflict, the negotiation of face, in-group loyalties (cf. Chapter 2, Section 2.1). These and other issues emerge in almost all dialogue interpreting encounters, e.g. courtroom proceedings, media interviews, medical consultations, social service interviews, business negotiations. Mason (2000b:218) argues, therefore, that the field of study is distinctive and "not co-terminous with what is generally referred to as community interpreting". 
Mason (2000b:218) acknowledges, however, that, though it is possible to recognize "a category of events which we may call dialogue interpreting", it is important not to ignore the diversity between different events within the field. For example, courtroom proceedings are obviously different from, say, business negotiations or social service encounters. Furthermore, Mason (2000b:218) observes that "the boundaries are fuzzy". For example, some dialogue interpreting is not dialogic, as e.g. courtroom proceedings may be interpreted in the simultaneous (whispered, or 'chuchotage') mode for the benefit of the defendant in a case (cf. Chapter 3, Section 3.2). Also, sign-language interpreting, for example, which shares all the interactional features of spoken language interpreting in dialogue interpreting encounters, is not quite a face-to-face event, because the face-to-face relationship is between receiver and producer of sign instead of between principal participants (cf. Mason 1999b:148). Finally, telephone interpreting shares some of the interactional features common to dialogue interpreting encounters, being an instance of dialogue, but not all (cf. Mason 1999b:148).

Nevertheless, despite this diversity, Mason (2000b:215) argues, dialogue interpreting may be regarded as constituting "an identifiable field of study within interpreting research", and there is thus "much to be gained by distinguishing it from conference interpreting". A look at the essential features, or characteristics, of dialogue and conference interpreting (cf. Mason 2000b:216), illustrated here in table 1.1, will explain the benefits of such a distinction: 
Table 1.1: The essential features of dialogue interpreting and conference interpreting

\begin{tabular}{|l|l|}
\hline Dialogue interpreting & Conference interpreting \\
\hline $\begin{array}{l}\text { Dialogue (typically, but not always, } \\
\text { two primary speakers) }\end{array}$ & Monologue \\
\hline $\begin{array}{l}\text { Spontaneous speech (some speech } \\
\text { may be pre-planned) }\end{array}$ & $\begin{array}{l}\text { Pre-planned speech (often scripted } \\
\text { source material) }\end{array}$ \\
\hline (Relatively) short turns & Sustained turns \\
\hline Bi-directional interpreting & Uni-directional interpreting \\
\hline
\end{tabular}

As Mason (2000b:216) points out, the different characteristics of dialogue and conference interpreting clearly invite different kinds of research. Whereas the characteristics of dialogue interpreting invite research of interaction (face-to-face, three-party), the characteristics of conference interpreting invite research of action (on the part of the interpreter). Consequently, the bulk of research in conference interpreting has focused on 'performance phenomena', i.e. issues such as interpreters' memory span, the time-lag (ear-voice span) between input and output, chunking (of input into manageable processing sequences) and anticipation (of immediately forthcoming input) (Mason 2000b:216).

Mason (2000b:216) observes that the simultaneous interpreting booth, standard equipment in conference interpreting, is "akin to a test tube". Researchers have thus been able to investigate the interpreter's performance in semi-isolation from interactional factors, which are not very prominent in this kind of activity. Dialogue interpreting studies, on the other hand, cannot afford to overlook the importance of these factors, since a dialogue interpreting event is essentially a three-party transaction (cf. Chapter 2, Section 2.1): the moves of one participant affect the other participants, and "progression towards a mutual goal (the accepted outcome of the event) is negotiated step-by-step by all three parties" (Mason 2000b:217). Thus, in dialogue interpreting, the object of study is interaction (face-to-face, three-party), and the issues that emerge (cf. above) are 
generally not observed in, or even considered as applying to, conference interpreting.

Following Mason (2000b) therefore, the activity investigated in this thesis is regarded as being included under the general heading of dialogue interpreting, i.e. interpreter-mediated communication in face-to-face interaction. In other words, the field of study is dialogue interpreting, the object of study is interaction, and the findings are considered relevant not only to dialogue interpreters working in courts of law, but also to dialogue interpreters working in other professional encounters. Nevertheless, throughout this thesis, I shall refer to the investigated interaction as court interpreting, and to the interpreters as court interpreters. Thus, considering that the investigation in this thesis so obviously centres on an area of common concern (pragmatics), rather than stress the diversity of dialogue interpreting events, there is no reason at this point to abandon a term which is so widely used and so easily recognized by interpreters, interpreter trainers and user of interpreting services alike.

\subsection{Hypotheses and research questions}

The present investigation is based on the following two hypotheses:

(1) The actual behaviour of court interpreters will show evidence of a preoccupation with pragmatics, that is, with building a mental model of speaker meaning and with conveying this mental model to end receivers.

(2) As a result of court interpreters' preoccupation with pragmatics, their target texts will contain a variety of additions.

In other words, I hypothesize that the primary objective of court interpreters is successful interaction; they are aware that in order for this objective to be reached, interactants will have to fully understand each other's intentions. The interpreters judge that, by providing merely literal (verbatim) translations of speakers' originals, they will not bring about such understanding, since end receivers who are unfamiliar with the 
context of the interaction (linguistic and/or situational) will not be able to fully infer speaker meaning. This judgment of end receivers' lesser inferencing ability is instinctive, because an interpreter will not wait for evidence before concluding that an end receiver will not be able to infer speaker meaning without assistance, and before acting on this conclusion.

Basically, the interpreters find that they need to compensate for the lesser inferencing ability of end receivers, and as a result they adopt a strategy for conveying source texts which will ensure that a speaker's intention, and not merely his words, is available, or more easily available, to end receivers. One consequence of such a strategy is that the interpreters' target texts will contain a variety of additions.

Evidently, by hypothesizing that court interpreters are preoccupied with pragmatics and therefore prepared to modify originals, by including additions in their target texts, I further hypothesize that the court interpreters in my investigation are prepared to violate the principle of Accuracy and Completeness which, as outlined above, require them to deliver absolute verbatim versions of originals. Thus, the two hypotheses dispute the view of the Danish legal system, as presented in the official guidelines, of the court interpreter as a mere translating device. However, throughout this thesis, I shall argue that this view is mistaken. I shall argue that, though a court interpreter may occasionally be able to function as instructed by the guidelines, she will often find herself in situations when she will not be able to. I shall also argue that the key element inherent in an interpreter's performance, that is, the very fact that she is present to ensure successful interaction, something which necessarily entails that the primary participants understand each other as if they spoke the same language, inevitably provides the interpreter with a much more active role than the one prescribed.

The two hypotheses were based partly on the findings of four contemporary studies in court interpreting (Morris 1989a; Berk-Seligson 1990b; Shlesinger 1991; Jansen 1995), conducted in courts outside Denmark, partly on my own experiences as a practising court interpreter, and partly on discussions with colleagues in the field. I shall explain this in more detail in Chapter 2 (Section 2.3). 
In order to test the two hypotheses, I shall attempt to answer the following four specific research questions:

(1) Will the target texts of the court interpreters in my investigation include a variety of additions?

(2) If so, can the additions identified in the court interpreters' target texts be categorized?

(3) If categories are established, will these then indicate the court interpreters' motives for including the identified additions in their target texts?

(4) If motives are indicated by the established addition categories, may these then be linked to a preoccupation with pragmatics on the part of the court interpreters?

\subsection{The investigation}

The setting of the present investigation is a criminal trial in a Danish district court, which is a court of first instance. The court interpreters are authorized $^{1}$ interpreters, i.e. fully qualified and competent professionals (cf. Chapter 3, Section 3.4). The languages spoken are Danish and English, and the mode of interpreting is the consecutive dialogue.

In order to address the four research questions, I recorded question-answer dialogues in two trials, a mock trial and an authentic trial, and transcribed them. I then conducted a source-text/target-text comparison of the collected data, which identified a number of additions in the court interpreters' target texts. I registered and categorized the identified additions according to their impact on the semantic and/or pragmatic content of the source text. Based on the established addition categories, I then discussed the interpreters' motives for including the additions in their target texts, arguing that their actual behaviour provided sufficient evidence to conclude that they were indeed preoccupied with pragmatics. The pragmatic theory of

1 The official title is state-authorized translator and interpreter, but I shall employ the shorter version throughout this thesis. 
conversational implicature proposed by H.P. Grice, which provides a framework for analysing the inferencing of speaker meaning, was applied in this latter process.

Of course, I shall not presume to claim that the findings reached in this thesis will provide conclusive evidence that all court interpreters are preoccupied with pragmatics all the time and thus always willing to include additions in their target text. However, as explained above (cf. Section 1.1), I believe that, by providing an insight into the work of some professional court interpreters, the findings will provide new insights into, and thus more understanding of, the work of court interpreters, as well as the work of interpreters in other dialogue interpreting events.

\subsection{Overview of chapters}

Apart from this introduction, the thesis contains Chapters 2 to 8, a list of figures and tables and a list of references.

Chapter 2 presents and discusses court interpreting research. I begin the chapter with a discussion of the state of the art of dialogue interpreting research, including court interpreting research. I then present and discuss in more detail the four studies whose findings helped establish the hypotheses presented in Section 1.2 above. Finally, I explain how the hypotheses were established.

Chapter 3 provides an overview of court interpreting in Denmark. In this chapter, I present and discuss the background of the investigation, including principles of criminal justice, general aspects of criminal proceedings and trial procedure in the setting. Next, I present and discuss the interpreting situation and the legal provisions for the use of court interpreters. Finally, I present the ethical guidelines stipulating the performance of court interpreters and discuss the principle of Accuracy and Completeness.

Chapter 4 presents and discusses the collected data. First, I present the two trials and the data collected at those trials. I then present and discuss the data collection process and the transcription process. Next, I present and 
discuss the status of the collected data. Finally, I present and discuss four examples of interpreter behaviour observed in the recorded material that I consider relevant for the present investigation.

Chapter 5 introduces and discusses H.P. Grice's theory of conversational implicature. Here I also set up a basic model accounting for conversational implicature in the kind of interaction investigated in this thesis, and I suggest eight strategies that court interpreters may resort to when confronted with implicature in the speech of an interactant.

Chapter 6 presents and discusses the various kinds of additions identified through a source-text/target-text comparison of the collected data. I also present and discuss the methodology adopted for this analysis. By categorizing the identified additions according to their impact on the semantic and/or pragmatic content of the source text, I was able to establish three main categories and a number of subcategories. I initially based the categories and subcategories on an analysis of the data from the mock trial and then tested them through an analysis of the data from the authentic trial.

Chapter 7 discusses the motives of the court interpreters for including the identified additions in their target texts. I begin the chapter with a discussion of the caveat concerning text receivers' access to the actual motivations of text producers and the implications of this for the court interpreter as a receiver of source texts and producer of target texts. Then I discuss interpreter motives. My discussion centres on the court interpreters' preoccupation with pragmatics and is based on conclusions reached by matching Grice's theory of conversational implicature and the assumptions presented and discussed in Chapter 5 to the various categories of additions established in Chapter 6. Finally, I return to the issue of strategies for conveying implicature and I discuss the strategies adopted by the court interpreters in this investigation for conveying implicatures to end receivers.

Chapter 8 sums up the investigation and discusses its findings. Here I revisit the conflict between the perception of the Danish legal system of the court interpreter as a kind of 'translating machine', reflected in the principle of Accuracy and Completeness, and the reality of the interpreting 
situation, reflected in the target texts of the court interpreters in this investigation. I discuss to what extent my findings support the hypotheses presented in Chapter 1 (Section 1.2). Finally, I discuss some research perspectives

A final point: The reader will have noted that I have referred to court interpreters as she throughout this chapter. In fact, throughout the thesis, I shall refer to interpreters as she, and to all other participants/speakers (with the exception of the witness and alleged victim of rape in the mock trial, cf. Chapter 4, Section 4.1) as he. This is strictly for clarification purposes. Thus, the assigned pronouns are not to be regarded as an expression of sexist attitudes, though, admittedly, the fact that I am myself a practising court interpreter, and female, may have had an impact. 


\section{Court interpreting research}

This chapter presents and discusses court interpreting research, and in particular the four studies whose findings helped establish the hypotheses in this thesis. I shall begin the chapter with a discussion in Section 2.1 of the state of the art of dialogue interpreting research, which includes studies of court interpreting. Then, in Section 2.2 I shall focus on court interpreting research and present and discuss the aforementioned four studies in more detail. Finally, in Section 2.3, I shall explain how the two hypotheses were established.

\subsection{The state of the art of dialogue interpreting research}

As explained in Chapter 1 (Section 1.1), dialogue interpreting may be regarded as constituting an identifiable and distinct field of study within interpreting research. All dialogue interpreting events are face-to-face and three-party transactions. Consequently, as Mason (2000b:215) observes, they share a number of contextual constraints, such as the immediacy of the face-to-face encounter and the often sensitive nature of the topics discussed, which "are bound to exert considerable influence on the unfolding of the exchange". Thus, the object of study in dialogue interpreting research is interaction (face-to-face, three-party), and prominent issues are role conflict, in-group loyalties, participation status, discourse, the negotiation of face, cross-cultural mediation, etc.

Dialogue interpreting is a relatively new field of study, compared to conference interpreting which has been the object of study in most interpreting research since it began back in the 1950s (cf. Pöchhacker 1995a, 1995b; Gile 2000). Yet, dialogue interpreting research has been conducted for at least 25 years. To the best of my knowledge, it began in 1976 when Lang (1976) observed interpreters at work in local courts in Papua New Guinea and published his findings. Lang's early work was followed in 1978 by a study of the behavioural aspects of an interpreter in a courtroom in Papua New Guinea (Lang 1978). Also in 1978, Harris \& Sherwood (1978) provided evidence of the behaviour of what they termed 'natural' interpreters, i.e. bilinguals with no interpreter training, who were (and still are) frequently called upon to act as interpreters in various events. 
In the introduction to the special issue of The Translator devoted to dialogue interpreting, Mason (1999b:147) points out that the issues referred to above as prominent issues in dialogue interpreting research were in fact already "implicitly or explicitly present in these early studies".

The number of dialogue interpreting studies carried out since 1976 has not been impressive (cf. Pöchhacker 1995b). Nevertheless, the studies have been increasingly significant and have provided useful insight into the work of dialogue interpreters. Some of the studies have already been referred to in Chapter 1 of this thesis, and others will be cited later. But it is of course impossible here to mention or give credit to all studies carried out since 1976. However, in the aforementioned introduction to the special issue of The Translator, Mason (1999b) presents an overview of major orientations in dialogue interpreting research to date, and he observes (1999b:149) that there is "a striking convergence between very different studies in terms of what they reveal about dialogue interpreting encounters". Describing this consensus, Mason (1999b:149) points to a number of recurring themes, and explains that these were "identified by various scholars in the context of different kinds of interpreted events".

Taking Mason's (1999b) observations as the point of departure, I shall here sum up the state of the art of dialogue interpreting research by outlining what seem to be six recurring themes and/or phenomena:

\subsection{1 'Translating machine' or active participant}

The first theme in dialogue interpreting research is the conflict referred to in the beginning of this chapter: the perception of the dialogue interpreter as a kind of 'translating machine' versus the reality of the interpreting situation. As mentioned in the beginning of Chapter 1, various studies have exploded the conduit myth by showing that a dialogue interpreter is not a neutral and uninvolved 'translating machine', but an active participant involved in the process of negotiating meaning. Of course, a court interpreter does not enjoy the latitude to participate actively in a talk exchange, hence the conflict referred to in Chapter 1. However, I shall return to this subject in more detail in Sections 2.2 and 2.3. 


\subsubsection{Participation framework}

The second major preoccupation of researchers in recent years is the participation framework (Goffman 1981) of dialogue interpreting encounters. According to Mason (1999b:151), Keith (1984) was the first study to apply Goffman's work to dialogue interpreting, and to use the concept of footing to characterize the principal participants' and the interpreter's relationship to each other (1984:313ff). However, Mason (1999b:151-152) observes that it is Wadensjö's (e.g. 1992, 1998) analysis of footing (referred to in more detail in Chapter 4 (Section 4.6.1) of this thesis) which has provided major insight into the role and status of the dialogue interpreter within a talk exchange. Briefly, footing is defined as the "alignment of an individual to a particular utterance, whether involving a production format, as in the case of a speaker, or solely a participation status, as in the case of a hearer" (Goffman 1981:227). In other words, participants adopt different, and shifting, roles and attitudes vis-à-vis each other and vis-à-vis utterances. Goffman (1981:128) explains that participants in a talk exchange constantly shift footing, and that shifts of footing are "a persistent feature of natural talk".

Applying Goffman's framework to her study of dialogue interpreting in health-care clinics and police stations in Sweden, Wadensjö (e.g. 1992, 1998) shows that shifts of footing (reflected in a shift of pronoun of address, cf. Chapter 4, Section 4.6.1) are commonplace in such events. She identifies (e.g. 1992:117-125) the various production roles and reception roles that participants can adopt, and shows how these fundamentally affect what is communicated and how it is communicated (cf. Roy 111-115). Wadensjö (e.g. 1992:127-134) demonstrates that, at various stages of the talk exchange, an interpreter may adopt all of the identified reception roles, not just as a result of free choice, but also as a reaction to the principal participants' assumptions about her appropriate role (cf. Chapter 4, Section 4.6.1). Thus, the dialogue interpreter plays an important role as a coordinator of others' talk by virtue of the footing she adopts. Indeed, Mason (1999b:153) observes, Wadensjö's major contribution to dialogue interpreting research has been her investigation of this role, which she sees as being "intimately interdependent" (Wadensjö 1998:145) with the role as a translator of others' talk. Wadensjö (1998:108-110) distinguishes 
between implicit coordination (interpreters are coordinating simply by talking every now and then) and explicit coordination (interpreters' utterances are visibly designed to do coordinating work). Explicitly coordinating utterances can be text orientated, i.e. more or less designed to bridge a linguistic gap (for example, requests for time to translate, or requests for clarification), or they can be interaction orientated, i.e. designed first and foremost to bridge a social gap by providing or sustaining the conditions for a shared communicative activity (for example, requests to observe the order of turn-taking, or requests for solicited but not yet provided information).

However, the dynamics of interpreter-mediated interaction are subject to negotiation not only by means of linguistic cues but also through the strong influence of paralinguistic features, e.g. laughter ${ }^{1}$ (Wadensjö 1992, 1998). By such means, primary participants "can signal inclusiveness or exclusiveness vis-à-vis the interpreter" (Mason 1999b:153). Thus, in his study of behavioural aspects in a Papua New Guinea court case, referred to above (cf. Section 2.1), Lang (1978) emphasizes the significance of features such as gestures, poses and gazes, and he concludes (1978:241) that the interpreter's behaviour depends "on the active co-operation of his clients and the extent to which they wish to include him as active participant".

Still, even when distance is created between primary participants and the interpreter, the dialogue interpreting encounter remains essentially a threeparty transaction, as emphasized earlier (cf. Chapter 1, Section 1.1 and Section 2.1 above).

\subsection{3 'Ownership' of meaning}

An interesting phenomenon relating from, or connected with, the issues referred to in Section 2.1.2 is the way in which an interpreter's lexical choice may have, as Mason (1999b:157-158) observes, "repercussions on later talk, and especially on the distribution of responsibility for use of the term to an interlocutor who has not, in fact, used it". Mason (1999b:153) refers to this phenomenon as 'ownership' of meaning. Wadensjö (1992:74)

1 I shall return to the issue of laughter in Chapters 6 and 7. 
cites an example from an interview in a health-care clinic where the interpreter's use of a particular term in her translation of the doctor's question to the patient was met with objection by the patient. Of course, the patient objected to the interpreter's lexical choice, and not to the doctor's, but the interpreter was still faced with the dilemma of having to relay the objection back to the doctor in a way which was coherent with the doctor's original utterance. Wadensjö (1972:75) argues that the interpreter's target text demonstrates her awareness of the problem, as well as her attempt at making explicit to the doctor the reason for the patient's disagreement.

In other cases, a lexical choice may have more far-reaching consequences. For example, in the special issue of The Translator, Kruglov (1999:295) demonstrates how a key phrase allegedly uttered by a Russian-speaking suspect in a murder investigation was interpreted into English in three different ways (I'll kill you/I'll get you/I'll stitch you up) by three different interpreters. Fortunately, this was indicated to the police investigators who thus avoided attributing to the suspect one particular lexical choice made by the interpreter.

\subsubsection{The interpreter as a cross-cultural mediator}

A fourth phenomenon investigated in dialogue interpreting research is the interpreter's role and status as a cross-cultural mediator. Thus, exploring the interpreter's role in face-to-face interaction as a bilingual and reporting on the consequences of one language being more dominant than the other, Anderson (1976:213) states:

"In general, it is expected that the greater the linguistic dominance the more likely an interpreter will identify with the speakers of the dominant language, rather than with clients speaking his "other" language".

In other words, Mason (1999b:154) observes, interpreters may be "sensitive to in-group loyalties towards relatively powerless participants whose language and culture they share". For example, Berk-Seligson (1990b:107ff) demonstrates in her study of court interpreting in the USA, 
referred to in Section 2.2 below, how a particular interpreter's sympathy towards illegal aliens may have influenced her target texts.

Similarly, Wande (1994:125) reports, when relating preliminary results from a research project involving Swedish-Finnish community interpreting in Sweden, that the Finnish clients expected the interpreters "to help and support them, to be on their side" in their communication with Swedish officials. However, Wande (1994) does not discuss to what extent, if any, this expectation influenced the interpreters in his research project.

In other situations, an interpreter may be perceived by the powerless parties to be an agent of those holding power. Thus, Barsky (1996:60) observes, reporting on the role of the dialogue interpreter in Convention refugee hearings in Canada, that an interpreter may be manipulated by authorities to help prove that refugees who come to a host country do so in a certain way, either in order to undermine or enhance their status as refugees, or in order for authorities to score a political point. Barsky (1996:58) further explains that most claimants at Convention refugee hearings "require some assistance in articulating their claim", finding themselves in a very 'foreign' environment, and that this assistance is "most likely to come from the interpreter, rather than the lawyer or adjudicator". Consequently, Barsky (1996:61) concludes, interpreters at these hearings should be allowed to function as "intercultural agents rather than translation devices", and they should be granted latitude to "fill in cultural gaps and compensate for tactical errors" so that "genuine stories of suffering and persecution" may be properly relayed.

Consequently, as demonstrated by these studies, dialogue interpreters may occasionally find themselves in situations in which it becomes very difficult to maintain impartiality and professional detachment.

\subsubsection{The 'natural' interpreter}

A fifth theme in dialogue interpreting research is the performance of what Harris \& Sherwood (1978) term the 'natural', i.e. untrained, interpreter. A number of studies have documented the consequences of relying on untrained bilinguals to act as interpreters (e.g. Knapp-Potthoff \& Knapp 
1987, Cambridge 1999; Pöchhacker \& Kadric 1999). However, as Mason (1999b:155) observes, investigating the spontaneous behaviour of bilinguals who have received no formal interpreter training and therefore have had no norms inculcated by training, may be the only way of understanding "the basic (cognitive and non-cognitive) mechanisms involved in the process of dialogue interpreting".

\subsubsection{The negotiation of face ${ }^{2}$.}

Finally, another recurring phenomenon in dialogue interpreting studies is the negotiation of face in relation to the variables of power and distance. Various studies (e.g. Morris 1989a; Berk-Selison 1990b; Tebble 1999; Mason \& Stewart 2001) have reported on these issues and have indicated that dialogue interpreters seem to be keenly aware of threats to face and therefore adopt politeness strategies, e.g. down-toning or hedging, aimed at protecting their own face, as well as the face of end receivers.

Mason (1999b:159) observes that, by virtue of being gate-keeper, i.e. controlling the attribution of turns, the dialogue interpreter controls a certain amount of power within the talk exchange. Besides, the fact that she is both bi-cultural and bilingual may provide her with "certain other forms of power" (Mason 1999b:159). However, the distribution of power within the talk exchange determines who gets to control the exchange, and "asymmetrical power relations may result in important information being skewed or overlooked" (Mason 1999b:159). For example, in medical consultations participants may tacitly acknowledge that the doctor, rather than the patient or any other participant, has the right to control the

2 Brown and Levinson (1987:61) define face as "the public self-image that every member wants to claim for himself", consisting in two related aspects: negative face and positive face. The authors (1987:61) define negative face as "the basic claim to territories, personal preserves, rights to non-distraction, i.e. to freedom of action and freedom from impositions", and positive face "the positive consistent self-image or 'personality' (crucially including the desire that this self-image may be appreciated and approved of) claimed by interactants". Face may be "lost, maintained or enhanced, and must be constantly attended to in interaction" (1987:61). Given the mutual vulnerability of face (everyone's face depends on everyone else's being maintained), participants will co-operate (and assume each other's cooperation) in maintaining face in interaction by seeking to avoid any face-threatening acts or by employing certain strategies to minimize threats to face (1987:61). 
exchange. However, when reporting on turn-taking in consecutively interpreted encounters between doctors and patients, Englund-Dimitrova (1997:152-153) cites an example of a doctor who, by claiming his turn before the interpreter had finished interpreting, potentially missed important information from the patient. Similarly, Roy (2000:92) reports how an interpreter who had to deal with overlapping talk during an interview between a professor and a student would interrupt the student but never the professor, apparently acknowledging that the status of professor granted the latter the right to control the exchange.

\subsubsection{Conclusion and discussion}

As Mason (1999b:159) rightly concludes in the introduction to the special issue of The Translator, the recurring themes outlined here above indicate that researchers are no longer concerned with conducting narrow sourcetext/target-text comparisons for the purpose of measuring e.g. interpreter error, correctness, or equivalence, but are moving "towards a more procedural account of dialogue interpreting". Mason (1999b:160) suggests therefore that descriptive studies of dialogue interpreting "have much to gain from linking observation of the interpreting process to pragmatic constraints such as power, distance and face-threat and to semiotic constraints such as genres and discourses". Recent studies (e.g. Mason 2001; Roy 2000) seem to indicate that researchers are indeed becoming more interested in these constraints, and thus more interested in the many issues shared by dialogue interpreting events. This is a welcome development; as Mason (2001:vi) points out, studies that explore shared issues, rather than focus on what is distinctive in a particular professional context, will contribute towards reinforcing the identity of this relatively new field of study within interpreting research (cf. Chapter 1, Section 1.1).

Having discussed the state of the art of dialogue interpreting research, including court interpreting research, I shall now focus, in Section 2.2, on court interpreting research alone. 


\subsection{Court interpreting research}

Most of the research conducted in dialogue interpreting since (and including) Lang's early work $(1976,1978)$ has focused on aspects of court interpreting (e.g. Bennett 1981; Berk-Seligson 1988, 1990a, 1990b; Brennan 1999; Colin \& Morris 1996; de Jongh 1991, 1992; Fenton 1997; Fowler 1997; Gonzales et al. 1991; Hale 1996, 1997a, 1997b, 1999, 2001; Harris 1981; Jacobsen 1998, 1999, 2000, 2001, 2002a, 2002b; Jansen 1995; Kadric 2000; Kelly 2000; Mason \& Stewart 2001; Mikkelson 1998, 2000; Morris 1989a, 1989b, 1993a, 1993b, 1995, 1999; Pym 1999; Shlesinger 1991).

However, studies of court interpreting are relatively few in Denmark, and the present investigation which centres on the interpreting process is the first of its kind. In fact, I personally know of only three previous studies of court interpreting in Denmark, and these have focused on different aspects: Madsen (1977) investigates the role of court interpreters in criminal cases, based on interviews with judges, prosecutors, defence counsels and stateauthorized interpreters; and Schweda Nicholson \& Martinsen (1997) and Bisgaard \& Martinsen (2000) discuss issues such as legal provisions for the use of court interpreters, the authorization process and the rights and obligations of court interpreters.

As mentioned earlier (cf. Chapter 1, Section 1.2), I shall here draw special attention to four studies of court interpreting in courts outside Denmark: Morris 1989a (Israel); Shlesinger 1991 (Israel); Berk-Seligson 1990b (USA); Jansen 1995 (Holland). Each of these studies demonstrate that, despite official requirements for verbatim translations, some court interpreters are prepared to exercise latitude and modify originals in order to convey their perception of speaker meaning, or in order to modify the impact of their renditions on end receivers. The four studies agree that the primary purpose of the interpreters' modifications was to achieve effective communication, but they differ as regards their view concerning the degree of latitude that court interpreters should be allowed to exercise. The four studies and their findings are presented and discussed in the listed order in Sections 2.2.1 to 2.2.5 below. 


\subsubsection{Ruth Morris' study}

In her MA thesis, "The Impact of Court Interpretation on Legal Proceedings" (1989a), Ruth Morris reports on a study of court interpreting at the war crimes trial of Ivan John Demjanjuk, which took place in Jerusalem, Israel in 1987-1988. The trial attracted a lot of attention and was transmitted via radio and television to listeners both inside and outside Israel. Six different languages were spoken at the trial, and the modes of interpreting were consecutive as well as simultaneous (in booth and whispered).

In her thesis, Morris (1989a:14) argues that court interpreters are far from being mere translators delivering verbatim versions of originals. Rather, in order to achieve effective communication, an interpreter may have to modify originals by applying a degree of latitude which has not been authorized by the court. Besides, Morris argues (1989a:25), language differences aside, an interpreter's rendition will be affected by "extrasemantic aspects such as speed, intonation and body language, as well as factors such as speaker/interpreter sex, age and education", all of which will serve to modify the impact of her rendition on the end receiver. For example, Morris' (1989a:33-35) study revealed that interpreters at the Demjanjuk trial tended to edit lawyers' questions (some of which tended to be extremely complex as regards syntax and vocabulary) in order to improve their intelligibility, though they generally refrained from editing the speech of testifying witnesses. Apparently the purpose of these modifications was to secure effective communication by conveying questions effectively to witnesses (1989a:33).

Morris (1989a:262ff) study also revealed that the renditions of the court interpreters at the Demjanjuk trial did indeed have an impact on the legal proceedings. She concludes (1989a:281ff), therefore, that the interpreters at the Demjanjuk trial were far from neutral elements, but rather mediators helping participants to communicate effectively. Actually, she argues (1989a:293), the mere fact that an interpreter's services are needed will affect proceedings in many ways. So, in order to ensure proper and efficient proceedings, courts should be willing to allow interpreters a certain amount of latitude to act as intercultural as well as interlingual 
mediators, "exercising some degree of authority where need be" (1989a:294).

Of particular relevance to the investigation in this thesis, Morris (1989a) devotes an entire chapter (Chapter 3 ) in her thesis to the examination of interpreter modifications. She identifies some of these modifications as additions and indicates various motives for their occurrence. These are:

(1) Additions completing fragmented originals. Morris argues that the overall purpose of these additions was to achieve effective communication, but she suggests (1989a:35) that the interpreters might also have been worried that listeners would assume fragmented renditions to be due to faulty interpreting.

(2) Additions explaining culture-bound references or technical terms. Morris (1989a:36) classifies such additions as belonging to a category of deliberate changes "designed to make communication more effective, and in particular to avoid confusion on the part of the listener".

(3) Additions providing renditions with a larger degree of explicitness, beyond what may be considered an inherent part of the translation process. Morris (1989a:56) explains that these were included for the purpose of conveying certain underlying messages or implications associated with originals, and in particular they were directed at listeners outside the courtroom, or even outside Israel. Examples include: (a) an addition which indicated the immediate addressee (the interpreter) as well as the ultimate recipient (the witness) of an utterance by the presiding judge (b) the addition of a lexical form used to render a non-lexical original, and (c) the addition of a specific word to convey a point implicit in the original (1989a:56-57). 
(4) An addition consisting of $\mathrm{atag}^{3}$, which was added to a declarative used as a question. According to Morris, this addition gave the question a more coercive form (1989a:73).

A point to be noted here is that example (4) was not found in the languages involved in the exchange, being Hebrew and Yiddish, but in the English version of the exchange ${ }^{4}$. As a result, Morris considers it "of informative value only" (1989a:73). Still, the addition is interesting, not least because of the added element of coercion. Morris lists no specific motive for its occurrence, however, except for a reference to language differences and the time constraints of simultaneous interpreting (1989a:74).

(5) Politeness markers. Morris (1989a:100) argues that the purpose of these additions was to modify originals so that they corresponded to what was perceived by the interpreters as a "culturally acceptable form in the target language" (i.e. as following conventions).

Apart from example (3) which occurred in the Hebrew (consecutive) rendition of an English original, all the listed additions occurred in English (simultaneous) renditions. All interpreting into English was conducted in the simultaneous mode, and the interpreters sat in interpreting booths, situated one floor above the court and overlooking proceedings, which meant that these interpreters were physically isolated from the participants (1989a:29). These variables, the modes of interpreting and the seating of the interpreters, may or may not have influenced interpreter performance, and ultimately the use of additions, but Morris does not refer specifically to the variables in connection with interpreter modifications.

3 Wales (1989:453) explains that tags (tag questions) in English are perceived by some as indicating a lack of confidence, at least those pronounced in a rising tone, because they invite hearer response (asking hearers to confirm the truth of the speaker's statement) (cf. note 5). However, a tag pronounced in a falling tone need not sound hesitant, but may serve instead to convey an impression of confidence, since it merely asks a hearer to confirm what the speaker already knows to be the truth. In other words, the speaker's utterance becomes more like a statement than a question (cf. Leech \& Svartvik 1994:127).

4 The entire proceedings were interpreted into English (Morris 1989a:28). 


\subsubsection{Miriam Shlesinger's study}

Miriam Shlesinger also investigated the Demjanjuk trial, and in her paper, "Interpreter Latitude vs. Due Process" (1991), she discusses the issue of interpreter latitude based on examples from the trial. Like Morris, Shlesinger argues (1991:153) that interpreters need to apply a degree of latitude in order to accommodate both their listeners and the courts, and that, without specific guidelines as to the leeway they have in performing their duties, they are left with "considerable discretionary power" to determine the degree of latitude which may be exercised in any given situation.

Shlesinger (1991:148) explains that, having followed the Demjanjuk trial and the interpreters' translations of proceedings into Hebrew and English, she especially wanted to analyse those situations which confronted them with the need to determine the degree of latitude to be exercised. She reports (1991:148-149) that these seemed to fall into three main categories: (1) the interpreter's discretionary accommodation of a direct addressee, that is, her discretionary introduction of explicitation whenever she anticipated that an end receiver would be unable "to contextualise and draw the correct inferences from the speakers' utterances" (1991:149); (2) the interpreter's discretionary introduction of stylistic shifts so as to avoid a rendering which would appear less than 'professional'; and (3) the interpreter's assertion of her own role as a persona in the proceedings, designed to register indignation, sympathy, etc.

Shlesinger (1991) reports on two specific occurrences of interpreter additions, both of which support the findings of Ruth Morris (cf. above):

(1) Additions explaining or clarifying culture-bound referents. Shlesinger (1991:149) explains that some interpreters would include these additions whenever they anticipated that "listeners' ignorance of culturebound referents would lead to breakdowns in communication". 
(2) Additions completing unfinished sentences. According to Shlesinger (1991:150), some interpreters were "loath to produce ungrammatical utterances" and "almost invariably 'grammaticized' them".

\subsubsection{Susan Berk-Seligson's study}

In "The Bilingual Courtroom. Court Interpreters in the Judicial Process" (1990b), Susan Berk-Seligson investigates court interpreting in the USA as a social and linguistic phenomenon. Her book reports on a study of interpreted proceedings in three tiers of US courts in 1982 and 1983. The languages involved were English and Spanish.

Like Ruth Morris (1989a) and Miriam Shlesinger (1991), Susan BerkSeligson (1990b) argues that court interpreters play a far more active verbal role than is allowed by the legal system. However, contrary to Morris and Shlesinger, Berk-Seligson does not discuss the need for interpreter 'latitude', but prefers to talk of 'intrusiveness' and an interpreter's 'intrusive behaviour'. In chapter 5 of her book she argues that this intrusiveness is manifested in several ways, even to the point of exercising control over proceedings. Two important examples are: (1) interpreters' interruption of lawyers for the purpose of clarifying questions or replies, which enables them to affect whatever power lawyers have over testifying witnesses or defendants (1990b:66ff); and (2) interpreters' prompting or silencing of witnesses during the course of their testimony, which enables them to control the flow of testimony (1990b:87ff).

Berk-Seligson (1990:119ff) further argues that court interpreters exert additional influence on the speech of participants through various kinds of pragmatic alterations, from the manipulation of grammatical case to the shifting of speech styles. In her study, she demonstrates (1990b:119) that, in particular, interpreters tend to lengthen witness testimonies interpreted into English, "and that in the process, they convert "fragmented" speech style into a more narrative testimony style". In other words, she argues 
(1990b:119), the lengthening is accomplished by introducing "elements that are characteristic of "powerless" testimony style".

Berk-Seligson (1990b:122) lists various processes by which the interpreters in her study accomplished the lengthening of source texts, focusing mainly on the effect of the processes, rather than on the motives for using them (1990b:131ff). Some of her conclusions regarding the effect (and the motives) are rather thinly based, but the lengthening processes are fully documented through examples from her data. These are:

(1) The adding of hedges. Berk-Seligson (1990b:131) argues that, since hedges are among the constellation of features that constitute 'powerless' testimony style (cf. note 5), their inclusion had the effect of making witnesses' testimonies sound weaker than originals, that is, witnesses sounded less sure and less definite, and appeared "less strongly committed to affirmation". Berk-Seligson (1990b:132) further argues that the inclusion of hedges makes a witness sound less competent, since he appears unable to understand questions.

(2) The adding of linguistic material perceived to be underlying or 'understood' in the original, but not explicitly stated. According to Berk-Seligson (1990b: 133-134), the effect of this lengthening process was to add substance to replies by making them sound more emphatic and definitive than did originals.

5 Looking at witness testimony, O'Barr and associates (e.g. Erickson et al 1978, Lind et al. 1978, O'Barr 1982) found that a constellation of speech traits previously thought to be characteristic of women's style alone could be found in the speech of male and female witnesses alike, and that the presence of these traits made witnesses sound less convincing, less truthful, less competent, less intelligent and less trustworthy. O'Barr and associates have named the speech style comprising these traits 'powerless' style. The traits are: hedges, intensifiers, superpolite forms, tag questions, empty adjectives, hypercorrect grammar and pronunciation, lack of a sense of humour, direct quotations, special lexicon and question intonation in declarative contexts (cf. Berk-Seligson 1990b:20-21). 
(3) The use of non-contracted forms when contraction would be the norm. Berk-Seligson (1990b:135) explains that this lengthening process would often coincide "with the insertion of linguistic material that is normally deleted in the surface syntax", and she argues (1990b:135) that the effect was to convey an impression of hyperformality.

(4) The rephrasing and repetition of interpreters' own renditions. Berk-Seligson (1990b:136) explains that rephrasing regularly occurred in order to accomplish greater precision and accuracy in renditions, and often in situations that gave rise to syntactic problems. Thus, she argues (1990b:136) that rephrasings was a conscious activity, whereas repetitions was often unconscious and appeared to be a kind of cognitive mechanism, the purpose of which was to gain the interpreter time to process the rest of the utterance. However, Berk-Seligson (1990b:136) further argues that repetitions may be associated with a lack of persuasiveness.

(5) The adding of polite forms. These were mostly added when defendants replied to questions from judges. Berk-Seligson (1990b:140) argues that the effect of polite forms was to make a defendant appear more deferential and polite before an examining judge, and she suggests (1990b:140) that they were included whenever interpreters themselves felt a need for politeness before a judge.

(6) The adding of particles and hesitation forms. As regards hesitation forms, Berk-Seligson (1990b:140) notes that these are often ignored by interpreters when they occur in originals, but that they are often inserted in renditions, and she concludes (1990b:140) that the forms are unconsciously introduced, being "a side effect of the great mental concentration and strain that 
interpreters experience, when they are in the process of interpreting". Nevertheless, she argues (1990b:141), hesitation forms have the effect of making a response appear hesitant and less confident-sounding.

As regards particles, on the other hand, Berk-Seligson (1990b:140) argues that "meaningless particles such as "well", and expressions such as "you know", can be considered hedges that serve a politeness function in discourse". Thus, she suggests (1990:142) that these hedges made a response "more colloquial-sounding", and perhaps more natural from the interpreter's point of view, and that they gave the response "a more logical connectedness to what the witness has just said in an immediately prior utterance".

Having discussed how court interpreters may exert additional influence on the speech of participants, Berk-Seligson (1990b:146ff) then reports on a set of experimental studies, which involved different categories of mock jurors, and which she conducted for the purpose of testing the impact of court interpreters on mock jurors' evaluation of witnesses and attorneys. The studies demonstrate that an interpreter's performance has a great impact on the kind of impressions that mock jurors form of both witnesses and lawyers, and Berk-Seligson (1990b:197) concludes:

"The implications of this is that interpreters and court administrators alike need to be made aware of the power that resides in the interpreter's role, and that interpreter training programmes should look to linguistics in general, and to the field of pragmatics in particular, to sensitize persons entering this profession as to the multiple ways in which they can affect a jury".

\subsubsection{Peter Jansen's study}

Peter Jansen's paper, "The Role of the Interpreter in Dutch Courtroom Interaction: the Impact of the Situation on Translational Norms" (1995), 
reports on a study of court interpreting in two criminal cases in a Dutch courtroom, the aim of which was to establish the kind of norms that govern an interpreter's choice of translation strategies. The languages involved were Dutch and Spanish, and the interpreting modes were consecutive and simultaneous (whispered). The same interpreter assisted at both trials.

Jansen (1995:149) acknowledges that his study does not in any way provide a complete picture of court interpreting in Dutch courts, dealing as it did with only two trials and the performance of only one interpreter (apart from one instance when he was able to observe the non-verbal behaviour of a second interpreter). Nevertheless, his findings support those of Morris (1989a), Shlesinger (1991) and Berk-Seligson (1990b) by pointing to the interpreter as being far from neutral. For example, Jansen (1995:150) reports that the interpreter in his study was quite prepared to adapt her renditions to the situation and the addressees, especially accommodating some of the defendant's needs "by simplifying complicated sentences and adapting or explaining technical terms". He also notes (1995:151) that she systematically marked her renditions as intermediary steps in the communication process, different from the discourse of the participants, through "prosodic, lexical and grammatical means, and sometimes narrative forms that differed from the respective originals".

Of particular relevance is Jansen's (1995:144ff) description of various kinds of interpreter modifications, though he only specifically refers to one interpreter modification as an addition (1995:148): At one point, the interpreter constructed a complete dialogue based on the defendant's fragmented original, rigorously patching up the logic of his story. Jansen (1995:149) argues that the addition may have been due to the interpreter's fear of losing information. Besides this specific example, Jansen (1995:145) also mentions modifications which explain technical terms, clear up ambiguities, or make presuppositions explicit. Presumably such modifications may be categorized as additions of one kind or another. 


\subsubsection{Conclusion and discussion}

First and foremost, the following, obvious conclusion may be reached by examining the findings from the above four studies:

- The primary concern of the court interpreters was the achievement of successful interaction, and this concern overrode the expectations of the courts in question that renditions be verbatim.

Consequently, to avoid breakdowns in communication, the court interpreters in the four studies were prepared to (1) simplify complex language and explain technical terms in order to compensate for differences in discourse level, (2) explicate culture-bound referents, (3) express implicit information explicitly, and (4) rephrase or repeat own renditions.

Three of the four studies (Morris 1989a; Shlesinger 1991; Jansen 1995) suggest that the interpreters' actions may be attributed to their perception of role: they regarded themselves as both interlingual and intercultural mediators, responsible for the success of the interaction. Apparently, the interpreters felt that, in order to achieve successful interaction, they had to be willing to render not merely a speaker's words, but also what they perceived as his intention.

A further concern of the court interpreters in the four studies appears to be one of face (cf. Section 2.1.6 above), their own as well as the face of end receivers. Thus, in order to maintain face, the interpreters adopted strategies that served to down-tone the effect of originals, such as the addition of politeness markers and hedges, and the changing of discourse from fragmented to narrative style. The latter strategy not only modified the impact of originals on end receivers, but also avoided blame being put on interpreters for delivering less than perfect renditions (Morris 1989a; Shlesinger 1991; Berk-Seligson 1990b).

In many settings, interpreters who adopt strategies intended to achieve successful interaction and maintain face in a stressful and sensitive situation will be regarded as simply 'doing their job'. But, as stated earlier 
(cf. Section 2.1.1 above), other rules apply in a courtroom setting. As explained in the beginning of Chapter 1, from the perspective of legal systems, lawyers may 'interpret' (the law as well as speakers' intentions), and interpreters may 'translate' (transform an utterance in one language into an exact replica in another language).

Of course, allowing the court interpreter to use her discretion and act as a mediator, with latitude to depart from verbatim standards in order to convey what she perceives to be a speaker's intended meaning, rather than merely his words, would mean accepting that she plays a much more active role in the communication process than the one initially prescribed, i.e. that of an invisible translating device. But the pretence of the court interpreter's invisibility cannot be sustained anyway, since the four studies documented multiple examples of how attention was inevitably drawn to her presence. These include:

- the presiding judge requesting that witnesses and lawyers adapt their behaviour to the requirements of the interpreting process (Morris 1989a:179),

- bilingual participants monitoring the interpreters' renditions and challenging their correctness (Morris 1989a:180; Berk-Seligson 1990b:55), and

- lawyers and witnesses addressing the interpreter directly, forgetting that she is not a part in the proceedings (Berk-Seligson 1990b:61 and 151).

Moreover, Berk-Seligson (1990b) and Jansen (1995) both cite examples of interpreters being asked to conduct activities officially restricted to lawyers and judges. Thus, Berk-Seligson (1990b:64) demonstrates that judges in lower courts sometimes rely heavily on interpreters to process cases, for example during the course of traffic arraignments (a proceeding that may result in sentencing), and she includes (1990b:64) an example in which the judge asks the interpreter for her opinion as to whether the defendant had understood the charges. Berk-Seligson (1990b:64) explains that such breaches of procedure are a result of the absence of defence counsels at various sorts of lower court proceedings. Similarly, Jansen (1995:143) 
presents an equally striking piece of information: as a matter of routine, the judge instructed the interpreter at the beginning of the trial to ask the defendant for his personal data, a procedure which entails having to formulate a number of questions. These two examples, which demonstrate how judges deliberately infringe the rules of interpreter neutrality, are not only extremely surprising, considering the formality of the setting, but they may also have serious implications for the interpreting process. First of all, a defendant with some command of the official language of the court may realize what has occurred, and as a result lose faith in the interpreter as a neutral mediator. Secondly, such transfer of a degree of authority over proceedings to the interpreter is in itself likely to cause considerable confusion about her role as a neutral part in the proceedings, and consequently it may have an impact on the way she chooses to conduct herself during the remaining part of a trial.

In conclusion, therefore, the four studies presented many interesting and relevant findings, besides demonstrating the presence of additions in the court interpreters' target texts. However, as regards additions, the studies did not determine why, or in which situations, court interpreters are prepared to include this kind of modification, though they did provide three significant clues: (1) The interpreters were primarily concerned with securing effective communication, and they sought to eliminate any threat of communication breakdown by modifying their renditions; (2) the interpreters regarded themselves as both interlingual and intercultural mediators; and (3) the interpreters were prepared to render not only a speaker's words but also his intentions. Based on these clues, I submit that the interpreters in the four studies demonstrated what appears to be a preoccupation with pragmatics, i.e. with building and conveying a mental model of speaker meaning to end receivers.

\subsection{Establishing the hypotheses}

As explained earlier (Chapter 1, Section 1.2), the intriguing evidence of the behaviour of court interpreters which was presented by the findings from the four studies in Sections 2.2.1 to 2.2.4 helped establish the two hypotheses on which this investigation is based. Of course, the court interpreters in the above four studies performed in legal systems in Israel, 
the USA and the Netherlands which are different from those of other nations, and which have their own legislation and/or ethical guidelines on interpreter behaviour in a court of law. However, at least two of the three legal systems, the Israeli and the American, like the Danish legal system, require court interpreters to deliver absolute verbatim versions of originals. Apparently, the Dutch legal system had not laid down any specific requirements when Jansen (1995) wrote his paper, but the Dutch Translators' Association had formulated a professional code and a code of honour for court interpreters which required them to limit themselves "to reproducing the meaning of what is being said" $(1995: 140)^{6}$. The interpreters in the four studies were all familiar with the ethical rules, and still some of them chose not to comply with them, in specific situations and for a variety of reasons. I have not found any evidence that such noncompliance may occur only in courts in Israel, the USA or the Netherlands, nor do I see any reason to assume that this will be the case.

My own experiences as a practising court interpreter also played a part in establishing the hypotheses, as did discussions with some colleagues in the field. These discussions revealed a general consensus that verbatim renditions were not always possible, and that additions would have to be included in certain situations: at the very least it would be necessary now and then to explicate culture-bound references, and perhaps also to explain complex legal terminology, especially to defendants or witnesses who did not speak English (or French, or German, etc.) as their mother tongue (cf. Chapter 3, Section 3.1). However, as a result of the particular nature of interpreter performance - high velocity and deep concentration - and because interpreter renditions in a Danish court of law are not recorded in a way which makes for comparison between source texts and target texts (cf. Chapter 3, Section 3.2), we were not able to prove or disprove the supposition that additions might be included, nor were we able to come up with any specific examples of interpreter additions. Besides, as mentioned earlier (cf. Section 2.2 above), there is no previous study of the interpreting process in Danish courts.

6 Dutch court interpreters now sign a professional code which requires them to limit themselves to translating what is being said, and to inform the court if they are unable to deliver a literal (verbatim) version of an original (personal communication with a Dutch court interpreter, October 2001). 
Admittedly, the issue of additions was not at any time discussed with what may be considered a representative number of Danish court interpreters. Still, I am rather intrigued by the fact that, despite their training and their knowledge of the official guidelines, and thus of the expectations of the courts, not one of the interpreters with whom I initially discussed the subject of verbatim versions and additions outright rejected the supposition that additions might be present in her rendition, nor did anyone speak of additions as constituting unprofessional (unethical) performance. (Of course, once the investigation was underway, the focus of it was discussed with very few interpreting colleagues in order to preserve the objectivity of the investigation: The court interpreting community in Denmark is comprised of relatively few members, and consequently most interpreter colleagues were regarded as either potential informants or people who might be talking to potential informants.)

Having now presented and discussed court interpreting research and the background of the hypotheses on which this investigation is based, I shall discuss in the next chapter, Chapter 3, court interpreting in Denmark, including the interpreting situation, legal provisions for the use of court interpreters and the ethical guidelines on interpreter performance. 


\section{Court interpreting in Denmark}

This chapter provides an overview of court interpreting in Denmark. In Section 3.1, I shall present and discuss the background of the investigation in this thesis. In Section 3.2 I shall present and discuss the interpreting situation. In Section 3.3, I shall present and discuss the legal provisions for the use of court interpreters, and, in Section 3.4, I shall present the authorization process. Then, in Section 3.5, I shall present the only official guidelines stipulating the performance of court interpreters and discuss the principle of Accuracy and Completeness that requires them to deliver verbatim versions of source texts. Finally, in Section 3.6, I shall conclude on the discussions in Chapter 3.

\subsection{The background of the investigation in this thesis}

Court interpreters are hired for both criminal and civil proceedings in courts of law. In Denmark, the ordinary courts of law are the Supreme Court (Højesteret), the two high courts, the Eastern High Court ( $\emptyset_{\text {stre }}$ Landsret) and the Western High Court (Vestre Landsret), the 82 district courts (byretter) and the Maritime and Commercial Court ( $S \phi$ - og Handelsretten). The administration of justice in these courts, both civil and criminal justice, is governed by the Danish Administration of Justice Act (Retsplejeloven).

The Danish judicial system is essentially three-tiered. The Supreme Court stands at the apex of the system and is the final court of appeal in civil and criminal matters ${ }^{1}$. The high courts hear civil cases not assigned to the district courts and they try the more serious indictable offences requiring the presence of a jury. The high courts are also courts of appeal for the hearings and decisions of the district courts ${ }^{2}$. The district courts hear civil and criminal cases and perform certain administrative functions, for example the registration of property in the land charges register and

1 Sections 2 and 2a(2), and Parts 36, 37, 82, 84 and 85 of the Danish Administration of Justice Act.

2 Sections 4(1) and 5 and Parts 36, 37, 83 and 85 of the Danish Administration of Justice Act. 
notarial functions ${ }^{3}$. The Maritime and Commercial Court hears civil and criminal cases which require expert knowledge of maritime and/or commercial issues, but which would otherwise have been heard by a high court or a district court ${ }^{4}$. Appeals against the decisions of this court lie to the Supreme Court. ${ }^{5}$

The setting of this investigation is a criminal case in a Danish district court sitting with one professional judge and two lay judges (cf. Chapter 4, Sections 4.1 and 4.2). As a rule, district courts will sit with lay judges if the alleged crime is liable to result in a sentence higher than a fine, or if the case is deemed to have particular consequences for the defendant or to be of special public interest ${ }^{6}$.

As explained in Chapter 1 (Section 1.3), the languages spoken are Danish and English. These languages were a natural choice, since I am myself an authorized court interpreter of English.

The investigated interaction is consecutively interpreted question-answer dialogues in criminal cases. Right from the beginning of this investigation, I wanted to concentrate on such dialogues, for two reasons: (1) Interpreter assistance is mainly required, and used, in criminal cases; and (2) interpreters assisting in criminal cases, and interpreting between Danish and English, are as a rule authorized interpreters who appear on the official list of court interpreters (cf. Section 3.5), and who are therefore fully familiar with the ethical guidelines as well as trial procedure (cf. Section 3.1.3).

Based on personal experience, as well as on communication with interpreting colleagues, a court interpreter of English will be hired to assist in criminal cases where the defendant or a witness may be categorized as (1) a national of a country where English is the national language, e.g. the USA, the UK, Australia, Canada, New Zealand; (2) a national of a country where English is, or used to be, an official language, i.e. former British

\footnotetext{
Sections 12, 13 and 14(1) of the Danish Administration of Justice Act.

4 Sections 6(5) and 9(2)-(6) of the Danish Administration of Justice Act.

5 Part 84 of the Danish Administration of Justice Act.

6 Section 686(2, 3 and 4) of the Danish Administration of Justice Act.
} 
colonies, such as Malaysia, Hong Kong, the Philippines, Kenya, Uganda or Zimbabwe; and (3) a national of a country which does not belong in category (1) or (2). Typically, defendants and witnesses belonging to categories (1) and (2) will speak English as a first, or at least a second language, whereas defendants and witnesses in category (3) will speak English as a second, or even a third language. So, even if English is the third language of a defendant, or a witness, if no interpreter is available in his first or second language, an interpreter of English may be hired. However, it is hard to imagine that this will happen very often, since interpreters are now available in a variety of languages. Also, the courts will presumably wish to avoid generating appeal cases by denying a defendant or a witness proper interpreting assistance (cf. Section 3.3). On the other hand, being assisted by an authorized interpreter in one's third language may be preferable to being assisted by a non-authorized interpreter in one's first or second language, who has received insufficient training, or no training at all, and who may not be profoundly familiar with the Danish language, or with the Danish society and its institutions (cf. Section 3.4).

Finally, a criminal case is conducted very differently in legal systems around the world (cf. Mikkelson 2000:34-43). As will be demonstrated by Sections 3.1.1 to 3.1.3 below, the Danish system is not an aggressive system.

\subsubsection{Principles of criminal justice}

In her introduction to the Danish legal system, Dübeck (1994:128) observes that criminal justice in Denmark as governed by Chapter 4 of the Danish Administration of Justice Act is based on an accusatorial principle, according to which proceedings shall be instituted on a charge, a charge shall be brought by the prosecution service, and an accused person shall be acknowledged as a party to the proceedings and be granted a number of rights, also during the pre-trial phase, i.e. during the preparation of the case against him. Generally, a defence counsel will be assigned to him, unless he hires one himself, and the proceedings shall in principle be open to the general public (cf. Chapter 4, Section 4.3). 
Dübeck (1994:128) also observes that the accusatorial system of the Danish Administration of Justice Act acknowledges the principle of "favor defensionis", which, by granting the defence of an accused person certain privileges, deviates from the general principle that the parties to a case should be granted equal access to justice. Furthermore, the principle of "favor defensionis" acknowledges another fundamental principle, namely that of "in dubio pro reo", that is, the principle that a case must be proven beyond reasonable doubt. In other words, the burden of proof rests with the prosecution service. Also, the prosecution must protect the interests of the accused, and the public prosecutor may thus lodge an appeal in favour of the defendant, also after the end of the period allowed for appeal.

Finally, the court will reach its decision based on oral presentations only ${ }^{7}$, i.e. statements and witness testimonies, which means that, as a rule, documents and statements will have to be read out in court in order to be considered evidence. This is known as the principle of orality, and is closely connected with another principle, the principle of immediacy, which stipulates that evidence relevant to the outcome of the case must be produced directly to those deciding on the case. Consequently, in order for a judge, a lay judge or a juror to decide on a case, he or she must be present during the entire proceedings ${ }^{8}$.

\subsubsection{General aspects of criminal proceedings}

As regards the pre-trial phase, the prosecution service is required to prepare a case without undue delay, in order to ensure not only that a guilty person may be held accountable, but also that an innocent person may avoid prosecution ${ }^{9}$. In other words, a prosecutor has to favour both sides, i.e. to consider evidence which may favour the prosecution as well as evidence which may favour the defence.

As a rule, the evidence produced at the trial must be real evidence, i.e. evidence afforded by the production and inspection of material objects and testimony, as opposed to rules of law and precedence, and will be the only

\footnotetext{
Section 148 of the Danish Administration of Justice Act.

Section 214(3) of the Danish Administration of Justice Act.

9 Section 96(2) of the Danish Administration of Justice Act.
} 
evidence regarded as admissible evidence. In principle, there is no limit to the kinds of real evidence which may be regarded admissible, though there may be grounds for exempting some witnesses from their witness duty ${ }^{10}$.

Under Section 896 of the Danish Administration of Justice Act, the assessment of evidence is free, and the decision of the court must be based solely on the evidence adduced at the trial, directly or indirectly according to law. The prosecution produces its evidence first, and then the defence ${ }^{11}$. A witness will be questioned first by the party who requested his presence, and then by the other party, but the court may also ask questions ${ }^{12}$. However, the examination-in-chief and the cross-examination (and the reexamination) of witnesses must be conducted for the purpose of eliciting clear and truthful statements ${ }^{13}$. If a party fails to comply with this provision, for example by attempting to discredit a witness, the court may intervene or even take over the questioning ${ }^{14}$. Clearly, therefore, the provision imposes conditions on the role-play of the prosecution and the defence which has the effect of making the Danish courtroom less adversarial than many other courtrooms throughout the world. Nevertheless, prosecutors and defence counsels do not always comply with the provision, and will not always be admonished by the court for failing to do so (cf. the discussion of example 133, Chapter 7, Section 7.3.3).

Finally, as a rule, the defendant must be present during the entire proceedings, or at least as long as he is entitled to make statements ${ }^{15}$. However, if he fails to appear despite having been lawfully summoned, and without providing lawful notice of his absence, the trial, or part of it, may take place without him ${ }^{16}$. Furthermore, the court may order the defendant to leave the courtroom, at least for part of the proceedings, because his presence is considered to intimidate a witness or a co-defendant, or because he behaves in a noisy and disruptive manner ${ }^{17}$. Once he returns to the

\footnotetext{
${ }^{10}$ Part 18 of the Danish Administration of Justice Act.

11 Section 870(1) of the Danish Administration of Justice Act.

2 Sections 183(1)-(2) and 872 of the Danish Administration of Justice Act.

3 Section 184(1) of the Danish Administration of Justice Act.

14 Sections 183(2) and 873 of the Danish Administration of Justice Act.

15 Section 846 of the Danish Administration of Justice Act.

16 Section 847(1)-(3) of the Danish Administration of Justice Act.

17 Sections 848(1) and 849(1) of the Danish Administration of Justice Act.
} 
courtroom, however, he must be informed of all evidence produced in his absence $^{18}$.

\subsubsection{Trial procedure in the setting}

The trial procedure in the setting for this investigation, a district court sitting with lay judges, is governed by Part 80 of the Danish Administration of Justice Act. The procedure is as follows:

Once the court is in session, the presiding judge announces the case and asks the prosecutor to call the defendant and bring him forward to the witness stand. If required, the judge may also call witnesses and take steps to guarantee their presence and bar them from communicating with one another.

The judge then orders the prosecutor to read out the indictment and asks the defendant how he pleads. The judge may also order the prosecutor to open and present the case. The defendant has the right not to answer questions relating to the charge ${ }^{19}$, and the judge informs him of this right and asks him whether he is willing to make a statement. If the defendant declares that he is willing to make a statement, he is questioned by the prosecutor first, and then by his defence counsel. His questioning by the defence counsel may give rise to further questions being asked by the prosecutor. In addition, the court may also ask him some questions. However, questions to a defendant may not be asked in a manner which implies that refusal to answer a particular question, or failure to acknowledge a particular fact, shall be considered admission of guilt ${ }^{20}$. Nor may he be punished for making a false statement ${ }^{21}$.

Following his questioning, the defendant is seated at the defence table, and the evidence is produced. After each piece of evidence, the defendant has the right to make a statement in relation to that evidence ${ }^{22}$.

\footnotetext{
18 Sections 848(2) and 849(2) of the Danish Administration of Justice Act.

19 A defendant's right not to answer questions is laid down by Sections 752(1) and 754(1) of the Danish Administration of Justice Act.

${ }^{20}$ Section 752(3) of the Danish Administration of Justice Act.

21 Section 159(1) of the Danish Penal Code.

${ }^{22}$ Section 870(2) of the Danish Administration of Justice Act.
} 
Witnesses have a duty to give evidence, and, prior to being heard, they are informed of this duty, as well as of the penalty for giving false evidence ${ }^{23}$.

When all the evidence has been produced, the prosecutor and then the defence counsel, and the defendant if he so wishes, are given the opportunity to comment on the production of evidence and any legal issues in relation to the case (closing argument). Then the case is set down for judgment. However, the court may decide to negotiate a decision before sentencing, in order that the question of guilt may be kept separate from the sentencing, and from any aggravating or mitigating circumstances which have to be taken into consideration when negotiating the sentence ${ }^{24}$.

\subsubsection{The participants and their role}

Generally, a minimum of eight participants take part in the proceedings: The presiding (professional) judge, the two lay judges, the prosecutor, the defence counsel, the defendant, the witness, and the interpreter. The seating of these participants may be as illustrated by Figure $3.1^{25}$ :

\section{Figure 3.1: The seating of participants in a criminal trial in a Danish district court sitting with lay judges}

LJ PJ LJ

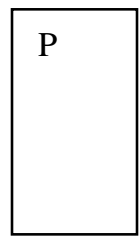

\begin{tabular}{|l|}
\hline $\mathrm{DC}$ \\
$\mathrm{D}$ \\
(I) \\
\hline
\end{tabular}

W (I)

${ }^{23}$ Witnesses' duty to give evidence is provided by Section 181 of the Danish Administration of Justice Act, and the penalty for giving false evidence is provided by Section 158 (1) and (3) of the Danish Penal Code.

24 Sections 928a(1) and 928b of the Danish Administration of Justice Act.

${ }^{25} \mathrm{LJ}=$ lay judge, $\mathrm{PJ}=$ presiding (professional) judge, $\mathrm{P}=$ prosecutor, $\mathrm{DC}=$ defence counsel, $\mathrm{D}=$ defendant, $\mathrm{W}=$ witness, $\mathrm{I}=$ interpreter. 
Under Part 80 of the Danish Administration of Justice Act, the prescribed roles of the above eight participants are as follows:

The (professional) judge presides over proceedings. He hears the case and passes judgment based on the produced evidence. He is responsible for overseeing that justice is done, which involves (1) monitoring the prosecutor and the defence counsel and admonishing them if they fail to comply with procedure, and (2) checking the identities of defendant(s) and witness(es) and informing them of the procedure, and of their rights and obligations, prior to their questioning.

The two lay judges also hear the case and pass judgment based on the produced evidence, and in this they have the same power as the professional judge. However, they do not participate in any judicial acts or decisions during the trial $^{26}$.

The prosecutor prosecutes the case, which involves opening and presenting the case, producing evidence, including the examination and the crossexamination (and the re-examination) of witnesses, and arguing the case.

The defence counsel presents the defence, which involves producing evidence, including the examination and the cross-examination (and the reexamination) of witnesses, and arguing the case.

The defendant has been charged with the crime and is present to hear the evidence against him and to make his own statement (cf. 3.1.3 above).

The witness is present to assist the prosecution or the defence in their production of evidence. He will appear only when being questioned.

The interpreter is present to interpret the proceedings, or part of the proceedings, in order that the primary speakers may communicate as if the entire interaction was monolingual. Thus, contrary to the other participants, the interpreter is not a party to the proceedings.

${ }^{26}$ Section 91(2) of the Danish Administration of Justice Act. 


\subsubsection{The discourse}

Trial discourse, including lawyers' questioning strategies and the impression of witness testimonies have been the subject of various investigations since the 1970s, particularly, though not exclusively, in the USA (e.g. Danet et al. 1980; Danet 1980; O’Barr 1982; Levi \& Walker 1990; Stygall 1994; Luchjenbroers 1997). To my knowledge, similar studies have yet to be conducted of trial language in Danish district courts. It is beyond the scope of this investigation to attempt such a study, and this section merely presents a brief description of the discourse in the investigated setting, which, based on personal observation, tend mostly to be relatively informal. Seemingly, the degree of formality depends largely on the attitude of the presiding judge: The speech and behaviour of some district court judges are rather informal, and the special role of the judge, the fact that he presides over proceedings (cf. Section 3.1.3.1), means that he, so to speak, 'sets the standard' for whatever language and behaviour will be accepted in 'his' courtroom. Of course, this is not to say that legal procedure is ignored or dispensed with, since this is certainly not the case. But efforts are sometimes made to simplify matters as much as possible, for example by avoiding an excessive use of complex legal terminology when questioning defendants and witnesses. Of course, this relative informality of the setting may be due to the great number of cases heard by the district courts, and the great variety of defendants and witnesses appearing in them, many of whom have in common their lack of familiarity with the legal procedure.

More specifically, the discourse consists of monologues and questionanswer dialogues. In order to categorize the discourse further for the purpose of identifying which parts are relevant to the present investigation, I have chosen as my starting point the five participants engaged in the discourse as speaker and/or end receiver (thus excluding the lay judges, who do not as a rule take an active part in the discourse, and the interpreter, who is not a party to the proceedings, cf. Section 3.1.3.1). I have said that a change of speaker or end receiver will necessary result in a change of discourse, and this enables me to conclude that the discourse consists of 10 different types of monologues and 9 different types of dialogues. 
A monologue may have one of the following four speakers: The (presiding) judge, the prosecutor, the defence counsel, and the defendant. Based on order of occurrence, the 10 different types of monologues are:

(1) The judge's initiating comments.

(2) The prosecutor's reading out of the indictment.

(3) The prosecutor's opening statement, presenting the case.

(4) The prosecutor's reading out of documents presented in evidence.

(5) The defence counsel's reading out of documents presented in evidence.

(6) The prosecutor's closing argument.

(7) The defence counsel's closing argument.

(8) The defendant's closing argument.

(9) The judge's closing comments.

(10) The judge's delivery of the judgment.

Generally, each monologue occurs only once. It is hard to imagine otherwise, unless a situation arises which gives a participant occasion to request the repetition of one or more of the monologues, perhaps because something made him unable to hear or understand what was said. Also, the fact that prosecutors and defence counsels, and/or defendants, often wish to add further comments to their initial closing arguments, usually to encounter some arguments put forward by their opposite number in his closing argument, does not cause monologues (6) and (7), and/or (8), to be delivered twice. By their very nature, the added comments merely serve to extend the initial closing arguments, instead of causing their re-delivery.

If interpreted, monologues are typically interpreted in the simultaneous (whispered) mode.

Whereas the monologues involved only four participants, thus excluding the witness, all five participants are engaged in one or more questionanswer dialogues during the course of the trial. First of all, the judge, the prosecutor and the defence counsel will be questioning the defendant and the witness. Secondly, each of these participants may request that points be clarified, or that evidence be specified, or that assurance be given that a 
procedure has been complied with, etc. Thus, the 9 different types of dialogues involve the following participants:

(1) The judge and the prosecutor.

(2) The judge and the defence counsel.

(3) The judge and the defendant.

(4) The judge and the witness.

(5) The prosecutor and the defence counsel.

(6) The prosecutor and the defendant.

(7) The prosecutor and the witness.

(8) The defence counsel and the defendant.

(9) The defence counsel and the witness.

Dialogues (3), (4), (6), (7), (8) and (9) represent the questioning of defendants and witnesses and, if interpreted, will typically be interpreted in the consecutive (dialogue) mode, whereas dialogues (1), (2) and (5), if interpreted, like the monologues will be interpreted in the simultaneous (whispered) mode. However, if the interpreter is assisting the defendant, then, as a rule, the entire discourse, excluding his questioning, is interpreted to him in the simultaneous (whispered) mode.

Since this investigation centres on question-answer dialogues interpreted in the consecutive mode, only the six types of dialogues that represent the questioning of defendants and witnesses are relevant to this investigation. The collected data, presented in Chapter 4 of this thesis, include all six types.

\subsubsection{Power relationship}

Clearly, considering the prescribed role of participants in criminal trials in district courts (cf. Section 3.1.3.1) and the discourse they are engaged in (cf. Section 3.1.3.2), the participants in the setting in this investigation (again excluding the interpreter, who is not a party to the case, cf. above) hold varying degrees of power. I have illustrated this power relationship in Figure 3.2: 


\section{Figure 3.2: Power relationship in a criminal trial in a Danish district court sitting with lay judges}

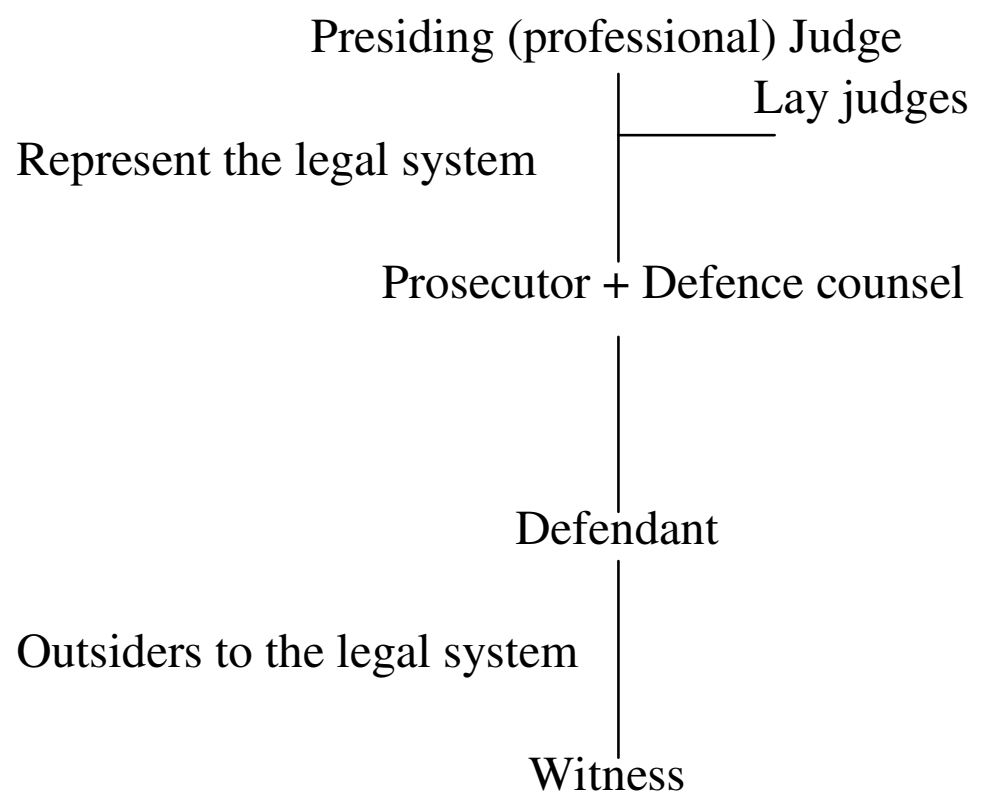

I have placed the presiding, and professional, judge at the top of the hierarchy, because, as mentioned in Section 3.1.3.1, he carries the overall responsibility for upholding the law throughout the trial. Consequently, he is in charge of the proceedings: he initiates and closes them. Thus, he controls the discourse by generating talk and initiating changes of speaker. In other words, he decides who says what and when. Besides, the fact that he passes judgment gives him the final say in the outcome of the case (disregarding the fact that the judgment may be appealed).

I have placed the lay judges slightly off the hierarchical line because of their special role. Contrary to the professional judge, they do not control the proceedings. They are not responsible for upholding the law, but they have an equal amount of power when it comes to passing judgment, i.e. determining the outcome of the case. Consequently, they merit a position below the judge, but above the remaining four participants.

I have placed the prosecutor and the defence counsel below the judge and the lay judges, but above the defendant and the witness, and also closer to the first three participants, because, like these, they represent the legal system, and are present in order to perform their jobs. Of course, the two adversaries have different objectives: The prosecutor is aiming for a 
conviction and the defence counsel is aiming for an acquittal (or a reduced sentence). Still, in terms of power, they are equal: They get an equal amount of time to present their case and produce their evidence, including time to examine and cross-examine (and re-examine) witnesses. (Thus, the fact that the prosecutor may open and present the case, and the fact that he produces his evidence first, does not provide him with more power.) Also, during the questioning of witnesses, the prosecutor and the defence counsel control the discourse to an equal extent, by generating talk and controlling turns. However, as mentioned earlier (cf. Section 3.1.3.1), the judge will be monitoring their performance and may take over the control at any time.

As for the defendant and the witness, I have placed them at the bottom of the hierarchical line. Both are outsiders to the legal system in their capacity as defendant or witness (i.e. ignoring the possibility that either may be a lawyer or a police officer outside the framework of the case, or that the witness may have been summoned as an expert witness). Both are in court because they have been summoned to appear, though the witness may of course have come voluntarily. They may have similar, or different, objectives. Like his defence counsel, the defendant will be aiming for an acquittal (or a reduced sentence). However, as regards the witness, depending on whether he appears for the prosecution or for the defence, and depending upon the extent of his involvement in the case, and his willingness to appear, he may have the same objective as the defendant, or the exact opposite objective, or no objective at all.

The defendant is placed above the witness, because he has certain rights, whereas the witness merely has obligations. As explained earlier (cf. Section 3.1.2 and Section 3.1.3), the defendant has the right to hear all the evidence against him, to produce his own evidence and to argue his case. But he also has the right not to co-operate with the court, by refusing to answer questions, or by producing less than complete answers, since he can never be called upon to produce evidence incriminating himself. Thus, there will be instances where he will control the discourse, at least to a certain extent. The witness, on the other hand, will never be in a position to control the discourse, since he is merely assisting the case and is called upon to provide responses only. Still, both the defendant and the witness may initiate turns, for example by requesting clarification of a legal point or of a speaker's intention. 
Of course, authorized court interpreters are fully familiar with the trial procedure, and therefore fully familiar with the role of participants, the discourse and the power relationship. Presumably, their knowledge of these factors influence their performance to some extent, but it will be beyond the scope of this investigation to attempt any definite conclusions as regards this influence.

\subsection{The interpreting situation}

As mentioned earlier (cf. Section 3.1.3.2), the questioning of defendants and witnesses are typically interpreted in the consecutive (dialogue) mode, while all other interaction is interpreted in the simultaneous (whispered) mode. Probably, this is due to the fact that headsets and microphones are not standard equipment in most Danish courtrooms. As a result, interpreters are seated next to the foreign participant, either at the defence table (if assisting the defendant, and excluding the time when he is being questioned), or at the witness table (cf. Figure 3.1). They are given a chair, but are not expected to need anything else, such as a table for note pads, law books, dictionaries, etc. Nor are they expected to prepare for the assignment to any large extent; often they are not even allowed a copy of the indictment beforehand. Presumably, both of these facts reflect the legal systems' perception of the court interpreter as a 'translation machine'.

Besides providing consecutive and simultaneous interpreting, court interpreters are often required to provide sight translations of documents presented in evidence.

Interpreting in the direct, first-person style is recommended (cf. Baaring 2001:24), and, ideally, the primary speakers will communicate as if the interpreter was not present - ideally, because attention is often, and inevitably, drawn to an interpreter's presence. Thus, as explained in Chapter 2 (Section 2.2.5), Morris (1989a), Shlesinger (1991), BerkSeligson (1990b) and Jansen (1995) documented multiple examples of how attention was drawn to the presence of the court interpreters in their studies. Besides, personal experience and observation, corroborated by the data collected for this thesis (cf. Chapters 4, 6 and 7), suggest that the following 
four occurrences may interrupt proceedings and inevitably draw attention to an interpreter's presence:

(1) An interpreter may have to ask a primary speaker to clarify his intention, either because she did not hear part of his utterance, or because she did not fully comprehend it, for example because he speaks in a dialect, or with an accent, with which she is not familiar, or in a language which is not his mother tongue (cf. Chapter 6, Section 6.3), or because he has a speech impediment, etc.

(2) A lawyer who is competent in the foreign language and therefore able to understand an utterance spoken by the foreign participant (a relatively frequent occurrence when the foreign participant speaks English, since many Danish lawyers are competent in that language) may forget, being immersed in his line of questioning, that the utterance must be interpreted and may proceed, therefore, without allowing the interpreter time to provide her rendition. This kind of behaviour typically results in simultaneous speech (cf. Chapter 6, Section 6.2.2.3 and Chapter 7, Section 7.2.3), and/or in him being admonished by the court for failing to comply with procedure.

(3) An interpreter, or one of the primary speakers, may choose for some reason to adopt the thirdperson, indirect style of address, either persistently throughout the proceedings (cf. Chapter 4, Section 4.6.1), or during part of the proceedings.

(4) An interpreter who has not received proper training may be unaware of the ethical guidelines and inadvertently behave in an unprofessional manner. For example, she may engage in dialogue 
with a defendant or a witness for an extended period of time, which will typically result in her being admonished by the court.

Furthermore, it is quite conceivable that, consciously or subconsciously, participants adjust their utterances to the interpreting situation, for example by selecting their words with special care, by shortening their utterances, or by introducing several and/or long, pauses. I have personally observed the latter to be the case when interpreters have no experience with the simultaneous (whispering) mode and therefore need to interpret the entire interaction in the consecutive mode; as a result, prosecutors and defence counsels tend to deliver their closing arguments in fragments, which may certainly have an impact on proceedings. Besides, Madsen (1997:59-60) explains that the prosecutor and the defence counsel interviewed for her study both acknowledged that the presence of an interpreter will have an effect on their questioning strategies. However, as far as I know, it has yet to be thoroughly documented to what extent, if any, an interpreter's presence may influence proceedings in a court of law by influencing the production of source texts.

A final aspect to consider here is that, as stipulated by law (cf. Section 3.3 below), the language of the courts is Danish. Consequently, utterances in a foreign language are not considered evidence and are therefore not entered into the court records in their original form. Incidentally, the records are not verbatim either ${ }^{27}$. As a result, an interpreter's performance is not documented, which, besides complicating the collection of data for interpreting research, makes it difficult for a party to appeal against a court's decision claiming interpreter incompetence. In fact, to my knowledge, such an appeal has yet to be successfully lodged in Denmark ${ }^{28}$.

27 Section 35(1)-(6) of the Danish Administration of Justice Act.

28 However, in 1999, in an action for damages brought against the Danish Government on behalf of Greenlanders, former residents of Thule, in the northern part of Greenland, who were forcefully resettled in 1953 in order to make room for an American base, a Greenlandic court interpreter was replaced during the proceedings when he himself drew attention to the fact that he had provided an incorrect translation of an important piece of evidence (Politiken, 9 April 1999). 


\subsection{Legal provisions for the use of court interpreters}

The use of court interpreters is regulated by statute, and the rules relating to interpreter assistance date back to 1919. As Bisgaard \& Martinsen (2000:577) observe, the rules reflect the fact that interpreter assistance was the exception rather than the rule back in 1919, and they may therefore be characterized as inadequate today. Section 149(1) of the Danish Administration of Justice Act reads:

The language of the courts is Danish. The questioning of persons who do not master the Danish language shall, as far as possible, take place with the assistance of an authorized interpreter. In civil cases, an interpreter need not be appointed, if none of the parties demands it, and if the court believes that it has sufficient knowledge of the foreign language. The latter of these aforementioned exceptions shall also apply to criminal cases, with the exception of cases heard by the high courts. ${ }^{29}$

Rules relating to interpreter assistance in Danish courts are also provided by Article 6(3) of the 1950 European Convention on Human Rights. Article 6(3) grants a person charged with a criminal offence some minimal rights, among which are the right "to be informed promptly, in a language which he understands and in detail, of the nature and cause of the accusation against him", and the right "to have the free assistance of an interpreter if he cannot understand or speak the language used in court". Evidently, there is a conflict between Article 6(3) and Section 149(1), but, according to Bisgaard \& Martinsen (2000:577), a Danish court may be presumed to grant a defendant the right to interpreter assistance even if the court believes that it has sufficient knowledge of the foreign language.

Still, a study of Section 149(1) reveals five significant facts: (1) The assistance of an interpreter is not always obligatory, (2) an interpreter need not be an authorized interpreter, (3) the provision only refers to the questioning of persons, and not to other parts of proceedings, (4) the provision does not specify how it may be established that a person masters the Danish language, and (5) the provision does not refer to the questioning

29 My translation. 
of persons outside the courts, i.e. the questioning of an accused person during the pre-trial phase.

(1) The assistance of an interpreter is not always obligatory. In civil cases, the assistance of an interpreter is not obligatory, if none of the parties demands it, and if the court believes that it has sufficient knowledge of the foreign language. As a rule, parties in civil lawsuits are in charge of producing their own evidence, and it will therefore have to be their own decision whether or not the production of a particular piece of evidence, i.e. the hearing of a particular witness, requires the assistance of an interpreter. Still, though the parties to a civil case may agree to hear a witness without the assistance of an interpreter, the court may request one anyway. In actual fact, based on personal experience it seems to be the rule, rather than the exception, at least as regards the questioning of witnesses in district courts, that an interpreter will be hired as a precaution, to make sure that all the evidence is properly produced, even when the foreign language is English, a language in which many Danes are competent (cf. Section 3.2).

In criminal cases, the assistance of an interpreter is always obligatory in one of the high courts, but not in the district courts. As explained above, under Section 149(1) a district court need not appoint an interpreter if the court believes that it has sufficient knowledge of the foreign language, but will presumably do so anyway (cf. above). Besides, the provision in Section 149(1) requires a court to establish that the judge, the lay judges, the prosecutor and the defence counsel in a particular case all have sufficient knowledge of the foreign language, and this must be almost impossible to establish for certain, especially as regards the lay judges, who only sit for a particular case. Consequently, and in line with Article 6(3), district courts will presumably request interpreters for the large majority of cases anyway, as a precaution. Also, the courts will presumably wish to avoid generating appeal cases based on a failure to provide proper interpreter assistance when necessary. As mentioned earlier (cf. Section 3.1 above), Danish appellate procedure generally allows appeal against judgment to a higher court, and the high courts have been known to quash district court convictions following appeals lodged on grounds relating to court interpreting. For example, in 1996, a successful appeal was lodged to the Western High Court on the grounds that telephone interpreting had been used in the district court. The Western High Court held that telephone 
interpreting did not constitute proper interpreting as the interpreter had been unable to interpret "gesture, body language and facial expressions, thus increasing the risk of errors and misunderstandings" ${ }^{30}$. In 1997, another successful appeal was lodged to the same court on the grounds that the district court had failed to appoint an interpreter. The Western High Court held that this failure amounted to a "fundamental breach" ${ }^{31}$ and ordered a new trial.

The difficulty of establishing whether lay persons in particular have sufficient knowledge of the foreign language may explain why the assistance of an interpreter is obligatory in criminal cases in the two high courts. First of all, as stated earlier (cf. Section 3.1), criminal proceedings in these courts are trials by jury, and, secondly, when they hear appeals against the convictions of district courts they are as a rule composed of three professional judges and three lay judges ${ }^{32}$. However, the fact that they try the more serious indictable offences may be a contributing factor.

Incidentally, there seem to be no specific rules as regards who hires and remunerates court interpreters. In civil cases, they are usually hired and remunerated by the party producing the evidence, though they may occasionally be hired and remunerated by the court (e.g. when hired for enforcement proceedings). In criminal cases, they are hired either by the prosecution service or by the court, but they are remunerated by the court. (cf. Bisgaard \& Martinsen 2000:581).

(2) An interpreter need not be an authorized interpreter. Section 149(1) does not provide that the interpreter should always be an authorized interpreter and the act thus takes into consideration that an authorized interpreter may not be available for a particular language, in which case a non-authorized interpreter may be hired (cf. Section 3.4).

(3) The provision refers only to the questioning of persons. By referring only to the questioning of persons, Section 149(1) does not say how a

${ }^{30}$ Vestre Landsrets dom (Judgment of the Western High Court) of 5 September 1996. My translation.

31 Vestre Landsrets dom (Judgment of the Western High Court) of 26 August 1997. My translation.

32 Sections 6(2) and 689(2) of the Danish Administration of Justice Act. 
foreign defendant in a criminal case shall be able to hear evidence against him, though Sections 848(2) and 849(2) of the Danish Administration of Justice Act specifically grants defendants that right (cf. Section 3.1.2), and Article 6(3) grants them the right to hear it in a language which they understand. Presumably, despite the wording of Section 149(1), the courts will tend to hire an interpreter for the entire proceedings anyway, as a precaution (cf. above), rather than just for the questioning of the defendant. Still, by referring to interpreter assistance for questioning procedures only, the act to some extent gives the courts the authority to grant a foreign defendant the stipulated right as they see fit.

(4) The provision does not specify how it may be established that a person masters the Danish language. Section 149(1) does not lay down the requirements for when a defendant or a witness may be said to master the Danish language. Thus, it is up to an individual court to establish this fact, but presumably it will do so with great caution, especially in criminal cases (cf. above). In fact, based on personal experience it seems that a foreign national appearing as the defendant in a criminal case is not considered to master the Danish language, unless he demonstrates extreme fluency and has lived in Denmark for a great number of years and/or explicitly waives his right to be assisted by an interpreter. Thus, no matter how fluent in Danish a defendant may appear to be, if he asks for an interpreter, one will be hired to assist him. This is in line with Article 6(3) and the observations by Bisgaard \& Martinsen (2000), referred to above.

\section{(5) The provision does not refer to the questioning of persons outside} the courts. Finally, Section 149(1) lays down the questioning procedure in courts only. Thus, it makes no reference to the questioning of an accused person during the pre-trial phase, i.e. at police stations, during the preparation of the case against him, though this procedure is also provided by the Danish Administration of Justice $\mathrm{Act}^{33}$. However, Article 5(2) of the 1950 European Convention on Human Rights grants a person arrested the right to be "informed promptly, in a language which he understands, of the reasons for his arrest and the charge against him". So, as a rule, the police will call an interpreter as soon as possible following the arrest of a person speaking a foreign language, in order to inform that person of the reasons

33 Sections 750, 751(1)-(3), 752 (1)-(5) and 753. 
for his arrest and the charge, as well as his rights, and in order for the interpreter to assist in the questioning of him. Nevertheless, based on personal experience, and further illustrated by a Danish television programme ${ }^{34}$ shown in the autumn of 2000 , which presented a number of authentic police interviews at a police station in central Copenhagen, police personnel seem to be more easy-going as regards the requirements for when a person may be said to be able to master the Danish language, or any other language for that matter, and seem to be especially confident as regards their ability to conduct interviews in English.

Still, despite the fact that police personnel seem to have a less rigid procedure for determining when the assistance of an interpreter is necessary during questionings, the Danish national police is the only institution under the jurisdiction of the Danish Ministry of Justice which has attempted to provide any kind of official guidelines for police and court interpreters in Denmark. I shall discuss this fact in further detail in Section 3.5 below.

\subsection{The authorization process}

As stated above, Section 149(1) provides that, as a rule, court interpreters should be authorized interpreters. Under Danish law ${ }^{35}$, an interpreter may be awarded authorization provided that she

(1) is a Danish national,

(2) is a resident in Denmark ${ }^{36}$,

(3) is twenty-five years of age or older,

34 Historier fra en politistation, TV2, 2000.

35 Lovbekendtgфrelse (Consolidation Act) No. 181 of 25 March 1988, as amended by Section 15 of Act No. 936 of 27 December 1991, Section 10 of Act No 377 of 22 May 1996, Section 16 of Act No 386 of 22 May 1996, and Section 4 of Act No 227 of 21 April 1999.

36 Since Bekendtg $\phi$ relse (Regulation) No. 810 of 12 September 1994, requirements (1) and (2) shall not apply to nationals of EU member states or EEA member states. 
(4) has not been declared legally incompetent or placed under guardianship or receivership, or is not having her estate administered in bankruptcy, and

(5) has passed the appropriate examination.

Due to the last of these requirements, authorization is not available to all court interpreters. As a rule, only interpreters with a master's degree in LSP (language for special purposes) from either the Aarhus School of Business or the Copenhagen Business School will have passed the appropriate examination. Furthermore, the two institutions only teach the six following languages: English, German, French, Spanish, Italian and Russian. Thus, court interpreters in other languages cannot usually become authorized interpreters, despite receiving formal training and passing exams ${ }^{37}$. So, as a rule, there are two groups of interpreters performing in Danish courts of law: (1) Authorized interpreters, who are Danish nationals who have studied a foreign language and culture and acquired a master's degree in that language and culture; and (2) non-authorized interpreters, who are foreign nationals, and who are, as a minimum, high school graduates of their own countries and have acquired a sufficient knowledge of Danish language and culture to be formally trained or pass exams ${ }^{38}$; or, if no

37 Section 1(3) and 3(1) of Consolidation Act No 181 (cf. note 35) provide for exceptions to this rule, and some interpreters in languages other than the six languages mentioned have in fact managed to become authorized interpreters. Generally, these interpreters may be either Danish nationals with a master's degree in a foreign language which cannot be studied at either of the two institutions referred to, or they may be Danish nationals of foreign extraction with university degrees in their first languages who have demonstrated a profound knowledge of the Danish language, and of the Danish society and its institutions.

38 In 1996, in response to an increasing demand for qualified interpreting for immigrants and refugees in all parts of Danish society, a two-year Open University programme was established at the Aarhus School of Business and the Copenhagen Business School. In the first year, students follow courses in interpreting (and translation) in medical and social settings, and in their second year they specialize in one of the following three fields: police and court interpreting, medical and psychiatric interpreting, or business interpreting. But, even if they specialize in police and court interpreting, they will not be qualified for authorization. In addition, the programme has met with some difficulties, so only a relatively small number of interpreters have successfully completed it (cf. Martinsen 2000). 
training and exams are available, who have demonstrated sufficient knowledge of Danish to function as interpreters.

As mentioned above (Section 3.3), the legal system recognizes that not all court interpreters can be authorized interpreters, hence the wording of Section 149(1). The system must also be aware of the fact that the above six languages are not the ones most in demand in Danish courts. Still, this awareness has not yet led to any definite plans, for example for changing the requirements for authorization, or for demanding formal training for non-authorized interpreters, or for setting out standards of professional conduct and responsibilities for court interpreters. As stated earlier (cf. Section 3.3 above), only the police have laid down any official requirements for what may be said to constitute qualified interpreting. Section 3.5 presents and discusses these requirements.

\subsection{Official guidelines on the performance of court interpreters}

In January 1994, the National Commissioner of the Danish Police (Rigspolitichefen) issued a proclamation ${ }^{39}$ announcing a general scheme for the recruitment of interpreters and the administration of their services within the institutions under the jurisdiction of the Ministry of Justice. In November 1994, the National Commissioner further published two documents, Instructions for Interpreters ${ }^{40}$ and a notice ${ }^{41}$, laying down ethical guidelines for police interpreters and for police personnel working with interpreters. Sections 3.5.1 and 3.5.2 present and discuss the contents of these documents.

39 Kundgфrelse (Proclamation) I, No. 11 of 12 January 1994.

40 Instruks for Tolke of November 1994.

${ }^{41}$ CENT-meddelelse (Notice from the Aliens Division) No. 9 of 24 November 1994. This is the document that Schweda Nicholson \& Martinsen (1997:263) and Jacobsen $(1998: 138,1999: 58)$ refer to as a list of rules. 


\subsubsection{The general scheme for the recruitment of interpreters and the administration of their services}

The general scheme for the recruitment of interpreters and the administration of their services which was announced by the National Commissioner's proclamation was the first attempt at providing standards for police interpreters in Denmark, as well as for interpreters hired by the other institutions under the jurisdiction of the Ministry of Justice. The scheme resulted in the establishment of an official list of interpreters approved for carrying out interpreting and translation tasks within the jurisdiction of the Ministry of Justice. The list is kept by the office of the National Commissioner, and it is continuously updated and sent out to the Ministry of Justice, the courts ${ }^{42}$ and all institutions under the Ministry of Justice, including all police districts.

Interpreters who wish to appear on the official list must apply in writing in Danish and sign a declaration promising, among other things, confidentiality and impartiality. Authorized interpreters are automatically added to the list after filing their application, but non-authorized interpreters also have to pass an oral test in interview format ${ }^{43}$, though the latter requirement will not be valid for applicants who have completed the 1996 Open University programme (cf. note 38).

Interpreters on the official list are approved for working in all institutions under the jurisdiction of the Ministry of Justice. In fact, the proclamation specifically announces that the scheme for recruiting them and for administering their services was endorsed by the Ministry. Still, it stipulates that police interpreters have to be approved by the office of the National Commissioner, and makes no mention of interpreters working in the other institutions. Consequently, the National Commissioner has no power of approval over those interpreters. The courts are thus not obliged

42 The day-to-day supervision of the courts is administered by the Court Administration which is part of the Ministry of Justice. But the Minister has no powers to issue practice directions to the Court Administration, and he cannot reverse its decisions, which underpins the separate authority and independence of the courts.

43 The interview tests an interpreter's competence in Danish. Her competence in the foreign language is not tested (Bisgaard \& Martinsen 2000:579). 
to consult the official list, though, in practice, the courts will presumably hire only interpreters whose names appear on the list, since they are, after all, approved for interpreting, as well as translating, in the courts also. Besides, court interpreters assisting in criminal cases are often initially contacted by the prosecution service, or at least approved by that service before being hired; in the district courts, this service consists of the chief constables (politimestrene), who delegate this authority to their legal representatives, i.e. lawyers employed by the police and working from the police stations (cf. Chapter 4, Section 4.3.1.5).

There are, however, exceptions to the rule that only interpreters on the official list will be hired for interpreter assignments at police stations and in courtrooms. If no interpreter is listed for a particular language, or if an interpreter on the list is unavailable for a particular assignment, police personnel and court officials may hire interpreters who do not appear on the list. Presumably, this happens most frequently for less used languages.

Furthermore, as mentioned in Section 3.3 above, court interpreters who assist in civil cases are usually hired by the parties to the case, or by their legal representatives, who are more likely to consult interpreting agencies than the official list. In addition, a court will presumably not bother to establish whether an interpreter hired for a civil case appears on the official list, because, as a rule, it will be the responsibility of a party to a civil case, rather than the court, to determine whether an interpreter is competent for assisting in the production of evidence. In all probability, though, as a precaution (to be in line with Section 149(1) and/or to ensure qualified interpreting) an authorized interpreter will be hired if one is available in the language required.

There are no permanent positions for police and court interpreters in Denmark. In fact, the proclamation states that interpreters on the official list shall be employed on a freelance basis only. Presumably, this reflects a belief that interpreters in permanent positions will be unable to maintain impartiality and/or avoid conflicts of interests (cf. Section 3.5.2 below). But it is hard to imagine permanent positions for interpreters anyway, since it is unlikely that any of the institutions under the jurisdiction of the Ministry of Justice will require the assistance of interpreters to an extent 
which justifies the permanent employment of one or more interpreters in one or more languages.

So, as demonstrated by this section, the legal system prefers the passive role when it comes to determining who, other than authorized interpreters, shall be approved for interpreting in courts of law. The next section, Section 3.5.2, will demonstrate that the system prefers an equally passive role when it comes to determining how interpreters shall perform their duties.

\subsubsection{Ethical guidelines}

As explained above (cf. Section 3.5), the ethical guidelines for police interpreters and for police personnel working with interpreters were laid down in two documents: Instructions for Interpreters and a notice. There is considerable overlap between the two documents, but Instructions for Interpreters is addressed to interpreters, who receive a copy upon being registered on the official list, whereas the notice is addressed to police personnel.

Schweda Nicholson \& Martinsen (1997:264) observe that the guidelines "are similar to many other codes of ethics which have been developed and promulgated by professional associations and judicial systems throughout the world". The guidelines essentially deal with four principles, which $\operatorname{are}^{44}$ :

(1) Accuracy and Completeness: Interpretations must be rendered faithfully and in their entirety. Information must not be changed or altered in any way (no additions or deletions). Emotion and tone of the original must be maintained and conveyed in the target language. Offensive and/or vulgar language must be preserved.

44 The translation of these principles first appeared in Schweda Nicholson \& Martinsen (1997:264). 
(2) Impartiality: The interpreter must function as a neutral and objective language intermediary, remaining professionally detached from the principals in the case. All displays of emotion, bias or personal opinion must be avoided, and an interpreter must never offer legal advice. It is the interpreter's responsibility neither to evaluate the value or truth of the testimony nor to make judgements about guilt or innocence.

(3) Confidentiality: Interpreters must maintain professional secrecy, and must take care not to divulge any information learned during the course of an assignment, nor to discuss a case in progress.

(4) Conflict of Interest: The interpreter must not have any personal or professional ties with the principals in a case; this means not interpreting for e.g. friends, relatives, an employer or any individual or entity upon which the interpreter is dependent for financial support.

Evidently, the first of these principles, the principle of Accuracy and Completeness, outlines the requirement for verbatim versions of source texts. I shall address this principle in more detail, therefore, in Section 3.5.2.1 below.

Like the proclamation, Instructions for Interpreters and the notice apply to police interpreters only. However, considering that all interpreters on the official list receive a copy of Instructions for Interpreters, the courts are likely to assume that these interpreters are familiar with the document and will abide by the guidelines laid down there. In fact, Madsen (1997) includes in her study of the role of court interpreters in criminal cases (cf. Chapter 2, Section 2.2) a letter from the district court of Aarhus, dated 17 December 1996, which states (1) that, as a rule, the court hires only interpreters who appear on the official list, since these may be assumed to be familiar with the ethical guidelines, (2) that if the court for some reason needs to hire an interpreter who may not be assumed to be familiar with the ethical guidelines, the court will ask the interpreter if she is familiar with the principles of the guidelines, and, if she claims not to be, the court will 
inform her of the content of these principles, and (3) that the court does not usually attempt to ascertain the competence of an interpreter hired by a party to a civil case, unless the other party to the case disputes her qualifications (1997:Appendix 10).

Besides the proclamation and the two documents which lay down ethical guidelines, statutory provisions on confidentiality and conflicts of interests are included in the Danish Penal Code, and in the Public Administration $\mathrm{Act}^{45}$. These provisions apply to court interpreters also, and interpreters receive copies of them upon being added to the official list. However, since they apply to all kinds of public duties, the provisions are extremely general.

Even more general is a provision on the performance of authorized interpreters, which is found in Section 6 of Consolidation Act No 181 (cf. note 35):

Authorized translators and interpreters shall perform the task assigned to them with care and accuracy, and as rapidly as the nature of the task permits. ${ }^{46}$

Evidently, rather than stipulate the standards of one particular profession, Section 6 provides the more or less implicit standards of any kind of profession. Thus, it applies equally to authorized translators and interpreters and to e.g. carpenters, accountants or brain surgeons.

Since the legal system prefers the passive role when it comes to laying down guidelines for interpreter performance, some court interpreters receive no guidelines whatsoever, namely those who do not appear on the official list. Fortunately, it is to be presumed that these interpreters will constitute a very small number. Nevertheless, considering how often the assistance of court interpreters is required in Danish courtrooms, it is certainly odd that the Danish Administration of Justice Act, which regulates the performance of everyone else in the courtroom, fails to regulate interpreter performance.

\footnotetext{
${ }^{45}$ Sections 152, 152a, 152b, 152c, 152d, 152e and 152f of the Danish Penal Code and Sections 3(1)-(3) and 27(1)-(4) of the Public Administration Act.

46 My translation.
} 


\subsubsection{The principle of Accuracy and Completeness}

As mentioned above, the principle of Accuracy and Completeness outlines the requirement for verbatim translations of source texts. The principle describes the interpreting process as a verbatim process involving no deviations whatsoever. The interpreter should just translate; she should translate everything and she should translate accurately. In other words, as stated in the beginning of Chapter 1, she should function as a 'translating machine', simply transferring language products from one language into another. Any modification of the source text is forbidden, and thus the principle specifically forbids interpreters to include additions in their target texts.

Of course, seen from the point of view of the legal system, this perception of the court interpreter has a major pragmatic advantage. As Morris (1995:30) observes, it "enables a court to function effectively as a monolingual setting, since the absolute verbatim requirement has been laid down and will, it is presumed, be met". A court is able to hold, therefore, that what is stated originally in a foreign language can, after being switched into Danish, continue to function as an original text. So, at least in theory, Danish speakers and non-Danish speakers are afforded equal opportunities in a Danish courtroom.

However, as Morris (1995:30) further observes, this view of the interpreting process is based on a two-level supposition: "that, as a matter of general principle, one language can be switched into another with no loss of substance or form, and, furthermore, that a standard of absolute accuracy will be achieved in a particular interpreting performance". Not surprisingly, therefore, the principle of Accuracy and Completeness disregards issues such as linguistic differences, cultural differences, or problems of ambiguity or non-explicitness, and it is seemingly based on the rather naive assumption that all interpreters perform equally well at all times. It is my hope that this investigation and further studies of police and court interpreting will result in an understanding of the relevance of these issues, and, ultimately, to new guidelines which will be more in line with the reality of the interpreting situation. 


\subsection{Conclusion}

In this chapter, I have provided an overview of court interpreting in Denmark. I presented the background of the investigation, including the setting: a district court hearing a criminal case and sitting with lay judges. I also presented some principles of criminal justice relevant to the investigation, and some general aspects of criminal proceedings which demonstrate that Danish criminal procedure is not an aggressive procedure. I further presented and discussed the trial procedure in the setting, including the prescribed role of participants, the discourse and the power relationship. I explained that authorized court interpreters are fully familiar with the trial procedure, and that this may or may not influence their performance.

Next, I presented and discussed the interpreting situation, and the legal provisions for the use of court interpreters in Danish courtrooms. I drew attention to the fact that many court interpreters lack proper training. I also drew attention to the fact that the Danish national police is the only institution under the Ministry of Justice who has laid down official guidelines for interpreter behaviour. I presented these guidelines and explained that, strictly speaking, they apply to police interpreters only, but that court interpreters are assumed to be familiar with them and to abide by them. The legal system has thus taken the passive role in this matter and has not attempted to provide any kind of statutory guidelines for interpreter performance during courtroom proceedings.

Finally, I presented the ethical guidelines in more detail and discussed the principle of Accuracy and Completeness which, by outlining the requirement for verbatim translations of source texts, specifically forbids the presence of additions in court interpreters' target texts.

Having presented and discussed the background of the investigation and the ethical guidelines stipulating interpreter performance, I shall now present and discuss the collected data in Chapter 4. 


\section{$4 \quad$ Data}

This chapter presents and discusses the collected data: consecutively interpreted question-answer dialogues in a Danish district court. The dialogues were recorded on minidisk at two trials, a mock trial and an authentic trial, and were then transcribed for the purpose of analysis. In Section 4.1, I shall present the mock trial and the data collected at that trial. In Section 4.2, I shall present the authentic trial and the data collected at that trial. In Section 4.3, I shall discuss the data collection process. In Section 4.4, I shall discuss the transcription process and present the conventions adopted in the transcriptions of the collected data, and the abbreviations used in the examples in Chapters 6 and 7. In Section 4.5, I shall discuss the status of the collected data. In Section 4.6, I shall present and discuss four examples of interpreter behaviour observed in the recorded material and considered relevant for the investigation in this thesis. Finally, in Section 4.7, I shall conclude on the discussions in Chapter 4.

\subsection{The mock trial}

The mock trial was staged in April 1999, and it was staged because, at the time, authentic data was neither available nor appeared to be immediately forthcoming (cf. Section 4.3). For arranging the trial, I shall be eternally grateful to Villy Sørensen, Deputy Chief Constable (Vicepolitimester) of the Aarhus Police. As a prosecutor in the judicial district of Aarhus, Villy Sørensen has taken an interest in court interpreting for some years now, and he has on several occasions been of assistance to me, and colleagues involved in interpreter training and research at the Aarhus School of Business.

Villy Sørensen not only staged the trial, the offence, the participants, the evidence, etc., which involved preparing a case description, but he also offered to play the part of the judge. Furthermore, he enlisted the assistance of two prosecuting colleagues, one who took the part of prosecutor and one who took the part of defence counsel. Consequently, these three participants were all trained professionals, familiar with the process of conducting a trial. 
The alleged offence tried before the mock court was rape. This particular offence was chosen because, at the time, Villy Sørensen was involved in the establishment of a centre for rape victims in Aarhus, and he was hoping that, though primarily staged to provide data for my investigation, the mock trial would also produce valuable teaching material for the centre for rape victims, that is, material which could be used to prepare rape victims for the ordeal of testifying to their experiences in court. Consequently, for teaching purposes as well as research purposes, the mock trial was recorded on both videotape and minidisk (cf. Section 4.3.1.1). The video equipment was placed at the back of the courtroom, and was thus not visible from the witness table where the defendant, the witness and the two interpreters were seated during the questionings.

The room in which the trial took place was turned into a courtroom for the day: I rearranged the furniture to make the room resemble an authentic courtroom (cf. Chapter 3, Fig. 3.1). Furthermore, I invited interpreting colleagues and interpreting students at the Aarhus School of Business to attend the trial as spectators, and about 40-50 people turned up.

There were 9 participants in the mock trial: 1 judge, 2 lay judges, 1 prosecutor, 1 defence counsel, 1 defendant, 1 witness and 2 interpreters, one assisting the defendant (male) and alleged rapist, and one assisting the witness (female) and alleged rape victim.

The 9 participants were not given a manuscript, or specific details. As mentioned, one of the participants, the judge (Villy Sørensen) had prepared the case description, and four other participants, the prosecutor, the defence counsel, the defendant and the witness, were given a copy of it about one week before the actual trial. However, the case description merely told them the main facts of the case and the essence of the statements to be made by the defendant and the witness. (These statements represented the only evidence in the case.) The case description thus provided more details than an indictment would have provided, but also less, since it did not specifically mention the charge.

The parts of defendant/alleged rapist and witness/alleged victim were taken by native English speakers, from the USA and the UK respectively. Both were exchange students at the Aarhus School of Business at the time, and 
had only been in Denmark for a few months. Neither of them spoke any Danish. As mentioned, they were not given any specific details, but were instructed to supply the necessary details themselves, i.e. to invent them. However, they had to stick to the main facts of their story as outlined by the case description. Finally, they were told to prepare for the fact that some of the questions asked of them during the trial would be very intimate questions.

Moreover, shortly before the trial, the defendant met with his defence counsel for consultation, where he was given some details of trial procedure in a Danish district court. His interpreter assisted him at this pretrial consultation.

The two interpreters were recruited from among a group of ten court interpreters who had agreed to participate in the investigation, which meant that they were both authorized interpreters and therefore fully competent professionals (cf. Section 4.3.1.4). They reported that they had 23 and 13 years of experience as court interpreters, respectively, and that they interpreted in court approximately 8 times per year, which is an average number for many English court interpreters (cf. Section 4.3.1.4). They also reported that, when interpreting in court, they mainly interpreted in the consecutive (dialogue) mode, but were often required to interpret in the simultaneous (whispering) mode also.

Reflecting a real-life situation, the interpreters were informed of the alleged crime, and were told whom they would be assisting at the trial. However, they were not given specific details either. In fact, I did not intend for them to read the case description, since court interpreters are often not provided with any documents relating to a case beforehand (cf. Chapter 3, Section 3.2). But the interpreter who assisted the defendant was handed a copy by the defence counsel immediately before the pre-trial consultation.

I had asked for volunteers among the students to take the parts of lay judges, but when none came forward, two friends of mine stepped in. Since these were non-speaking parts (cf. Chapter 3, Section 3.1.3.2), the lay judges' close relationship with the researcher was not considered a problem. The lay judges were contacted at the last minute and I did not have time to send them the case description, or even to hand it to them 
immediately before the trial. Instead I gave them the main facts over the phone, so that they would be sufficiently prepared for their role in the trial.

The trial was conducted as an authentic trial, in the sense that a correct trial procedure was followed throughout (cf. Chapter 3, Section 3.1.3).

\subsubsection{Data collected at the mock trial}

The trial lasted approximately 2 hours, and the entire interaction was recorded, but only the question-answer dialogues, interpreted in the consecutive mode, were transcribed for the purpose of analysis. These dialogues took up most of the trial, however, amounting to approximately 80 minutes on minidisk, because there was no forensic evidence, and no other witnesses (cf. above).

The entire interaction at the pre-trial consultation was also recorded and transcribed for the purpose of analysis, because the ethical guidelines referred to in Chapter 3 (Section 3.5.2) apply in this setting also, and because the pre-trial consultation was conducted in the manner of an authentic consultation between a defence counsel and his client. This interaction consisted solely of question-answer dialogues, all of which were transcribed for the purpose of analysis. These dialogues amounted to approximately 15 minutes on minidisk.

As stated, the trial was recorded on video also. However, as it turned out, the video equipment was too poor to provide any useful data, neither for research purposes nor for teaching purposes, and the video tapes were thus not subjected to further study.

The following dialogues were transcribed: (1) The pre-trial consultation between the defendant and his defence counsel, and, during the trial itself, (2) the questioning of the defendant by the judge, the prosecutor and the defence counsel, and (3) the questioning of the witness by the same three participants.

When transcribing the dialogues, sensitive information, i.e. information identifying the defendant or the victim, or information identifying sensitive 
aspects of the alleged offence (names, dates, etc.) was not included in the transcriptions, for reasons of comparability. Thus, I adopted the standards that I would have to adopt for transcribing recordings of authentic proceedings for transcribing the recordings of the mock proceedings also. I was still hoping to collect authentic data, and to be able to test the findings from the analyses of the mock data through the findings from analyses of any authentic data, and consequently I needed to adopt the exact same standards (as well as conventions, cf. Section 4.4.1) for both kinds of data.

\subsection{The authentic trial}

The authentic trial was conducted in the district court of Copenhagen, the Copenhagen City Court, in November 1999. Luckily, getting permission to record these proceedings turned out to be a simple matter, thanks to the kind assistance of the presiding judge, another person to whom I shall be eternally grateful. The judge not only gave me permission to record the interpreted dialogues, but also contacted the prosecutor and the defence counsels on my behalf, deciding that this would be the easiest way of getting the co-operation of these participants and the defendants. So, all I had to do was turn up with my recording equipment and be prepared to record the interpreted dialogues.

12 people were involved in the trial: 1 judge, 2 lay judges, 1 prosecutor, 3 defence counsels, 3 defendants, 3 witnesses and 2 interpreters.

The alleged offence was fraud, the defendants having allegedly obtained a number of items from various shops in Copenhagen with the aid of stolen credit cards.

The three witnesses were Danish nationals and thus of no relevance for my study. The defendants were Chinese-speaking individuals with some knowledge of English, but with no knowledge of Danish. Two defendants were assisted by a Chinese interpreter and thus of no relevance either. But one defendant was assisted by an English interpreter (she initially informed me of the trial), because though he did not have English as a mother tongue, he had asked specifically for an English interpreter, arguing that, since he had lived in Great Britain for most of his life, he was fluent in that 
language also. Besides, he felt, or so he was reported to have said, that, by speaking English, he would have a greater chance at influencing what was going on, by which he presumably meant that the similarity between Danish and English, as opposed to Danish and Chinese, would enable him to monitor the interpreter's performance, e.g. by comparing the length of source texts and target texts. Moreover, he may have presumed that, by speaking English, he would to some extent be able to speak directly to the court, since the Danish participants would understand his utterances, or at least some of them, before they were interpreted. Of course, all of his utterances would have to be interpreted nevertheless.

Like the interpreters at the mock trial, the English interpreter at this trial was an authorized interpreter and therefore a competent professional. She reported to me that she had 4 years of experience as a court interpreter, and that she interpreted in court approximately once a week, which is certainly above average (cf. Section 4.3.1.4 below). She also reported that she interpreted in both the simultaneous (whispered) mode and the consecutive (dialogue) mode at every court hearing.

\subsubsection{Data collected at the authentic trial}

Contrary to the mock trial at which the entire interaction was recorded, only the question-answer dialogues interpreted by the English interpreter, in the consecutive mode, were recorded at the authentic trial. However, the defendant was questioned extensively by the judge, the prosecutor and the defence counsel, so the dialogues amounted to approximately 2 hours on minidisk.

Again, sensitive information, i.e. information identifying the defendant or his co-defendants, or identifying victims, or information identifying sensitive aspects of the alleged offence (names, dates, etc.) was not included in the transcriptions of the recorded data (cf. Section 4.1.1). 


\subsection{The data collection process}

Collecting data for studies of dialogue or conference interpreting is generally a very complicated process, as many researchers will attest to (e.g. Dam 1995:95; Dam \& Schjoldager 1994:170-171; Gile 1995:20-21; Shlesinger 1989:114). First of all, it is often extremely difficult to get permission to record interpreted interaction from participants and interpreters in real life settings, especially in sensitive settings such as courts of law, and, secondly, professional interpreters are not always willing to have their target texts recorded and scrutinized for research purposes. So, bearing these obstacles in mind, I assumed right from the beginning of this investigation that authentic data would not necessarily be available, and that I might have to collect data at a simulated setting. However, a simulated setting would have to resemble a real life setting in the sense that it would have to be as agenda-bound and controlled as a real life courtroom. Furthermore, the subjects of study, the court interpreters, would have to be authorized court interpreters.

Of course, I was able to observe interpreted courtroom proceedings, and thus authentic renditions of courtroom dialogues, but as my observations alone would not provide sufficient data, I needed to be able to record interpreted dialogues in a way that would facilitate the transcription of these dialogues for the purpose of analysis. Naturally, I preferred the dialogues to be authentic, rather than simulated, because of the obvious advantages connected with obtaining and analysing data from a real life setting (cf. Section 4.5.2 below).

My assumptions concerning the availability of authentic data were based on two facts: (1) The lack of publicity connected with court hearings in Denmark, and (2) the fact that, to the best of my knowledge, authentic courtroom proceedings in Denmark, whether interpreted or not, had never been recorded for the purpose of analysis. (In fact, I believe that I am the only researcher so far who has been able to bring recording equipment into a Danish courtroom for the purpose of recording proceedings.)

As a rule, court hearings in Denmark are public, but there is nevertheless a general tendency on the part of the legal system to exhibit caution in 
connection with the publication of details from a hearing, especially as regards criminal proceedings where the rights of defendants and/or victims have to be considered. Rules relating to the reporting of details from court hearings are laid down by Danish law ${ }^{1}$, which provides that no details from court hearings in camera may be reported, unless the doors are closed for the sole purpose of maintaining order and discipline in the courtroom. The law thus permits the reporting of court hearings in open court (and in camera when the doors are closed for the reason just mentioned). However, in the case of criminal trials, even when a trial is open to the public, a court may rule to prohibit the reporting of the entire proceedings, or of specific details, such as details relating to the identity of defendants and/or victims, for the purpose of protecting these individuals, or because it deems that public reporting may harm the proceedings.

The law also provides that, as a rule, the recording or transmission of pictures or sounds from a court hearing is prohibited, but that a court may exceptionally grant permission for recording and transmission to take place, in which case it will have to inform all individuals testifying before the court (defendants and/or witnesses) that they are being recorded. Finally, the law provides that drawings made during proceedings may be made public, but that a court may nevertheless rule to prohibit the making and publication of drawings. Consequently, as a rule, reporters and other interested parties who want to record and/or report details from a trial have to rely on their hand-written notes.

Though I was familiar with the above provisions, I decided nevertheless to investigate the possibility of obtaining authentic data, because of the obvious advantages connected with obtaining this kind of data, rather than simulated data, and because of the thrill of actually recording the performance of 'real' court interpreters in 'real' settings, and, moreover, of being the first Danish researcher to do so. Besides, I hoped that, by persuading the courts to grant me permission to record interpreted proceedings, and by demonstrating to them that the recording process would not obstruct a trial in any way, nor the study itself violate the rights of defendants and/or victims in a case, I would be able to lead the way for

1 Chapter 2 of the Danish Administration of Justice Act provides the rules on court hearings and the reporting of these. 
other research projects and thus help facilitate more studies of court interpreting in Denmark.

The decision to investigate the possibility of collecting authentic data was further encouraged by two specific developments: (1) The growing awareness during the 1990s on the part of the Danish legal system of the role and performance of court interpreters and of the need for proper training programmes, referred to in Chapter 1 of this thesis, which resulted, among other things, in the ethical guidelines presented in Chapter 3 (Section 3.5.2). (2) By the late 1990s, the Folketing, the Danish parliament, was debating a bill which proposed to grant the public more access to details of court cases. Among other things, the bill proposed that, as a rule, reporters should be allowed to bring tape recorders to hearings and record relevant details. (However, this particular proposal had been removed from the bill by the time it finally became law in 1999).

So, motivated by the advantages and the thrill of collecting authentic data, and encouraged by the focus of the legal system on the role of court interpreters, as well as by a political will for granting the public more access to court hearings, I took steps towards collecting data from real life proceedings. I was aware that a number of practical issues would have to be solved before I would be able to start recording, and consequently I began contemplating how to solve these issues.

\subsubsection{Practical issues}

Listed in order of priority, the issues that would have to be solved were:

(1) Deciding on the method of recording and acquiring the right recording equipment.

(2) Preparing a project description.

(3) Getting the co-operation of the legal system, i.e. courts and/or judges. 
(4) Getting the co-operation of authorized court interpreters.

(5) Getting the co-operation of prosecutors, i.e. the police.

(6) Getting the co-operation of defence counsels.

(7) Getting the co-operation of defendants and witnesses.

(8) Locating suitable trials.

Issues (1) and (2), in that order, were prioritized, because solving these issues was considered essential to solving Issues (3) to (7). Thus, it was essential, first of all, that I would be able to guarantee participants a safe recording process, i.e. one that would not obstruct proceedings. Secondly, it was essential that I would be able to guarantee my safe handling of any data collected, i.e. that I would not reveal the identity of defendants or witnesses, or reveal sensitive aspects of the offence, in the transcriptions of the recorded material, nor grant other researchers access to the recorded material. In order to be able to provide the first of these guarantees, I needed first of all to acquire the right recording equipment, and then to prepare a project description that would specify the method of recording. The description had also to present the investigation in a way that would not only guarantee my safe handling of data, but also convince participants of the importance of the investigation, and thus of the value of collecting and analysing authentic data.

Having solved Issues (1) and (2), the next step would be to solve Issue (3). Solving this issue was considered essential to solving Issues (4) to (7), because these participants would presumably take the position of the legal system and be unwilling to contemplate their own co-operation, unless I was able to guarantee the co-operation of the courts and the judges.

Solving Issue (4) was considered a higher priority than solving Issues (5) and (6). Thus, bearing in mind that the court interpreters, or rather their target texts, would be the object of study, I considered that getting their co- 
operation would be more complicated than getting the co-operation of prosecutors and defendants. Issue (5) would also be a higher priority than Issue (6), since prosecutors could be contacted as a group (cf. Section 4.3.1.5), whereas defence counsels would have to be contacted individually, immediately before a trial. Finally, solving Issues (5) and (6) was essential to solving Issue (7), because defendants and witnesses would not be directly accessible and would have to be contacted by prosecutors and/or defence counsels.

A solution to Issue (8) was not easily contemplated. First of all, the number of criminal trials in Danish courtrooms which require the assistance of court interpreters of English is generally not very large, though it varies. Consequently, I had to consider that simply entering one of the large district courts every weekday for, say, two months, and record all criminal proceedings being interpreted into English in that court during the twomonth period would presumably be a waste of time, because there might be no trials, or only a few trials, requiring the assistance of interpreters of English during those months. Secondly, I had no way of knowing beforehand whether the courts, or some other participants, would be able to help me get information about suitable trials. Finally, I considered that getting the co-operation of participants would presumably be a lot more complicated than locating suitable trials, and that, during the course of solving Issues (3) to (7), I might be able to solve Issue (8) also. Consequently, I listed this issue last.

\subsubsection{Deciding on the method of recording and acquiring the right recording equipment}

The method of recording had to be inconspicuous, for two reasons. First of all, it was essential that the participants did not deviate from their usual performance, but behaved as if they were not being recorded. Secondly, as stated above, it was essential that the recording process did not in any way interfere with the business of conducting a trial. Besides, for the benefit of my research project, and in order to facilitate future projects, it was extremely important to acquire, and to hold on to, the goodwill of participants. Consequently, it was essential to carry out the recording process in a way that would leave no doubts as to the safety of it. 
Video recording was not considered sufficiently inconspicuous and, for that reason, was ruled out. Checking the market for suitable equipment, I then decided to record the proceedings on a minidisk recorder, and I subsequently acquired a portable Sony MZ-R30. The recording time of a minidisk, 74 minutes, enabled me to record for relatively long periods of time without having to change disk, thus minimizing the risk of losing vital data.

Finding a suitable microphone was more difficult. As mentioned in Chapter 3 (Section 3.2), as a rule, microphones are rarely used in Danish courts. Thus, I considered that microphones placed in front of speakers, or clipped onto speakers, would be highly conspicuous. Finally, inspired by BerkSeligson's (1990b:49) choice of microphone for tape-recording interpreted proceedings in courts in the USA (cf. Chapter 2, Section 2.2.3), I settled on a Sennheiser ME67, which is a sensitive "Zoom" type microphone that picks up sounds over long distances, and from all directions, and magnifies them. Since this type of microphone picks up sounds equally well whether it is pointed at a particular speaker, or just held still, I was able to sit anywhere in the courtroom and record all participants equally well at all times, without drawing attention to myself.

The entire recording equipment, minidisk recorder and microphone, as well as minidisks, power adaptor, extra batteries, and headphones fit comfortably into a small bag. Thus, the equipment was easily transported, as well as inconspicuous.

\subsubsection{Preparing a project description}

As stated above, the project description would need to guarantee the legal system and participants of the safe method of recording and of the safe handling of data, and would need also to convince them of the importance of the investigation and thus of the value of collecting and analysing authentic data. However, presuming that the people to whom I would send the project description would have neither the time, nor the energy, to read a long and detailed description, I prepared a relatively brief and concise document, which, apart from providing the above-mentioned guarantees, included information about the objective and the background of the investigation and the method of research. I emphasized that, not only had I 
taken steps to ensure that the recording process would be inconspicuous and safe, I was aware also that every single participant would have to give his permission before any actual recording would take place. I also drew attention to the fact that I am an authorized and practising court interpreter myself, and therefore familiar with criminal procedure and fully aware of the need for confidentiality.

\subsubsection{Getting the co-operation of the legal system}

I started the process of getting the co-operation of the legal system as early as October 1997. I started by contacting the Ministry of Justice in Copenhagen. I considered that, by contacting the Ministry, I might be able to get access to the courts as a group ${ }^{2}$. I was informed, however, that it would be up to an individual court, or rather the judges at that court, to decide whether or not they wanted to participate in my research project, which meant that I would have to contact each court separately. Since this would be extremely time-consuming, I then decided to contact the four courts which I considered most likely to require the assistance of English interpreters relatively frequently: the two Danish high courts and the district courts in Copenhagen and Aarhus (cf. Chapter 3, Section 3.1).

The high courts were considered suitable for my purpose because, as explained in Chapter 3 (Section 3.1), they try the more serious indictable offences and thus conduct relatively long and time-consuming trials, involving a multitude of witnesses. Unfortunately, however, in January 1998 the high courts informed me that they were not at the time able to participate in any research projects. They did not offer any explanation why, and of course they may have declined simply as a matter of principle. Interestingly, about one year later, in early 1999, I contacted one of the high courts again, by telephone (cf. Section 4.3.1.9 below), and spoke to one of the judges at that court who said that, personally, he would await the result of the bill referred to in Section 4.3 above before deciding if he would allow anyone to bring recording equipment into his courtroom, but that he was not in favour of granting this kind of access to trials, because, in his opinion, there was a high risk of the recorded material being used for all kinds of purposes. He maintained that it would be difficult for

2 Cf. Chapter 3, note 42. 
researchers, including myself, to keep a promise of confidentiality, despite our good intentions, because, as he put it, "others may get access to the data and use them as they please". Of course, he was expressing his own views, but it is possible, I presume, that other high court judges were of the same opinion.

The two district courts were considered suitable because they are situated in the two largest cities in Denmark and therefore get the bulk of cases in which interpreters appear. However, having been informed that the high courts were not able to participate in my research project, I transported the focus of the investigation from criminal cases in high courts and district courts to criminal cases in district courts only. I subsequently contacted four more district courts, the court in Odense, the third largest city in Denmark, and the courts in three other large Danish towns, assuming, because of the size and/or location of each of these towns, that the courts would be likely to try a relatively large number of cases requiring the assistance of interpreters. All district courts expressed a great interest in my research project and willingly agreed to participate. However, the four courts outside Copenhagen and Aarhus eventually informed me that they did not very often require the assistance of court interpreters of English and therefore might not be able to help me after all.

I made initial contact with each of these courts by phoning them, asking to speak to the chief judge. I then informed the chief judge of the purpose of my call, and arranged to send him the project description right away. I also promised him a copy of this thesis. He on his part promised to present my request and the project description to the other judges of his court at the earliest opportunity. As predicted, deciding on and acquiring the recording method and equipment (as well as preparing the project description, of course) before contacting the courts turned out to be a good strategy, because the immediate concern of the chief judges (and their colleagues) was that the recording process would neither disrupt the trial process nor violate rights. Luckily, by drawing attention to the recording equipment, I was able to assure them that this was my concern also, and to demonstrate to them that I had already taken steps to ensure that the recording process would not obstruct proceedings in any way. 
I was subsequently informed, in writing, that all the judges at the six district courts were interested in my research project and therefore willing to participate, in principle, but that it would always be up to a presiding judge to decide whether or not I would be granted permission to record the interpreted dialogues at a particular trial. The courts stressed that the recording process had to be inconspicuous and safe, and that each participant at a trial had to grant his or her permission for me to be able to record proceedings. Of course, these conditions were not unexpected, as I had in fact already guaranteed that I would meet them (cf. Section 4.3.1.2).

Unfortunately, however, the courts also informed me that they wanted no part of the administrative work involved. In other words, I was not to expect any help from court personnel, but had to find another way of getting information about suitable trials and establishing contact with participants.

\subsubsection{Getting the co-operation of authorized court interpreters}

Once I had obtained the co-operation of the two courts in Copenhagen and Aarhus, in January 1998, I began steps to get in contact with as many authorized court interpreters as possible. I started out by contacting the two Danish trade associations for authorized interpreters: the Association of Danish Authorized Translators (Translatørforeningen) and the Danish Association of State-Authorized Translators and Interpreters (Dansk Translatørforbund). The two associations represent all but a few authorized interpreters in Denmark, and both kindly supplied me with a list of members, which enabled me to pinpoint the interpreters who functioned as court interpreters interpreting between English and Danish. I contacted each and every one of these interpreters. Furthermore, when some of them referred me to authorized interpreters who were not members of either trade association, I contacted these interpreters also, and as a result I must have spoken to nearly every English court interpreter in Denmark at the time. All the interpreters that I spoke to expressed an interest in my research project, though some said, not unexpectedly (cf. Section 4.3 above), that they did not like the idea of being recorded. However, all in all, ten interpreters agreed to co-operate, which I considered a fair representative sample, considering that there could have been no more than 25 authorized interpreters in Denmark at the time who worked regularly as 
court interpreters interpreting between English and Danish. The figure of 25 was reached by attempting a fair guess at the (limited) number of authorized interpreters not on either list of members, including those that I had spoken to already, and adding this number to the number of interpreters who were members of either trade association. In all likelihood, the total figure was less than 25 .

I contacted the court interpreters by telephone. I did not promise to send them a project description since I did not want to give them specific details of the objective of the investigation, but I gave them some information about the recording process and the handling of data over the phone. I took pains to assure them that the recording process would not in any way interfere with, or disturb, their performance, that is, they would not be required for example to wear a microphone, or to speak in a certain direction, or in a very loud voice, etc. I also told them that, if I would be recording their performance, I would like to ask them a few questions concerning their training and experience as court interpreters (cf. Section 4.1 and 4.2). However, I assured them that I would not be contacting them afterwards with additional questions, etc. Finally, I promised them that, once I had finished recording and transcribing an interpreter's performance, I would provide her with a copy of the relevant transcriptions, as well as a copy of this thesis.

Naturally, the court interpreters were curious about the objective of the investigation and wanted specific details, but I told them that I was not able to provide these details, since I wanted to avoid influencing their performance, which they appeared to understand and accept. I took pains to assure them, however, that I was not undertaking a study of interpreter errors, nor would I be judging their performance in order to present it as 'good' or 'bad' interpreting. Finally, I pointed out to them that I was a practising court interpreter myself and therefore fully familiar with the strain of court interpreting.

\subsubsection{Getting the co-operation of prosecutors}

Having obtained the co-operation of the courts and the court interpreters, the next step was to get the co-operation of prosecutors. The prosecution service in Denmark is controlled by the Ministry of Justice, and it consists 
of the Director of Public Prosecutions (Rigsadvokaten), the regional public prosecutors (statsadvokaterne) and the chief constables (politimestrene). The Director of Public Prosecutions is head of the prosecution service and conducts prosecution in criminal cases before the Supreme Court. The regional public prosecutors attend to criminal cases before the high courts and superintend the chief constables. The chief constables, or their legal representatives (cf. Chapter 3, Section 3.5.1), attend to criminal cases in district courts in their respective districts.

This time, I did not make the mistake of contacting the Ministry of Justice, but I contacted the office of the Director of Public Prosecutions instead, considering that this would enable me to get the co-operation of prosecutors in district courts as a group. Again, I used the method of making initial contact over the phone and then sending a description of the research project.

The office of the Director of Public Prosecutions informed me that the chief constables in the relevant judicial districts had been notified of my research project and had agreed to participate. However, four conditions were specified: (1) I was only to record proceedings in open court, (2) all participants had to agree to my recording beforehand, (3) I was not to transcribe sensitive information, e.g. names, addresses, etc., and (4) I was to use the tapes and the transcriptions for research purposes only, and they had to be stored in a safe place. The three latter conditions I had in fact already specified in the project description. They were thus acceptable and anticipated conditions. However, the first condition was a restricting factor, since it would limit the number of suitable trials. Nevertheless, though the judges at the four district courts had not imposed this condition, I had to consider that a district court judge would not be likely to grant me permission to record interpreted proceedings at a hearing in camera anyway (cf. Section 4.3 above).

Besides, imposing the four conditions, the office of the Director of Public Prosecutions also emphasized, as did the courts, that the recording process was not to disturb or interrupt the trial, and that it would be a matter for the individual judge to grant permission as he saw fit. 


\subsubsection{Getting the co-operation of defence counsels}

The co-operation of a defence counsel would have to be obtained immediately prior to a trial, as explained above (cf. Section 4.3.1). In Denmark, defence counsels are lawyers in private practices who are hired to represent individual clients in individual cases. Consequently, defence counsels would not as a group be privy to my request for permission to record interpreted proceedings.

\subsubsection{Getting the co-operation of defendants and witnesses}

As mentioned earlier (cf. Section 4.3.1), I would not able to contact defendants and witnesses directly, so their co-operation would have to be obtained through defence counsels or prosecutors.

\subsubsection{Locating suitable trials}

Since the district courts had made it clear to me that I was not to enlist the assistance of court personnel (cf. Section 4.3.1.3), I had to find a way of getting information about suitable trials that would not involve the courts. However, considering that a trial had to require the assistance of a specific court interpreter, in order to be considered suitable for my purpose, I solved Issue (8) by asking the ten interpreters to inform me about trials, to which they willingly agreed. I then supplied them with my telephone numbers and other details and asked them to contact me whenever they were hired for a trial, and inform me of the venue and any other information available to them. I would then contact the court and all participants. I took pains to emphasize to the interpreters that they needed only to inform me of their assignments, that is, they should not attempt to get in touch with participants on my behalf, nor should they to worry about details, such as whether I would be able to get to the court in time to record proceedings.

\subsubsection{Final comments}

I began the process of collecting data in August 1997, and by April 1998 I had found solutions to Issues (1) to (8) and was ready and eager to start recording as soon as possible. But by August 1998 I had still not been contacted by any of the ten court interpreters. I then contacted all ten 
interpreters again. They responded that they had not been called to interpret, or that they had been called to interpret cases heard in camera, or in one of the high courts, or that they had been called just 15-30 minutes before a hearing which would not have enabled me to get to the court in time to record proceedings. These things happen, of course. I kept in touch with the ten interpreters, contacting them as often as possible. But still nothing happened. One interpreter finally said that she did not after all like the idea of being recorded. She was the only one who expressed any doubts, but of course I did speculate that more interpreters had changed their mind and regretted their initial willingness to co-operate. Still, I have to say that three of the ten interpreters did finally participate in the research project, for which I am of course extremely grateful (cf. Sections 4.1 and 4.2 above). Besides, two more of the ten interpreters contacted me from time to time, but, again, they were either hired for cases in the high courts (which led to my telephone conversation with the high court judge, referred to in Section 4.3.1.3 above), or for cases heard in camera. Presumably, had circumstances allowed this, more interpreters would have contacted me.

Naturally, with the wisdom of hindsight, I have to conclude that it took me a long time to surrender to the fact that authentic data would not after all be available, at least not for some time. My excuses are (1) that I was set on getting authentic data, for the reasons stated in Section 4.3 above, (2) that I was spurred on by the fact that, as a group, the courts, the court interpreters and the prosecutors expressed great interest in my research project and declared that they were willing to participate, and (3) that there was, and still is, much focus on court interpreting in Denmark, though, sadly, often on the need for more properly trained interpreters.

In any case, I finally gave up the wait in January 1999 and began seriously contemplating how I would be able to obtain suitable data from a simulated setting. As explained in Section 4.1 above, my contemplations resulted in a mock trial being staged at the Aarhus School of Business in April 1999, and involving two of the above-mentioned ten court interpreters. Fortunately, the trial provided suitable data and enabled me to carry out analyses. Then, in November 1999, I was contacted by a third of the abovementioned ten court interpreters, who informed me that she had been called to assist at a trial in the district court of Copenhagen. As stated in Section 
4.2, I was able to record her performance in that trial and thus to acquire authentic data also.

\subsection{The transcription process}

Like Wadensjö $(1992,1998)$ and many others (e.g. Dam 1995, Schjoldager 1996), I transcribed the recorded dialogues myself. Like Wadensjö (1998:100), and others, presumably, I found transcribing an eye-opening process. In particular, I found, like Wadensjö (1998:100), that it sharpened my awareness of the peculiarities of spoken language, and of the significant difference between spoken language conventions and written language norms. I was aware of this difference beforehand, of course, but I was not aware of how significant it would turn out to be. Moreover, I agree with Wadensjö (1998:100) that transcribing recorded data sharpens "one's ear and sense of detail", and that it promotes "a general understanding of what spontaneous spoken interaction is all about".

Since the 1970s, transcription as method and theory has been the focus of a variety of studies (e.g. Ochs 1979; Heritage \& Atkinson 1984; Button \& Lee 1987; Du Bois 1991; Edwards \& Lampert 1993). The general view expressed in these studies is that transcriptions cannot constitute raw data, and that they should always be used in close combination with recordings, since transcriptions will not be able to present all the details and peculiarities of the recordings. Besides, O'Connell \& Kowal (1990:453, cf. also 1999:104) point out that "transcription of spoken discourse is not theory neutral". In other words, transcriptions are always theory-induced, and therefore selective and biased, which must be taken into account when using them for the purpose of analysis. Consequently, as Schjoldager (1996:68) observes, we should regard transcriptions as merely "practical tools which facilitate repeated and detailed examination by being readily available and relatively manageable". Bearing this in mind, I was careful to use the transcriptions in my investigation in close combination with the recorded material, rather than regard them as the data.

Since the recording process was relatively simple (cf. Section 4.3.1.1) I was able also to observe proceedings at both trials, and to make written notes of my observations (cf. Section 4.6). These did not deal with linguistic 
aspects, but they nevertheless have to be taken into consideration, since they may have influenced the transcription process, as well as the analyses in Chapters 6 and 7.

\subsubsection{Transcription conventions}

The conventions adopted for the transcription of the recordings have been inspired by the conventions adopted by Wadensjö $(1992,1998)$ and by the works of O'Connell \& Kowal (1994, 1995, 1999). Following the lead of these scholars, the research purpose is considered the key element. With this in mind, the conventions are as follows:

- Only material essential to the research purpose is transcribed.

- The transcripts are given a simple structure, making them easy to read. Whenever a new speaker starts talking, i.e. whenever there is a change of turn including interrupted onsets, feedback items and simultaneous talk - a new line indicates this. Initials represent speakers, e.g. J for Judge and D for defendant (cf. Section 4.4.2 below).

- The transcription method is orthographic transcription. The orthography is generally conventional orthography, but does include variants such as spoken language particulars (e.g. cause for because, and the Danish og instead of the Danish at in connection with infinitives) and syntactic errors (e.g. incorrect use of prepositions).

- $\quad$ Each symbol indicates only one thing.

\subsubsection{Transcription symbols}

The transcription symbols are presented in Table 4.1 below. The reader should note that punctuation symbols are not necessarily grammatical 
boundaries; rather they are used to mark what Wadensjö (1992:65) refers to as "communicatively relevant prosodic (intonation) terminals".

\section{Table 4.1: Transcription symbols}

\begin{tabular}{|c|c|}
\hline • & $\begin{array}{l}\text { "Terminating intonation" (usually with a falling tone), } \\
\text { indicating that the speaker is prepared to relinquish the turn, } \\
\text { or, at least, that an information unit has been completed. }\end{array}$ \\
\hline$?$ & $\begin{array}{l}\text { "Questioning intonation" (usually with a rising tone), } \\
\text { indicating that the speaker wants a response from the } \\
\text { addressee. }\end{array}$ \\
\hline , & $\begin{array}{l}\text { "Continuing intonation" (usually with a rising or sustained } \\
\text { tone, with or without a short pause), indicating that the } \\
\text { information unit has not been completed and/or that the } \\
\text { speaker does not want to relinquish the turn. }\end{array}$ \\
\hline- & Indicates a sudden cut-off of the current sound. \\
\hline$\ldots$ & $\begin{array}{l}\text { "Open-ended intonation" (utterance fading out with an } \\
\text { ambiguous intonation terminal). }\end{array}$ \\
\hline : & $\begin{array}{l}\text { Indicates that the sound just before has been noticeably } \\
\text { lengthened. }\end{array}$ \\
\hline$()$. & Indicates a pause of less than a second. \\
\hline$(.)$. & Indicates a pause of a second or more. \\
\hline$(())$ & Indicates paralinguistics. \\
\hline underlining & Indicates simultaneous talk. \\
\hline$* *$ & $\begin{array}{l}\text { Frames an utterance or part of an utterance and indicates that } \\
\text { the framed part is pronounced in a low voice. }\end{array}$ \\
\hline boldface & Indicates emphasis. \\
\hline[] & $\begin{array}{l}\text { Indicates a language switch within an utterance, or indicates } \\
\text { that Danish is spoken to the English-speaking participant } \\
\text { and/or vice versa. }\end{array}$ \\
\hline$(\mathrm{xxx})$ & $\begin{array}{l}\text { Indicates that the transcriber heard talk but could not } \\
\text { identify the words. }\end{array}$ \\
\hline
\end{tabular}


A formal translation (cf. Chapter 6, Section 6.1.2) of each source text is written in italics under each source text line.

\subsubsection{Abbreviations}

Table 4.2 presents the abbreviations used in the examples in Chapters 6 and 7:

\section{Table 4.2: Abbreviations in examples}

\begin{tabular}{|l|l|}
\hline ST-initial & Source text. The initial identifies the speaker. \\
\hline FT & Formal translation. \\
\hline TT-I & Interpreter's target text. \\
\hline PC & Pre-trial consultation. \\
\hline QD & The questioning of the defendant. \\
\hline QW & The questioning of the witness. \\
\hline J & Judge. \\
\hline P & Prosecutor. \\
\hline DC & Defence counsel. \\
\hline D & Defendant. \\
\hline W & Witness. \\
\hline I & Interpreter. \\
\hline
\end{tabular}

Numbers following the abbreviations PC, QD or QW refer to particular pages and lines in the transcribed data, so that e.g. QW.7.12-15 refers to the transcription of the questioning of the witness, page 7, lines 12 to 15 .

Double underlining marks important points. 


\subsection{Status of data}

The data collected for this investigation may be open to criticism on three points: (1) the data were collected at two trials only, resulting in a relatively small amount of data being available for analysis, (2) one of the two trials was a simulated trial, which may have influenced the performance of both the interpreters and the primary speakers at that trial, and (3) the interpreters and the primary speakers at both trials were aware that the interaction was being recorded for the purpose of analysis, which may also have influenced performances. However, considering the limited accessibility of data for interpreting research in general (cf. Section 4.3), it is fortunate indeed that such issues have not been allowed to prevent empirical research into the work of interpreters in courtroom proceedings and in other dialogue interpreting events. Obviously, without the various studies conducted since the late 1970s (cf. Chapter 2, Section 2.1), we would still know very little, if anything at all, about the many important issues that dialogue interpreters, including court interpreters, are confronted with as a matter of course. Consequently, I submit that, as long as relevant points in connection with the data are kept in mind throughout an investigation, there is no reason why empirical research into the work of interpreters may not be carried out on, for example, data collected at a simulated setting. Thus, I agree with Schjoldager (1996:95) who argues in her study of simultaneous interpreting that "simulated performances may constitute a valid object of study, as long as the lack of authenticity is kept in mind during the study".

In the next three sections, 4.5.1 to 4.5.3, I shall discuss in more detail each of the three points referred to above, all of which had to be kept in mind during the analyses of the collected data (cf. Chapters 6 and 7).

\subsubsection{Amount of data}

The amount of data analysed in the investigation in this thesis seems to compare well to the amount of data analysed in other studies of court interpreting (e.g. Hale 1997b; Jansen 1995; Kadric 2000), though it is not nearly as extensive as the amount of data analysed by Berk-Seligson (1990b) in her study of court interpreting in the USA. However, since the 
fact that large amounts of data would not necessarily be available was taken into account right from the beginning of this investigation, the objective has never been to make generalizations about the performance of court interpreters, in Denmark or elsewhere, but to explore and describe the work of some court interpreters (cf. Chapter 1, Section 1.2). The amount of data was certainly more than sufficient to reach that objective. Moreover, the data collected at the two trials presented a lot of both interesting and relevant aspects, since the assignments presented the interpreters with a number of challenges which presumably added to the strain of interpreting the dialogues: First of all, the alleged crime tried in the mock court, rape, was a highly sensitive issue. Consequently, the two interpreters at this trial were required to interpret sensitive, as well as stressful, interaction. Secondly, the indictment at the authentic trial listed nine counts of fraud committed with the use of false credit cards, and referred to a large number of shops, restaurants, etc. Consequently, the defendant at this trial was questioned about many details and for an extensive period of time. Moreover, since he did not have English as a mother tongue, many of his utterances were fragmented and/or did not display a correct use of grammar and terminology (cf. Sections 4.6.2 and 4.6.3 below and Chapter 6, Section $6.3)$.

\subsubsection{Lack of authenticity}

The performance of the interpreters and the primary speakers at the mock trial may have been influenced by their awareness of the fact that the proceedings were simulated only. Obviously, all participants at this trial, including the interpreters, knew that they were not taking part in a real life situation, that no actual crime had been committed, and that the outcome of the trial would have no real consequence for either the defendant or the victim/witness, or for any other participant for that matter. Thus, all participants may have performed differently from how they would perform in an authentic setting. Nevertheless, transcriptions of recordings from both trials and the analyses of both kinds of data (cf. Chapters 6 and 7) did not reveal any significant difference between the two kinds of data as regards the question-answer procedures, or the performance of participants, including the performance of the interpreters. Thus, for example, the prosecutor and the defence counsel at the mock trial did not refrain from 
asking the kind of intimate questions that is usually asked in connection with a rape case, and the interpreters did not refuse to interpret intimate details. Rather, the participants appeared to be 'conducting business as usual' (cf. Section 4.1 above). Perhaps, to some extent, this may be due to the fact that, when staging the mock trial, I had taken every possible step to make it resemble an authentic trial: the interpreters were fully competent professionals, the judge, prosecutor and defence counsel were all lawyers practising criminal law and experienced in conducting trials, the defendant and the witness knew no Danish whatsoever, the furniture was rearranged in order to make the room look like a courtroom, and, last but not least, the case description was made out by someone who had prosecuted numerous rape cases, and who had his own reasons for wanting the trial to be conducted in the manner of an authentic trial (cf. Section 4.1).

As regards the simulated pre-trial consultation (immediately before the mock trial), it is of course quite conceivable that, despite the fact that this consultation was conducted in a professional manner, the participants, i.e. the defence counsel, the defendant and the interpreter, was at that moment more conscious of the fact that they were performing in a simulated setting, than during the actual trial. It is also conceivable that they regarded the pretrial consultation as a less controlled setting than the actual trial. Consequently, they may have performed in one manner during the pre-trial consultation and in another manner during the trial itself. However, nothing in the data from the pre-trial consultation indicates a less than professional attitude on their part to the job at hand.

Nevertheless, I do not dispute the fact that there may be a difference between simulated and authentic performances. But, as submitted earlier, as long as the lack of authenticity is kept in mind, there is no reason why the simulated performances recorded at the mock trial should not be considered a valid object of study.

\subsubsection{Awareness of the recording process}

A final point which has to be kept in mind during analyses is the fact that the participants' awareness of the recording process, that is, of the fact that speakers' originals and subsequent renditions would be recorded for the 
purpose of analysis, may have influenced the production of both source texts and target texts at both trials. However, in a courtroom setting, which, as mentioned in Section 4.3 above, is by definition controlled and agendabound, and where participants have predefined roles and, at least at the authentic trial, their own reasons for being involved, people may forget, at least part of the time, that they are being recorded and observed (cf. e.g. Wadensjö 1992:58-60). Moreover, at both trials (and also during the pretrial consultation), the subjects of study, the interpreters, were merely doing their ordinary job, as were most of the other professionals, so presumably they quickly became submerged in the process of conducting a trial. As for the two defendants and the witness, they were presumably too busy handling their own affairs to pay much attention to the recording process: The defendant at the authentic trial was struggling to avoid a long prison sentence for a crime to which he had willingly confessed; and the performance of the defendant and the witness at the mock trial demanded a lot of concentration and inventive skills on their part, since it meant having to come up with realistic answers to unexpected questions, relating to a crime which had not been committed in real life.

Furthermore, as mentioned in Chapter 2 (Section 2.3), the particular nature of the interpreting performance - high velocity and deep concentration makes it extremely difficult for interpreters to pay attention to details outside the interpreting process. In addition, neither of the three interpreters appeared to be particularly self-conscious, or to be monitoring their own performance in order to be doing what they perceived as their best, which would presumably indicate that they did not pay much attention, at least not all of the time, to the fact that they were being recorded and observed: First of all, immediately after the conclusion of the mock trial, the professionals, the lawyers and the interpreters, agreed that the interpreting students who attended the trial as spectators should be allowed to ask questions regarding the proceedings and the performance of participants. The two interpreters did not remember many details of their own performance, though. Presumably, they would have remembered more details, had they been monitoring their performance more than usual, in order to do their best for the recorder. Secondly, when I spoke to the interpreter at the authentic trial during and immediately after the trial, she was likewise unable to recall many details of her performance, which would seem to indicate that, just as the two interpreters at the mock trial, she did not monitor her own 
performance to any unusual extent either, in order to do her best for the recorder.

Finally, as stated above, I had taken steps to make the recording process as inconspicuous as possible, which meant that, among other things, the interpreters did not have visual contact with the recording equipment during questionings (though some other participants were able to spot it from time to time). This is not to say, of course, that the interpreters, or the other participants, were able to ignore the fact that they were being recorded and observed throughout the trial periods (and the pre-trial consultation), but merely that, in all probability, they were able to do so some of the time.

\subsection{Four kinds of interpreter behaviour}

Before concluding this chapter, I should like to discuss four kinds of interpreter behaviour observed in the recorded material: (1) One interpreter changed footing almost persistently when rendering utterances spoken by the foreign participant, (2) all three interpreters completed fragmented source texts as a rule, (3) the interpreter assisting the defendant who did not have English as a mother tongue invariably corrected his grammatical errors, and (4) all three interpreters engaged in dialogue with the foreign participants when these participants requested repetition or clarification of source texts, or when the interpreters needed them to repeat or clarify their source texts. All four kinds of behaviour are considered relevant for the investigation in this thesis, for the following reasons: (1) The interpreters' behaviour constituted a violation of ethical guidelines (cf. Chapter 3, Section 3.5.2), which occurred as a rule, rather than as an exception; (2) the other participants tolerated the interpreters' behaviour and thus their noncompliance with ethical rules; (3) though only the second kind of behaviour was directly linked to the presence of additions in the interpreters' target texts, the other three will play a part in the analyses in Chapters 6 and 7; and (4) three kinds of behaviour, (2), (3) and (4), demonstrated the interpreters' preoccupation with achieving successful interaction and thus serve to support the hypotheses presented in Chapter 1 (Section 1.2). 


\subsubsection{Change of footing}

As explained in Chapter 2 (Section 2.1.2), Goffman (1981:227) defines footing as the "alignment of an individual to a particular utterance, whether involving a production format, as in the case of the speaker, or solely a participation status, as in the case of a hearer". Thus, a person's footing concerns the relation between himself and an utterance to which he has some kind of access, as speaker or hearer, and a change in footing is therefore a change of his relation to that utterance, expressed in the way he manages the production or the reception of it. Goffman (1981:128) observes that "participants over the course of their speaking constantly change their footing, these changes being a persistent feature of natural talk". In other words, participants in interaction adopt different roles and attitudes towards each other, or towards the interaction, which are subject to constant renegotiation, and therefore constantly shifting.

Goffman (1981:226) suggests that speakers may assume or be ascribed the following three production roles: animator, the sounding box from which utterances come, author, responsible for putting together or composing the expressed utterances, and principal, carrying full responsibility and authority for the expressed utterances. In her study of dialogue interpreting encounters, referred to in Chapter 2 (Section 2.1.2) of this thesis, Wadensjö (e.g. 1992, 1997, 1998) expanded Goffman's terms and furthered his analysis to include listeners. Thus, developing the notion of reception format, corresponding to production format on the speaking side, Wadensjö (e.g. 1998:92) suggests the following three reception roles that listeners may assume or that may be ascribed to them: reporter, listening in order to repeat a speaker's words without assuming responsibility for them, responder, listening in anticipation of speaking as a primary participant, and recapitulator, listening in order to give an account of what was said as animator or author. An interpreter may adopt all three roles at various stages in an exchange, not just as the result of a free choice, but also as a reaction to primary speakers' assumptions about what constitutes the appropriate interpreter role, which is evidenced by the way they choose, consciously or unconsciously, to address each other. Wadensjö (1997:48) observes that there are four possibilities: third-person, indirect style (he, 
she, they, one), first person inclusive, direct or indirect style (we), secondperson, direct style (you), or no address form (no pronouns).

As explained in Chapter 2 (Section 2.1.2), Wadensjö (e.g. 1992, 1997) demonstrates that shifts of footing reflected in a shift of pronoun of address are commonplace in interpreter-mediated communication in face-to-face interaction. Not surprisingly, therefore, the data collected for this investigation also presented various examples of this kind of behaviour, for example when clarification was required. However, one interpreter changed footing almost persistently, when rendering utterances spoken by the foreign participant, the witness at the mock trial (cf. example 53 in Chapter 6, Section 6.2.2.2, and the discussion of this example in Chapter 7, Section 7.2.2). Since primary speakers opted for the direct style as a rule, the interpreter's choice of the indirect, third-person style in her renditions of these responses was certainly the result of a free, and conscious, choice. The ethical guidelines referred to in Chapter 3 (Section 3.5.2) of this thesis do not specify rules on this particular kind of interpreter behaviour, but the question is whether, by almost persistently rendering utterances in the indirect, third-person style, an interpreter truly complies with the principle of Accuracy and Completeness, or with the principle of Impartiality, for that matter, which requires, among other things, that an interpreter functions "as a neutral and objective language intermediary, remaining professionally detached from the principals in the case" (cf. Chapter 3, Section 3.5.2). In any case, the Danish participants who were presumably familiar with the ethical guidelines did not question, or comment on, the interpreter's use of the indirect style and thus seemingly tolerated her behaviour.

Of course, by persistently using the indirect, third-person style, an interpreter is able to create a certain distance between herself and the interaction (Mason 1999b:153; cf. also Harris 1981). Consequently, considering that the alleged crime at the mock trial was rape and that the witness had allegedly been a victim of rape, the interpreter in this investigation may have changed footing deliberately in order to create a distance between herself and what was likely to be a both stressful and sensitive testimony. However, she might have opted for the indirect style anyway: She was trained in the late 1980s when the indirect, third-person style in interpreter-mediated communication in face-to-face interaction was 
considered the norm by Danish interpreters and interpreter teachers alike. Some of the interpreters who were taught to use this style claim (personal communication) that they feel uncomfortable rendering utterances in the first person, especially utterances spoken by defendants and witnesses, and that, whenever possible, they deliberately opt for the indirect style.

\subsubsection{Completion of fragmented source texts}

For some reason, the court interpreters in this investigation completed fragmented source texts as a rule (cf. examples 116 and 117 in Chapter 6, Section 6.3.2.4.1, and the discussion of these examples in Chapter 7, Section 7.2.4.1.6), which certainly constitutes a violation of the principle of Accuracy and Completeness. Of course, as a result of their behaviour, a number of additions were included in their target texts.

Fragmented speech is not uncommon in spoken interaction, and thus not uncommon in dialogue interpreting events either. However, as demonstrated by Morris (1989a), Shlesinger (1991), Berk-Seligson (1990b) and Jansen (1995), as well as by Wadensjö (1992), regardless of setting, interpreters often complete fragmented source texts, apparently being loath to produce fragmented target texts, possibly fearing that end receivers will assume fragmented target texts to be due to interpreter incompetence. Shlesinger (1991) and Berk-Seligson (1990b) do not discuss in more details why the court interpreters in their studies were loath to produce fragmented utterances. However, Morris (1989a:35) and Jansen (1995:149) suggest that the court interpreters in their studies were motivated by a need for achieving successful interaction. Wadensjö (1992:77) suggests a similar motive, when presenting an example from an interview at a health-care clinic in which the interpreter's completion of the patient's original helped clarify her intention.

Likewise, the court interpreters in this investigation were presumably motivated first and foremost by a need for achieving successful interaction, and thus only secondarily, if at all, by fear that end receivers would assume fragmented target texts due to faulty interpretation. There is no obvious reason why the interpreters in this investigation should have been motivated by such fear: All three interpreters were competent and 
experienced professionals who did not appear to lack confidence in their own skills and professionalism. Furthermore, the similarity between the two languages involved, Danish and English, and the fact that many lawyers are sufficiently competent in English to understand many source texts in that language, makes monitoring of interpreter performance a relatively simple matter, so presumably the interpreters would assume that participants, especially the Danish lawyers, would realise that fragmented target texts were merely verbatim versions of fragmented source texts. A much more plausible explanation is, therefore, that the interpreters completed fragmented responses as a rule, because they perceived such responses as providing insufficient information of speaker meaning for an end receiver to infer this meaning, especially if he was unfamiliar with the context of the interaction (linguistic and/or situational).

Interestingly, considering that the monitoring of the interpreters' performance in this investigation was presumably, as stated, a relatively simple matter, and considering also that their behaviour must occasionally have been blatantly obvious to the other participants (cf. examples 116 and 117 in Chapter 6, Section 6.3.2.4.1), these did not at any time question, or comment on, an interpreter's completion of a fragmented source text.

\subsubsection{Correcting errors of grammar}

Apart from completing fragmented source texts, the interpreter assisting the defendant in the authentic trial, who did not have English as a mother tongue, invariably corrected his errors of grammar (cf. examples 102 and 112 in Chapter 6, Sections 6.3.2.2 and 6.3.2.4.1 respectively). Again, her action constituted a violation of the principle of Accuracy and Completeness (cf. above), and, again, she seems to have been motivated primarily by a need for achieving successful interaction, for the reasons outlined in Section 4.6.2 above (cf. the discussion of example 112 in Chapter 7, Section 7.2.4.1.3).

\subsubsection{Engaging in dialogue with participants}

Finally, the court interpreters in this investigation also engaged in dialogue with the foreign participants who requested repetition or clarification of 
source texts in Danish (cf. example 39 in Chapter 6, Section 6.1.3 and the discussion of examples 121 and 133 in Chapter 7, Sections 7.2.4.2 and 7.3.3 respectively). Likewise, the interpreters engaged in dialogue with these participants whenever they needed them to repeat or clarify their source texts in English. Presumably, the interpreters were once again motivated by a need for achieving successful interaction, that is, they needed participants to fully understand each other. Nevertheless, their behaviour constituted a violation of the principle of Accuracy and Completeness (cf. above).

Again, the interpreters' behaviour was tolerated, though the violation was so blatantly obvious that the Danish participants must have been fully aware of it. Once again, however, their apparent acceptance of this kind of behaviour may have been wholly, or partly, due to the foreign language being English. In other words, the Danish participants may have felt that they were able to monitor such dialogues, and therefore able to intervene if the interpreters engaged in them to a further extent than they, the Danish participants, were prepared to accept. Thus, it is likely that their nonintervention reflected their belief that requests for repetition, or clarification, are common features in spoken interaction; consequently they saw no reason for preventing the interpreters from complying with such request, considering perhaps that this would enable the interaction to proceed without undue delay.

Interestingly, nevertheless, by allowing the interpreters in this investigation to behave as illustrated in Sections 4.6.2 to 4.6.4, the court granted them latitude to explicate their own interpretation of speakers' intentions, which could be an indication that even participants in courtroom interaction accept that, in some situations at least, interpreters should be allowed to convey speaker meaning in order to accommodate participants, and, in turn, ensure successful interaction. Still, as stated above, the participants at the two trials may have been influenced by the fact that the foreign language in this investigation was English, as well as the fact that the interpreters were authorized interpreters, and therefore competent professionals. Possibly, the same degree of latitude would not have been granted an interpreter of a language very dissimilar to Danish, and/or who is not an authorized interpreter. 


\subsection{Conclusion}

In this chapter, I have presented and discussed the data collected for the investigation in this thesis. At first, I presented the two trials which provided the data for this investigation, the mock trial and the authentic trial, and the data collected at those trials. Then I presented the data collection process and a number of practical issues that had to be solved before any data could be collected. This was followed by a discussion of the transcription process and a presentation of the conventions and symbols used in the transcriptions, as well as a presentation of the abbreviations used in examples in Chapters 6 and 7. As recommended by the literature, the transcriptions of the data in this investigation were used only in close combination with the recorded material.

Next, I discussed the status of the collected data and concluded that these are perfectly valid for conducting the investigation in this thesis, provided that three issues, the amount of data, the lack of authenticity in the mock data and the interpreters' awareness of the recording process, are kept in mind during the analyses. The three issues were then discussed in more detail.

I also presented and discussed four kinds of interpreter behaviour observed in the recorded material. The four kinds of behaviour are considered relevant to the current investigation, because they demonstrate a noncompliance with ethical rules, which occurred as a rule, rather than as an exception, and which was tolerated by the courts. Furthermore, one kind of interpreter behaviour was directly linked to interpreter additions, and the other three will play a part in the discussion of interpreter motives in Chapter 7. Finally, the second, third and fourth kind of behaviour demonstrate the interpreters' preoccupation with achieving successful interaction and thus serve to support the hypotheses presented in Chapter 1 (Section 1.2).

However, before proceeding to present examples of additions identified through analyses of the collected data, I shall present and discuss, in Chapter 5, the pragmatic theory of conversational implicature, and apply the theory to the investigated interaction. 


\section{Conversational implicature}

This chapter presents and discusses the pragmatic theory of conversational implicature, proposed by the philosopher H.P. Grice, which provides a framework for analysing the inferencing of pragmatic, or speaker, meaning, and applies this theory to the interaction investigated in this thesis, consecutively interpreted question-answer dialogues in criminal proceedings in a Danish district court. In Section 5.1, I shall present the definition of pragmatics used in this thesis. In Section 5.2, I shall discuss the theory of conversational implicature. In Section 5.3, I shall set up a basic model accounting for conversational implicature in the investigated interaction and present various strategies court interpreters may resort to when confronted with implicature in the speech of an interactant. Finally, in Section 5.4, I shall conclude on the discussions in this chapter.

\subsection{Defining pragmatics}

The field of pragmatics has to account for a wide variety of topics, such as deixis, presupposition, speech acts, and the topic discussed in this chapter, conversational implicature. Presumably, this explains why the scope of pragmatics is so wide, or why it faces definitional dilemmas (Levinson 1983:Chapter 1; Schiffrin 1994:190). In her textbook on pragmatics, Thomas (1995:1-2) explains that the most common definition of pragmatics, or pragmatic meaning, in general textbooks on linguistics from the early 1980s, was meaning in use or meaning in context, but that more modern textbooks tend to equate pragmatics which either speaker meaning, thus putting the focus of attention on the text producer (e.g. Levinson 1983; Leech 1985; Yule 1996), or with utterance interpretation, thus focusing mainly on the text receiver (taking a broadly cognitive approach) (e.g. Green 1996; cf. also Sperber \& Wilson 1986), without necessarily using these terms explicitly. However, Thomas (1995:208) argues against adopting an approach "which is exclusively hearer-oriented or exclusively speaker-oriented". Instead she argues (1995:22) in favour of a definition of pragmatics as meaning in interaction, observing (1995:22) that the process of making meaning should be regarded as a joint accomplishment between speaker and hearer: "a dynamic process, involving the negotiation of 
meaning between speaker and hearer, the context of utterance (physical, social and linguistic) and the meaning potential of an utterance".

However, here the aim is not to discuss the scope of pragmatics as such, or the problem of definition. Instead, I shall focus on one particular type of pragmatics: Gricean pragmatics. As Schiffrin (1994:191) observes, a central concept in Gricean pragmatics is speaker meaning (another being the Co-operative principle, cf. Section 5.2.2), a concept which "not only allows a distinction between two kinds of meaning" (semantic meaning and pragmatic meaning), but which "also suggests a particular view of human communication that focuses on intentions" (Schiffrin 1994:191). In other words, speaker meaning is defined as the meaning a speaker intends to convey (his communicative intention), which may or may not relate to the semantic meaning of his words, as we shall see in Section 5.2.1 below. Hearers have no access to this meaning (cf. Chapter 7, Section 7.1), but the theory of conversational implicature provides a framework for analysing how a hearer may "infer the intentions underlying a speaker's utterance" (Schiffrin 1994:197).

For the purpose of this thesis, therefore, pragmatics, or pragmatic meaning, is equated with speaker meaning in the Gricean sense, and the terms pragmatic meaning and speaker meaning are used interchangeably throughout.

\subsection{The theory of conversational implicature}

H.P. Grice's theory of conversational implicature has been outlined and discussed in numerous textbooks and articles since the early 1980s (e.g. Levinson 1983; Leech 1985; Schiffrin 1994; Thomas 1995; Green 1996; Yule 1996). Consequently, I shall contain myself here to a discussion of its basic principles, focusing on issues relevant to the investigation in this thesis.

Grice first outlined his theory of conversational implicature in a series of lectures in 1967, a shorter version of which was published in a paper "Logic and Conversation" in 1975 (Grice 1975). He expanded on his theory in 1978 (Grice 1978) and 1981 (Grice 1981), but he never fully 
developed it. Basically, as explained in Section 5.1 above, the theory of conversational implicature is an attempt at explaining the mechanisms that allow hearers to infer a speaker's intention (speaker meaning) from the conventional (semantic) meaning of the words uttered, by relying on a number of available data. The additional level of meaning is conveyed by means of implicature.

Grice (1975:44-45) initially distinguished between two kinds of implicature: conversational implicature and conventional implicature. The two kinds of implicature both convey an additional level of meaning, but whereas conversational implicature is context-dependent and must be capable of being worked out, conventional implicature always conveys the same implicature, regardless of context (cf. e.g. Thomas 1995:57). In other words, conventional implicature is not derived from pragmatic principles, but is "simply attached by convention to particular lexical items or expressions" (Levinson 1983:127). However, the literature holds comparatively few examples of conventional implicature: Grice (1975:44) provided only one example: therefore; and Levinson (1983:127), who discusses implicature in great detail, merely suggests four: but, therefore, even, yet.

Besides distinguishing between two kinds of implicature, Grice (1975:5657) also distinguished between two kinds of conversational implicature: particularized conversational implicature, which requires a particular context of utterance to be worked out, and generalized conversational implicature, which requires no specific context. Generalized conversational implicature is, in normal (non-special) circumstances, regularly associated with a linguistic expression. For example, in "Logic and Conversation" (1975), Grice described a generalized conversational implicature associated with the indefinite article $a$ that the referent of the noun it modifies "does not belong to or is not otherwise closely connected with some (contextually) identifiable person" (1975:57). However, the notion of generalized conversational implicature is of peripheral concern here, and it will not be explored any further. The remaining part of this chapter will thus be devoted to particularized conversational implicature, generally referred to as conversational implicature, or just implicature (I shall generally employ the shorter version throughout this thesis). 
In order to fully understand how Grice's theory may provide a framework for analysing the inferencing of speaker meaning, however, it is helpful first to look at the concept of semantic meaning in relation to one of Grice's other major theories, the theory of meaning-nn.

\subsubsection{Semantic meaning and the theory of meaning-nn}

Semantic meaning, sometimes referred to as linguistic meaning, lexical meaning or decontextualized meaning (Thomas 1995:2), may be defined as the literal, conventional meaning of a word, phrase or sentence (or utterance) as understood by fully competent language users. Thus, semantic meaning "is concerned with what a word, phrase, sentence, etc. could mean" (Thomas 1995:2). The basic distinction between semantic meaning and pragmatic meaning is that, basically, semantic meaning is meaning devoid of context (hence the term decontextualized meaning), whether situational or linguistic, whereas pragmatic meaning is meaning in context (hence it is sometimes referred to as contextual meaning) (cf. Yule 1996:3).

Green (1996:6) observes that the "meanings of basic expressions are conventional, and arbitrary except for the vagaries of history". Simply put: we call water water, because that is what everyone else in our speech community calls it, and because that is what we have been taught to call it by the people from whom we learned to talk, and what they in turn were taught to call it by the people from whom they learned to talk, etc. So, we are accustomed to calling water water, and we know that if we call it something else people in our speech community cannot be expected to understand that we are in fact talking about water. Similarly, in the following example, inspired by Green (1996:6) ${ }^{1}$ :

\section{Example 1: $\quad$ The red light means 'stop' and the green light} means 'go'.

The traffic lights get their meaning purely by convention among humans, and not because there is a natural connection between a red light and the word 'stop' or between a green light and the word 'go'.

1 Unless specifically stated, the provided examples are my own. 
In a seminal paper from 1957 (reproduced in 1971), Grice referred to this kind of conventional meaning as non-natural meaning, or meaning-nn, and distinguished it from natural meaning, which he reserved for uses of the word meaning more akin to "natural consequences" (Green 1996:6), as in Those spots mean measles (Grice 1971:53) Natural meaning is devoid of human intentionality, whereas non-natural meaning, or meaning-nn, "is roughly equivalent to intentional communication" (Schiffrin 1994:191). Thus, a critical feature of meaning-nn is that the speaker intends it to be recognized in a particular way by a hearer. As Grice put it (1971:58):

'A meant-nn something by $\mathrm{X}$ ' is (roughly) equivalent to ' $\mathrm{A}$ intended the utterance of $\mathrm{X}$ to produce some effect in an audience by means of the recognition of this intention'.

But implicit in this definition of meaning-nn is also a second intention: the intention that a hearer recognize the speaker's communicative intention (1971:58). In his seminal paper, Grice provided the following example to illustrate meaning-nn (1971:53):

\section{Example 2: $\quad$ Those three rings on the bell (of the bus) mean} that "the bus is full".

For the three rings to have meaning-nn, bus riders must recognize that the bus driver or whoever caused the three bells to ring intended the effect of the bells, i.e. 'the bus is full', to be produced by their recognition of his intention.

So, in Grice's framework, "communication is a complex kind of intention that is achieved or satisfied just by being recognized" (Levinson 1983:16). In other words, the speaker's communicative intention becomes mutual knowledge to the speaker and the hearer, and achieving this state of mutual knowledge is to have successfully communicated. As e.g. Levinson (1983:17) observes, this provokes the question of how this complex reflexive intention is meant to be recognized by the hearer. Certainly, a speaker may intend to communicate precisely the conventional meaning associated with his words, and nothing more. However, this is not Grice's point. Instead, as e.g. Schiffrin (1994:192-193) observes, his framework allows "speaker meaning to be relatively free of conventional meaning", 
and therefore his critical insight is "that what the speaker intends to communicate need not be related to conventional meanings at all, and need not be conventionally "attached" to the words being used". The full communicative intention is thus to be recognized by taking into account not only the conventional meaning of an utterance, but also the precise mechanisms which may cause a divergence between the meaning of the utterance and what is communicated by the utterance in a particular context (Grice 1975). These mechanisms, in Grice's framework called conversational principles, are the ones that allow hearers to infer speaker meaning, i.e. to deduce from evidence, whether linguistic, paralinguistic or non-linguistic, what a speaker intends to imply (cf. Thomas 1995:58). In other words, speaker meaning is interpreted by examining the semantic content of a speaker's utterance and by relying on some specific assumptions abut the co-operative nature of ordinary interaction ${ }^{2}$ (cf. Levinson 1983:104).

\subsubsection{The Co-operative Principle (CP) and the maxims}

In "Logic and Conversation" (1975), Grice defined the conversational principles, the mechanisms that allow the inferencing of speaker meaning, as a set of general principles about rationally based communicative conduct which tells speakers and hearers how to communicate, that is, the same kind of rational conduct as the one which guides people in their behaviour towards each other in other spheres of life. Grice (1975:45) explained that the principles are based on the assumption that conversation characteristically consists, to some degree at least, of co-operative efforts, and that each participant recognizes in these co-operative efforts, to some extent, a common purpose or set of purposes, or at least a mutually accepted direction. This purpose or direction may be fixed from the start or it may evolve during the conversation; it may be fairly definite, or it may be so indefinite as to leave very considerable latitude to the participants. At each stage of the conversation, however, some possible conversational moves will be excluded as conversationally unsuitable. Based on this assumption, Grice (1975:45) explained, it is possible to formulate "a rough

2 Grice initially meant his theory to refer to spoken interaction, but it applies equally well to written texts, as will be demonstrated by some of the examples in this chapter. 
general principle which participants will be expected (ceteris paribus) to observe". Grice labelled this principle the Co-operative Principle (CP) (1975:45):

Make your contribution such as is required, at the stage at which it occurs, by the accepted purpose or direction of the talk exchange in which you are engaged.

Underlying the $\mathrm{CP}$ are four more specific, conversational maxims. Grice did not list them in any order of importance, but they are generally reproduced in the order in which he initially presented them (1975:45-46):

\section{The maxim of Quantity:}

1. Make you contribution as informative as is required (for the current purposes of the exchange).

2. Do not make your contribution more informative than is required.

The maxim of Quality: Try to make you contribution one that is true.

1. Do not say what you believe to be false.

2. Do not say that for which you lack adequate evidence.

The maxim of Relation: Be relevant.

The maxim of Manner: Be perspicuous.

1. Avoid obscurity of expression.

2. Avoid ambiguity.

3. Be brief (avoid unnecessary prolixity).

4. Be orderly.

In short, these principles specify how participants may be expected to behave in order to converse in a maximally efficient, rational, co-operative way. Of course, one immediate objection will be that no one actually speaks like this the whole time. However, that would be missing Grice's point, which is that, since conversation, like any other transaction in human life, is goal-directed, and since the maxims express principles which are ways of efficiently achieving goals, participants will assume that these principles are adhered to in some way in ordinary conversation, so that when a speaker's utterance appears not to be, a hearer will not dismiss it off 
hand as irrelevant, or ridiculous, or out of order, but rather look for an alternative interpretation of the utterance, i.e. an implicature (Grice 1975:48-49).

Though Grice expressed the $\mathrm{CP}$ and the maxims in the imperative mood, he did not intend to lay down norms or rules for how people ought to behave, as some have come to believe (e.g. Brown \& Yule 1983:32; Sperber \& Wilson 1986:162). The CP and the maxims do not express what people should do in ordinary conversation, but what they assume each other to be doing in order to achieve their communicative objective. As Green (1996:96) observes, nothing in "Logic and Conversation" suggests that Grice regarded "the maxims as statistical principles that people tend to conform to, or as ideals that people aspire to conform to".

Likewise, Grice did not intend the maxims to be regarded as constituting the CP (as seen by e.g. Sperber \& Wilson ${ }^{3}$ 1986:36; Schiffrin 1994:194). As Green (1996:96) points out, the CP is just "a very general principle which determines, depending on the values shared by participants, any number of maxims instantiating ways of conforming to it". Thus, Grice (1975) never regarded the four maxims as an exhaustive list, but explicitly suggested (1975:47) that more maxims might be needed, for example maxims that might be aesthetic, social, or moral in character, "such as 'Be polite"”.

However, a crucial feature of implicatures is that they must be capable of being worked out, and Grice (1975:50) described the calculation process as follows:

To work out that a particular conversational implicature is present, the hearer will rely on the following data:

(1) the conventional (semantic) meaning of the words used, together with the identity of any references that may be involved;

(2) the CP and its maxims; 
(3) the context, linguistic or otherwise, of the utterance;

(4) other items of background knowledge;

(5) the fact (or supposed fact) that all relevant items falling under the previous headings are available to both participants and both participants know or assume this to be the case.

To illustrate by an example:

Example 3: $\quad$ I am in a restaurant with a friend. A waiter carrying a tray with two bowls of soup is passing our table when he accidentally trips, pouring the soup down the back of my friend. My friend says to me:

Fantastic! That's really made my day!

Pursuing Grice's suggestion, this might be my deductive process:

(1) My friend has expressed pleasure at having soup poured down his back. People do not usually express pleasure in such situations.

(2) I have no reason to believe that my friend is trying to deceive me. However, if he is observing the $\mathrm{CP}$ and the maxims, he must be trying to put across some other proposition.

(3) The context supports my deduction that my friend must be trying to put across some other proposition: We were having a quiet dinner, and were discussing a serious issue; neither of us was in a particular joyful mood; etc.

(4) I have an idea how I and other people would feel if the same thing happened to us. I know that my friend is not given to taking things like this

3 In fact, as explained in Chapter 7 (Section 7.1.1.1) of this thesis, Sperber \& Wilson (1986, cf. Wilson \& Sperber 1981) argue that Grice's four maxims may be reduced to a single well-defined principle, the principle of Relevance. 
lightly. I know that he was wearing a brand-new suit.

(5) All of the above facts are available to both of us.

My conclusion: My friend is extremely annoyed at having soup poured down his back ${ }^{4}$.

As this basic process shows, implicatures can be created by the nonobservance of the maxims. As will be demonstrated below, participants in ordinary interaction may fail to observe the maxims on many occasions and for a number of reasons.

\subsubsection{Non-observance of the maxims}

In "Logic and Conversation" (1975), Grice listed three ways in which a participant in a talk exchange may fail to fulfil a maxim: violating, opting out, or flouting (1975:49). As Thomas (1995:72) observes, his original distinctions are important for a full understanding of his theory. It is unfortunate, therefore, that Grice does not always use the terms consistently; for example, in "Logic and Conversation" (1975:51-52) he alternately used the terms 'violating' and 'infringing' for violating a maxim, and the terms 'flouting', 'infringing' and 'violating' for flouting a maxim. Regrettably, other textbooks are not much clearer on the matter: Levinson (1983:104ff), who acknowledges the problems connected with terminology, first refers to flouting as 'breaching' or 'infringing' a maxim, and then later uses the terms 'flouting', 'exploiting' and 'infringing' alternately; Brown \& Yule (1983:31-33), who provide only a brief account of implicature, use the term 'flouting' for all kinds of non-observance, and use it alternately with 'infringing'; Green (1996:92ff) alternates between 'exploiting', 'violating' and 'flouting' maxims, but also refers to 'opting out'. Perhaps this apparent confusion is the reason why Schiffrin (1994:195ff) adheres to Grice's original designations. Thomas (1995:64ff) also adheres to Grice's original three designations, but observes (1995:72) that he later added a fourth category: infringing. Moreover, Thomas (1995:72) convincingly argues the need for a fifth category: suspending a maxim, which results in the following five categories of non-observance:

4 Cf. example 7, p. 113. 
- $\quad$ Flouting

- Violating

- Infringing

- Opting out

- $\quad$ Suspending

The five categories are listed here in the order in which they are presented and discussed by Thomas (1995:64ff). Since Thomas' distinctions relate to actual cases in the collected data they are considered useful for the purpose of this thesis (cf. Chapter 6 and Chapter 7). Following Thomas (1995), therefore, I shall review and exemplify in Sections 5.2.31 and 5.2.3.2 below each of the five categories of non-observance in the order listed here.

The first category of non-observance, flouting, is the one that generates implicatures. It is therefore the most important category, which explains why it is listed first and why it will be dealt with first. The other four categories, violating, infringing, opting out and suspending, which cover non-observance where speakers have no desire to generate implicatures, but nevertheless fail, deliberately or not, to observe the maxims for one reason or another, will be dealt with second.

\subsubsection{Flouting a maxim}

Grice (1975:49-50) explained that flouting occurs when a speaker blatantly fails to fulfil a maxim, not because he intends to deceive or mislead, but because he wishes to prompt a hearer to look for a meaning which is different from, or in addition to, the expressed meaning. Since participants operate on the assumption that, as a rule, the maxims will be observed, a hearer confronted with a blatant non-observance of a particular maxim will be prompted to look for an implicature (1975:52). In other words, as demonstrated by the different examples of floutings in Sections 5.2.3.1.1 to 5.2.3.1.5 below, it is the very blatancy of the non-observance, which triggers the search for an implicature.

According to Grice (1975:49), floutings may be necessitated by a clash between maxims, or because a speaker blatantly fails to observe a maxim in order to generate an implicature. 


\subsection{Flouting necessitated by a clash between maxims}

When a speaker cannot observe one maxim without failing to fulfil another, he may signal his dilemma by blatantly flouting one of the maxims. Grice (1975:51) provided the following example to illustrate this kind of nonobservance:

Example 4: $\quad$ A is planning with $B$ an itinerary for a holiday in France. Both know that A wants to see his friend C, if to do so would not involve too great a prolongation of his journey:

A: Where does $C$ live?

B: $\quad$ Somewhere in the South of France.

According to Grice (1975:51), B's answer is less informative than is required to meet A's needs, and as such it constitutes a flouting of the first maxim of Quantity. However, since A has no reason to believe that B is being deliberately uncooperative, i.e. that he is failing to observe the $\mathrm{CP}, \mathrm{A}$ must conclude that B's failure to observe the maxim is due to a wish to observe the CP in some other way. In this example, according to Grice (1975:51), B cannot observe the first maxim of Quantity without flouting the second maxim of Quality ('Do not say that for which you lack adequate evidence'). So, faced with a clash between the two maxims, B blatantly flouts the first maxim of Quantity and provides an answer which implicates that he does not know in which town $\mathrm{C}$ lives.

However, the majority of Grice's examples illustrated the second and most interesting kind of flouts: those that occur for the express purpose of generating an implicature. In Grice's terminology, such flouts exploit maxims (1975:49).

\subsection{Flouting the maxim of Quantity}

Flouts which exploit the maxim of Quantity occur when a speaker blatantly provides less or more information than required. Thus, example 5, provided by Thomas (1995:69), illustrates a flouting of the first maxim of Quantity:

Example 5: A: How are we getting there? 
B: Well we're getting there in Dave's car.

Thomas (1995:69) explains that B's reply blatantly provides less information than A requires, thereby generating the implicature that, while B and some other person, or persons, have a lift arranged, A is not included in this arrangement and will therefore not be travelling with them.

Example 6 illustrates how a speaker may flout the second maxim of Quantity, by providing more information than required:

Example 6: A: Were all the players professional football players?

$\mathrm{B}$ : At the time of planning the matches, all players were professional football players.

The information in the first part of B's utterance seems superfluous. However, by including it, B manages to generate the implicature that, by the time the matches were played, one or more players were not professional football players.

According to Grice (1975:52), utterances of patent tautologies like Women are women and War is war provide extreme examples of floutings of the first maxim of Quantity. (Presumably, they flout the maxim of Manner also, by being repetitive, though Grice did not discuss this possibility.) Grice (1975:52) argued that such remarks are totally non-informative at the level of what is said, but informative at the level of what is implicated. In other words, if the assumption that the speaker is actually co-operating is to be preserved, some informative inference must be made, i.e. that an implicature was intended and that the tautology was uttered for some pragmatic purpose, e.g. emphasis. Levinson (1983:111) draws attention to the fact that Grice omitted to clarify exactly how the hearer will predict the appropriate implicature, but observes (1983:111) that "the maxim of Relation would presumably play a crucial role", that is, the hearer will look for a proposition which is relevant to the topic at hand (cf. Chapter 7, Section 7.1.1). 


\subsection{Flouting the maxim of Quality}

Flouts which exploit the maxim of Quality occur when the speaker blatantly utters something which he believes to be false, or for which he lacks adequate evidence. According to Grice (1975:53), flouts of the first maxim of Quality will occur whenever tropes are used to generate implicatures. Thus, example 7 illustrates the use of irony (cf. example 3 above):

Example 7: $\quad$ A: So how do you feel about $C$ now?

B: $\quad$ Oh C is a really good friend.

$\mathrm{A}$ and $\mathrm{B}$ are talking about $\mathrm{C}$, who was a friend of B's until he started going out with a girl he knew B was in love with. A knows this, and therefore he knows that B's utterance is blatantly false, and B knows that A knows this. So, B cannot be trying to deceive A. Consequently, as per Grice's theory (1975:53), unless B's utterance has to be regarded as entirely pointless and thus uncooperative, B must be taken to mean something rather different from what he actually said. However, the proposition that B intends to convey must be obviously related to the proposition that he claims to present; searching around for an obviously related proposition that B might be intending to get across, A will arrive at the opposite, or negation, of what B has stated, namely that $\mathrm{C}$ is not a good friend (1975:53).

Example 8, provided by Levinson (1983:110), illustrates the use of a metaphor:

Example 8: $\quad$ Queen Victoria was made of iron.

According to Levinson (1983:110), by working along the same lines of suppositions as in the irony example, a hearer will arrive at the straightforward interpretation that, since Queen Victoria as a human being lacked the definitional properties of iron, the speaker merely intends to convey that she "had some of the incidental properties like hardness, resilience, non-flexibility or durability". As Levinson (1982:110) observes, an utterance such as the one in example 8 may thus be intended both as a commendation and denigration, depending on who says it and in which context it is said. 
Obviously, the whole issue of metaphor is rather more complex than Grice takes notice of, though his work does suggest ways in which metaphors can be brought within the scope of pragmatic theory. Thus, Levinson (1983) devotes a whole section of his textbook to establishing the limitations of Grice's theory when applied to metaphors (1983:147ff). In addition, strong criticism of Grice's treatment of metaphors (and irony and other tropes) has been voiced by Wilson \& Sperber (1981; cf. also Sperber \& Wilson 1981,1986), who consider it fundamentally incorrect.

However, pursuing Grice's theory (1975), example 9 illustrates the use of meiosis, or litotes (understatement):

Example 9: A: Why on earth did $C$ react so violently?

B: He was a bit upset.

Actually meiosis flouts both the first maxim of Quantity (by saying too little) and the maxim of Quality (since it distorts the truth by saying too little). Hyperbole (exaggeration) works in the same way by, at least superficially, flouting both the second maxim of Quantity (by saying too much) and the maxim of Quality (since it distorts the truth by saying too much). Grice (1975:53) provided the following example:

Example 10: $\quad$ Every nice girl loves a sailor.

Finally, Grice (1975:53) noted that metaphor and irony may be combined by imposing two stages of interpretation on the hearer, and he provided the following example to illustrate this:

Example 11: $\quad$ You are the cream in my coffee.

According to Grice (1975:53), the speaker intends the hearer to reach first the implicature generated by the use of the metaphor 'You are my pride and joy', and then the implicature generated by the use of irony 'You are my bane'. Grice (1975:53) did not discuss combining irony with the other tropes, but, going by his example, it seems obvious that this possibility is just as viable. 
Finally, Thomas (1995:68) notes that other Quality floutings include individuals' attempts "to deflect unwelcome attention by giving an improbable or obviously untrue response", like the one in example 12:

Example 12: A: What do you do?

B: I'm the King of France.

\subsection{Flouting the maxim of Relation}

Flouts which exploit the maxim of Relation occur when a speaker provides a response, or makes an observation, which is very obviously irrelevant to the topic in hand, for example, Thomas (1995:70) observes, "by abruptly changing the subject, or by overtly failing to address the other person's goal in asking a question". Grice (1975:54) remarked that floutings of the maxim of Relation "are perhaps rare", but according to Thomas (1995:70), they may in fact be encountered quite frequently. Her claim is supported by examples 13 to 16 below.

In example $13, \mathrm{~B}$ blatantly refuses to make a remark relevant to the utterance of $\mathrm{A}$ :

Example 13: A: What did you think of the speech given by $C$ ?

B: Lovely weather, isn't it?

By abruptly changing the subject, B implicates that A's utterance cannot be addressed directly, or at that moment, for one reason or another (maybe B did not like the speech but would be embarrassed, or even afraid, to say so, perhaps because $\mathrm{C}$ is close by and may hear his words, or maybe $\mathrm{B}$ is simply not interested in talking about C's speech, because he was bored by it, etc.).

Similarly in example 14:

Example 14: A: Do you want to play Scrabble?

B: How is your homework coming along?

By failing to address A's question directly, B is able to implicate that A will not be able to play until after he has finished his homework. 
Now consider example 15:

Example 15: A: Where are you going?

B: Out.

B's response represents a blatant flout of the maxim of Relation, because though it is truthful, clear, etc., it blatantly fails to address A's goal in asking the question: Since it is obvious to A that B is going out (being dressed for this, etc.), and since B is aware of this, it must be clear to B that A's goal in asking the question is to establish exactly where B was going. But clearly, for some reason, B cannot, or does not want to, answer A's question.

As Thomas (1995:71) points out, a response such as B's in example 15 could also be analysed as a flout of the first maxim of Quantity, rather than of the maxim of Relation, since it so obviously provides less information than the situation requires, or alternatively, as a simultaneous flout of both maxims, Quantity and Relation.

Example 16, which was provided by Green (1996:102), is clearly an example of a simultaneous flout, this time of the maxim of Relation and of the first maxim of Quality:

Example 16: A: You know, I can crush rocks with my bare hands.

B: Yeah, and the sun rises in the west.

Green (1996:102) explains that, by uttering a statement which has no apparent relation to A's remark, and which is also both obviously and outrageously false, B is able to implicate that A's assertion is equally false. I shall return to the issue of simultaneous flouts in Section 5.2.5.3 below.

\subsection{Flouting the maxim of Manner}

Flouts which exploit the maxim of Manner occur when a speaker flouts the various maxims under the heading of the supermaxim 'Be perspicuous'. Grice (1975:55) provided the following example of a review of a musical performance: 
Example 17: $\quad$ Miss $X$ produced a series of sounds that corresponded closely with the score of 'Home sweet home'.

According to Grice (1975:56), the reviewer could have chosen, instead of the long-winded statement, to express himself in a much shorter, and simpler, way:

Miss X sang 'Home sweet home'.

However, according to Grice (1975:56), by blatantly avoiding the short and simple statement in favour of the long-winded one, the reviewer intends "to indicate some striking difference between Miss X's performance and those to which the word singing is usually applied". In other words, the reviewer implicates that Miss X's performance did not at all live up to expectations.

Thomas (1995:71) provides an example from a radio interview with an unnamed official from the United States Embassy in Haiti:

Example 18: A: Did the United States Government play any part in Duvalier's departure? Did they, for example, actively encourage him to leave?

B: I would not try to steer you away from that conclusion.

According to Thomas (1975:71), B (the official) could have simply replied 'Yes'. Instead she blatantly flouts the maxim of Manner by providing an extremely long-winded and convoluted response. Thomas (1995:71) asserts that there is "no reason to believe that the official is being deliberately unhelpful", as she could have just refused to answer A's question. Thus, Thomas' view is (1995:71) that "there is nothing in Grice's theory to help us explain her flouting of the maxim of Manner", and that the flouting is due to a clash of goals (claiming credit for a desirable outcome, i.e. Duvalier's departure, but avoiding any on-record admission that her government had intervened in the affairs of another country), and not a clash of maxims. However, the mechanism whereby the official manages to achieve these goals is surely Gricean: By blatantly flouting the maxim, she manages to generate the implicature that she wants A to take her answer as meaning 'Yes' (thus claiming credit), but that she cannot possibly admit 
openly to her government's intervention, and neither can she admit to this being the reason for her type of response.

\subsubsection{Other categories of non-observance}

As stated earlier (Section 5.2.3), a speaker may fail to observe a maxim, deliberately or not, without intending to generate an implicature. He may violate or infringe a maxim, he may opt out of observing a maxim (as well as the $\mathrm{CP}$ ), or he may suspend a maxim.

\subsection{Violating a maxim}

In "Logic and Conversation" (1975), Grice defined violation as quiet and unostentatious non-observance (1975:49). According to Grice (1975:49), a speaker who violates a maxim "will be liable to mislead". The following example illustrates a violation of the first maxim of Quantity:

Example 19: A: Did you buy the blue sofa then?

B: No, I did not buy it.

B's response states something which is true, but not the whole truth: B did not buy the blue sofa referred to by A, but he bought a green sofa instead. By withholding information, that is, by unostentatiously failing to observe the maxim, B manages to generate (whether intentionally or not) the misleading implicature that he did not buy any sofa at all. Thomas (1995:74) asserts that utterances like B's utterance in example 19, which are pragmatically misleading (or potentially pragmatically misleading), "are regularly encountered in certain activity types", and she lists (1995:74) trials, parliamentary speeches and arguments as examples of such activity types. She further claims (1995:74) that these utterances may be encountered so regularly in the specified activity types that they could be regarded as "the norm for this type of interaction, and be interpreted in that light by participants". Of course, she has a point, as such utterances will be common in confrontational situations, or for that matter in any kind of situation where one person wants to deceive another person, or for some reason is reluctant to fully answer another person's question. However, there is a marked difference between trials and other activity types in that trial procedure is generally provided by law which lays down rules for how 
such utterances may or may not be recognized. I shall return to the issue of violations in courtroom interaction in Section 5.3.

\subsection{Infringing a maxim}

According to Thomas (1995:74), a speaker who fails to observe a maxim, "with no intention of generating an implicature and with no intention of deceiving", is infringing the maxim. She explains (1995:74) that this kind of non-observance stems from "imperfect linguistic performance", rather than from a desire to generate an implicature. Thomas (1995:74) further presents some examples of when a maxim may be infringed: The speaker may have an imperfect command of the language (being a young child, or a foreign learner), or his performance may be impaired in some way (he may be nervous, drunk, excited etc.), or he may suffer from some cognitive impairment, or he may be constitutionally incapable of speaking clearly, to the point, etc.

Excluding Thomas (1995), infringing is not listed and/or discussed in the textbooks and articles cited at the beginning of Section 5.2 above. Presumably, the lack of attention to this category of non-observance may be explained by reference to the fact that a speaker's non-observance is unintentional. Thomas (1995:72) does not specify when or why Grice added this category to his list of categories of non-observance, and I have not been able to find a reference to it in his writings (Grice 1975, 1978, 1981, 1989). However, seeing that it makes perfect sense to add infringing to the list of categories of non-observance, I have no reason to doubt Thomas' claim that it was Grice who originally included this category.

\subsection{Opting out of observing a maxim}

Grice explains (1975:49) that a speaker may opt out of observing a maxim (and of observing the CP as well) by saying, indicating, or allowing it to become plain "that he is unwilling to co-operate in the way the maxim requires". Thus, a speaker may explicitly opt out of observing e.g. the first maxim of Quantity by saying, for example, I am not able to tell you anything else, or the first maxim of Quality by saying, for example, I am not sure that this is true, but ... (cf. Green 1996:92). 
Thomas (1995:74) observes that opting out is bound to occur frequently in public life whenever a speaker cannot reply in the way normally expected (perhaps for legal or ethical reasons), but wants to avoid "generating a false implicature or appearing uncooperative". In addition, Thomas (1975:75) observes, speakers often provide another reason for opting out, which is that, by giving the requested information, they may hurt or endanger a third party. Finally, Thomas (1995:75) points to the interesting fact that, when a speaker expressly opts out of observing a maxim, as in either of the two examples here above, he makes explicit reference to the way in which he would normally observe the maxim. In other words, Thomas (1995:75) reminds us, the fact that speakers are able to opt out actually serves to support Grice's contention (1975:45) that participants in talk exchanges assume that the $\mathrm{CP}$ and the maxims, ceteris paribus, and unless indication is given to the contrary, will be observed.

\subsection{Suspending a maxim}

Finally, Thomas (1995:76) argues that a speaker may suspend a maxim, and that this kind of non-observance may occur on certain occasions, or in certain events, when there will be no expectation on the part of the participants that the maxim will be observed (hence the non-observance does not generate any implicatures), and therefore no need for the speaker to opt out of observing it.

Thomas (1995:76) argues that suspensions may be culture-specific, or specific to particular events. Thus, she explains (1995:77) that among the Navajo it is taboo in some circumstances to mention a person who died a violent or premature death, and therefore non-observance of the first maxim of Quantity by leaving out the name of such a person would generate no implicature.

As regards particular events, Thomas (1995:77) argues that the maxim of Quantity appears to be selectively suspended in e.g. courts of law, committees of inquiry or in any other confrontational situation where someone will attempt to elicit the truth from a witness. In these situations, she argues (1995:77), witnesses "are not required or expected to volunteer information which may incriminate them, and no inference is drawn on the basis of what they do not say". Naturally questioning procedures may 
differ, as well as the rights and obligations of witnesses, but Thomas's point is supported by the fact that witnesses are often asked to state information which is already well-known to those who request it. Consequently, witness statements would constitute floutings, or violations, of the second maxim of Quantity ('Do not make your contribution more informative than is required'), unless the maxim was suspended. This latter situation is typical of classroom interaction also. In any case, I shall return to the issue of implicature and witness statements in section 5.3 below.

Similarly, Thomas (1995:78) observes that the maxim of Quality appears to be suspended in the case of funeral orations and obituaries, the maxim of Manner in poetry, the first maxim of Quantity in telegrams, and the maxims of Quantity, Quality and Manner in jokes.

\subsubsection{Testing for implicature}

In "Logic and Conversation" (1975) Grice suggested that implicature possesses six characteristic features which could be used to determine the presence of an implicature. He later expressed doubts (Grice 1978:115) that these features could be made to provide any sort of "knock-down test", but he maintained that at least some of them would serve to provide "a more or less strong prima facie case" in favour of the presence of an implicature. However, it seems that only few scholars have shown any particular interest in this issue (e.g. Sadock 1978). Nevertheless, a presentation of the six features, or 'tests', will serve to illustrate further the important points in Grice's theory.

Two of the six features have already been dealt with: (1) Implicature may be calculated, that is for every implicature conveyed it is possible to construct an argument showing how, from the semantic meaning of the utterance on the one hand, and the $\mathrm{CP}$ and the maxims on the other, it follows that a hearer would make the inference in question to preserve the assumption of co-operation (cf. Section 5.2.2 above); and (2) implicature is the property of utterances (a general point), i.e. intended to generate meaning beyond the semantic content of the words uttered (Levinson 1983:103) The remaining features are (3) defeasibility, (4) nondetachability, (5) non-conventionality and (6) indeterminacy (Grice 
1975:57-58, cf. also Levinson 1983:114-118 and Thomas 1995:78-84). I shall present and discuss each of these remaining four features in Sections 5.2.4.1 to 5.2.4.4 below.

\subsubsection{Defeasibility}

Defeasibility, which is the notion that an implicature can be cancelled, is perhaps the most important feature. Defeasibility allows a speaker to generate an implicature, and then deny the implicature by adding some additional premises to the original ones (Grice 1975:57). Thomas (1995:82) illustrates this with the following example:

Example 20: A: Let's have a drink.

B: It's not one o'clock yet.

An hour or so later:
A: Let's have a gin and tonic - it's after one o'clock.
B: I didn't say that you could drink after one o'clock. I said that you couldn't drink before.

As Thomas (1995:82) points out, B's first utterance in example 20 is capable of implicating 'You can drink after one o'clock', but his second utterance cancels that implicature.

Thomas (1995:83) also provides an example which demonstrates how, by cancelling an implicature, a speaker can generate humour or make a point. The example is taken from a letter to a British newspaper in November 1990, shortly before Margaret Thatcher resigned as British Prime Minister:

Example 21: $\quad$ For the sake of the country the PM should hold on until the summer.

This is no time of year for street parties.

Obviously, Thomas (1995:83) observes, the writer of the letter manages quite effectively to make a political point by deliberately generating a false implicature ('I regret the fact that Ms Thatcher may resign'), which he then 
immediately cancels. As Thomas (1995:84) points out, similar techniques are often used to generate humour.

Grice (1975:57) also suggests that an implicature may be "contextually cancelled", that is, the context of the utterance may clearly show that the implicature could not have been intended. Levinson (1983:116) illustrates this kind of defeasibility with the following example:

Example 22: A: Has John really got the requisite number of cows?

B: Oh sure, he's got three cows all right.

Levinson (1983:116) explains that $\mathrm{A}$ is an inspector associated with a subsidy scheme and that B is John's neighbour. In this context, B's reply does not commit him to the implicature (as per the maxim of Quantity) usually associated with this kind of answer ('John has only three cows and no more'), because it is clear that all the information that is required is whether John has enough cows to come under the subsidy scheme, not the exact number of cows he might in fact have.

\subsubsection{Non-detachability}

Non-detachability is another important feature of implicatures (Grice 1975:57-58). As explained earlier (cf. Section 5.2.4 above), an implicature is attached to the semantic content of an utterance, and not to its linguistic form, and so it follows that the implicature "cannot be detached from an utterance simply by changing the words of the utterance for synonyms" (Levinson 1983:116). This may be illustrated by the following example:

Example 23: $\quad$ Three people, A, B and C, are sitting at a dinner table. A and $\mathrm{B}$ have finished eating, but $\mathrm{C}$ only picks at his food. He has eaten very little. A remarks:

Hungry, aren't you?

Of course, by his remark $\mathrm{A}$ is implying the opposite, i.e. that $\mathrm{C}$ is not hungry. The same implicature will be maintained however the utterance is relexicalised and regardless of whether or not the chosen adjective has positive or negative connotations. So, instead of hungry, A could have said, 
for example, starving, peckish, famished, hollow, empty, ravenous, or even full up, replete, satiated, and still have generated the same implicature.

Consequently, implicatures are as a rule non-detachable, except "those arising under the maxim of Manner that are specifically linked to the form of the utterance" (Levinson 1983:117; cf. Grice 1975:58).

\subsubsection{Non-conventionality}

A third distinguishing feature is non-conventionality. Grice (1975:58) acknowledged that it may be possible for meaning generated by implicatures to become conventionalized, given time, but he suggested (1975:58) that, "initially at least", implicatures are non-conventional in the sense that they are not part of the conventional meaning of linguistic expressions. This fact is proven by the manner in which implicatures are worked out: Since a hearer needs to know the semantic meaning or content of an utterance before he can calculate its implicatures in a context, it follows that implicatures cannot be part of that meaning (Grice 1975:58; Levinson 1983:117). In addition, Levinson (1983:117) asserts, it is possible to demonstrate "that an utterance can be true while its implicature is false, and vice versa", and he provides (1983:117) the following example to demonstrate this:

Example 24: $\quad$ Herb hit Sally.

According to Levinson (1983:117), based on the assumption that the speaker is complying with the $\mathrm{CP}$ and the maxims, a hearer will take this utterance by the first maxim of Quantity ('Make your contribution as informative as is required') to implicate

Herb didn't kill Sally by hitting her.

But, the speaker may easily have been intending to mislead the hearer, Levinson (1983:117) asserts, by deliberately saying something which is true, while creating an implicature which is false (cf. section 5.2.3.2.1 above). In other words, the speaker may have blatantly flouted the first maxim of Quantity (by providing less than the required information) for the 
express purpose of generating a false implicature (assuming that Herb did in fact kill Sally).

\subsubsection{Indeterminacy}

Finally, implicature can have indeterminacy in the sense that, as Levinson (1983:113) observes, "an expression with a single meaning can give rise to different implicatures on different occasions" (cf. Grice 1975:58). Thomas (1995:80-81) illustrates this point with the sentence How old are you?, demonstrating how it may give rise to at least three implicatures. The utterances in example 25 are modified versions of three examples presented and discussed by Thomas (1995:80-81):

Example 25:
Happy birthday. How old are you?
or
What an earth are you doing? How old are you?
What do you mean you can't come to the party
tonight? How old are you?

In each of these three utterances, the semantic meaning of How old are you? is the same, but the implicature is different. In the first utterance the speaker expresses a straightforward request for information; in the second utterance the speaker implies that the person addressed is behaving in a way which is inappropriate for someone his age; and in the third utterance the speaker implies that the person addressed is old enough to decide for himself whether or not he is able to go to the party referred to.

\subsubsection{Problems associated with the theory of implicature}

Since Grice's theory has never been fully developed there are naturally a number of problems associated with it. His writings have many gaps and inconsistencies; in fact, Thomas (1995:93) asserts that his theory merely outlines "a set of very informal procedures for calculating conversational implicature, which cannot really withstand close scrutiny". Similarly, Green (1996:91) observes that the maxims seem to be simply expressing "common sense, wishful thinking, or composition teachers' futile rules". However, what makes Grice's theory so attractive, Green (1996:91) 
acknowledges, "is its ability to explain how in being honoured, as much as in the (apparent) breach as in the observance, the maxims provide explanations for otherwise puzzling phenomena". Thus, Grice's theory of conversational implicature has doubtlessly been one of the most influential theories in the development of pragmatics; it has been applied (and may still be applied) to resolving a number of problematical issues, including coherence, indirect speech acts, the range of illocutionary force, politeness, and the nature of presupposition and reference (cf. Levinson 1983; Leech 1985; Schiffrin 1994; Thomas 1995; Green 1996).

Levinson's textbook (1983:118-166) includes a section on the revisions, problems and applications of Grice's theory. But such a detailed discussion is beyond the scope of this thesis. Likewise, Thomas (1995:87) explains that a detailed discussion of the problems connected with Grice's theory is beyond the scope of her textbook, and she thus contains herself (1995:88ff) to a brief discussion of what she regards as its main problems. However, considering the purpose of the current investigation, I shall present an even shorter review here, containing myself to a brief discussion of what appears to be the most obvious problems associated with Grice's theory. Furthermore, for the sake of clarity and simplicity, I have grouped these problems into five different categories: (1) determining and distinguishing between types of non-observance, (2) distinguishing between implicatures, (3) different and overlapping maxims, (4) calculability, and (5) speaker motives. I shall now discuss each of these categories in Sections 5.2.5.1 to 5.2.5.5 below.

\subsubsection{Determining and distinguishing between types of non- observance}

As Thomas (1995:90) observes, nothing in Grice's framework explains how hearers are supposed to determine that speakers fail to observe a maxim, or to distinguish between the different kinds of non-observance. In other words, how are hearers supposed to know that the non-observance is intentional, for the purpose of generating an implicature? According to Grice, a flout is so blatant (e.g. 1975:49) that a hearer will know for certain that an implicature has been generated (though he may not know for certain what it is). This may not always be the case, though. Consider example 26: 
Example 26: A: Where are you going?

B: I'm going to see the Queen.

A: Yeah, sure, so am I.

A obviously thinks that B deliberately and blatantly flouts the first maxim of Quality ('Do not say what you believe to be false'). But in fact B does not intend to generate an implicature. He is really going to see the Queen, because he is on his way down to the main square where she will shortly be driving by in an open carriage. Strictly speaking, though, B's response violates the first maxim of Quantity by being less informative than required (unless the Queen driving by the main square in an open carriage may be assumed a common occurrence, or an occurrence that A would be fully aware of), by which he ends up misleading A, whether intentionally or not.

\subsubsection{Distinguishing between implicatures}

In addition, B's utterance above may be generating at least two different implicatures: (1) B is in fact going some place ordinary (i.e. he was being ironic), or (2) B does not welcome A's attention. Grice $(1975,1978,1981)$ did not discuss the possibility that a speaker might intentionally or unintentionally generate more than one implicature by the same utterance. However, if more than one implicature is possible, how will a hearer know which one is intended, or whether more than one is intended? Presumably, as Levinson (1983:111) points out when referring to patent tautologies (cf. Section 5.2.3.1.2 above), the maxim of relation will play an important part, i.e. the hearer will look for a proposition which is relevant to the topic at hand (cf. Chapter 7, Section 7.1.1).

\subsubsection{Different and overlapping maxims}

A third problem, and one closely connected to the previous problem of determining and distinguishing between types of non-observance, is the problem of different and overlapping maxims. For example, Thomas (1995:91) points out that Grice's maxims are not all of the same order. Thus, she observes (1995:91) that the maxim of Quality is straightforward and generally easy to operate: A speaker is either telling the truth or he is not, "and (in the case of a flout) it is usually pretty easy to tell which is 
which". On the other hand, she observes (1995:91), it may be difficult for a speaker to comply fully with the maxims of Quantity and Manner, since "it is rarely possible to give precisely the right kind of information or to speak with perfect clarity". Furthermore, these two maxims in particular seem to overlap and co-occur, so that it is not always possible to determine which one is being invoked, for example in the case of patent tautologies (cf. section 5.2.3.1.2). Likewise, the maxims of Quantity and Quality seem to overlap and co-occur in connection with tropes (cf. section 5.2.3.1.3), and, finally, the maxim of Relation may occur simultaneously with the maxims of Quantity and Quality, respectively (cf. Section 5.2.3.1.4).

In actual fact, as Thomas (1995:92) points out, the maxim of Relation seems always to be in operation, because unless a hearer assumes that a speaker's contribution is somehow relevant to what has gone before, he will not begin to search for an implicature (cf. above).

\subsubsection{Calculability}

A fourth important problem is the problem of calculability. As Thomas (1995:92) observes, Grice's theory fails to explain how a hearer searching for a proposition other than the one expressed will be able to determine when he needs to search for a proposition which is the exact opposite (cf. example 7), to search for a comparison (cf. example 8), to search for an implicature which is in no way related (cf. example 16), etc.

\subsubsection{Speaker motives}

Finally, Grice's theory lacks a framework for explaining why speakers deliberately flout maxims in order to create implicatures. Why don't they just say straight out what they want to communicate, instead of merely implying their intention? Of course speakers may be motivated to speak indirectly by social constraints, power relations, clashes of goals and many other factors. However, Grice's theory does not explain when and why this is so. 
Thomas (1995:70) observes that scholars such as Leech $\left(1985^{5}\right)$ and Brown \& Levinson $\left(1987^{6}\right)$ have attempted to solve some of these problems by developing theories of politeness which are seen as 'rescuing' the theory of implicature "by explaining the social constraints that govern utterance production and interpretation".

\subsection{Implicature in court interpreting}

In this section, I shall apply Grice's theory of conversational implicature to the interaction investigated in this thesis, question-answer dialogues in criminal proceedings in a Danish district court. Considering that flouts intending to generate implicatures will be bound to occur in this kind of interaction also, I shall assume that a court interpreter who is confronted with implicature will choose a particular strategy for conveying the generated meaning to an end receiver, based on her instinctive judgment about the end receiver's inferencing ability. Thus, I shall elaborate on the hypothesis presented in Chapter 1 (Section 1.2) that the behaviour of court interpreters will show evidence of a preoccupation with pragmatics, that is, with building a mental model of speaker meaning and with conveying their perception of speaker meaning to end receivers.

I shall begin with a discussion of the role of the $\mathrm{CP}$ and the maxims in the investigated interaction, and of the various categories of non-observance which may occur, taking as the point of departure the questioning procedure in criminal proceedings in a Danish district court. I shall then establish a model which illustrates this role. Next, focusing on one kind of non-observance, flouting, I shall discuss how court interpreters may deal with implicatures. I shall assume that eight strategies for conveying implicature are available to a court interpreter, and I shall discuss each of these strategies in turn, by applying them to theoretical examples of flouts.

5 Leech (1985) regards politeness as crucial in explaining "why people are often so indirect in conveying what they mean" (1985:80). In Chapter 4 of his pragmatics textbook (1985:79ff), he introduces a Politeness Principle (PP) which he sees as being a necessary compliment to the $\mathrm{CP}$, and as rescuing the $\mathrm{CP}$ by explaining why speakers sometimes fail to observe Grice's maxims. Leech (1985:132ff) also introduces a number of maxims which he sees as underlying the PP in the manner of Grice's maxims and the CP.

6 Cf. Chapter 2, note 2. 


\subsubsection{The role of the $\mathrm{CP}$ and the maxims}

The questioning procedure in a criminal trial in a Danish district court is as follows: a judicial member, i.e. a judge, a prosecutor, or a defence counsel, asks questions, and a witness or a defendant answers questions. As outlined in Chapter 3 (Section 3.1.3), this procedure is governed by Danish law, which lays down different requirements for defendants and witnesses. Thus, defendants are not obliged to answer questions put to them, nor can they be punished for giving false evidence ${ }^{7}$. Witnesses, on the other hand, are always obliged to answer questions, and to answer them truthfully, and may be sentenced to a maximum term of imprisonment of four years if they perjure themselves ${ }^{8}$. The same law further provides that defendants shall be informed of their rights and witnesses of their obligations, before the questioning starts (cf. Chapter 3, Section 3.1.3).

As regards the 'interrogators', i.e. the judges, prosecutors, or defence counsels, these are obliged by law to ask questions that will elicit clear and truthful responses ${ }^{9}$ (cf. Chapter 3, Section 3.1.2). As a result of this obligation, I shall assume that 'interrogators' will observe the $\mathrm{CP}$ and the maxims at all times, and that they will avoid asking non-explicit questions. I shall therefore proceed to discuss non-observance in responses only, that is, in utterances spoken by defendants and witnesses.

\subsubsection{Defendants and non-observance}

Because of their statutory rights, defendants are as a rule not assumed to observe the $\mathrm{CP}$ and the maxims, and no inference may be drawn on the basis of their lack of co-operation in this regard (cf. Chapter 3, Section 3.1.3). Still, the suspension of the $\mathrm{CP}$ and the maxims is selective, because defendants are regularly suspected of failing to observe maxims, whether deliberate or not, evidenced by the fact that specific attention will be drawn

7 The rights of defendants are provided by the Danish Administration of Justice Act, sections 752 and 754, and the Danish Penal Code, section 159(1).

8 The obligations of witnesses are provided by the Danish Administration of Justice Act, section 181, and the punishment for perjury by the Danish Penal Code, section 158 .

9 This obligation is provided by section 184 of the Danish Administration of Justice Act. 
to any suspected non-observance; as a consequence of the aforementioned obligation to elicit precise and truthful responses, 'interrogators' will generally prefer to repeat or rephrase questions rather than risk inferring something a defendant (or a witness) did not intend to imply.

First of all, defendants may be suspected of flouting maxims. It is of course fully conceivable that a defendant will specifically intend, for some reason or another, to blatantly flout a maxim for the purpose of generating an implicature, and that the court will recognize his intention, or at least suspect it. But, as explained above, an 'interrogator' will be disinclined to accept a defendant's ambiguous utterance, and either he, or one of the other judicial members, will ask for verification of the recognized, or suspected, implicature. Nevertheless, some flouts may be considered so blatant (and the generated implicature so 'obvious') that verification is considered unnecessary.

In addition, defendants may be suspected of violating maxims, especially the maxim of Quantity, by providing less or more information than is required (cf. Section 5.2.3.2.1). For example, since a defendant (and a witness) is usually asked to state information which is already 'known' to the court, seeing that it constitutes evidence gathered in preparation for the trial, a response which does not give the required information may be taken as a violation of the maxim. This is evidenced by the fact that attention will be directed towards the (suspected) non-observance by the 'interrogator', or another judicial member, who will make explicit reference to the 'missing' information, stating that the defendant's response does not match his response to the same question when it was posed earlier (e.g. during his interrogation by the police or at a previous court hearing), or that it does not fit in with the evidence gathered. As a result, the defendant will be asked to explain the reason for this discrepancy to the court. However, as explained above, since he is not obliged to answer questions, or to answer them fully, no inference may be drawn from his unwillingness to cooperate in this regard. Thus, if he makes excuses, stating for example that he did not understand the question, or that the transcript of his previous statement contains a mistake, the 'interrogator', or another judicial member, may question him about it, but will as a rule accept his explanation and not pursue the matter any further. In another setting, it would be possible to conclude, of course, that the violation was intentional 
and meant to mislead, and the prosecutor may be tempted to imply, for tactical reasons, that this was in fact the defendant's intention.

Defendants may also choose to opt out of observing a maxim, by informing the 'interrogator', or the court, either implicitly or explicitly, that they are unable or unwilling to answer particular questions. For example, a defendant may explicitly opt out of observing the first maxim of Quantity ('Make your contribution as informative as is required') by responding with utterances like no comments, or with words to that effect (cf. example 117 in Chapter 6, Section 6.3.2.4.1). This will likewise be an accepted course of action, and again no inference may be drawn on the basis of it. Nevertheless, an 'interrogator', or, again, another judicial member, may ask the defendant to verify his opting out, rather than just accept it, again drawing specific attention to the non-observance.

Finally, it is quite possible that a defendant may infringe a maxim, for example because of a slight speech impediment, or nervousness, or because of imperfect command of the language. Clearly, when a defendant is questioned in a language which is not his mother tongue, as occasionally happens (cf. Chapter 3, Section 3.1), there is a risk that he may fail to observe maxims without intending to flout or violate them. But again, though it may seem evident that the defendant's non-observance was unintentional, he will be asked to verify this, with the result that specific attention will be directed towards this kind of non-observance also.

\subsubsection{Witnesses and non-observance}

As a result of their obligation to answer questions put to them and to answer them truthfully, witnesses, contrary to defendants, are assumed to conform to the $\mathrm{CP}$ and the maxims, and therefore intentions to generate implicature will be recognized as such. Nevertheless, specific attention will as a rule be directed towards witnesses' non-observance also; an 'interrogator', or another judicial member, will presumably prefer to ask a witness, just like he will a defendant, to verify a particular implicature, rather than risk alerting the court to something which the witness did not intend to imply. But again the flout may be considered so blatant (and the implicature so 'obvious') that the 'interrogator', and the court, will have no doubt of the witness' intention. 
In addition to flouting maxims, witnesses, like defendants, may occasionally find that they are suspected of violating maxims, again especially the maxim of Quantity, by providing less or more information than required. Again, attention will be specifically directed towards a suspected violation by the 'interrogator', or another judicial member, who will make explicit reference to the fact that the witness' response does not match his response to the same question when it was posed earlier (e.g. when questioned by the police), or that it does not fit in with the evidence gathered. Like a defendant in a similar situation, the witness will be asked to explain the reason for the discrepancy to the court. The witness may make the same kind of excuses, i.e. that he did not understand the question, or that the transcript of his previous statement contains a mistake, but since he does not have the right of a defendant, the 'interrogator', or another judicial member, will pursue the matter, and as a result he may find himself being openly suspected, and/or even accused, of intending to mislead the court.

Witnesses may also opt out of observing the maxims. Obviously, unlike defendants, witnesses cannot opt out by stating that they are not willing to answer particular questions. Nevertheless, a witness who finds himself in a situation where he cannot honour one maxim without ignoring the requirements of another can opt out by informing the 'interrogator' of his dilemma. For example, he can explicitly opt out of the first maxim of Quality by beginning his response with the words I'm not sure, but ..., or I don't really know, but ..., or words to that effect. Presumably, in many situations, specific attention will be drawn towards this kind of nonobservance also, because the witness will be asked to verify that he is indeed opting out.

Finally, again, like defendants, and for similar reasons, witnesses may infringe maxims. But again, though it may seem evident that the nonobservance was unintentional, the witness will be asked to verify this, with the result that specific attention will be directed towards his nonobservance.

The role of the $\mathrm{CP}$ and the maxims in question-answer dialogues in criminal proceedings in a Danish district court is illustrated by the model in table 5.1: 
Table 5.1: The role of the $\mathrm{CP}$ and the maxims in question-answer dialogues in criminal proceedings in a Danish district court

\begin{tabular}{|l|l|l|}
\hline & $\begin{array}{l}\text { OBSERVANCE OF } \\
\text { THE CP AND THE } \\
\text { MAXIMS }\end{array}$ & $\begin{array}{l}\text { CATEGORIES OF } \\
\text { NON-OBSERVANCE } \\
\text { OF THE CP AND } \\
\text { THE MAXIMS }\end{array}$ \\
\hline $\begin{array}{l}\text { JUDGES, } \\
\text { PROSECUTORS, } \\
\text { AND DEFENCE } \\
\text { COUNSELS }\end{array}$ & Full observance & None \\
\hline DEFENDANTS & Selective observance & $\begin{array}{l}\text { Flouting } \\
\text { Violating } \\
\text { Opting out } \\
\text { Infringing } \\
\text { Suspending }\end{array}$ \\
\hline WITNESSES & Full observance & $\begin{array}{l}\text { Flouting } \\
\text { Violating } \\
\text { Opting out } \\
\text { Infringing }\end{array}$ \\
& &
\end{tabular}

\subsubsection{Strategies for conveying implicature}

As a rule, Danish court interpreters are fully aware of the rights of defendants and the obligations of witnesses and 'interrogators', and they are assumed, therefore, to infer speaker meaning on the basis of this awareness. Thus, I shall assume that an interpreter will anticipate that utterances delivered by 'interrogators' will as a rule be precise and unambiguous, whereas utterances delivered by defendants and witnesses may be ambiguous, or non-explicit. I shall further assume, therefore, that an interpreter will be able to detect and calculate a particular implicature. Finally, as explained earlier (cf. Section 5.3 above), I shall assume that, once she has detected and calculated the implicature, she will adopt what she judges to be a proper strategy for conveying it to the end receiver, her chosen strategy being determined by her instinctive judgement regarding 
the end receiver's ability to infer the implicature from the semantic content of the speaker's utterance. In theory at least, the following eight strategies are available to her:

(1) Interpret the semantic content only.

(2) Interpret part of the semantic content only.

(3) Interpret the semantic content and explicate the implicature.

(4) Interpret part of the semantic content and explicate the implicature.

(5) Interpret the semantic content and explicate part of the implicature.

(6) Interpret part of the semantic content and explicate part of the implicature.

(7) Explicate the implicature only.

(8) Explicate only one implicature.

In Sections 5.3.2.1 to 5.3.2.8 below, I shall discuss each of these strategies in more detail and apply them to theoretical examples of flouts.

\subsubsection{Interpret the semantic content only}

The strategy of interpreting only the semantic content preserves the ambiguity of the original utterance and leaves it to the end receiver to infer the implicature. An interpreter is assumed to adopt this strategy if she instinctively judges (1) that the end receiver's inferencing ability enables him to fully detect and calculate the implicature without assistance, or (2) that inference of the implicature is not necessary for the interaction to succeed, because the speaker will be asked to verify it, or for some other reason. Example 27 serves to illustrate the application of this strategy: 
Example 27: A: Did you go with $C$ to see Schindler's List on the night in question?

B: I rarely miss a chance to see Liam Neeson.

The interpreter: $\quad$ I rarely miss a chance to see Liam Neeson.

B's response is a flout of the first maxim of Quantity, since he could have replied with a simple 'Yes', which would have provided the maximum amount of information possible in the situation, instead of opting for the much weaker and less informative response. B's failure to provide the required information may stem from a clash between the first maxim of Quantity and the second maxim of Quality: He cannot say for certain whether he went with $C$ on the night in question to see the film; he can only speak on the basis of the evidence he has, and he believes that, since he rarely misses a chance to see Liam Neeson, he did go to see the film.

\subsubsection{Interpret part of the semantic content only}

Like Strategy (1), the strategy of interpreting only part of the semantic content preserves the ambiguity of the original utterance and leaves it to the end receiver to infer the implicature. I shall assume that an interpreter will adopt this strategy if she instinctively judges that omitting part of the semantic content will make the implicature more easily available to the end receiver. Consider example 28:

Example 28: A: Did you go with $C$ to see Schindler's List on the night in question?

B: I rarely miss a chance to see Liam Neeson. I think he is really good.

The interpreter: $\quad$ I rarely miss a chance to see Liam Neeson.

Again, B's response is a flout of the first maxim of Quantity, since he could have provided the maximum amount of information possible by replying with a simple 'Yes'. Instead, like in example 27 above, he opted for the much weaker and less informative response. The interpreter judges (1) that the information in B's second utterance is not essential, since it merely elaborates on the information in his first utterance, and (2) that rendering 
both utterances will obscure the implicature. Consequently, she omits B's second utterance.

\subsubsection{Interpret the semantic content and explicate the implicature}

The strategy of interpreting the semantic content and explicating the implicature preserves the ambiguity of the original utterance, but at the same time makes it apparent to the end receiver how the ambiguity is to be interpreted. An interpreter is assumed to adopt this strategy if she instinctively judges (1) that the full semantic content should be available to the end receiver, perhaps considering that he should be informed of all that is said and done, but (2) that she needs to explicate the implicature for it to be fully available, since the end receiver will not be able to infer it from the semantic content alone. The strategy is illustrated by example 29:

Example 29: A: Did you buy the car and the motorbike?

B: I bought the car.

The interpreter: I I bought the car. I didn't buy the motorbike.

B blatantly flouts the first maxim of Quantity by providing less information than required, by which he manages to generate the implicature that he only bought the car, and not the motorbike. The interpreter's second utterance, which explicates the implicature, constitutes an interpreter addition.

\subsubsection{Interpret part of the semantic content and explicate the implicature}

Like Strategy (3), the strategy of interpreting part of the semantic content and explicating the implicature also preserves the ambiguity of the original utterance, while at the same time making it apparent to the end receiver how the ambiguity is to be interpreted. I shall assume that an interpreter will adopt this strategy if she instinctively judges (1) that she needs to explicate the implicature for it to be available to the end receiver, and (2) that the explication of the implicature makes parts of the semantic content redundant. Consider example 30:

Example 30: A: Did you buy the car and the motorbike?

B: I bought the car. That's correct. 
The interpreter: $\quad$ I bought the car. I didn't buy the motorbike.

B's second utterance, That's correct, serves to emphasize the implicature generated by his first utterance, which is the same as in example 29 above, namely that he only bought the car, and not the motorbike. The interpreter leaves out B's second utterance in her rendition, instinctively judging that, since she is explicating the implicature, she does not need the emphasis. Thus the application of Strategy (4) involves both an addition and an omission.

\subsubsection{Interpret the semantic content and explicate part of the implicature}

The strategy of interpreting the semantic content and explicating part of the implicature preserves the ambiguity of the original utterance and at the same time provides clues to its interpretation. I shall assume that an interpreter will adopt this strategy if she instinctively judges that interpreting the semantic content as well as explicating part of the implicature will make it more easily available to the end receiver. The strategy is illustrated by example 31 :
Example 31: A: Did you and $C$ travel back to your house together?
B: Mycar wasn't working.

The interpreter: $\quad$ My car wasn't working, so I couldn't give him a ride.

B's response simultaneously flouts the maxim of Relation by seemingly being irrelevant to the topic at hand, and the first maxim of Quantity by providing less than the required information. By his flout $\mathrm{B}$ manages to generate the implicature that he and $\mathrm{C}$ did not travel back together, and he also manages to imply that the reason why they did not travel back together is somehow connected to the fact that there was something wrong with his car. By adding so I couldn't give him a ride, the interpreter attempts to make this connection more explicit, and thus the implicature more easily available. 


\subsubsection{Interpret part of the semantic content and explicate part of the implicature}

Like Strategy (5), the strategy of interpreting part of the semantic content and explicating part of the implicature preserves the ambiguity of the original utterance while at the same time providing clues to its interpretation. I shall assume that an interpreter will adopt this strategy if she instinctively judges that omitting part of the semantic content as well as explicating part of the implicature will make it more easily available to the end receiver. Consider example 32:

\section{Example 32: A: Did you and $C$ travel back to your house together? \\ B: My car wasn't working, and I had to take it in for repairs.}

The interpreter: $\quad$ My car wasn't working, so I couldn't give him a ride.

B's response is longer this time, but again it constitutes a simultaneous flout of the maxim of Relation and the first maxim of Quantity, and the implicature is the same as in example 31, namely that he and $\mathrm{C}$ did not travel back together. Once again $\mathrm{B}$ implies that the reason why he and $\mathrm{C}$ did not travel back together is somehow connected to the fact that there was something wrong with his car. Judging (1) that the second part of B's utterance is not essential, since it merely elaborates on the information in the first part, and (2) that rendering both parts will obscure the implicature, the interpreter omits the second part. Instead she adds so I couldn't give him a ride, attempting by her addition to make the implied connection more explicit, and thus the implicature more easily available. Consequently, the application of this strategy, like the application of Strategy (4), involves both an addition and an omission (cf. Section 5.3.2.4 above).

\subsubsection{Explicate the implicature only}

The strategy of explicating only the implicature preserves nothing of the ambiguity of the original utterance, but merely enlightens the end receiver to the implicature inferred by the interpreter from the semantic content of the speaker's utterance. I shall assume that an interpreter will adopt this 
strategy if she instinctively judges (1) that she has to explicate the implicature for it to be available to the end receiver, and (2) that explicating the implicature makes the semantic content redundant. Example 33 serves to illustrate this strategy:

Example 33: A: How do you get on at work?

B: $\quad$ They are giving me a raise next month.

The interpreter: I'm getting on very well

B's response constitutes a blatant flout of the first maxim of Quantity by giving less than the required information. Judging that only the implicature itself, and not the semantic content from which it was calculated, is essential to the success of the interaction, the interpreter delivers a rendition which explicates the implicature but contains nothing of the semantic content of B's utterance.

\subsubsection{Explicate only one implicature}

The strategy of explicating only one implicature is adopted when an original utterance leaves room for more than one definite interpretation. I shall assume that an interpreter will adopt this strategy if she instinctively judges (1) that more than one implicature may be calculated from the speaker's utterance, but (2) that she needs to explicate one particular implicature in order to restrict the possibility of ambiguity, and communication failure. Thus, restricting ambiguity becomes the dominant strategy, and the interpreter will explicate only the (particular version of the) implicature, therefore, while omitting (any part of) the semantic content. Example 34 serves to illustrate this strategy:

Example 34: A: Do you know why $C$ put on his coat?

B: He was going out.

The interpreter: $\quad I$ don't want to be more specific.

I don't want to answer a silly question like that.

B's response simultaneously flouts the maxim of Relation since it fails to address A's goal in asking the question (C's actions are already known to 
the court, but A needs B to confirm his knowledge of them) and the first maxim of Quantity since it provides less information than is required. Assuming that B is a reluctant witness (or the defendant), then at least two distinct implicatures may be generated by his response: (1) he prefers not to be more specific about C's whereabouts, or (2) he considers the question rather silly, because the court knows the answer to it, and/or since he has already been asked to confirm his knowledge once before, or simply because it should be obvious to anyone why someone would put on a coat. The interpreter explicates the implicature which she perceives to be the correct interpretation of B's utterance.

\subsubsection{Conclusion and discussion}

I shall assume that the above eight strategies for interpreting implicature are all theoretically possible strategies, but that they are not equally plausible: Strategies (7) and (8) constitute such an extreme form of noncompliance with the ethical rules that an interpreter will probably prefer to avoid this option altogether; and Strategies (2), (4) and (6), though seemingly plausible, are rather risky strategies, since omitting parts of the semantic content may result in the loss of all kinds of valuable information, which may in turn lead to communication failure, rather than successful interaction. As a result, I shall assume that Strategies (1), (3) and (5) are the only really plausible strategies, because they leave the semantic content as it is, thus preserving the ambiguity of the original utterance, while, in the case of Strategies (3) and (5), explicating all or part of the implicature. Nevertheless, Strategies (3), (4), (5), and (6) are all relevant strategies for the purpose of this investigation, since an interpreter's application of any of them will involve the inclusion of additions in her target text. Consequently, I shall discuss the plausibility of these four strategies in Chapter 7 (Section 7.4), which discusses the motives of the court interpreters in this investigation for including the additions identified in the collected data (cf. Chapter 6) in their target texts.

A final note: The theoretical examples of flouts in sections 5.3.2.1 to 5.3.2.8 are chosen only for their capacity to illustrate the eight strategies. However, based on personal experience, as well as observation, I consider each of them to be good examples of the kind of dialogue that an 
interpreter may encounter in the particular interaction, and in the particular setting.

\subsection{Conclusion}

In this chapter, I have presented the pragmatic theory of conversational implicature proposed by H.P. Grice, which provides a framework for analysing the inferencing of speaker meaning. At first, I presented the definition of pragmatics used in this thesis. I then presented and discussed the basic principles of Grice's theory, focusing on issues relevant to the investigation in this thesis. Next, I applied the theory of conversational implicature to the investigated interaction, question-answer dialogues in criminal proceedings in a Danish district court. Following a discussion of the different kinds of non-observance of maxims which may occur in such dialogues, I established a model of the role of the $\mathrm{CP}$ and the maxims in the interaction. Focusing on flouts intending to generate implicature, I then suggested eight strategies that interpreters may adopt for conveying implicatures to end receivers, and illustrated the strategies by providing theoretical examples of flouts. Four of the eight strategies involve the inclusion of additions and are therefore considered particularly relevant to this study. Their plausibility will be discussed in Chapter 7, which discusses the motives of the court interpreters in this investigation for including additions in their target texts. However, before proceeding to discuss the court interpreters' motives, I shall present and discuss in the next chapter, Chapter 6, the various categories of additions identified in their target texts. 


\section{$6 \quad$ Addition categories}

This chapter presents the different kinds of additions identified in the collected data through a source-text/target-text comparison. The additions have been registered and categorized according to their impact on the semantic and/or pragmatic content of the source text, which established three main categories and a number of subcategories. The categories and subcategories were initially based on findings from an analysis of the data from the mock trial, and were then tested through an analysis of the data from the authentic trial.

The following two facts should be noted, however: (1) Some of the registered categories will list the number of interpreter renditions found to include these additions, but this will only occur in order to illustrate points of significance, and thus not for the purpose of undertaking any form of quantitative analysis of the gathered data; and (2), the objective of this chapter is only to present the different categories of additions, since the discussion of the court interpreters' motives for including the identified additions in their target texts will be reserved for the following chapter, Chapter 7.

In Section 6.1, I shall discuss the methodology employed in carrying out the source-text/target-text comparison. In Section 6.2, I shall discuss the findings from the source-text/target-text comparison of the data collected at the mock trial ${ }^{1}$, and present the three main categories of additions and their subcategories. In Section 6.3, I shall discuss the findings from the sourcetext/target-text comparison of the data from the authentic trial. Finally, in Section 6.4, I shall conclude on the discussion of the findings from both data analyses.

\subsection{The methodology}

As explained above, the additions were identified through a sourcetext/target-text comparison of the data from the two trials. The analysis was

1 As explained in Chapter 4 (Section 4.1.1), the data from the mock trial included dialogues recorded at the pre-trial consultation. 
carried out in the following five steps: (1) The data were organized into manageable parts which could be defined as source texts; (2) a formal translation was prepared for each source text; (3) a court interpreter's rendition of a particular source text, her target text, was compared with the equivalent formal translation and the source text, matching both target text and source text with their respective contexts of utterance ${ }^{2}$; (4) any discrepancy, or modification, in the interpreter's target text which could be identified as an addition was marked and registered; and (5) the registered additions were categorized according to the criteria established for categorization.

\subsubsection{Organizing the data}

The first step, organizing the data into manageable parts which could be defined as source texts, and ultimately, units of analysis, proved to be a relatively easy task. One of the principles of spoken interaction is that speakers take turns, so from the outset of this investigation I assumed that turns would make useful units of analysis. Stenström (1994:4) identifies a turn as "everything the current speaker says before the next speaker takes over". So, turntaking presupposes a shift of speakers. Another characteristic feature of turns is that their size varies from one word upward.

There were two reasons why turns were assumed useful units of analysis. First of all, turntaking is an important process in spoken interaction, and generally occurs at fairly short intervals. Consequently, I assumed that the organizing of data from any kind of spoken interaction in turns would be likely to result in fairly manageable chunks of dialogue. Secondly, the kind of interaction analysed in this investigation, question-answer dialogues in courtroom proceedings, is generally characterized by very short turns (consisting of a relatively small number of words), and smooth speaker shifts (a speaker is generally given time to complete his utterance before the next speaker takes over). Therefore, when I found that the collected

2 Thus, I considered that the context of source texts and target texts are not identical context (despite unity of time and place as in the present investigation), because the mutual assumptions (about a shared cognitive environment) of producers and receivers of source texts are not necessarily identical to the mutual assumptions of producers and receivers of target texts (cf. Chapter 7, Section 7.1.1). 
data fully complied with this characterization, I decided that turns would indeed make useful units of analysis.

Not all utterances are proper turns, though. Backchannels, utterances consisting of feedback items, do not involve a change of speaker, but simply serve to acknowledge what the current speaker is saying and generally to encourage him to continue speaking (Stenström 1994:5). However, the identified backchannels were not considered relevant for the purpose of this study, because they generally consisted of only one word (yes) or a short feedback item $(\mathrm{hmhm})$ and were never interpreted.

Finally, a note on utterances: An utterance is commonly defined as a stretch of speech preceded and followed by silence or a shift in speakers (cf. Brown \& Yule 1983:19; Goffman 1981:22; Schiffrin 1988:33, 1994:39-41; Stenström 1994:1-29). This definition may prove difficult in some situations, as it applies equally well to a one-word response and a lecture, but it was found more or less to fit the purpose of this study. So, bearing in mind the aforementioned characteristics of the interaction in this investigation, I decided that it would be practical, and useful, to define an utterance as a stretch of speech preceded and followed by either a "terminating intonation" or a "questioning intonation" (Wadensjö 1992:66, cf. Chapter 4, Table 4.1). Both kinds of intonation serve to indicate that speakers are prepared to relinquish their turns, so, adhering to this definition, the majority of utterances in the data not only constitute turns, but generally consist of completed sections of dialogue, more or less like paragraphs in written texts, though definitely shorter.

\subsubsection{A formal translation}

The second step of the source-text/target-text comparison was to prepare a formal translation ${ }^{3}$ of each source text. The definition of a formal translation corresponds with Nida's (1964) definition of formal equivalence. A formal-equivalence translation is basically source-oriented, that is, designed to reveal as much as possible of the form and content of

3 In adopting this method for the comparison of a source text with the interpreter's target text, I was inspired by Hatim \& Mason (1990:7ff). Different methods have been adopted by other interpreting scholars, for example, Dam $(1995,2001)$ and Schjoldager (1996, 2001), who both discuss the issue at some length. 
the original text, and in doing so it attempts to reproduce the formal elements (1964:165). This reproduction includes matching grammatical units by corresponding grammatical units, matching terms for corresponding terms (maintaining consistency in word usage), and preserving meanings in terms of the source context, e.g. by reproducing idioms more or less literally, "so that the reader may be able to perceive something of the way in which the original document employed local cultural elements to convey meanings" (1964:165). Thus the formal translations prepared for this analysis likewise attempt to reproduce all the formal elements of the source texts, the exception being consistency of word order, since this is not always possible without distorting the semantic (and pragmatic) content of the original utterances.

Nida (1964) distinguished formal equivalence from dynamic equivalence as basic orientations in translating. Whereas formal equivalence is directed towards equivalence of form, dynamic equivalence is directed towards equivalence of response; it is designed to recreate the effect of the original text on the receiver of the target text (1964:166). Presumably, most translations will fall somewhere in between the two orientations. However, it is not the aim of this section to contribute to a discussion of Nida's theory, but merely to explain the merits of formal equivalence for the purpose of the present investigation.

Bearing in mind that the objective of the source-text/target-text comparison is to compare like with like, there are two reasons why the preparation of a formal translation of each source text was judged an appropriate technique for carrying out this comparison. First, a formal translation is an extreme form of translation, reflecting exactly what is said and totally disregarding sense and effect on the receptor of the message. Second, formal equivalence is a means of achieving some degree of insight into the lexical, grammatical or structural form of a source text. These factors facilitate the source-text/target-text comparison and an identification of discrepancies, or modifications, in target texts. However, for this investigation, two facts in particular had to be taken into consideration when carrying out the actual comparison. First of all, a formal translation does not necessarily represent everything that is inherent in a source text, since it represents the analyst's (more or less subjective) version of it. Consequently, the formal translations are not the basis of comparison, but are aids to comparison 
(since the true comparison is between the source text and the target text). Secondly, the analyst is bilingual, which may have an impact not only on the comparisons of source texts and target texts, but also on the formal translations.

Another interesting characteristic of a formal translation is that it complies with the requirement outlined in the principle of Accuracy and Completeness (cf. Chapter 3, Section 3.5.2), because it represents the closest possible match of form and content between source texts and target texts. Thus, a formal translation equals a verbatim translation and is to be distinguished from a translation of speaker meaning (cf. Chapter 5, Section $5.1)$.

A note: Besides formal translations of source texts, back-translations into English of utterances in Danish are prepared for the English-reading audience, in order to illustrate important points. Such back-translations are prepared in accordance with the principles outlined for formal translations.

\subsubsection{Examples illustrating formal translations}

The following two examples illustrate formal translations. Example 35 illustrates an English source text translated into Danish, and example 36 a Danish source text translated into English ${ }^{4}$ :

\section{Example 35:}

QD.11.32-33 ST-D: no she took the clothes off me and I took them off of her.

FT: $\quad$ nej hun tog tøjet af mig og jeg tog det af hende.

\section{Example 36:}

QW.38.35-38: $\quad$ ST-J: $\quad$ og retten er enig med dig i at det giver også den bedste oplysning for netop- fordi- netop $i$ en voldtægtssag.

FT: $\quad$ and the court agrees with you that this also provides the best information for preciselybecause-precisely in a rape case.

\footnotetext{
4 The formal translation is transcribed in italics (cf. Chapter 4, Section 4.4.1.1).
} 
Example 36 further illustrates a problem frequently encountered during the process of preparing formal translations: the translation of fragmented source texts. As explained in Chapter 4 (Section 4.6.2), fragmented texts are quite common in spoken language and occurred also in the data collected for this investigation. However, some of the fragmented source texts were so incomplete that part of their material could only be translated by hypothesizing what the speaker was going to say. This hypothesis of speaker intentions was usually accomplished by examining the linguistic context, that is, the textual environment of the problem items. Consider, for example, the English source text in example $37^{5}$ :

\section{Example 37:}

QD.17.33-37: ST-D: I I still wanna be friends and, (.) she she I think she wants more and, (.) my job took me away from (.) us and put- too- took us apart and, (.) she can't deal with it.

FT: jeg jeg vil stadig gerne vare venner og, (.) hun hun jeg tror hun vil mere og, (.) mit job tog mig vak fra (.) os og lagde- fjerfjernede os fra hinanden og, (.) hun kan ikke håndtere det.

Evidently, the speaker, here the defendant, experiences difficulty in making up his mind about what he is going to say. He starts off with put-, then he abruptly stops and starts again with too-, but abruptly stops again and finally decides on took us apart.

The problem material is the English word put which may be translated into Danish in multiple ways, depending entirely on its complementation. Since this was unavailable, I had to examine the linguistic context in order to hypothesize the complementation. Based on the fact that the defendant finally decided on took us apart, I hypothesized that he was initially intending to say put strain on (our relationship), and consequently translated put into the Danish word lagde.

5 Important points are marked by double underlining in all examples (cf. Chapter 4, Section 4.4.2) 
Of course, when encountering fragmented source texts, Danish court interpreters are required to translate them word for word (as per the principle of Accuracy and Completeness). But example 37 demonstrates that this is not always possible without a certain amount of guesswork. Of course, another option is to give up altogether and ask the speaker to repeat his utterance, which may not always a popular course of action, because of the extra time required. In any case, when encountering the source text in example 37, the interpreter opted for a course of action which avoided the problem of translating put, but which, incidentally, included four additions (cf. Chapter 4, Section 4.6.2). Example 38 presents her target text and the equivalent back-translation:

\section{Example 38:}

QD.17.39-41: TT-I: han vil sta- $\emptyset$ h jeg vil stadig gerne være venner med hende, men mit arbejde har gjort at jeg (.) har været meget væk fra hende og, (.) hun kunne ikke rigtig $\underline{\underline{\phi h}}$ finde sig til rette med det.

Back-translation: $\quad$ he still wan- er I still want to be friends $\underline{\underline{\text { with her}}} \underline{\underline{\text { but }}}$ my work has meant that I (.) have been away a lot from her and, (.) she couldn't really er accept that.

Starting from the top, the additions in example 38 may be categorized as (1) a false start, (2) an obvious-information addition, (3) a connective addition and (4) a voice-filled pause. Cf. Section 6.2 for a discussion of these categories.

\subsubsection{Defining additions}

The third and fourth steps of the source-text/target-text comparison were to compare a court interpreter's rendition of a particular source text, her target text, with the equivalent formal translation and the source text, matching both with their respective context of utterance (linguistic and/or situational), and to identify any discrepancy, or modification, in her target text which could be identified as an addition. In order to carry out those steps of the investigation, I had to define additions, that is, to set up criteria 
for which element, or elements, in an interpreter's target text could be said to constitute an addition, or additions.

I wanted to avoid two problems, especially. First of all, I wanted to avoid the problem of confusing additions with elements which might be explained as obligatory adjustments caused by the translation process. Since the purpose of the analysis was to identify material in an interpreter's target text, the presence of which would be constituting a violation of the official requirements (i.e. the principle of Accuracy and Completeness), by adding information, additions caused by a need to adapt to the requirements of the structure of the target language would not be identified as additions for the purpose of this investigation; such additions must be presumed to add nothing to the semantic and/or pragmatic content of a source text. Furthermore, by their very nature, many of these additions would probably be present in the formal translations also. Examples are additions caused by grammatical restructuring, e.g. change of tense ${ }^{6}$ or of word-classes, or caused by translating a term in the source language into an equivalent in the target language which is made up of more words ${ }^{7}$.

Secondly, I wanted to avoid also the problem of confusing additions with items which had to be identified as interpreter errors. Examples 39 and 40 will serve to illustrate such errors:

\section{Example 39:}

QD.13.15-25: $\quad$ ST-P: $\quad$ og hvordan foregik det her samleje?

FT: $\quad$ and how did this intercourse take place?

TT-I: and how was that?

ST-D: and how was it? you-

TT-I: $\quad$ yeah well not how was it ((laughs)), I- what happened? in what way?

ST-D: erm, (.) I don't know.

6 For example, in Danish, the present perfect is often used in collocation with a time adverbial or with another adverbial denoting circumstance, where English has the simple past. Thus, the utterance, in English, she left a couple of days ago translates as hun er rejst (has left) for et par dage siden (Sørensen 1991:114).

7 For example, the English equivalent of the Danish compound bevisbyrde is burden of proof. 
In example 39, the interpreter mistakenly translates the prosecutor's general question into one that is much more specific, and also rather intimate. The question is not an addition, because the interpreter does not add more material, i.e. she does not add a question, but she merely substitutes one question for another. This fact is supported by the ensuing dialogue between the interpreter and the defendant: When the defendant reacts by repeating the question instead of answering right away, the interpreter (1) realises her mistake (demonstrated by ((laughs))), (2) confirms that she made it (well not how was it), and (3) proceeds to correct it (I- what happened? in what way? $)^{8}$.

\section{Example 40:}

QW.8.5-11: $\quad$ ST-W: hmhm. yeah. and I agreed that I should let him in, there was no reason why I shouldn't, I mean we- we were good friends before that.

FT: $\quad$ hmhm. ja. og jeg sagde ja til at lukke ham ind, der var ingen grund til at jeg ikke skulle, jeg mener vi-vi var gode venner før det.

TT-I: hmhm. ja. hun $\emptyset$ h han kom og bankede på og hun lukkede ham ind, fordi der var ingen grund til hun ikke skulle gøre det, de var gode venner på det tidspunkt.

Back-translation: $\quad$ hmhm. yes. she er he arrived and knocked on her door and she let him in, because there was no reason why she shouldn't do that, they were good friends at that time.

In example 40, the interpreter mistakenly translates before that into at that time (på det tidspunkt). Again, she does not include an addition, but merely substitutes one adverbial phrase for another. Contrary to what occurred in

8 Interestingly, the court allows this dialogue, though, strictly speaking, it constitutes a violation of the principle of Accuracy and Completeness (cf. Chapter 3, Section 3.5.2). However, as explained in Chapter 4 (Section 4.6.4), the court interpreters in this investigation were generally not prevented from repeating or clarifying questions upon requests from the foreign participants, nor were they prevented from asking clarifying questions of these participants. 
example 39, however, none of the participants (including the interpreter and the witness) seemed to realise that the error had occurred. At least, no one drew attention to it or attempted to correct it. But presumably this kind of subtle error, which resulted in no dramatic change of dialogue, will not be easily detected

My considerations regarding the avoidance of these two problems resulted in the following definition:

An addition is an item in a court interpreter's target text which has no precedent on the surface of the original utterance. An addition is considered to have no precedent when its presence may not be explained by reference to the formal aspects of the interpreting process (in the sense of being required because of structural differences between the two languages), or by identifying it as constituting an interpreter error. Thus, an addition may be

- $\quad$ an item introduced in the interpreter's target text which is not in any way warranted, or justified, by the source text; or

- $\quad$ an item implicit, or possibly implicit, in the source text, which has been made explicit in the interpreter's target text; or

- an item which was not present in the source text, but which appears at least implicit, if not explicit, in the interpreter's target text.

Such an item may be a pause (silent or word-filled), a paralinguistic feature, a word or a phrase, or it may also be the result of matching an interpreter's linguistic choice (or even its absence) with its context. For example, it is quite plausible that an implicature may be generated in a target text, but that it has no trace in the corresponding source text, in which case the interpreter will have introduced an addition (the significance does not lie in what the interpreter says but in what she does not say).

The above definition includes additions which may be explained by reference to commonly acknowledged translation strategies derived from 
translational norms, i.e. strategies adopted by translators in order to produce appropriate target texts (cf. Chesterman 1997:63-70 and Chapter 4). For example, translation theory has long recognized that translators tend to adopt the strategy of explicitation, which is the strategy of including items explicitly in the target text which are only implicitly present in the source text (Chesterman 1997:71, cf. Blum-Kulka 1986:19). Thus, it may be that explicitation is responsible for some of the additions identified in the target texts of the court interpreters in this investigation. In fact, the fours studies of court interpreting referred to in Chapter 2 (Section 2.2) of this thesis, as well as Wadensjö's (e.g. 1991:74-97) study of dialogue interpreting in health-care clinics and police stations (cf. Chapter 2, Section 2.1.2), all refer to additions which serve to explicitly express implicit information. Similarly, Setton (2002:184) reports that simultaneous interpreters are often found to expand or insert structure in their target texts, and to include text-external knowledge of the situation or conference event, as well as interclausal elements, e.g. connectives.

Also, Schjoldager (1996), who explores translational norms in simultaneous interpreting, finds (1996:232-246) that interpreters may adhere to norms which legitimize e.g. the presence of additions in their target texts. Schjoldager (1996:128) defines an addition as an item in an interpreter's target text which has no precedent in the original utterance, and her norm-oriented analysis of target-text/source-text relations enables her to establish several categories of additions, ranging from additions included in order to avoid violating target language norms, to additions explicating information which was implicitly present in the source text, to additions conveying information which was neither explicitly nor implicitly present in the source text (1996:129ff).

On the other hand, Barik (1971, 1972, 1975), who likewise investigates simultaneous interpreting, analyses additions as a category of translation departures. Thus, Barik (e.g. 1975:276) defines an addition as an item in the interpreter's target text which was not present in the source text. This narrow definition not only excludes material connected with the interpreting process, such as repetitions and false starts (1971:202), but also excludes material resulting from an interpreter's adherence to a translational norm. Barik's definition enables him to establish four main categories of additions: qualifier addition (a qualifier or a short qualifying 
phrase), elaboration addition, relationship addition (e.g. connectives) and closure addition (material accompanying rephrasing, omission or misinterpretation) (1971:202-203 and 1975:276-277). He also refers (e.g. 1975:277) to some "minor" additions, explaining that these were disregarded in his study.

Obviously, some of the categories of additions established by Schjoldager (1996) and Barik (1971) will be identified also in the data collected for this investigation. In fact, Schjoldager's (1996:110) model of target-text/sourcetext relations inspired the model presented in Table 6.1. Nevertheless, principles of translational correspondence are not a primary concern in the present investigation. As explained in Chapter 1 (Section 1.1), the object of study is interaction (face-to-face and three-party), rather than action (interpreter performance). Thus, similar to Wadensjö's study (cf. above), the investigation in this thesis provides a more procedural account of court interpreting, taking into consideration the significant influence that interactional factors are bound to exert on the performance of the interpreters. Consequently, rather than attempt to explain the categories of additions presented in this chapter as resulting from the interpreters' adherence to norms, or failure to adhere to norms, I shall attempt to explain them as resulting from the interpreters' need for achieving successful interaction, i.e. as resulting from their need for ensuring the retrievability of speaker meaning.

Finally, the above definition illustrates the importance of distinguishing between information which may be classified as given, or shared, since it is already present in the context of the interaction, having been previously introduced, explicitly or implicitly, and information which may be classified as new, since it is being introduced, explicitly or implicitly, into the interaction for the first time. The next section will explore this concept further.

\subsubsection{Given versus new information}

The general notion of given versus new information figures in much literature (e.g. Halliday \& Hasan 1976; Brown \& Yule 1983; Levinson 1983). However, of particular relevance to this study is the investigation of 
the role of given versus new information from a discourse perspective conducted by Prince (1981), who introduced a taxonomy of what she termed Assumed Familiarity. Prince (1981:233) explains that her taxonomy is an attempt at finding answers to the following questions:

"From the point of view of a speaker/writer, what kinds of assumptions about the hearer/reader have a bearing on the form of the text being produced, where that form is not uniquely determined by the "objective" information that the speaker/writer is attempting to convey?"

"From the point of view of the hearer/reader), what inferences will s/he draw on the basis of the particular form chosen?"

Working on the assumption that a text is a set of instructions from a speaker to a hearer on how to construct a particular discourse model, Prince (1981:237) established seven categories of discourse-model objects which may occur within a particular discourse model. Four of these categories, Brand-new, Textually evoked, Situationally evoked, and Inferrable, were found to be useful for distinguishing between some of the given and new information occurring in this investigation (cf. Sections 6.2.2.4, 6.2.3). Slightly modified to suit the present analysis they may be defined as follows:

Brand-new: Information is brand-new if it is introduced into the interaction for the first time, whether explicitly or implicitly.

Textually evoked: Evoked information is already either explicitly or implicitly present in the context of the interaction. When information is textually evoked, the hearer had evoked it earlier, on textual grounds, by following instructions from the speaker, i.e. the information was once brand-new or inferrable.

Situationally evoked: When information is situationally evoked, the hearer knew how to evoke it all by himself, for situational reasons. Situationally evoked information represents 
participants in the interaction and salient features of the situational context.

Inferrable: Inferrable information is implicitly present in the context of the interaction. Information is inferrable if the hearer can infer it, via logical, or, more commonly, plausible, reasoning, from information already evoked or from other inferrable information. In other words, inferrable information is capable of being worked out by any normal, rational human being.

Each of the four categories will be referred to again and discussed in the order in which they appear in the remaining part of this chapter.

\subsection{Source-text/target-text comparison of the data from the mock trial}

The source-text/target-text comparison of the data collected at the mock trial, employing the specified methodology, identified a large number of additions. As explained in the beginning of this chapter, these findings served to establish the various categories and subcategories of additions which were then tested through an analysis of the data collected at the authentic trial. Taking as the point of departure the semantic and pragmatic content of a source text, represented in the formal translation of it, the additions have been registered according to whether or not they were judged to have an impact on the semantic and/or pragmatic content. Thus, additions which did not add to the semantic and/or pragmatic content were judged to have no impact, whereas additions which added to the semantic and/or pragmatic content were judged to have an impact, and their impact was judged to be either minimal or significant. Additions which added to the semantic and/or pragmatic content by explicitly expressing information which was implicitly present in the context of the interaction (linguistic and/or situational), or by elaborating on items which had already been rendered once in an interpreter's target text were judged to have minimal impact; while additions which added to the semantic and/or pragmatic content by introducing information which may be categorized as brand- 
new, by being explicitly or implicitly introduced into the interaction for the first time, were judged to have significant impact.

Besides, the source-text/target-text comparison established three subcategories of additions, the impact of which was judged to be potential only (marked with a p ). However, since I judged the potential impact of these additions to be minimal, I decided that, rather than establish a separate category, they would be entered in the category of additions with minimal impact.

Table 6.1 presents the three main categories and their subcategories':

9 As mentioned earlier (cf. Section 6.1.3 above), this model was inspired by Schjoldager's (1996:110) model of target-text/source-text relations. 
Table 6.1: Additions identified in the data from the mock trial

\begin{tabular}{|c|c|c|}
\hline \multirow{4}{*}{$\begin{array}{l}\text { Additions with no } \\
\text { impact on the } \\
\text { semantic and/or } \\
\text { pragmatic content of } \\
\text { the source text }\end{array}$} & \multicolumn{2}{|l|}{ Repetitions } \\
\hline & \multicolumn{2}{|l|}{ Silent pauses } \\
\hline & \multicolumn{2}{|l|}{ Voice-filled pauses } \\
\hline & \multicolumn{2}{|l|}{ False Starts } \\
\hline \multirow{7}{*}{$\begin{array}{l}\text { Additions with } \\
\text { minimal impact on } \\
\text { the semantic and/or } \\
\text { pragmatic content of } \\
\text { the source text }\end{array}$} & \multicolumn{2}{|l|}{ Repetitions $_{p}$} \\
\hline & \multicolumn{2}{|l|}{ Fillers $_{\mathbf{p}}$} \\
\hline & \multicolumn{2}{|l|}{ Paralinguistics $_{\mathbf{p}}$} \\
\hline & \multirow[t]{3}{*}{ Explicating additions } & $\begin{array}{l}\text { Obvious-information } \\
\text { additions }\end{array}$ \\
\hline & & Connective additions \\
\hline & & $\begin{array}{l}\text { Additions explicating } \\
\text { non-verbal } \\
\text { information }\end{array}$ \\
\hline & \multicolumn{2}{|l|}{ Elaborating additions } \\
\hline \multirow{3}{*}{$\begin{array}{l}\text { Additions with } \\
\text { significant impact on } \\
\text { the semantic and/or } \\
\text { pragmatic content of } \\
\text { the source text }\end{array}$} & \multicolumn{2}{|l|}{ Emphasizing additions } \\
\hline & \multicolumn{2}{|l|}{ Down-toning additions } \\
\hline & \multicolumn{2}{|c|}{ New-information additions } \\
\hline
\end{tabular}

In Sections 6.2.1 to 6.2.3, I shall discuss the different categories and subcategories and illustrate them by examples. The reader should note, however, that the various examples are chosen mainly for their illustrative powers, and not because they are statistically representative of the corpus. Besides, since an individual source text, the relevant formal translation and the interpreter's target text may serve to illustrate several interesting points simultaneously, the examples often represent shortened versions of texts in order to highlight material of particular interest. Also, symbols indicating terminals and simultaneous talk have largely been ignored, for the same reason. 


\subsubsection{Additions with no impact on the semantic and/or pragmatic content of the source text}

Additions with no impact on the semantic and/or pragmatic content of the source text were identified as features typical of normal conversation. Generally such features may be attributed to the particular nature of spoken interaction, requiring fast, almost instantaneous production and understanding $^{10}$. I shall presume, therefore, that their presence in the interpreters' target texts may be attributed to the special nature of the interpreting process, also requiring fast, almost instantaneous production and understanding, but this time in two different languages. Probably, the additions functioned mainly as disguised translational repairs, i.e. as stalling devices (cf. Stenström 1994:76), meant to 'buy' the interpreters time to process the input from participants and/or to prepare their own output.

However, despite occurring in great numbers, additions with no impact, that is, not adding to the semantic and/or pragmatic content of the source text, were not considered relevant for the purpose of this study, but were identified and categorized purely for elimination purposes. Examples 41 to 48 illustrate the category and its subcategories.

\subsubsection{Repetitions}

The interpreter repeats one or more items in her target text, which were not repeated in the source text. The repetitions in examples 41 and 42 are typical examples of the additions registered as belonging to this subcategory:

${ }^{10}$ In fact, these features were found to be abundant also in source texts. Interestingly, the strategy of the court interpreters in this study was generally to omit them, perhaps because they were regarded as insignificant, having no impact on the semantic and/or pragmatic content of the source text, or because the interpreters feared that their presence in renditions might be attributed to faulty interpretation (cf. the discussion in Chapter 4, Sections 4.6.2 and 4.6.3). Of course, this is purely speculation on my part, and, in any case, it has no bearing on the present investigation. 


\section{Example 41:}

QW.22.16-23: ST-W: I think that he did this deliberately in front of me

FT: $\quad$ jeg tror at han gjorde det med fuldt overlag foran mig

TT-I: hun hun regner med han han gjorde det foran hende

Back-translation: $\quad$ she she reckons that he he did this in front of her

\section{Example 42:}

PC.9.10-13: $\quad$ ST-DC: og om du har $\varnothing$ h børn og kone

FT: $\quad$ and whether you have er children and a wife

TT-I: and and if you have got a wife and children

\subsubsection{Silent pauses}

The interpreter includes one or more silent pauses in her target text. Examples 43 and 44 are typical examples of the additions registered as belonging to this subcategory:

\section{Example 43:}

QW.38.12-15: ST-W: I have a season ticket

FT: jeghar buskort

TT-I: hun har (.) kort

Back-translation: $\quad$ she has (.) season ticket

\section{Example 44:}

QD.19.33-36: $\quad$ ST-DC: og foregik det sådan under hele samlejet?

FT: and was it like that during the entire intercourse?

TT-I: was it like that during the whole (.) time? 


\subsubsection{Voice-filled pauses}

The interpreter includes one or more voice-filled pauses in her target text. Examples 45 and 46 are typical examples of the additions registered as belonging to this subcategory:

\section{Example 45:}

QW.10.1-9: ST-W: and particularly because of the way in which he was behaving

FT: $\quad$ og isar på grund af den måde han opførte sig på

TT-I: $\quad$ og især $\underline{\varnothing h}$ på grund af hans opførsel

Back-translation: and particularly er because of his behaviour

\section{Example 46:}

PC.8.17-20: $\quad$ ST-DC: og hun vil blive afhørt på samme måde

FT: $\quad$ and she will be questioned in the same way

TT-I: and she will be erm asked questions in the same way

\subsubsection{False starts}

The interpreter includes one or more false starts in her target text. Examples 47 and 48 are typical examples of the additions registered as belonging to this subcategory:

\section{Example 47:}

QW.25.45-26.3: ST-W: the skin wasn't pierced at all, because he didn't hold it tight enough to to pierce it

FT: huden var ikke gennemboret overhovedet, fordi han ikke holdt den tat nok til at til at gennembore den

TT-I: der var ik- der var ikke gået hul på huden, фh for for da han holdt den ikke hårdt nok mod huden til at det kunne ske 
Back-translation $\quad \underline{\underline{\text { it wasn't- }}}$ the skin wasn't pierced, $\underline{\underline{\mathrm{er}}}$ because because as he didn't hold it tight enough against the skin for this to happen

Example 48:

QD.8.13-16: $\quad$ ST-P: da du kom derover hvad skete der så

FT: $\quad$ when you got there what happened then

TT-I: $\quad$ wouldn't- once you arrived what happened

\subsubsection{Additions with minimal impact on the semantic and/or pragmatic content of the source text}

Additions with minimal impact on the semantic and/or pragmatic content of the source text were registered as Repetitions, Fillers $_{\mathbf{p}}$, Paralinguistics $_{\mathbf{p}}$, Explicating additions or Elaborating additions. The subcategory of Explicating additions was further divided into three subsubcategories: Obvious-information additions, Connective additions and Additions explicating non-verbal information. Examples 49, 50 and 52 to 79 illustrate the category and the various subcategories.

As explained above (cf. Section 6.2), the first three subcategories of additions were registered as having potential impact only. Presumably, like additions registered as having no impact, these additions may also be attributed to the special nature of the interpreting process. However, as mentioned in the beginning of this chapter, the question of the interpreters' motives for including the identified additions in their target texts will be taken up for discussion in Chapter 7.

\subsubsection{Repetitions $s_{p}$}

The additions of this subcategory resemble the additions registered as Repetition, and thus as having no impact. But, contrary to the additions in the former subcategory, additions registered as Repetitions $\mathbf{p}_{\mathbf{p}}$ added a degree of hesitancy to the target text, which may have the potential to decrease, or down-tone, the force of the original utterance. This potential impact was judged to be minimal, however, since the additions were merely repetitions of material which was explicitly present in the source text, and which had already been rendered once in the interpreter's target 
text. Thus the subcategory should not be confused with the subcategory of Down-toning additions (cf. Section 6.2.3.2), which serve to significantly alter the semantic and/or pragmatic content of a speaker's utterance by introducing information which may be categorized as brand-new (cf. Section 6.1.4 above).

Additions registered as $\mathbf{R e p e t i t i o n s}_{\mathbf{p}}$ were quite rare, since they were only identified in three interpreter renditions in the data from the mock trial. The subcategory is illustrated by examples 49 and 50 :

\section{Example 49:}

QW.37.3-10: ST-W: but I know he is aggressive sometimes towards other people, like particularly other men when we were going out, if they were to pay me any attention.

FT: $\quad$ men jeg ved han er aggressiv nogen gange overfor andre mennesker, såsom specielt andre mand da vi gik ud sammen, hvis de viste mig nogen opmarksomhed.

TT-I: men men han hun ved han har været aggressiv eller (.) ja været aggressiv overfor andre mænd, som $ø$ h som var opmærksom på hende når de har været $\mathrm{i}$ byen.

Back-translation: but but he she knows he has been aggressive or (.) yes been aggressive towards other men, who er who were aware of her when they have been out.

The interpreter's repetition of varet aggressiv (been aggressive), especially combined with the other three additions, the conjunction eller (or), the silent pause, and the affirmative ja (yes), indicates a hesitancy regarding the use of the term aggressive, which may reflect on the speaker (the witness). Thus the addition may potentially change the witness' firm statement into one that is less definite. Similarly, in example 50:

\section{Example 50:}

QW.25.26-31: $\quad$ ST-P: $\quad$ var der nogen mærker eller noget efter $\varnothing \mathrm{h}$ at du havde fået kniven holdt $ø$ hod struben? 
FT: $\quad$ were there any marks or anything after er you had had the knife held er against your throat?

TT-I: were there any bruises or marks after the: the knife was held against you? your neck?

The interpreter repeats the definite article the, and she also noticeably lengthens the sound of the $e$ in the first the. The total effect is an added degree of hesitancy, which may potentially decrease the level of assertiveness in the original question.

\subsubsection{Fillers}

Only three types of fillers were added: ja (well), altså (I mean) and jo (you know), but they were nevertheless judged to have potential impact on the semantic and/or pragmatic content of the source text, because of their potential discourse functions (cf. Schiffrin 1988:102-127 and 267-311; Leech \& Svartvik 1994:13-14; Green 1996:141-142). However, the term 'fillers' may imply that these items function only in order to fill a gap, and therefore it may be useful to start out by presenting an example of the way the three types of fillers may be used as markers of discourse, before presenting the potential discourse functions of the fillers identified in the data collected for this investigation. Consider example $51^{11}$ :

Example 51: $\quad$ Well, my brother used to drive a Fiat. But he always had to take it in for repairs, you know, so he exchanged it for a Volkswagen, you know. That was four years ago, but he's only had to take it in for repairs twice. $\underline{\underline{\text { mean }}}$, he did take it in three times, but the third time was only to check for rust.

Schiffrin (1988:102ff) explains that the filler well is a response marker, showing a speaker's awareness of the need for building coherence, and anchoring him into the interaction precisely at those points where upcoming coherence is not guaranteed. Thus, in example 51, assuming that the main topic of the interaction is the advantages of German cars over Italian cars and that the participants had just been exchanging views on a subordinate topic (e.g. the price of petrol), the filler is used to mark the

${ }^{11}$ Cf. Chapter 5, note 1. 
speaker's return to the main topic at a point in the interaction where coherence is not necessarily guaranteed.

According to Schiffrin (1988:267ff), the filler you know has both informational and interactional functions. The informational function of the filler is to mark information which the speaker assumes is shared between him and the hearer, and its interactional function is to negotiate the status of the information (whether it really is shared), or to enlist the hearer's agreement when this is not otherwise forthcoming. Example 51 illustrates how the filler may be used in this dual capacity in argument: the speaker appeals to shared information as a way of convincing the hearer of his point of view ('the Volkswagen is a better car').

As for the filler I mean, Schiffrin (1988:295ff) explains that it marks a speaker's modification of his previous ideas and intentions, and that it is used to maintain speaker and hearer focus on this information. In example 51, therefore, the filler instructs the hearer to maintain focus on the speaker's preceding utterance (That was ... twice) in order to hear how this utterance will be modified.

So, because of the potential discourse functions of the three types of fillers, the additions registered as Fillers $_{\mathbf{p}}$ were identified as having the potential to indicate a particular attitude on the part of the speaker towards the interaction, or part of the interaction, or towards his addressee, or addressees. However, similar to the additions registered as $\mathbf{R e p t i t i o n}_{\mathbf{p}}$, Fillers $_{\mathbf{p}}$ did not introduce information which may be categorized as brandnew, and consequently their potential impact was judged to be minimal only.

Interestingly, the added fillers were identified only in renditions in Danish, and only in the renditions of one interpreter. Besides, with a few exceptions, these additions appeared primarily to function as starters, i.e. introductory devices meant to help the speaker (the interpreter) start the turn (Stenström 1994:70). These facts may suggest that, in certain situations, this interpreter found the processing of outputs in English more strenuous than the processing of outputs in Danish (her mother tongue). This question will be taken up again in Chapter 7 (Section 7.2.2). 
The subcategory is illustrated by examples 52 to 54 . Examples 52 and 53 illustrate the additions which appeared to function as starters:

\section{Example 52:}

QW.4.16-38: $\quad$ ST-P: hvornår gik det forbi mellem jer?

FT: $\quad$ when did it end between you?

TT-I: when did your relationship end?

ST-W: it just reached the end. the natural end of a relationship where two people can't take it any further.

FT: $\quad$ det nåede bare sin afslutning. den naturlige afslutning på et forhold hvor to mennesker ikke kan nå laengere med det.

TT-I: ja det løb bare ud i sandet som- for to som ikke (.) kan sammen mere.

Back-translation: $\quad$ well it just fizzled out like- for two people who can't (.) get along any more.

The witness was asked to state when her former relationship with the defendant came to an end. The addition of the filler ja (well) in the rendition of her response has the potential to indicate a need for building coherence. Consequently, the filler has the potential to indicate that she (the witness) believes that her answer is somehow insufficient, not providing the required information. In other words, the filler may potentially change the witness' firm answer into one that is less definite.

\section{Example 53:}

QW.26.6-17: $\quad$ ST-P: altså du- du siger han har brugt kniven til at true med men har han taget fat i dig eller,

FT: $\quad$ well you-you say that he used the knife to threaten you with but did he grab hold of you or,

TT-I: you said he used the knife to threaten you, did he did he grab hold of you or anything else?

ST-W: other than what I've demonstrated

FT: $\quad$ andet end hvad jeg har demonstreret 
TT-I: $\quad \underline{\underline{\text { altså }}}$ (.) yderligere $\mathrm{i}$ forhold til det hun har

Back-translation: $\quad \underline{\underline{\text { mean }}}($.$) additionally compared to what$ she has shown

The addition of the filler altså (I mean), by potentially instructing the end receiver (the prosecutor) to maintain focus on a previous utterance (his question), adds a degree of hesitancy to the interpreter's target text (especially in combination with the silent pause) which potentially indicates that the speaker (the witness) is surprised, or even incredulous, at being asked to provide the required information. In other words, the addition may potentially change the witness' co-operative attitude into one that is uncooperative. Furthermore, the interpreter's change of footing, her use of the third person in the target text, may have indicated to the end receiver (the prosecutor) that the problem lies with her, i.e. the interpreter, rather than with the witness. On the other hand, any such indication may have been 'cancelled out' by this particular interpreter's almost habitual use of the indirect, third-person style in target texts in Danish (cf. Chapter 4, Section 4.6.1).

Example 54 illustrates the addition of the filler jo (you know):

\section{Example 54:}

QW.14.47-15.4: ST-W: he spoke very calmly, and not very loudly, and just said it right in my ear 'cause he was behind me just here, and his mouth was towards my ear.

FT: $\quad$ han talte meget roligt, og ikke sarlig højt, og sagde det bare lige ind $i$ mit $\phi r e$ fordi han var bag mig lige her, og hans mund var mod mit фre.

TT-I: og han sagde det meget langsomt og tydeligt og ikke særlig højt, øh og lige ind i øret på hende for han stod jo bag hende.

Back-translation: and he said it very slowly and clearly and not very loudly, er and right into her ear because you know he was behind her. 
The filler you know has the potential to indicate that the speaker (the witness) wants to negotiate the status of the information he was behind her which was introduced at an earlier stage of the interaction, i.e. whether this information really was shared, or that she wants to enlist the hearer's (the prosecutor's) agreement that the information really was shared. Thus, like the filler $j a$ (well) in example 52 above, you know potentially indicates that the speaker (the witness) believes her answer is somehow insufficient, not providing the required information. So, this addition may likewise potentially change the speaker's (the witness') firm answer into one that is less definite.

\subsubsection{Paralinguistics}

Only three interpreter renditions in the data collected at the mock trial included added paralinguistic features, and the same feature was registered in all three: laughter.

Wadensjö $(1992,1998)$ demonstrates in her study of dialogue interpreting encounters (cf. Chapter 2, Section 2.1.2) that paralinguistic features, including laughter, may have an impact on the semantic and/or pragmatic content of the source text that may not necessarily be minimal, since their presence may result in events of miscommunication. Furthermore, Adelswärd (1989) who studied the social significance of laughter in institutional discourse demonstrates (1989:115) that "laughter can be both mutual and unilateral, self-initiated or other-initiated". Thus, laughter is regularly triggered by something considered funny, and it has a strong inviting character. However, Adelswärd (1989:129) explains that laughter is not only connected with amusement, since, in dialogue, participants often laugh alone and not always at funny things. So, whereas mutual laughter is a sign of rapport and consensus, unilateral laughter is often used to modify verbal expressions or attitudes and to assist in handling ambiguities and tensions (1989:129).

However, the unilateral laughter which occurred in the three renditions in the data from the mock trial did not result in events of miscommunication, nor did it introduce information which may be categorized as brand-new. Consequently, the impact of these renditions was judged to be minimal. Furthermore, since they appeared to be attributed to the special nature of 
the interpreting process, like Repetitions $\mathbf{p}_{\mathbf{p}}$ and Fillers $_{\mathbf{p}}$, their impact was judged to be potential only. In other words, like fillers, these additions were identified as having the potential to indicate a particular attitude on the part of the speaker towards the interaction, or part of the interaction, or towards his addressee, or addressees. The subcategory is illustrated by examples 55 and 56:

\section{Example 55:}

QW.34.42-35.4: ST-W: that was to begin with, he was on the chair. er but then he moved across (.) to the sofa to just come and sit next to me. I was sitting at the end of the sofa, and he came to sit on the middle seat up (xxx).

FT: det var til at begynde med, han sad $i$ stolen. oh men så flyttede han sig over (.) til sofaen for bare at komme og sidde ved siden af mig. jeg sad $i$ den ene ende af sofaen, og han satte sig $i$ det midterste sade oppe (xxx).

DC: okay.

FT: $\quad \underline{o k a y}$.

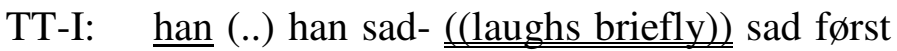
i stolen, og hun sad i sofaen i den ene ende, og han kom så over og satte sig øh ved siden af hende i midten.

Back-translation: $\quad \underline{\text { he }}$ (..) he was- ((laughs briefly)) was sitting on the chair at first, and she was sitting in the sofa at the one end, and he then came across and sat down er next to her in the middle.

The 'interrogator' (the defence counsel) did not wait for the translation of the witness' statement before responding to it, which resulted in the simultaneous speech illustrated by example 55. I assume that this is what triggered the interpreter's unilateral laughter. However, irrespective of whether the interpreter's laughter was directed at the court in general, or at the defence counsel or the witness in particular, and irrespective of who was at the focus of it, the paralinguistic feature has the potential to 'damage' the interpreter's neutrality by demonstrating a level of intimacy 
between her and the interactants which constitutes a violation of the principle of Impartiality (cf. Chapter 3, Section 3.5.2).

\section{Example 56:}

QD.19.2-8: $\quad$ ST-DC: $\varnothing:$ h jeg ved godt $\varnothing \mathrm{h}$ at du synes det er ubehageligt at tale om, $\varnothing \mathrm{h}$ men jeg vil gerne stille dig nogen spørgsmål, der omhandler det der skete i soveværelset.

FT: e:r I know that er that you think it is unpleasant to talk about, er but I would like to ask you some questions, concerning that which happened in the bedroom.

TT-I: $\quad(\mathrm{xxx})$ to talk about, but she wants to tal- ask you some questions about what happened (laughs briefly)) in the bedroom.

Unlike the interpreter's unilateral laughter in example 55, this addition does not appear to be connected with amusement, but it seems nevertheless to have been triggered by a feature of the interaction: the need for tension reduction and face protection which was explicitly expressed by the wording of the original question. However, since this need was explicitly expressed in the original, there was no apparent reason for further explication for the purpose of limiting threats to the defence counsel's face. Furthermore, bearing in mind that the defendant had been asked similar, and even more potentially 'dangerous' questions at an earlier stage of the interaction, and that these questions had been interpreted without the interpreter apparently having needed to use laughter (or any other feature) as a means of reducing tension, there is no reason to assume that she included the laughter for the sole purpose of limiting threats to her own face. Accordingly, her laughter seems to have been just as spontaneous as her laughter in example 55. It may be perceived, nevertheless, as an expression of discomfort on her part alone which may potentially 'damage' her neutrality (cf. above).

\subsubsection{Explicating additions}

Additions of this subcategory serve to explicate material implicitly present in the context of the source text. Thus, additions registered as Explicating 
additions mainly illustrate the interpreter's explicit expressing of information which may be categorized as either Textually evoked, i.e. implicitly present in the context of the interaction, having been introduced explicitly or implicitly at an earlier stage, Situationally evoked, i.e. implicitly present in the context of the interaction and representing participants and the situation, or Inferrable, i.e. implicitly present in the context of the interaction and capable of being inferred by a normal, rational human being from already evoked (implicitly or explicitly introduced) information or from other inferrable information (cf. Section 6.1.4). However, additions explicitly expressing textually and situationally evoked information did not occur very often. In fact, as will be demonstrated by examples 57 to 75 below, most additions of this subcategory were identified as explicitly expressing inferrable information.

The reader will note that some of the additions illustrated here may, at least at a first glance, appear also to be emphatic, and perhaps it may be possible to argue that by explicating implicit material, an interpreter will serve to add emphasis. However, the subcategories of Explicating additions and Emphasizing additions should not be confused. Explicating additions only have minimal impact on the semantic and/or pragmatic content of the source text, whereas Emphasizing additions, as will be demonstrated in Section 6.2.3.1 below, have significant impact on the semantic and/or pragmatic content, since they introduce information which may be categorized as Brand-new, i.e. explicitly or implicitly introduced into the interaction for the first time.

\subsection{Obvious-information additions}

The interpreter explicitly expresses information which may be classified as obvious by being implicit in the context of the interaction (linguistic and/or situational), and in the process she introduces a greater degree of specificity. The subcategory is illustrated by examples 57 to 69 .

Examples 57 and 58 illustrate additions explicitly expressing textually evoked information. In example 57, the interpreter includes items which express information implicitly present in the situational context, having been provided at an earlier state of the questioning of the defendant and therefore known to the participants: 


\section{Example 57:}

QD.4.32-5.9: $\quad$ ST-P: du siger I ses éen gang om ugen, det lyder næsten som sådan en fast aftale. er det en fast aftale eller er det sådan noget der der sker tilfældigt?

FT: $\quad d u$ say you meet once a week, that sounds almost like a steady date. is it a steady date or is it something which which occurs by chance?

TT-I: the fact that you meet once a week is that a sort of a (.) an established er (.) routine?

ST-D: no it's not a routine, we we just er if one of us want to meet each other we call each other up. call the other one up and ask if they wanna come over. it's nothing important, nothing special.

FT: $\quad$ nej det er ikke en fast praksis, vi vi bare $\phi h$ hvis en af os vil at vi skal ses ringer vi til hinanden. ringer til den anden og spфrger om de vil komme forbi. det er ikke noget sarligt, ikke noget specielt.

TT-I: nej det er ikke sådan (.) bestemt men $\varnothing \mathrm{h}$ hvis de får lyst til at se hinanden så ringer de til til hinanden.

P: $\quad$ hm

FT: $\quad h m$

TT-I: $\quad$ og det sker så en gang om ugen cirka.

Back-translation: $\quad$ no it is not sort of (.) fixed but er if they feel like seeing each other then they call each each other.

and this happens about once a week.

Similarly in example 58:

\section{Example 58:}

QD.15.28-34: $\quad$ ST-P: $\quad$ og hele vejen igennem $\varnothing:$ h det her samleje både før og ef- under og efter, har $<$ person> da på noget tidspunkt $\varnothing: h$ protesteret imod det der skete?

FT: $\quad$ and all the way through e:r this intercourse both before and af- during and after, did 
$<$ erson> then at any time e:r protest against what happened?

TT-I: this evening did <person> ever protest against anything that happened before during or after the intercourse.

Example 59, on the other hand, illustrates an addition which explicitly expresses information that may be either textually evoked (being implicit in the situational context since the witness had answered a similar question once before), or inferrable (being implicit also in the linguistic context as evidenced by the past tense):

\section{Example 59:}

QW.34.5-27: $\quad$ ST-DC: du forklarer at $\varnothing \mathrm{h}<$ person $>$ var lidt underlig da han kom?

FT: $\quad$ you explain that er $<$ person $>$ was a bit odd when he arrived?

TT-I: $\quad$ you explain that $<$ person $>$ was a bit strange when he came?

ST-W: yes.

FT: $\quad j a$.

ST-DC: $\varnothing$ h havde du indtryk af hvorfor, han var det?

FT: er did you have any impression why, he was that?

TT-I: did you have any idea why?

ST-W: no, like I said I I did ask him er tried to approach him about this but, he was he was agitated and I know him well enough not to push him about something if he if he says that nothing is wrong.

FT: nej, som jeg sagde spurgte jeg jeg ham faktisk фh prøvede at snakke med ham om det her men, han var han var ophidset og jeg kender ham godt nok til ikke at presse ham vedrørende noget hvis han hvis han siger at der ikke er noget galt.

TT-I: nej som hun har forklaret tidligere, hun spurgte ham om det men $\varnothing \mathrm{h}$ men $\varnothing \mathrm{h}$ men kender ham godt nok til at vide at at man skal ikke skubbe, man skal ikke prøve at 
presse ham til at sige noget, hvis han ikke vil.

Back-translation: $\quad$ no like she explained earlier, she asked him about it but er but er but knows him well enough to know that that you shouldn't push, you shouldn't try to press him to say something, if he doesn't want to.

Example 60 illustrates one of only three additions explicitly expressing situationally evoked information: The interpreter turns a passive construction with no agent into an active construction which specifies the agent. The identity of the particular agent is implicit in the context of the situation, i.e. in the context of the proceedings, and therefore the hearer (the interpreter) knew how to evoke the information, for situational reasons, without any instructions from the speaker (the judge):

\section{Example 60:}

QW.2.10-14: $\quad$ ST-J: du skal sige sandheden under forklaringen.

FT: you must speak the truth during your testimony.

TT-I: you must speak the truth,

ST-J: hvis du ikke siger sandheden, (.) så kan du straffes for falsk forklaring for retten.

FT: if you do not speak the truth, (.) then you may be punished for giving false evidence to the court.

TT-I: and if you don't do that, the court may punish you.

Examples 61 to 65 illustrate additions explicitly expressing inferrable information. In examples 61 and 62, the interpreter not only interprets the speakers' utterances, but also explicitly expresses the implicit, as well as obvious, conclusions to be drawn (inferred) from them. It may be possible to confuse the additions in examples 61 and 62 with additions registered as belonging to the subcategory of Elaborating additions. But there is a difference. The additions of the latter subcategory serves to elaborate on one or more items explicitly present in an interpreter's target text, while the additions in examples 61 and 62, rather than elaborate on information 
already explicitly present, express information only implicitly present (in the linguistic context).

The addition in example 61 serves to explicate part of an implicature (Strategy (5), Chapter 5, Section 5.3.2.5), generated by the defendant's blatant flout of the maxim of Relation ('Be relevant'), which he used to emphasize his firm denial of an alleged fact: that he picked up a bread knife in the kitchen of the witness' apartment and threatened her with this knife. Thus, by his seemingly irrelevant elaboration on his firm denial, I never went out of the living room and the bedroom, he managed to generate the implicature 'I did not pick up a bread knife in the kitchen and threaten her with it', and to imply also that the fact that he was never in the kitchen ought to prove him innocent (cf. Chapter 7, Section 7.2.4.1.3):

\section{Example 61:}

QD.16.12-33: $\quad$ ST-P: $\quad$ du er jo altså tiltalt for og $\varnothing$ h og skulle have voldtaget $\varnothing \mathrm{h}<$ person $>$ og $\mathrm{i}$ den forbindelse brugt en kniv, har du haft en kniv på noget tidspunkt den aften? en brødkniv?

FT: you know you have been charged with er having raped er <person> and in this connection used a knife, did you have a knife at any time that evening? a bread knife?

TT-I: you have been charged with er raping $<$ person> and having had a knife that you used to threaten her with. have you at any time had a knife in your possession?

ST: no.

FT: $\quad n e j$.

TT-I: a bread knife?

ST-D: no. never.

FT: $\quad$ nej. aldrig.

TT-I: nej aldrig.

ST-D: I never went out of the living room and the bedroom.

FT: jeg gik aldrig ud af stuen og sovevarelset.

TT-I: han var kun i i stuen og soveværelset. han har ikke været andre steder 
Back-translation: he was only in in the living room and the bedroom. he hasn't been anywhere else

Similarly in example 62, though the addition in this example does not serve to explicate an implicature or any other kind of non-observance of a maxim:

\section{Example 62:}

QW.32.26-33.12:ST-DC: i perioden fra I flyttede fra hinanden $\emptyset$ h og så til den aften $\mathrm{i}$ januar, hvor mange gange vil du da anslå at I har haft sex?

FT: $\quad$ in the period from when you stopped living together er and then to the night in January, how many times would you then estimate that you had sex?

TT-I: from the time you split up along to this night er, how many times do you think you had sex?

ST-W: no more than a handful, maybe about four or five times.

FT: $\quad$ ikke ret mange gange, måske omkring fire eller fem gange.

TT-I: måske en fire fem gange.

Back-translation: maybe four or five times.

ST-DC: okay. og det er så fordelt på et år kan jeg forstå?

FT: $\quad$ okay. and that is over a year I understand?

TT-I: that's over over a year?

ST-W: yes.

FT: $\quad j a$.

TT-I: ja.

ST-DC: okay.

FT: okay.

ST-W: more at the beginning obviously 'cause we were just getting out of things.

FT: $\quad$ mere i begyndelsen selvfølgelig fordi vi var lige på vej ud af forholdet.

TT-I: mer- mere mest i starten og mindre senere $\underline{\underline{\text { hen. }}}$. 
Back-translation: $\quad$ mor- more at the beginning and less later on.

In example 63, the interpreter explicitly expresses information implicitly present in the situational context and capable of being inferred by any normal, rational human being: The defendant was being questioned about the time when he and his former girlfriend split up and he moved out of what was then their mutual flat (now her flat):

\section{Example 63:}

QD.18.18-21: $\quad$ ST-DC: var det din ide at flytte

FT: $\quad$ was it your idea to move out

TT-I: $\quad$ was it your idea to move out of her flat

Similarly in examples 64 and 65:

\section{Example 64:}

PC.6.16-19: ST-DC: og at du havde drukket noget inden du kom

FT: $\quad$ and that you had drunk somthing before you arrived

TT-I: and that you had also been drinking before arriving at her place

\section{Example 65:}

QW.12.10-17: ST-W: after I'd made it perfectly clear that that's not what I want, he'd gone into the kitchen

FT: $\quad$ efter jeg havde gjort det fuldstondigt klart at det ikke er hvad jeg har lyst til, var han gået ud i køkkenet

TT-I: efter hun havde gjort det helt klart for ham at det ikke var det de skulle, så gik han ud i køkkenet

Back-translation: $\quad$ after she had made it totally clear to him that that was not what they were going to do, then he went into the kitchen 
Finally, examples 66 to 69 illustrate a different kind of obvious-information additions. Example 66 illustrates how the interpreter, in her rendition of the defendant's response, includes material which takes up, or repeats, parts of the question put to him. In some renditions, this uptake served to complete fragmented source texts, as illustrated by example 67. Example 68, on the other hand, illustrates the reverse, that is, the witness responds in the negative, by repeating parts of the question being put to her, and the interpreter includes the item no, by which she explicitly expresses the negation inherent in the context of the witness' words. As illustrated by example 69, this kind of addition, also occurred in affirmative responses:

\section{Example 66:}

PC.5.25-33: $\quad$ ST-DC: nej jeg jeg ved ikke om om I var i stuen?

FT: no I I don't know whether whether you were in the living room?

TT-I: wer- were you in the sitting room?

ST-D: yes

FT: $\quad j a$

TT-I: ja de var i stuen

Back-translation: $\quad$ yes they were in the living room

\section{Example 67:}

QD. 16.24-35: ST-P: og det var ikke ham der tog tøjet af dig, det var dig selv?

FT: $\quad$ and it wasn't he who took your clothes off, you did so yourself?

TT-I: he didn't undress you, you took your clothes off?

ST-W: oh yes. myself yeah.

FT: åh ja. mig selv ja.

TT-I: ja hun tog selv tøjet af.

Back-translation: $\quad$ yes she took her clothes off herself.

\section{Example 68:}

QW.6.43-7.3: $\quad$ ST-P: er det sådan noget der er sket hver gang I er mødtes eller er det bare en gang imellem? 
FT: is that something which happened each time you met or is it just now and again?

TT-I: is that something that has happened always or just (.) every now and then?

ST-W: just every now and then.

FT: $\quad$ kun en gang imellem.

TT-I: nej kun en gang imellem.

Back-translation: no just every now and then.

Evidently, the addition in example 68 serves to explicate part of an implicature (Strategy (5), Chapter 5, Section 5.3.2.5). Thus, by blatantly flouting the first maxim of Quantity ('Make your contribution as informative as is required'), the witness was able to generate the implicature 'it did not happen always' (cf. Chapter 7, Section 7.2.4.1.5).

\section{Example 69:}

QW.28.2-10: $\quad$ ST-P: er du blevet lægeundersøgt?

FT: $\quad$ have you been examined by a doctor?

TT-I: did a doctor examine you?

ST-W: the police doctor did the- examine, the woman police doctor.

FT: politiets lage foretog- undersфgte, den kvindelige politilage.

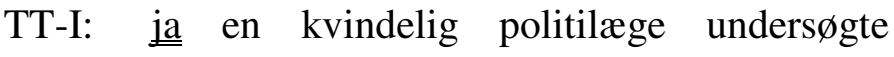
hende.

Back-translation: $\quad$ yes a female police doctor examined her.

\subsection{Connective additions}

The interpreter adds an item, or items, the purpose of which is to connect, or link together, utterances or parts of utterances, and, like in the case of Obvious-information additions, she introduces a greater degree of specificity. The additions of this subcategory were identified as explicitly expressing inferrable information.

Moreover, since connective additions were included in order to make relations between utterances, or parts of utterances, explicit, they served to provide clarity and orderliness. Consequently, it may be that, at least in 
theory, a speaker's omission of a connective in his source text constitutes a flouting of the maxim of Manner ('Be perspicuous'), generating the implicature that a certain relation exists. So, also in theory, when an interpreter includes a connective in order to explicate an implied relation, she adopts the strategy of interpreting the semantic content and explicating the implicature (Strategy (3), Chapter 5, Section 5.3.2.3). In other words, Connective additions may serve to explicate implicatures.

With the sole exception of the adverbial link then, Connective additions were identified as conjunctions, which, adhering to their grammatical properties, were identified as either co-ordinators or subordinators. The conjunctions were found to express relations of addition, alternatives, contrast and result, and the adverbial link to express relations of time (cf. Quirk et al 1979; Leech \& Svartvik 1994). The subcategory is illustrated by examples 70 to 74 .

In example 70, the interpreter includes the co-ordinating conjunction and, expressing relations of addition. By including this co-ordinator, the interpreter explicitly expresses information implicitly present in the situational context: the defendant's utterance was linked to a preceding utterance, being part of a sequence of questions and answers, the purpose of which was to establish the intimate details relating to the alleged crime, the rape:

\section{Example 70:}

QD.13.5-13: $\quad$ ST-P: og hvad skete der ellers?

FT: $\quad$ and what else happened?

TT-I: and then?

ST-D: then we had sex.

FT: $\quad$ så gik vi i seng sammen.

TT-I: $\quad$ og så havde de samleje.

Back-translation: $\quad \underline{\underline{\text { and }}}$ then they had intercourse.

In example 71, the interpreter includes the co-ordinator or, expressing relations of alternatives. By including this co-ordinator, the interpreter explicitly expresses the information implicit in the linguistic context: the three utterances in the turn expressed alternatives: 


\section{Example 71:}

QD.13.30-39: ST-P: du kan ikke beskrive nærmere hvilken stilling det her samleje foregik i? hvordan? hvad I gjorde ved hinanden?

FT: you can't describe further the position in which this intercourse took place? how? what you did to each other?

TT-I: you can't describe which position you you were when you had intercourse or what you did to each other?

Example 72 illustrates the addition of another co-ordinating conjunction but, which expresses relations of contrast. Thus, by including this coordinator, the interpreter explicitly expresses the contrast implicit in the linguistic (and situational) context: though the defendant would be asked questions, he would not be obliged to answer them:

\section{Example 72:}

QD.2.13-34: $\quad$ ST-J: $\quad \varnothing \mathrm{h}$ så vil jeg gerne fortælle tiltalte at $\emptyset \mathrm{h}$ det der skal ske nu er at $\varnothing \mathrm{h}$ først vil anklagemyndigheden stille dig nogle spørgsmål,

FT: er then I would like to tell the defendant that er what will happen now is that er first the prosecution will ask you some questions,

TT-I: what is going to happen now is that erm the prosecutor will ask you some questions,

ST-J: derefter eventuelt din forsvarer,

FT: after that possibly your defence counsel,

TT-I: and then possibly your defence counsel,

ST-J: du skal også vide at du ikke behøver at besvare spørgsmål som tiltalt.

FT: $\quad$ you should also know that you do not have to answer questions as a defendant.

TT-I: but you are under no obligation to answer any of the questions.

Example 73 illustrates the addition of the subordinating conjunction så (so), which expresses relations of result. By including this subordinator, 
which introduces the second part of the utterance in her target text, the interpreter explicitly expresses that this part expresses the result of the situation mentioned in the first part. In actual fact, the interpreter's target text reversed the two parts of the original utterance, whereby the (implicit) meaning of cause in the second part of the original utterance was reversed also. The opposite meaning of cause is result, and by expressing this meaning explicitly the interpreter in fact explicitly expresses information implicit in the original utterance:

\section{Example 73:}

QW.5.31-34: ST-W: yeah we're in contact regularly, we see each other about once a week.

FT: ja vi har regelmassig kontakt med hinanden, vi ser hinanden cirka en gang om ugen.

TT-I: ja de ser hinanden en gang om ugen cirka, $\emptyset \mathrm{h}$ (.) $\underline{\underline{\text { å }}}$ der er jævn kontakt.

Back-translation: $\quad$ yeah they see each other about once a week, er (.) so there is regular contact.

Finally, example 74 illustrates the addition of the adverbial link then expressing time (= 'after that'). By including the adverbial, the interpreter explicitly expresses the information implicit in the situational context (the rules of courtroom procedure) that the action described in the original utterance is subsequent to a previously described action:

\section{Example 74:}

PC.8.9-12: $\quad$ ST-DC: og $<$ person $>$ bliver ført som vidne.

FT: $\quad$ and $<$ person $>$ will be called as a witness.

TT-I: and then $<$ person> will be produced as a witness.

\subsection{Additions explicating non-verbal information}

The interpreter includes an item, or items, in her target text which explicates non-verbal, but nevertheless inferrable, information. This kind of 
addition occurred only once in the data from the mock trial and is illustrated by example 75 :

\section{Example 75:}

QW.25.33-38: ST-W: there was a red mark against my neck just there

FT: $\quad$ der var et rødt marke mod min hals lige der

TT-I: der var et rødt mærke på på siden af halsen

Back-translation: there was a red mark on on the side of my neck

The witness indicates a point on her neck, presumably by pointing to it with her hand or her finger, and the interpreter explicates this non-verbal information.

\subsubsection{Elaborating additions}

Additions of this subcategory serve to elaborate on material already rendered once in an interpreter's target text and, again, to create a greater degree of specificity. The subcategory is illustrated by examples 76 to 79 , and, as these demonstrate, the additions seem to function as disguised translational repairs. I shall return to this issue in Chapter 7 (Section 7.2.5).

In example 76, the interpreter elaborates on her translation of argue in the defendant's second utterance. Incidentally, this utterance serves to explicate the implicature generated by his blatant flout of the maxim of Relation ('Be relevant') as well as the first maxim of Quantity ('Make your contribution as informative as is required') in his first utterance:

\section{Example 76:}

QD.16.38-17.4: ST-P: har der været nogen uoverensstemmelser imellem dig og Susan?

FT: $\quad$ has there been any disagreements between you and Susan?

TT-I: has there been any arguments between you and Susan?

ST-D: she just wanted to talk. we didn't argue at all 
FT: hun ville bare snakke. vi skandtes overhovedet ikke

TT-I: hun ville bare snakke. hun- de havde ikke nogen skænderier. unoverensstemmelser.

Back-translation: she just wanted to talk. she- they didn't have any quarrels. disagreements.

In example 77, the interpreter elaborates on her translation of serious relationship in the defendant's first utterance:

\section{Example 77:}

QD.17.48-18.16: ST-DC: hvorfor gik jeres forhold i stykker da I flyttede fra hinanden?

FT: why did your relationship end when you stopped living together?

TT-I: why did you split up and move out?

ST-D: <person> wanted a a real serious relationship and she wanted me to be around all the time. and after graduating from college I- my job took me away during the week and I was only home, sometimes during weekends sometimes during the week. I wasn't home all the time.

FT: $\quad<$ person> ville have et et virkeligt alvorligt forhold og hun ville have at jeg var der hele tiden. og efter jeg fik min eksamen jeg- mit arbejde gjorde at jeg var vak i ugens lфb og jeg var kun hjemme, nogen gange $i$ weekenden og nogen gange i ugens l $\phi b$. jeg var ikke hjemme hele tiden.

TT-I: <person> ville have et $\varnothing \mathrm{h}$ (.) et $\varnothing \mathrm{h} \mathrm{(.)}$ alvorligt forhold et varigt forhold og han var lige blev- jeg var lige blevet færdig med mine studier og mit job har betydet at jeg nu er meget væk (.) fra (.) vores bolig og også i weekender, og sommetider er det kun i weekender jeg var hjemme. 
Back-translation: $\quad$ <person> wanted a er (.) a er (.) serious relationship a lasting relationship and he had just finished- I had just finished my studies and my job has meant that I am now away a lot (.) from (.) our residence and also during weekends, and sometimes I was only home during weekends.

In example 78, the interpreter elaborates on her translation of fuld (drunk):

Example 78:

PC.6.26-29: $\quad$ ST-DC: følte du dig fuld?

FT: $\quad$ did you feel drunk?

TT-I: did you feel intoxicated in any way? did you feel drunk?

Finally, in example 79, the interpreter elaborates on her translation of samleje (intercourse):

Example 79:

QW.20.11-14: ST-P: hvor lang tid tog det her samleje?

FT: $\quad$ how long time did this intercourse take?

TT-I: how long did it take? the intercourse?

\subsubsection{Additions with significant impact on the semantic and/or pragmatic content of the source text}

Additions with significant impact on the semantic and/or pragmatic content of the source text were classified as Emphasizing additions, Down-toning additions or New-information additions. As explained earlier (cf. Section 6.2. above), the additions registered as belonging to these subcategories introduced information, which may be categorized as Brand-new, i.e. introduced into the interaction for the first time, either explicitly or implicitly. The category and its subcategories are illustrated by examples 80 to 93. 


\subsubsection{Emphasizing additions}

This subcategory serves to emphasize, or increase the force of, the utterance, or part of the utterance, in the source text. The interpreter adds emphasis by including one or more items which were not present in the source text, either explicitly or implicitly, or by stressing one or more items in her target text which were not stressed in the source text. Examples 80 to 83 illustrate the first kind of additions, and examples 84 and 85 illustrate the second kind. As specified in Chapter 4 (Table 4.1), stress is marked by boldface.

In example 80, the interpreter includes the adverb ganske (absolutely), which has an emphatic effect on the adjective that it modifies, almindelige (regular). The effect is to increase the force of original utterance, so that what appeares to be a straight answer to a relatively straight question becomes a firm declaration:

\section{Example 80:}

QD.7.32-8.1: $\quad$ ST-P: hvad havde du fået at drikke inden du kom over til <person $>$ ?

FT: $\quad$ what did you have to drink before arriving at <person>'s place?

TT-I: what had you been drinking before going there?

ST-D: erm, just beer.

FT: $\quad \phi h m, k u n \phi l$.

TT-I: $\quad$ kun $\varnothing 1$.

Back-translation: only beer.

ST-P: ja, o:g almindelig $\varnothing 1$, og hvor mange?

FT: $\quad y e s$, a:nd regular beer, and how many?

TT-I: ordinary beer, and in that case how many?

ST-D: we had regular beer. two.

FT: vi fik almindelige $\phi l$. to.

TT-I: ganske almindelige $\varnothing 1$. to.

Back-translation: $\quad$ absolutely regular beer. two. 
In example 81, the interpreter includes the adverb particular, moving from the general to the specific in the description of gesture. The addition adds emphasis, stating that, rather than being interested in hearing about gestures in general, the prosecutor is interested in hearing about one specific kind:

\section{Example 81:}

QW.14.42-45: $\quad$ ST-P: eller fulgt op af en gestus af en eller anden art?

FT: or followed by a gesture of some kind?

TT-I: or did he gesture in any particular way?

The interpreter's addition of the modal verb skulle (the equivalent of the modal phrase have to) in example 82 has the effect of implying that the speaker (the defendant) may be forced to carry out the action referred to in his utterance. This was never explicitly expressed, nor was it implicit in the situational and/or linguistic context:

\section{Example 82:}

QD.14.8-16: $\quad$ ST-P: kan du så ikke beskrive det?

FT: can't you describe it then?

TT-I: can't you describe it?

ST-D: I prefer not to.

FT: $\quad$ jeg foretrakker ikke at gøre det.

TT-I: han vil foretrække ikke at skulle beskrive det.

Back-translation: $\quad$ he will prefer not to have to describe it.

Finally, in example 83, the interpreter includes the adverb actually, which serves to emphasize, or draw attention to, the situation, or the event, referred to. Simultaneously, the meaning of actually appears to be equivalent to really or genuinely, which increases the force of the original question so that it becomes more like a request for 'the full details of' or 'the real truth about' the situation, or the event. Interestingly, this had already been emphasized once by the stress on skete (happened), and thus the interpreter's addition caused double emphasis to occur: 


\section{Example 83:}

QD.11.14-17: $\quad$ ST-P: kan du huske $\emptyset$ h mere præcist hvad der skete i soveværelset?

FT: $\quad$ do you remember er more precisely what happened in the bedroom?

TT-I: do you remember more in detail what actually happened in the bedroom?

As already mentioned, examples 84 and 85 illustrate emphasis added by stress. In example 84, the interpreter adds stress in her translation of the negative adverb never, and, again, the effect is to increase the force of the original utterance, so that the negation becomes a firm denial (cf. example 80):

\section{Example 84:}

QD.15.46-49: ST-D: no. no never.

FT: $\quad$ nej. nej aldrig.

TT-I: nej aldrig.

Back-translation: $\quad$ no never.

In example 85, emphasis is added twice. First of all, emphasis is added when the interpreter in her target text stresses the adjective usual and the verb had, though the equivalent items in the source text were not stressed. Secondly, emphasis is added by the interpreter's choice of words: usual has more force than ikke usadvanligt (not unusual). Again, the addition increases the force of the original utterance:

\section{Example 85:}

PC.4.28-34: $\quad$ ST-DC: $\varnothing$ h og jeg har også forstået at $\varnothing$ h det ikke var usædvanligt at $\varnothing \mathrm{h}$ (.) at I havde sex selvom I ikke boede sammen.

FT: $\quad$ er and I also understand that er it was not unusual that er (.) that you had sex though you did not live together.

TT-I: also I understood that it was usual that you had sex even though you weren't living together. 


\subsubsection{Down-toning additions}

The additions of this subcategory have a reverse function, compared to the subcategory of Emphasizing additions, because they serve to down-tone, or decrease, the force of the utterance, or part of the utterance, in the source text. The interpreter down-tones by including one or more items in her target text which were not present in the source text, neither explicitly nor implicitly. As illustrated by examples 86 to 89 , additions registered as Down-toning additions appeared to function as hedges. However, this question will be taken up for discussion in Chapter 7 (Section 7.3.2).

In example 86, the interpreter includes the adverb måske (maybe) which expresses uncertainty. Thus, the addition serves to decrease the force of the speaker's (the witness') utterance by giving the impression that the degree of uncertainty expressed by the witness is higher on the scale than was originally intended:

\section{Example 86:}

QW.7.25-31: ST-W: I think he had been out, in town or somewhere, drinking, 'cause he was slightly drunk when he arrived and his breath did smell of alcohol.

FT: $\quad$ jeg tror han havde varet ude, i byen eller et andet sted, for at drikke, fordi han var lidt fuld da han kom og hans ånde lugtede faktisk af alkohol.

TT-I: og hun mener han havde måske havde været $\mathrm{i}$ byen og og drikke fordi han han lugtede af alkohol da han kom.

Back-translation: and she thinks he had maybe had been out and and drinking because he he smelled of alcohol when he arrived.

In example 87, the interpreter includes the modal verb may, which, again, adds an element of uncertainty. Thus, the addition changes a statement expressing facts into a statement expressing possibility: 


\section{Example 87:}

PC.10.7-12: ST-DC: det er fordi det har betydning for spørgsmålet om en betinget eller en ubetinget straf.

FT: it is because it is relevant in connection with the question of a suspended or a nonsuspended sentence.

TT-I: it may have some bearings on the question of whether you are given a er suspended or a non-suspended erm sentence.

In example 88, the interpreter includes the expression på en eller anden måde (in some way or other), and the words sådan (sort of) and helt (quite). The effect is to change a firm description in the speaker's (the witness') utterance into a vague description:

\section{Example 88:}

QW.8.24-30: $\quad$ ST-W: he did seem a little agitated there. I could tell there was something that was bothering him or that wasn't quite right with him, he didn't seem himself.

FT: $\quad$ han virkede faktisk lidt ophidset der. jeg kunne se der var noget som plagede ham eller som ikke var helt i orden med ham, han virkede ikke som sig selv.

TT-I: ja han han var lidt $\varnothing$ h ophidset på en eller anden måde, hun kunne fornemme at han ikke sådan var helt sig selv.

Back-translation: well he he was a little er agitated in some way or other, she could sense that he sort of wasn't quite himself.

Example 89 illustrates a different kind of down-toning, but with similar effect. By adding the words as and it, the interpreter changes a firm statement into a less definite statement (cf. Chapter 7, Section 7.3.2):

\section{Example 89:}

PC.3.7-10: $\quad$ ST-DC: og jeg har forstået at du nægter dig skyldig. 
FT: $\quad$ and I understand that you plead not guilty.

TT-I: and $\underline{\underline{a s}}$ I understand it you plead not guilty.

\subsubsection{New-information additions}

Additions of this subcategory do not serve to emphasize or down-tone the force of the original utterance, but they nevertheless introduce information, explicitly or implicitly, which may be categorized as brand-new, i.e. introduced into the interaction for the first time. The subcategory is illustrated by examples 90 to 93 .

In example 90, the interpreter adds the time adverb nu (now):

\section{Example 90:}

QW.33.29-42: $\quad$ ST-DC: er det rigtigt at du havde problemer på dit arbejde som I talte om den aften?

FT: $\quad$ is it correct that you had problems at work which you talked about that evening?

TT-I: is it correct that you had problems? at your job?

ST-W: no I'm getting on very well at work, I'm even in line for a promotion at the moment.

FT: $\quad$ nej jeg klarer mig rigtig godt på mit arbejde, jeg har endda udsigt til en forfremmelse i фjeblikket.

TT-I: nej hun har det fint med sit arbejde $\underline{\underline{\text { nu}}} . \varnothing \mathrm{h}$ regner endda med at blive forfremmet.

Back-translation: no she is all right with her job now. er even expects to get promoted.

The witness' utterance in example 90 responded to an allegation made by the defendant. Her answer presents a firm denial, followed by a blatant flout of the second maxim of Quantity ('Do not make your contribution more informative than is required'), by which she managed to generate the implicature 'he was lying', and to imply also that the fact that she was experiencing no work-related problems, emphasized by her reference to her impending promotion, ought to prove him a liar. However, by adding the time adverb, the interpreter introduces the brand-new information that the 
situation described in the utterance existed at a certain time, i.e. 'the present time'. Furthermore, the specification of $n u$ (now) creates the implicature that the situation used to be the reverse. The witness did not explicitly express this implicature, though her use of the present continuous tense in the first part of her utterance may have been an attempt to imply this information. Still, she may also have intended to imply 'generally', which is a more reasonable conclusion, since by implying 'the present time', she would in fact contradict the firm denial by which she began her utterance (cf. Chapter 7, Section 7.3.3).

In example 91, the interpreter adds the adverbial phrase med det samme (right away):

\section{Example 91:}

QD.7.26.30: $\quad$ ST-D: yes I went. she said it was urgent. she said she needed to see me.

FT: $\quad$ ja jeg tog derover. hun sagde det hastede. hun sagde hun havde brug for at se mig.

TT-I: hun sagde det var at det var $\varnothing$ h stærkt nødvendigt han kom. så han tog derover med det samme.

Back-translation: she said it was that it was er extremely necessary that he came. so he went over there right away.

By adding this phrase, the interpreter introduces the brand-new information that the defendant carried out the action described in the first utterance immediately. However, the defendant did not express this information, either explicitly or implicitly.

In example 92, the interpreter adds the items in your hand, introducing brand-new information, and moving from the general to the specific. By this process, a question that appears to relate to a rather general state of affairs (though the information 'that evening' is implicit in the situational context) becomes a question about a specific matter (cf. the sub category of Emphasizing additions, example 81): 


\section{Example 92:}

PC.5.45-48: ST-DC: men altså du har ikke på noget tidspunkt haft en kniv?

FT: $\quad$ but you did not at any time have a knife then?

TT-I: but you have at no time had a knife in your hand?

Finally, in example 93, the interpreter includes the linking adverbial in that case, by which the second part of the utterance in her target text becomes conditional to the outcome of the first part. Thus, whereas the parts of the original utterance are co-ordinate parts, as indicated by the co-ordinator and, the second part of the utterance in the interpreter's target text is subordinate to the first part:

\section{Example 93:}

QD.7.42-45: $\quad$ ST-P: ja, o:g almindelig $\varnothing 1$, og hvor mange?

FT: $\quad y e s$, a:nd regular beer, and how many?

TT-I: ordinary beer, and in that case how many?

\subsection{Source-text/target-text comparison of the data from the authentic trial}

The purpose of the source-text/target-text comparison of the data from the authentic trial was to test the validity of the addition categories, established by analysing the data collected at the mock trial (cf. Table 6.1 ). Thus the specified methodology (cf. Section 6.1) that was employed in the analysis of the data from the mock trial was employed in the analysis of the data collected at the authentic trial also.

But the data from the authentic trial presented one particular problem: The English-speaking defendant did not have English as a mother tongue. Consequently, as explained in Chapter 4 (Sections 4.6.2 and 4.6.3), many of the English source texts were fragmented, or did not display a correct use of grammar or terminology, which complicated the formal translations of these texts. The first issue, fragmented source texts, was discussed and exemplified in Section 6.1.2.1 above. However, as regards the second 
issue, the defendant's incorrect use of grammar and terminology, I decided simply to preserve the incorrect grammar and terminology in the formal translations, since I assumed, correctly as it turned out, that this would not obstruct the identification of additions. The problem is illustrated by example 94:

\section{Example 94:}

QD.9.13-19: $\quad$ ST-D: I mean he- (.) er he came here the same reason as me. but he might have the credit card in Denmark, I don't know.

FT: $\quad$ altså han- (.) $\phi$ h han kom her samme grund som mig. men han har måske kreditkortet $i$ Danmark, jeg ved det ikke.

TT-I: altså han kom her $\underline{\underline{h}}$ med samme forhold som jeg kom her, men han kan godt have fået $\underline{\emptyset \mathrm{h}}$ kreditkortene i Danmark. det ved jeg ikke.

Back-translation: I mean he came here er with the same conditions as I came here, but he may well have received er the credit cards in Denmark. I don't know.

The problem material in example 94 is the prepositional phrase (for) the same reason in the defendant's first utterance which lacks the preposition for, and the missing verb after might have in his second utterance which presumably would have been received or got. Apparently, the interpreter experienced some difficulty with the incorrect prepositional phrase, evidenced by her introduction of the voice-filled pause. The missing verb did not seem to present a problem, however, but was supplied by the interpreter. As illustrated by example 94, her rendition included a total of four additions: two voice-filled pauses, one obvious-information addition and one emphasizing addition.

Generally, the same categories and subcategories of additions as were identified in the data from the mock trial were identified in the data from the authentic trial also, with one exception: the subcategory of Additions explicating non-verbal information. This subcategory was not identified in the data from the authentic trial. 
However, the analysis of the data from the authentic trial established a new subcategory of additions: Additions explicating culture-bound information. Like the subcategory of Additions explicating non-verbal information, this new subcategory was also registered as belonging to the subcategory of Explicating additions, and thus to the category of Additions with minimal impact.

Table 6.2 presents the categories and subcategories of additions identified in the data collected at the authentic trial:

Table 6.2: Additions identified in the data from the authentic trial

\begin{tabular}{|c|c|c|}
\hline \multirow{4}{*}{$\begin{array}{l}\text { Additions with no } \\
\text { impact on the } \\
\text { semantic and/or } \\
\text { pragmatic content of } \\
\text { the source text }\end{array}$} & \multicolumn{2}{|l|}{ Repetitions } \\
\hline & \multicolumn{2}{|l|}{ Silent pauses } \\
\hline & \multicolumn{2}{|l|}{ Voice-filled pauses } \\
\hline & \multicolumn{2}{|l|}{ False Starts } \\
\hline \multirow{7}{*}{$\begin{array}{l}\text { Additions with } \\
\text { minimal impact on } \\
\text { the semantic and/or } \\
\text { pragmatic content of } \\
\text { the source text }\end{array}$} & \multicolumn{2}{|l|}{ Repetitions $_{\mathbf{p}}$} \\
\hline & \multicolumn{2}{|l|}{ Fillers $_{\mathbf{p}}$} \\
\hline & \multicolumn{2}{|l|}{ Paralinguistics $_{\mathbf{p}}$} \\
\hline & \multirow[t]{3}{*}{ Explicating additions } & $\begin{array}{l}\text { Obvious-information } \\
\text { additions }\end{array}$ \\
\hline & & Connective additions \\
\hline & & $\begin{array}{l}\text { Additions explicating } \\
\text { culture-bound } \\
\text { information }\end{array}$ \\
\hline & \multicolumn{2}{|l|}{ Elaborating additions } \\
\hline \multirow{3}{*}{$\begin{array}{l}\text { Additions with } \\
\text { significant impact on } \\
\text { the semantic and/or } \\
\text { pragmatic content of } \\
\text { the source text }\end{array}$} & \multicolumn{2}{|l|}{ Emphasizing additions } \\
\hline & \multicolumn{2}{|l|}{ Down-toning additions } \\
\hline & \multicolumn{2}{|c|}{ New-information additions } \\
\hline
\end{tabular}


The different categories and subcategories are presented and discussed in Sections 6.3.1 to 6.3.3. The various examples were selected and presented by employing the same criteria as were employed for selecting and presenting examples from the data collected at the mock trial (cf. Section $6.2)$.

\subsubsection{Additions with no impact on the semantic and/or pragmatic content of the source text}

Excluding the subcategory of Silent Pauses (cf. Section 6.3.1.2 below), this category of additions occurred in great numbers in the authentic data also. Again, the additions were identified and categorized merely for eliminating purposes (cf. Section 6.2.1). The category and its subcategories are illustrated by examples 95 to 98 .

\subsubsection{Repetitions}

Example 95 is a typical example of the additions registered as belonging to this subcategory:

Example 95:

QD.11.9-14: $\quad$ ST-D: I I did not but I usually do

FT: $\quad$ det det gjorde jeg ikke men jeg gor som regel

TT-I: jeg gjorde det ikke men men det gør jeg normalt

Back-translation: $\quad$ I did not but but I normally do

\subsubsection{Silent pauses}

As mentioned above, this subcategory of additions was registered in only six target texts in the authentic data and thus did not occur very often. Example 96 is a typical example of the additions registered as belonging to this subcategory:

Example 96:

QD.7.22-25: $\quad$ ST-P: hvor foregik det henne?

FT: $\quad$ where did this take place? 
TT-I: and where (.) did this take place?

\subsubsection{Voice-filled pauses}

Example 97 is a typical example of the additions registered as belonging to this subcategory:

\section{Example 97:}

QD.13.2-8: $\quad$ ST-P: fik du egentlig in- instruktioner om hvad det var du skulle købe

FT: did you get in- instructions about what it was that you were to buy

TT-I: did you receive any instructions about er what items you were going to purchase

\subsubsection{False starts}

Example 98 is a typical example of the additions registered as belonging to this subcategory:

Example 98:

QD.36.28-31: $\quad$ ST-D: if if he bought it there, I don't know.

FT: $\quad h v i s h v i s h a n$ har købt det der, jeg ved det ikke.

TT-I: $\quad \varnothing$ h hvis $\varnothing$ h han har været- eller har købt det der. det ved jeg ikke.

Back-translation: $\quad$ er if er he has been- or has bought it there. I don't know.

\subsubsection{Additions with minimal impact on the semantic and/or pragmatic content of the source text}

This category and its subcategories are illustrated by examples 99 to 127 . Again, the first three subcategories of additions were registered as having potential impact only, and again it is to be presumed that these additions may in fact be attributed to the special nature of the interpreting process (cf. Section 6.2.2). 


\subsubsection{Repetitions $s_{p}$}

The additions of this subcategory identified in the data from the mock trial potentially added a degree of hesitancy to the target text, which in turn potentially decreased, or down-toned, the force of the original utterance. But, with one exception only, the additions of this subcategory identified in the data from the authentic trial tended to have the opposite effect, that is, they tended to have the potential to increase, or emphasize, the force of the original utterance. Nevertheless, it is once again important to note that, since the additions of this subcategory were merely repetitions of material which was explicitly present in the source text, and which had already been rendered once in the interpreter's target text, the potential impact of additions registered as Repetitions $\mathbf{p}_{\mathbf{p}}$ was judged to be minimal. Consequently, the subcategory should not be confused with the subcategories of Emphasizing additions or Down-toning additions, which serve to significantly alter the semantic and/or pragmatic content of a speaker's utterance by introducing information which may be categorized as brand-new.

Again, the additions classified as Repetitions $_{\mathbf{p}}$ did not occur very often. They were identified in only 11 target texts in the data from the authentic trial, and the exact same addition occurred in seven of these target texts.

The subcategory is illustrated by examples 99 to 101 . Example 99 presents the one rendition in which the interpreter's addition had the effect of potentially decreasing, or down-toning, the force of the original utterance:

\section{Example 99:}

QD.28.36-42: $\quad$ ST-P: er det rigtigt forstået at de indkøb der er foretaget i <shop> er fortrinsvis $\varnothing \mathrm{h}$ strømper og underbukser og og tøj i det hele taget, sko?

FT: do I understand correctly that the purchases that were made in <shop> are mainly er socks and underpants and and clothes on the whole, shoes? 
TT-I: $\quad$ so is it correct that the purchases that you made in <shop $>$ is mainly socks and shoes and clothing? eh- main- mainly?

The interpreter's repetition of mainly, preceded by the false start, indicates her hesitancy regarding the use of the term. By adding this degree of hesitancy, her addition potentially decreases the force of the prosecutor's question.

Examples 100 and 101 illustrate additions with the opposite effect, that is, with the potential to increase the force of the original utterance:

\section{Example 100:}

QD.38.34-48: $\quad$ ST-P: det er dig der har købt (..) $\emptyset$ h det her? og kan det passe det er et ur $\varnothing \mathrm{h}$ til <amount $>$ ?

FT: it is you who bought (.. ) er this? and is it correct that it is a watch er costing $<$ amount>

TT-I: $\quad$ so is it correct that is a watch in the amount of <amount $>$ ?

ST-P: og nogen slips $\mathrm{i}<$ shop $>$ ?

FT: $\quad$ and some ties in $<$ shop $>$ ?

TT-I: and some ties in $<$ shop $>$ ?

ST-D: yeah.

FT: $\quad j a$.

TT-I: ja. [you bought also some ties?]

In this example, the prosecutor was listing a number of purchases and asked the defendant to confirm whether or not he had made them. The defendant's answer to the first two questions, concerning the watch, is inaudible, and presumably he merely nods his head in confirmation. This is evidenced by the linguistic context: It is a fair assumption that the prosecutor would not have proceeded unless the defendant had indicated an affirmative response to those two questions. (For some reason, the interpreter failed to render the prosecutor's first question. I shall discuss this issue again in Chapter 7, Section 7.2.1). By repeating the prosecutor's third question, and by including part of his first question (you bought), the interpreter's addition may potentially increases the force of the question, a 
process which in this example may serve to demonstrate distrust, i.e. lack of faith in the truthfulness of the defendant's answer.

Example 101 presents the one addition which appeared in seven target texts:

\section{Example 101:}

QD.46.21-25: ST-DC: kan du nævne hvilke ting, vi har hørt nu, som har været til dit eget brug?

FT: could you mention which items, we have heard now, which were for your personal use?

TT-I: could you mention which items were for you own personal use?

This addition was probably an illustration of the interpreter's habit of translation. However, since the Danish eget may be translated by either own or personal, the interpreter in fact repeats the item. Moreover, since she repeats it by using two different terms, her repetition may potentially serve to emphasize brug (use), which may in turn potentially increase the force of the original utterance.

\subsubsection{Fillers}

Once more, all added fillers, because of their potential discourse functions (cf. Section 6.2.2.2) were judged to have potential impact on the semantic and/or pragmatic content of the source text, and their potential impact was judged to be minimal. Again, these additions were identified in renditions in Danish only (cf. Section 6.2.2.2). Moreover, the added fillers all appeared to function as starters. The subcategory is illustrated by examples 102 and 103.

Only two types of fillers were added: $j a$ (well) and altså (I mean). The fillers either co-occurred, as in example 102, or altså (I mean) occurred on its own, as in example 103. In either case, the addition of these fillers added a degree of hesitancy to the interpreter's target texts (by potentially indicating a need for building coherence, or by potentially instructing the end receiver to maintain focus on a previous utterance), which potentially 
served to give the impression that the defendant was quite annoyed, or exasperated, at having to provide the required answers. Thus, the additions potentially made him appear less co-operative than was actually the case (cf. example 53):

\section{Example 102:}

QD.39.26-35: $\quad$ ST-D: I bought two watches all together, and (..) I know, when I bought it, I can't remember the the name of the shop.

FT: $\quad$ jeg købte to ure alt $i$ alt, og (..) jeg ved, hvornår jeg købte det, jeg kan ikke huske navnet navnet på butikken.

TT-I: ja. altså jeg har købt to ure alt i alt. og jeg ved hvor jeg købte dem, men jeg kan ikke huske hvad butikkerne hed.

Back-translation: $\quad$ well. I mean I have bought two watches all together. and I know where I bought them, but I cannot remember what the shops were called.

\section{Example 103:}

QD.54.21-27: ST-D: how do you want me to describe? I would say most of them was for the personal use.

FT: $\quad$ hvordan vil du have mig til at beskrive? jeg vil sige det meste af det var til eget brug.

TT-I: $\underline{\underline{\text { altså, }}}$ hvordan skal jeg for- forklare det. beskrive det. altså jeg vil bare sige det meste af tøjet var til personligt brug.

Back-translation: $\quad \underline{\underline{\text { m mean }}}$, how should I ex- explain it. describe it. I mean I would just say most of the clothes were for personal use.

\subsubsection{Paralinguistics}

Only one kind of paralinguistic feature was identified in the data from the authentic trial: audible breathing. Furthermore, it occurred in only one target text. According to Wadensjö (1992:179, 1998:201), this feature, like laughter, may have an impact that is not necessarily minimal, since it may 
be perceived as an expression of uncertainty, irritation or discomfort, and since it may lead to events of miscommunication. However, the interpreter's audible breathing in example 104 did not result in any such event, nor did it introduce information which may be categorized as brandnew. Consequently, its impact was judged to be minimal. Besides, it was judged to be potential only, just like the impact of the paralinguistic features identified in the mock data:

\section{Example 104:}

QD.9.30-35: $\quad$ ST-D: I did not I did not see anyone, giving him the air ticket or the card or whatever.

FT: $\quad$ jeg så ikke jeg så ikke nogen, der gav ham flybilletten eller kortet eller noget.

TT-I: $\varnothing \mathrm{hm}$, jeg så ikke nogen $\varnothing \mathrm{h}$ give ham $\varnothing \mathrm{h}$ billetten eller ((inhales noisily)) kreditkort eller noget som helst ((exhales noisily)).

Back-translation: erm, I did not see anyone er give him er the ticket or ((inhales noisily)) the credit card or anything at all ((exhales noisily)).

Seemingly, this addition was triggered by processing efforts. However, like the fillers in examples 102 and 103, it may potentially demonstrate annoyance, or exasperation, and in turn potentially make the defendant appear less co-operative than was actually the case.

\subsubsection{Explicating additions}

As mentioned above, the additions of this subcategory were identified as either Obvious-information additions, Connective additions or Additions explicating culture-bound information. The additions registered as belonging to this subcategory mainly illustrate the interpreter's explicit expressing of information which may be categorized as either Textually evoked or Inferrable, with inferrable information once more being the dominant category. Thus, contrary to the data from the mock trial, no additions were registered as explicitly expressing information which may be categorized as Situationally evoked (cf. Section 6.2.2.4). 
The subcategory is illustrated by examples 105 to 125 .

\subsection{Obvious-information additions}

Again, the additions of this subcategory introduced a greater degree of specificity. The subcategory is illustrated by examples 105 to 117 .

Examples 105 and 106 illustrate additions explicitly expressing textually evoked information, that is, information evoked earlier, on textual grounds (cf. examples 57 and 58). In example 105, the interpreter includes items which express information implicitly present in the situational context, having been provided at an earlier state of the questioning of the defendant and therefore known to the participants:

\section{Example 105:}

QD.57.32-58.3: ST-D: and then by <year $>$ I was manager. I mean, from <year $>$ I've got my own restaurant. it was a little later in $<$ year $>$. and all the- all my I mean all my old employers, I- I- you probably don't need it, I mean they will give people reference, that I was working there.

FT: $\quad$ og så $i<$ <ear > var jeg direktør. altså, fra $<y e a r>$ har jeg fået min egen restaurant. det var lidt senere, $i<y e a r>$ og alle de-alle mine gamle arbejdsgivere, jeg-jeg- I har sandsynligvis ikke brug for det, altså de vil give folk anbefaling, at jeg arbejdede der.

TT-I: $\quad$ og i <year> blev jeg $\varnothing$ h direktør, (.) og i $<$ year $>$ der fik jeg min egen restaurant. $\underline{\underline{\text { men }}}$ desværre så blev det firma jeg arbejdede for, $\varnothing$ h det- $\varnothing$ h gik konkurs i <year $>$. men I kan spørge al- alle de mennesker jeg har arbejdet for, alle mine tidligere arbejdsgivere de vil bestemt give mig gode anbefalinger med.

Back-translation: $\quad$ and in $<$ year $>$ I became er manager, (.) and in <year> I got my own restaurant. but unfortunately then the company I was 
working for, er it- er went bankrupt in $\leq$ year $>$. but you can ask al- all the people I've worked for, all my former employers they will definitely give me good references.

Similarly in example 106:

\section{Example 106:}

QD.12.34-41: $\quad$ ST-P: men hvordan skulle det her regnskørb renregnskab så gøres op? hvis du skulle have ti procent af det hele?

FT: but how was this accont acc-account to be settled then? if you were to get ten per cent of everything?

TT-I: how were you going to mak- how were you going to: finish this er statement of the amounts? if you were going to have ten percent of of the- the value of it, $\underline{\text { and you }}$ didn't have any receipts

Example 107, on the other hand (cf. example 59), illustrates an addition which explicitly expresses information that may be either textually evoked (being implicit in the situational context since the witness had answered a similar question once before), or inferrable (being implicit also in the linguistic context):

\section{Example 107:}

QD.34.1-4: $\quad$ ST-P: o- og igen var det dig betalte?

FT: $\quad$ a- and again it was you who paid?

TT-I: and again you were the one who paid? for all of you?

Examples 108 to 112 illustrate additions explicitly expressing inferrable information. In examples 108 and 109, the interpreter not only interprets the original utterances, but also explicitly expresses the implicit, as well as obvious, conclusions to be drawn (inferred) from them (cf. examples 61 and 62). Once more, it is important not to confuse this subcategory with the 
subcategory of Elaborating additions for the reasons stated earlier (cf. Section 6.2.2.4.1).

Example 108 illustrates what appears to be a blatant flout of the second maxim of Quantity ('Do not make your contribution more informative than is required') caused by a clash between that maxim and the second maxim of Quality ('Do not say that for which you lack adequate evidence'): The defendant was asked to confirm his purchase of a specific watch. He was not able to confirm the purchase, but instead of merely saying 'no' or 'no, I did not buy that watch', or words to that effect, he provided a long and ambiguous answer. The interpreter's strategy for dealing with his answer was to render less than the semantic content, but simultaneously explicate part of the implicature (cf. Strategy (6), Chapter 5, Section 5.3.2.6), which preserved the ambiguity in his answer while providing clues to the interpretation of it. Thus, her first addition explicitly expresses information implicit in the situational context, and her second addition explicitly expresses the implicit, as well as obvious, conclusion to be inferred from some of the information provided by the defendant (cf. Chapter 7, Section 7.2.4.1.3):

\section{Example 108:}

QD.37.40-38.27: ST-D: can I can I say, because I think it's it's this card that, when the police was questioning me, they give me some items, ask me whether I bought this I bought that, or not. and we were then, I remember they they gave me a ladies watch with a tag. I think it's bought with this card, but when they show me- show it to me, I did not recognize it. I think, I mean I think it's the first second and the fourth items. which I made purchases. I I think I think this is the one that, that is the watch that that I know nothing about.

FT: $\quad k a n j e g$ kan jeg sige, fordi jeg tror det er det er det her kort som, da politiet afhфrte mig, giver de mig nogle ting, spфrger mig om jeg

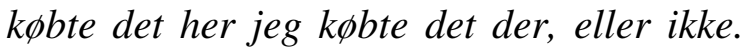
og vi var så, jeg husker de de gav mig et dameur med en markeseddel. jeg tror det 
blev købt med det her kort, men da de viser mig- viser det til mig, genkendte jeg det ikke. jeg tror, altså jeg tror det er det forste andet og fjerde forhold. som jeg foretog indkøb. jeg tror jeg tror det her er det som, det er det ur som som jeg ikke ved noget om.

TT-I: ja. altså da jeg blev afhørt af politiet, og de havde de her $\varnothing$ h genstande foran mig, da var der et et dameur, som jeg ikke kunne genkende jeg havde købt. og jeg mener det må være punkt tre.

Back-translation: well. I mean when I was questioned by the police, and they had these er objects in front of me, then there was a a ladies' watch, which I did not recognize I had purchased. and I believe it must be number three.

Similarly in example 109 which presents the defendant's response to a question requesting him to state which room he had stayed in at a particular hotel. The example also illustrates the defendant's implicit opting out of observing the second maxim of Quality ('Do not say that for which you lack adequate evidence'):

\section{Example 109:}

QD.14.14-17: $\quad$ ST-D: I I think it's <number>, I can't remember exactly.

FT: $\quad$ jeg jeg tror det er <number>, jeg kan ikke huske det pracist.

TT-I: jeg mener at kunne huske at det var var værelse $<$ number $>$. men jeg er ikke sikker.

Back-translation: I believe I remember that it was was room $<$ number $>$. but I am not sure.

Examples 110 and 111 illustrate the interpreter's explicit expressing of information implicitly present in the situational context and capable of being inferred by any normal, rational human being (cf. examples 63 to 65): 


\section{Example 110:}

QD.15.26-29: $\quad$ ST-P: $\quad \emptyset$ h hvem checkede jer ind?

FT: $\quad$ er who checked you in?

TT-I: who checked in? at the hotel?

\section{Example 111:}

QD.44.37-40: ST-D: were they bought on the same day?

FT: $\quad$ blev de købt på den samme dag?

TT-I: blev de købt samme dag? er spørgsmålet.

Back-translation: were they bought the same day? is the question.

Example 112 illustrates an addition which was not identified in the data from the mock trial: The interpreter includes two possessive determiners that explicitly express relationships implicit in the situational context. The defendant's first utterance in this example further illustrates his implicit opting out of observing the second maxim of Quality ('Do not say that for which you lack adequate evidence'). However, this intention was to some extent 'cancelled out' by the information conveyed by his other utterances (cf. Chapter 7, Section 7.2.4.1.3):

\section{Example 112:}

QD.31.16-27: ST-D: I think they said they needed to phone or something, I can't remember 'cause it's a long time ago. they need to phone the organization centre or something like that. and I just tell them that in the case I I haven't got time for waiting. I just took the card and left the shop.

FT: $\quad$ jeg tror de sagde de var nødt til at ringe eller noget, jeg kan ikke huske det fordi det er laenge siden. de er nodt til at ringe til organisationscentret eller sådan noget. og jeg siger bare til dem at $i$ det fald har jeg jeg ikke tid til venten. jeg tog bare kortet og forlod butikken.

TT-I: altså de sagde de blev nødt til og og ringe til $\varnothing \mathrm{h}$ deres organisationshovedkontor. $\varnothing \mathrm{h}$ 
$\emptyset$ h med kortet. så sagde jeg det havde jeg ikke tid til at vente på, og tog $\underline{\underline{\text { mit }}}$ kort $\mathrm{og}$ forlod forretningen.

Back-translation: $\quad$ I mean they said they needed to to phone er their organization head office. er er with the card. then I said I did not have time to wait for this, and took my card and left the shop.

Example 113 illustrates an addition which takes up, or repeats, parts of a question (cf. example 66). The question itself was not interpreted to the end receiver (the defendant), since this was prevented by his continued speech, elaborating on his previous response (a process which incidentally served to provide the required information):

\section{Example 113:}

QD.5.31-48: $\quad$ ST-D: I know <person $>$ in $<$ city $>$,

FT: $\quad$ jeg kender $<$ person $>i<$ city $>$,

TT-I: $\quad \varnothing:$ h jeg- jeg kender $<$ person $>$ fra $<$ city $>$,

Back-translation: $\quad$ e:r I- I know < person $>$ from $<$ city $>$,

ST-P: $\quad$ hvor lang tid

FT: $\quad$ how long

ST-D: for

FT: $\quad i$

ST-P: har du kendt ham?

FT: $\quad$ have you known him

ST-D: for about a year now.

FT: $\quad$ i omkring et år nu.

TT-I: $\quad \varnothing$ h $\varnothing$ h cirka et år nu. har jeg kendt ham.

Back-translation: $\quad$ er er about a year now. have I known him.

Example 114 illustrates an addition which explicitly expresses the negation inherent in the context of the defendant's response (cf. example 68). Incidentally, this addition also (cf. example 68) serves to explicate an implicature (cf. Strategy 3, Chapter 5, Section 5.3.2.3): The defendant's answer constituted a blatant flout of the first maxim of Quantity ('Make 
your contribution as informative as is required'), by which he managed to generate the implicature 'no', or 'no it is not correct':

\section{Example 114:}

QD.11.43-12.12: ST:P: er det rigtigt forstået du gemte kvitteringerne på de forskellige indkøb?

FT: do I understand correctly you kept the receipts from the different purchases?

TT-I: is it correct that you er kept the receipts? from the various purchases that you made?

ST-D: er (..) I usually destroy them. most of them. fo- for example because some of the stuff, I don't want to carry the receipts. I mean along.

FT: $\quad \phi h$ (..) jeg plejer at tilintetgфre dem. de fleste af dem. fo- for eksempel fordi nogen af sagerne, jeg onsker ikke at have kvitteringerne. altså med mig.

TT-I: $\quad \varnothing: h$ nej normalt så tilintetgør jeg dem, fordi jeg ikke ønsker at $\varnothing \mathrm{h}$ tage kvitteringen med mig.

Back-translation: $\quad$ e:r no normally I destroy them, because I don't want to er take the receipt with me.

Again this kind of addition also occurred in affirmative responses (cf. example 69), illustrated by example 115 :

\section{Example 115:}

QD.22.46-23.3: ST-P: og det- de kort du selv havde med, lad os lige få bekræftet o- om- er det rigtig nok at det var dem der var udstedt i navnet $<$ person $>$ ?

FT: $\quad$ and that- the cards you yourself brought, let us just get confirmed $i$ - if is it correct that they were the ones that were issued to a $<$ person>?

TT-I: er just had- want you to confirm, that the cards that you brought along, was those issued to er a $<$ person $>$ ? 
ST-D: that's correct.

FT: det er rigtigt.

TT-I: det er korrekt, 迆.

Back-translation: that's correct, yes.

Finally, examples 116 and 117 illustrate additions which serve to complete fragmented source texts. In example 116, the interpreter repeats, or takes up, parts of a question put to the defendant by the defence counsel, and referring to a number of purchases allegedly made by him (cf. example 67). This addition serves to explicate part of an implicature (Strategy (5), Chapter 5, Section 5.3.2.5) generated by the defendant's blatant, and simultaneous, flout of the maxim of Relation ('Be relevant') and the first maxim of Quantity ('Make your contribution as informative as is required). By blatantly failing to address the defence counsel's question in example 116 directly, and by providing less than the required answer, the defendant managed to generate the implicature 'they were not to be returned (for settlement) when I came back':

\section{Example 116:}

QD.50.40-51.4: ST-DC: var det til afregning når du kom hjem? eller var det til eget brug?

FT: $\quad$ was it for settlement when you came back home? or was it for personal use?

TT-I: were they to be er (.) erm returned, when you came back? or were they for your own personal use?

ST-D: for gifts.

FT: $\quad$ til gaver.

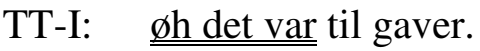

Back-translation: $\quad$ er it was for gifts.

In example 117, the interpreter completes the defendant's fragmented response, which, incidentally, constitutes an explicit opting out of observing the first maxim of Quantity ('Make your contribution as informative as is required'): 


\section{Example 117:}

QD.19.6-14: $\quad$ ST-DC: er du bange for vedkommende?

FT: $\quad$ are you afraid of this person?

TT-I: are you afraid of him? of her?

ST-D: no comment.

FT: ingen kommentar.

TT-I: det har jeg ikke kommentarer til.

Back-translation: $\quad \underline{\underline{\text { I have }}}$ no comments to that.

\subsection{Connective additions}

As in the data from the mock trial, additions of this subcategory introduced a greater degree of specificity. Also, the additions were once again identified as explicitly expressing inferrable information. Moreover, with the exception of the adverbial links så (then), så (so), and også (also), they were identified as co-ordinating or subordinating conjunctions (cf. Section 6.2.2.4.2). The conjunctions were found to express relations of addition, contrast, and condition, and the adverbial links to express relations of addition, result, cause or reason, and time (cf. Quirk et al 1979; Leech \& Svartvik 1994). The subcategory is illustrated by examples 118 to 124 .

In example 118, the interpreter includes the co-ordinating conjunction and, expressing relations of addition. By including this co-ordinator, the interpreter explicitly expresses the information implicit in the situational context: the prosecutor's utterance was linked to a preceding utterance, being part of a sequence of questions and answers, the purpose of which was to establish who financed the defendant's trip to Denmark:

\section{Example 118:}

QD.7.17-25: $\quad$ ST-D: I was given the ticket e:r, together with the credit cards.

FT: jeg fik billetten $\phi: h$, sammen med kreditkortene.

TT-I: altså ja, der var en der gav mig flybilletten sammen med kredi- kreditkortene.

Back-translation: I mean well, someone gave me the plane ticket together with the credi- credit cards. 
ST-P: hvor foregik det henne?

FT: $\quad$ where did this take place?

TT-I: and where (.) did this take place?

Relations of addition were likewise expressed by the adverbial link også (also), as illustrated by example 119. By including the adverbial, the interpreter explicitly expresses the information implicit in the situational and linguistic context that the second part of the utterance is more closely linked to the first part than to the third part, that is, the action described as walk around took place while being here, and before going to the hotel. (Though the defendant did not explicitly say so, the obvious conclusion, based on the situational context, is that here in his utterance refers to the centre of Copenhagen where he and his co-defendants allegedly went shopping):

\section{Example 119:}

QD.55.28-46: ST-D: we were here together first, and then we walk around, and then I go to hotel.

FT: vi var her sammen først, og så går vi omkring, og så går jeg til hotel.

TT-I: vi var først inde i byen sammen, og vi gik tur også rundt sammen, og så tog vi så hen til hotellet bagefter.

Back-translation: $\quad$ first we were in town together, and we $\underline{\underline{\text { also }}}$ went for a walk around together, and then we went to the hotel afterwards.

Example 120 illustrates the addition of the co-ordinator men (but), which expresses relations of contrast. Thus, by including this co-ordinator, the interpreter explicitly expresses the contrast implicit in the linguistic context: first the defendant claims that he cannot remember how many suitcases he bought, but then he proceeds to provide a number. Incidentally, like example 109, this example illustrates the defendant's implicit opting out of observing the second maxim of Quality ('Do not say that for which you lack adequate evidence'): 


\section{Example 120:}

QD.45.40-48: $\quad$ ST-P: hvor mange kufferter har du egentlig købt?

FT: $\quad$ how many suitcases did you actually buy?

TT-I: how many suitcases did you buy?

ST-D: I can't remember now, I believe it's two.

FT: $\quad$ jeg kan ikke huske det nu, jeg tror det er to.

TT-I: $\quad \varnothing \mathrm{h}$ jeg kan ikke huske det nu, men jeg tror det var to.

Back-translation:

er I can't remember now, but I believe it was two.

Example 121 illustrates the addition of the subordinating conjunction hvis (if), expressing positive (open) condition, in combination with the adverbial link så (then), expressing the result of the condition. Thus, the interpreter explicitly expresses the information implicit in the linguistic context that whether or not the second part of the utterance in her target text, introduced by så (then), expresses the required answer depends on, or is the result of, the condition expressed in the first part:

\section{Example 121:}

QD.10.36-11.1: ST-D: erm, I would get ten percent.

FT: $\quad \phi h m, j e g$ ville få ti procent.

TT-I: $\emptyset \mathrm{hm}-$

ST-D: you- you mean wha- what would be my reward?

FT: $\quad d u$ - $d u$ mener hva- hvad ville blive min belфnning?

TT-I: yeah.

DT-D: as a,

FT: somen,

TT-I: yeah.

ST-D: I I would get ten percent of whatever I pick up from the shop.

FT: $\quad$ jeg jeg ville få ti procent af alt hvad jeg henter fra butikken.

TT-I: altså hvis I mener min belønning, så ville jeg få ti procent af alle de varer jeg kunne tage med mig ud af butikkerne. 
Back-translation: $\quad$ I mean if you mean my reward, then I would get ten percent of all the goods that I could bring with me out of the shops.

Example 122 illustrates another addition which expresses relations of result: the subordinating conjunction $s a ̊$ (so). By using this subordinator to introduce the second part of the utterance in her target text, the interpreter explicitly expresses the information implicit in the linguistic context that this part is the result of the situation referred to in the first part:

\section{Example 122:}

QD.56.38-57-8: ST-D: my parents are divorced, my grandmother sent me to boarding school in <country $>$. and my last education was in <university $>$.

FT: mine forceldre er skilt, min bedstemor sendte mig på kostskole $i<c o u n t r y>$ og min sidste uddannelse var på <university>.

TT-I: men mine forældre er skilt, $\underline{\underline{\text { så }}} \min$ bedstemor sendte mig på kostskole i $<$ country $>$, øhm og jeg har læst på øh (.) $<$ university $>$.

Back-translation: but my parents are divorced, so my grandmother sent me to boarding school in $<$ country $>$, erm and I have studied at er (.) $<$ university $>$.

Example 123 illustrates the addition of the adverbial link so, expressing relations of cause or reason. By including this adverbial link, the interpreter explicitly expresses the information implicit in the linguistic context: the question was linked to a preceding utterance, since the cause of it, or the reason for it, was the defendant's response in example 123:

\section{Example 123:}

QD.6.18-28: ST-D: well I I know that I will be coming to Denmark, and I know that he will be coming to Denmark as well. 
FT: $\quad$ jo jeg jeg ved at jeg vil komme til Danmark. og jeg ved at han også vil komme til Danmark.

TT-I: $\quad \varnothing \mathrm{h}$ jeg vidste jeg skulle rejse til Denmark, og at han også skulle rejse til Danmark.

Back-translation: er I knew I was travelling to Denmark, and that he was also travelling to Denmark.

ST-P: okay, hvorfor skulle I til Danmark?

FT: $\quad$ okay, why were you going to Denmark?

TT-I: $\quad$ so why were you going to Denmark?

Finally, example 124 illustrates the addition of the adverbial link så (then), expressing time (= 'after that'). By including the adverbial, the interpreter explicitly expresses the information implicit in the linguistic context (evidenced by afterwards) that the action in the speaker's (the defendant's) second utterance is subsequent to the action in his first utterance.

\section{Example 124:}

QD.29.22-35: ST-P: så de at de- du betalte med det her kreditkort?

FT: did they see that they-you paid with this credit card?

TT-I: er did they see that you used this credit card

$\underline{\text { for }}$

DT-D: $\underline{\text { no. }}$

FT: $\quad \underline{n e j}$.

TT-I: payment? [nej]

ST-D: because they got out. I paid up afterwards.

FT: $\quad$ fordi de steg ud. jeg betalte bagefter.

TT-I: $\varnothing$ h de steg ud af bilen, $\underline{\underline{\text { så }}}$ betalte jeg bagefter.

Back-translation: $\quad$ er they got out of the car, then I paid afterwards.

\subsection{Additions explicating culture-bound information}

The interpreter includes an item, or items, in her target text which explicates culture-bound, but nevertheless inferrable, information. This 
occurred only once in the authentic data, when the interpreter explicitly expressed information inferrable from the name of a particular shop, as illustrated by example 125 :

\section{Example 125:}

QD.40.9-15: $\quad$ ST-P: hvorfor er du af den opfattelse at du ikke har- har købt det der ur, øh som er nævnt fra $<$ shop $>$ på $<$ amount $>$ ?

FT: $\quad$ why do you believe that you did not- not buy that watch, er which is mentioned from $<$ shop $>$ at <amount $>$ ?

TT-I: er (.) why do you think that you did not buy this watch from $<$ shop $>$, a watch shop, er for $<$ amount $>$ ?

\subsubsection{Elaborating additions}

Again, additions of this subcategory served to elaborate on material already rendered once in an interpreter's target text and to create a greater degree of specificity. As illustrated by examples 126 and 127, the identified additions closely resembled additions of the same subcategory identified in the data from the mock trial.

In example 126, the interpreter elaborates on her translation of unemployment benefit:

\section{Example 126:}

QD.5.3-7: $\quad$ ST-D: and I- and but I was living on unemployment benefit.

FT: og jeg- og men jeg levede af arbejdslфshedsunderstøttelse.

TT-I: $\quad$ og jeg jeg modtog dagpenge $\varnothing \mathrm{h} \underline{\underline{\text { dag- }}}$ eller arbejdsløshedsdagpenge, som jeg levede af.

Back-translation: and I I received benefit er ben- or unemployment benefit, which I lived on.

In example 127, the interpreter elaborates on her translation of vedstå (confirm): 


\section{Example 127:}

QD.1.28-31: $\quad$ ST-P: $\quad$ så skal jeg høre dig om du kan vedstå den her forklaring i dag?

FT: then I would like to ask you if you can confirm this statement today?

TT-I: $\quad$ can you er stick to this statement today? is it correct?

\subsubsection{Additions with significant impact on the semantic and/or pragmatic content of the source text}

The category and its subcategories are illustrated by examples 128 to 134 .

\subsubsection{Emphasizing additions}

Again, this subcategory of additions serves to emphasize, or increase the force of, the utterance, or part of the utterance, in the source text. Once more, the interpreter added emphasis by including one or more items that were not present in the source text, either explicitly or implicitly, or by stressing one or more items in her target text which were not stressed in the source text. Examples 128 and 129 illustrate the first kind of additions, and example 130 illustrates the second kind. Again, as specified in Chapter 4, Table 4.1, stress is marked by boldface.

In example 128, meget (very) modifies the adverb muligt (likely), which represents the interpreter's translation of might have in the original utterance. The effect is to increase the force of the speaker's (the defendant's) utterance, almost to the point of eliminating the level of uncertainty in the original utterance:

\section{Example 128:}

QD.19.22-39: $\quad$ ST-DC: nævner han noget om hvor mange kort han har med?

FT: $\quad$ does he mention anything about how many cards he brought?

TT-I: did he mention any number of credit cards that he brought along with him?

ST-DC: gør han slet ikke det på noget tidspunkt? 
FT: doesn't he do that at any time?

TT-I: he doesn't do that at any time?

ST-D: er, I can't remember but he he might have done, he might have told me that, I I honestly can't remember. because it's not it's not my business how many he has got.

FT: $\quad \phi h$, jeg kan ikke huske det men han han kan have gjort det, han kan have fortalt mig det, jeg jeg kan arlig talt ikke huske det. fordi det kommer ikke det kommer ikke mig ved hvor mange han har.

TT-I: $\varnothing$ h jeg kan ikke huske det. det er meget muligt han på et tidspunkt har nævnt det, men men det vedrørte ikke mig hvor mange kort han har.

Back-translation: er I can't remember. it's very likely that he mentioned it at some point, but but it was no concern of mine how many cards he has.

Example 128 further illustrates an interpreter's strategy for dealing with implicature: The defendant's second utterance constitutes a blatant flout of the maxim of Relation ('Be relevant'), by blatantly failing to address the defence counsel's goal in asking the question in example 128, as well as the first maxim of Quantity ('Make your contribution as informative as is required'), by which he managed to generate the implicature 'I had no reason to request this information', and also to imply that, since he had no reason to request it, there was no reason why he should have received it, so probably he did not receive it (cf. Chapter 7, Section 7.3.1). Thus, the implicature was used to emphasize his first utterance. When rendering it, the interpreter adopted the strategy of rendering the semantic content and explicating part of the implicature (Strategy (5), Chapter 5, Section 5.3.2.5).

Example 129 presents the defendant's answer to a question requesting him to state why he bought some specific items. His utterance clearly expresses a possibility, not a certainty, as evidenced by the modal could in his first utterance and or things like that in the last part of his third utterance. However, when rendering his answer, the interpreter not only omits this last part, but also adds the adverb simpelthen (simply), emphasizing as a 
gift and indicating that the expressed possibility was the only possibility that might be considered. The effect is to increase the force of the original utterance, so that what was expressed as a possibility in the original utterance becomes a certainty in the interpreter's utterance:

\section{Example 129:}

QD.47.6-29: $\quad$ ST-D: I I mean I could have- because I was buying it, I mean I could have bought some for $<$ person $>$ as well.

FT: jeg altså jeg kan have-fordi jeg købte det, altså jeg kan have købt noget til $<$ person>også.

TT-I: der er købt noget- det kan også være jeg har købt noget til <person>.

Back-translation: $\quad$ something was bought- it could also be I bought something for $<$ person $>$.

ST-DC: at du har købt noget til <person>?

FT: that you have bought something for $<$ person $>$ ?

TT-I: do you-

ST-D: bought it for him as a gift. I mean, as a gift, not not to charge him or anything, or things like that.

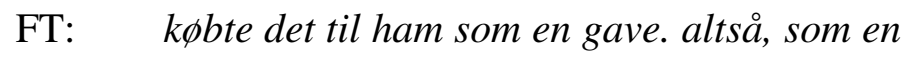
gave, ikke ikke for at tage betaling af ham eller noget, eller andet $i$ den retning.

TT-I: ja. altså jeg har købt det til ham som en gave, ikke for at jeg vil- vil bonne ham bagefter, men altså simpelthen som en gave.

Back-translation: well. I mean I have bought it for him as a gift, not because I want- want to charge him afterwards, but I mean simply as a gift.

Finally, example 130 illustrates emphasis added by stress. The interpreter adds stress in her translation of the pronoun you, and again, the result is an utterance with more force than the original: 
Example 130:

QD.40.43-48: $\quad$ ST-P: men men du siger jo at det er dig der har $\emptyset \mathrm{h}$ gjort brug af det her kort $\varnothing$ h udstedt til $<$ person $>$ ?

FT: but but you say that it is you who has er made use of this here card er issued to $<$ person>?

TT-I: but you just said that you used the card issued to $<$ person $>$ ?

\subsubsection{Down-toning additions}

Again, contrary to emphasizing additions, additions of this subcategory served to down-tone, or decrease, the force of the utterance, or part of the utterance, in the source text. Again, the interpreter down-tones by including one or more items in her target text which were not present in the source text, explicitly or implicitly, and again her additions appeared to function as hedges (cf. Section 6.2.3.2). However, for some reason, additions registered as Down-toning additions in the data from the authentic trial occurred only in target texts in Danish, which may be significant, perhaps indicating that this interpreter found the processing of outputs in English more strenuous than the processing of outputs in Danish, her mother tongue (cf. the subcategory of Fillers, , Sections 6.2.2.2 and 6.3.2.2 above). I shall return to this question in Chapter 7 (Section 7.3.2).

The subcategory is illustrated by examples 131 and 132. In example 131, the interpreter includes the adverbs sikkert- (probably) and måske (possibly), linked by the co-ordinating conjunction eller (or), expressing alternatives. The two adverbs express uncertainty, and thus the addition serves to decrease the force of the original utterance by giving the impression that the degree of uncertainty expressed by the speaker (the defendant) is higher on the scale than originally intended (cf. example 86).

\section{Example 131:}

QD.55.27-45: $\quad$ ST-D: I mean, (..) I did tell him which direction (.) is the shops etceteras.

FT: $\quad$ altså, (..) jeg fortalte ham godt nok $i$ hvilken retning (.) butikkerne er og så videre. 
TT-I: $\varnothing \mathrm{hm}$ jeg har sikkert- eller måske $\emptyset \mathrm{h}$ peget udpeget retningen for ham han skulle gå.

Back-translation: $\quad$ erm I have probably- or possibly er pointed pointed out the direction he had to go.

In example 132, the interpreter includes the adverb lidt (somewhat), which, again, serves to decrease the force of the original utterance. The effect is to change a firm statement into a less definite one:

\section{Example 132:}

QD.11.27-41: $\quad$ ST-D: no, no, that was in my mind.

FT: $\quad n e j$, nej, det var i mine tanker.

TT-I: $\quad \varnothing \mathrm{h}$ nej-

Back-translation: $\quad$ er no-

ST-D: that I was going to do it. but because, you know, things get confused sometimes.

FT: $\quad \underline{t}$ jeg ville gøre det. men fordi, du ved, tingene bliver nogen gange blandet sammen.

TT-I: $\varnothing$ h, nej. $\varnothing$ h men det var hvad jeg- hvad jeg havde tænkt lidt at gøre. øh men fordi det hele blev så forvirret så: ja. så nåede jeg det ikke.

Back-translation: er no, er but it was what I- what I had thought somewhat of doing. er but because everything was so confusing then: well. then I didn't have time to do it.

Example 132 also illustrates an interpreter's strategy for dealing with implicature: The defendant attempted by his answer to explain why he did not keep accounts of his purchases in Denmark, and his last utterance constituted a blatant flout of the first maxim of Quantity ('Make your contribution as informative as is required'), by which he managed to generate the implicature 'I did not have an opportunity to keep accounts', and to imply also that this was the reason why he failed to keep them (cf. Chapter 7, Section 7.3.2). Thus, the implicature was used to emphasize previous utterances (cf. example 128). The interpreter's strategy for 
conveying it was to render the semantic content and explicate the implicature (cf. Strategy (3), Chapter 5, Section 5.3.2.3).

\subsubsection{New-information additions}

Again, additions of this subcategory did not serve to emphasize or downtone the force of the original utterance, but they nevertheless explicitly or implicitly introduced information which may be categorized as brand-new. The subcategory is illustrated by examples 133 and 134 .

In example 133, the interpreter adds the prepositional phrase in advance, by which she introduces the brand-new information that, rather than relate to a general state of affairs, the question concerns a specific time period (cf. example 92). Furthermore, when she needs to repeat the question, she includes the addition once more, but this time substituting in advance with before you left. The speaker (the defence counsel) did not express this information, nor was it inferrable from the data.

\section{Example 133:}

QD.19.41-20.4: ST-DC: det vil sige I har faktisk ikke talt meget om, hvad skal vi sige, om det som jeres rejse gik ud på?

FT: $\quad$ this means you haven't really talked much about, how shall we say, that which was the purpose of your trip?

TT-I: it means that you- didn't talk very much $\underline{\underline{i n}}$ advance about the purpose of your travel. is that-

ST-D: sorry?

FT: undskyld?

TT-I: you didn't er discuss, before you left, er what you were going to Denmark to do?

Example 134 illustrates the reverse, that is, moving from the specific to the general. The defendant was asked to state his profession, and when he wanted to know whether or not he should state his last profession only, the interpreter took it upon herself to instruct him to provide a general answer. 


\section{Example 134:}

QD.3.36-44: $\quad$ ST-P: og hvad laver du egentlig?

FT: $\quad$ and what do you do?

TT-I: what is your job, you profession?

ST-D: er my last profession or whatever?

FT: $\quad \phi h$ mit sidste erhverv eller hvad?

TT-: $\quad$ in general.

\subsection{Conclusion}

In this chapter, I have presented the various kinds of additions identified in the target texts of the court interpreters in this investigation. Generally, the same categories and subcategories of additions were identified in both kinds of data, the mock data and the authentic data, the only two exceptions being the subcategories of Additions explicating non-verbal information and Additions explicating culture-bound information. The first subcategory only occurred in the mock data, and the second only in the authentic data. Neither of these two subcategories occurred more than once, but this fact may not be significant: (1) Non-verbal information only had to be rendered once at the mock trial, and culture-bound information of the kind explicated by the interpreter in the authentic trial did not occur in the mock trial; and (2) non-verbal information did not occur in the authentic trial, and culture-bound information was generally explicated by the speaker, which meant that the question of whether or not the end receiver would be able to infer it did not arise very often.

The fact that, apart from these two subcategories, all other categories and subcategories of additions were identified in both kinds of data may however be significant, since it serves to support the validity of the established categories and subcategories. Consequently, the findings from the two data analyses not only demonstrate that additions do occur in court interpreting, but also that not all additions have equal impact on the semantic and/or pragmatic content of the source text.

Finally, I have also demonstrated in this chapter that some of the identified additions served to explicate implicatures, and I have presented some of the strategies adopted by the court interpreters in this investigation for 
conveying the identified implicatures to end receivers. I shall return to this issue in the next chapter, Chapter 7, which discusses the interpreters' motives for including the identified additions in their target texts. 


\section{$7 \quad$ Interpreter motives}

This chapter discusses the motives of the court interpreters in this investigation for including the identified additions in their target texts. The discussion is based on conclusions reached by matching the findings in Chapter 6 to the theories and assumptions presented in Chapter 5, and it will thus centre on the interpreters' pre-occupation with pragmatics, i.e. with building and conveying a mental model of speaker meaning to end receivers.

In Section 7.1, I shall discuss the caveat concerning text receivers' access to the actual motivations of text producers, the inference process and the implications of this for the court interpreter. Next, taking as the point of departure the various categories and subcategories of additions presented in Chapter 6, I shall discuss, in Section 7.2, the court interpreters' motives for including additions with minimal impact on the semantic and/or pragmatic content of the source text in their target texts, and, in Section 7.3, their motives for including additions with significant impact. ${ }^{1}$ Then, in Section 7.4, I shall comment on the interpreters' strategies for conveying implicature. Finally, in Section 7.5, I shall conclude on the discussions of interpreter motives.

\subsection{The caveat concerning access to the motivations of text producers}

Clearly, since it is not physically possible to transport thoughts from one brain to another, human beings have no means of gaining access to each other's thought processes. As a result, producers and receivers of text, whether oral or written text, can have no actual knowledge of the thoughts, intentions, etc. of their interactants. Human beings never actually know what their interactants know.

\footnotetext{
As explained in Chapter 6, section 6.2.1, additions registered as having no impact on the semantic and/or pragmatic content of the source text were not considered relevant for the purpose of this study, but were registered purely for elimination purposes. Besides, these additions appeared to be attributed solely to the special nature of the interpreting process, and not to any specific motive on the part of the interpreters.
} 
But if human beings have no actual knowledge of each other's thought processes, then how is communication possible? The widely accepted answer to this question is the one provided by Grice (1975) and presented in Chapter 5 of this thesis, which is that human beings infer the intentions of their interactants (cf. Hatim \& Mason 1990:91). Thus, it is the ability to infer motivations that enables human communication.

Naturally, this raises the very important question of how, or by which process, a text receiver may infer the motivations of a text producer. Or, put differently, bearing in mind that this investigation centres on spoken interaction: Since, an utterance, like any other kind of text, is not a static entity, but rather an evolving entity with meaning potential, representing a range of possible interpretations, how does a receiver of an utterance manage to select one particular interpretation of it as representing the speaker's intentions?

Consider, for example, the following dialogue, taking place between two people who have just met by pre-arrangement in a bar':

\section{Example 135: $\quad$ A: So, how are things? \\ B: I've decided to take the job.}

The meaning potential of an utterance such as A's utterance above is not unlimited (cf. Thomas 1995:23). For example, it would not be reasonable to interpret A's words as requesting the return of his book, or as inviting B to join him on a skiing holiday. Besides, the context of a bar provides certain social constraints, so it would not be reasonable for B to interpret A's utterance as, for example, a request to show him the scar from his recent operation for acute appendicitis. But even excluding these possibilities, A's utterance still represents a range of possible interpretations. For example, it could be interpreted as a general greeting, or as a request for information about any number of things, such as B's health, family, house, car, etc.

However, despite the range of possible interpretations of A's utterance, B had no trouble interpreting it as a request for information relating to a

2 Cf. Chapter 5, note 1. 
particular job. But how did B manage to select this interpretation of A's utterance? The next section, Section 7.1.1, will attempt to answer this question.

\subsubsection{The inference process: interpreting the motivations of text producers}

As established earlier (cf. Chapter 5, Section 5.2.2), in the Gricean framework of utterance comprehension, there is an underlying assumption that speakers and hearers will act in accordance with the Co-operative Principle (CP) and the maxims. Taken together, the $\mathrm{CP}$ and the maxims express the general assumption that participants in interaction will behave in a maximally effective and efficient, rational and co-operative manner in order to achieve their communicative objectives.

However, once again it should be stressed that the $\mathrm{CP}$ and the maxims do not express norms, or rules, for how people ought to behave (cf. Chapter 5, Section 5.2.2); rather they express what speakers and hearers generally assume each other to be doing in order for an interaction to proceed. As Myers (1999:42) observe, when "Hearers interpret Speakers, they assume that the Speaker must be thinking of what the Hearer needs next".

Hence, in the Gricean framework, a hearer will infer a speaker's communicative intention based on the following factors: (1) the hearer's assumptions that the speaker will act in accordance with the $\mathrm{CP}$ and the maxims, (2) indications forthcoming from the context of utterance (linguistic and/or situational), (3) the hearer's knowledge of the world at large, (4) his assumptions ${ }^{3}$ concerning whether all of these factors are available to the speaker also, and (5) his assumptions concerning the speaker's assumptions.

So, applying these factors to the meaning potential of A's utterance in example 135 above, B's interpretation of it may be explained as having relied on the following data:

3 When initially outlining this inference process (cf. Chapter 5, Section 5.2.2), Grice (1975:50) referred to speakers and hearers as sharing actual, or supposed, knowledge or assumptions. However, as established above, human beings have no actual knowledge about what may be shared; they can only make assumptions. 
$\mathrm{B}$ assumes that $\mathrm{A}$ is acting in accordance with the $\mathrm{CP}$ and the maxims. A and $\mathrm{B}$ meet in a bar, a public place, and they meet by pre-arrangement. A and $\mathrm{B}$ are close friends. Some days before, when A and B arranged to meet, B had told A that he, B, had been offered a very good job, and that he was very flattered and wanted to accept the job offer, but that his wife did not want him to accept it, since it meant him having to live away from his family four days a week, and, as a result of this, he was not sure that he would take the job. B assumes that all of the above factors are available to A also. B assumes that A assumes that all of the above factors are available to both of them.

Based on all of the above, it was perfectly reasonable for B to infer that A was requesting information about the job.

In addition, this process of inference emphasizes the crucial fact that speakers and hearers co-operate and communicate by making assumptions about a shared cognitive environment. Such mutual assumptions of speakers and hearers often have a decisive influence on the form of utterance produced as well as on the kind of inferences drawn. Prince's (1981) taxonomy of Assumed Familiarity and her distinction of discourse entities, referred to in Chapter 6 (Section 6.1.4) of this thesis, was thus an attempt to account for this influence. More precisely, speakers and hearers form judgments concerning what may be assumed shared (given) information and what may be assumed new information, and they assume that every utterance represents a balance between given and new information which will allow for a speaker's intentions to be inferred. Hatim \& Mason (1990: 93) explain that this balance between given and new information is "regulated by the principles of effectiveness (achieving maximum transmission of relevant content or fulfilment of a communicative goal), and efficiency (achieving it in the most economical way, involving minimum expenditure of processing effort)".

So, based on these principles (maximum effect for minimum processing effort), therefore, B's interpretation of A's utterance in example 135 may be further explained as follows: Among a range of possible interpretations of A's utterance, B selected the one interpretation of it which would require minimum processing effort but yield maximum effect. For B to select any other interpretation of A's utterance, for example, that A was requesting 
information about the state of B's car, would require extra processing effort, and be less effective, since the interaction would not have been successful, and since A would have failed to achieve his communicative objective. Of course, if B had selected another interpretation than the one intended by A, a possible course of action for A could be to make another attempt at achieving his objective by presenting his request once more, perhaps further specifying his intentions; or A could choose to abandon his objective altogether and go along with B's selected interpretation.

So, human beings co-operate and communicate by making assumptions about a shared cognitive environment, and by establishing relevance to each other's communicative objectives according to principles yielding maximum effect for minimum processing effort. Assessing relevance is thus important in human communication, and it may be appropriate, therefore, to briefly examine a framework that views relevance as the central factor governing utterance interpretation: the theory of relevance.

\subsubsection{The theory of relevance}

The theory of relevance was developed by Sperber \& Wilson (1986) and has a cognitive basis. According to Sperber \& Wilson (1981, 1986), Grice's maxims may be reduced to a single principle, the principle of relevance, since, in communication, hearers focus their attention on what seems to them to be the most relevant information available. As a result, every utterance produced by a rational speaker brings with it an expectation of optimal relevance, that is, an expectation on the part of the hearer that the speaker believes the interpretation of his intention will yield adequate effects without unnecessary processing.

Sperber \& Wilson developed a view of communication as an ostensiveinferential process: the speaker produces a stimulus which makes it mutually manifest to speaker and hearer that the speaker intends, by means of the produced stimulus, to make manifest or more manifest to the hearer a set of assumptions (1986:63). In other words, speakers provide evidence of their intentions and hearers infer speakers' intentions based on the provided evidence. Sperber \& Wilson (1986:103) suggest that hearers will assess the relevance of new information in terms of the improvements it brings to 
their representation of the world. Hence, it is clear that the interaction of given versus new information may give rise to improvements, or modifications, technically referred to as contextual effects (1986:108ff). These may be: (1) contextual effects which strengthen, or confirm, previously held assumptions (new information confirming given information), (2) contextual effects which eliminate, or weaken, previously held assumptions (new information contradicting given information), or (3) contextual effects which consist in the derivation of contextual implications (the fusion of given and new information). For an assumption to be relevant to a context, therefore, it has to achieve some contextual effect.

Thus, according to Sperber \& Wilson's view of inferential communication, relevance is dependent on the interplay of two factors: contextual effects and processing effort (1986:125). Furthermore, relevance is contextdependent (since contextual effects and processing effort are contextdependent). Finally, relevance is a comparative notion, meaning that texts may vary according to the degree of relevance they achieve in a context.

So, applying the framework of relevance theory to the dialogue in example 135 above, the process by which B interpreted A's utterance may be explained as follows: Assuming that A is a rational speaker, B selected the first interpretation of A's utterance he arrives at that a rational speaker might have expected to yield adequate contextual effects without unnecessary processing. Such an interpretation is consistent with the principle of relevance, and it is therefore the intended meaning of A's utterance, because there is never more than one interpretation that fulfils this condition ${ }^{4}$.

Sperber \& Wilson (1986:172) argue that relevance theory offers "a pragmatic framework in which serious questions can be raised and new answers developed". Hence, they argue that relevance theory may be applied to issues such as speech acts, implicature, presupposition,

4 Of course, it may be that no interpretation fulfils the condition of adequate contextual effects without unnecessary processing, in which case communication will have failed. However, Sperber \& Wilson (1986:159) argue that "from the presumption of relevance there follows a more reliable assumption that relevance has been attempted, if not achieved". Presumably, then, if no interpretation fulfils the condition, the hearer will ask the speaker to clarify his intentions. 
metaphor, irony, and style. Therefore, they criticize Grice's CP and maxims, and in particular Grice's treatment of metaphor and irony and other tropes which, as mentioned in Chapter 5 (Section 5.2.3.1.3), they consider incorrect. Nevertheless, Sperber \& Wilson's view on utterance comprehension as governed by the principle of relevance does not appear to be totally inconsistent with the Gricean view in which the CP and the maxims represent conventions adhered to in communication. Fundamentally, both views treat communication as a goal-directed process in which text producers will seek to achieve their communicative goals, or objectives, by being maximally effective and efficient, in order for text receivers to be able to infer their motivations on the basis of maximum effect at minimum processing cost.

So, having thus established that a hearer will infer a speaker's intentions by selecting an interpretation of his utterance which yields maximum effect for minimum effort, I shall now discuss, in Section 7.1.2 below, the implications of this for the court interpreter as a receiver of source texts and a producer of target texts.

\subsubsection{Implications for the court interpreter}

Naturally, the official view of the court interpreter referred to throughout this thesis does not allow for considerations regarding her role other than those connected with her performance as a mere transformer of words. However, hypothesizing (cf. Chapter 1, Section 1.2) that the court interpreter is not just a translating machine but very much an active part in the process of negotiating meaning, I shall argue that the inference process has certain implications for the way she performs her interpreting task.

First of all, the court interpreter, though a receiver of source texts, is not specifically an addressee in the sense that she is not the end receiver, or the intended receiver of a speaker's utterance. Ideally, therefore, the speaker will direct his utterance at the end receiver and frame it based on assumptions about the kind of cognitive environment that he shares with the end receiver. The interpreter is an observer of this environment only, and she will infer speaker meaning based on what she assumes the speaker assumes to be shared with the end receiver (rather than shared with her). 
Secondly, the interpreter will not only seek to interpret the meaning of a source text, she will also consider the impact of it on the person it was directed at, the end receiver. In other words, she will form judgements concerning whether or not the end receiver will be able to infer the speaker's intentions from his words alone, based on her assumptions concerning the separate, as well as the mutual, cognitive environments of the speaker and the end receiver (cf. above). Her assumptions will necessarily determine the kind of target text she will produce, since she will want to reproduce her interpretation of speaker meaning in a way that will achieve the speaker's intended effect, as she perceives it, on the end receiver. Thus, she will assume that the end receiver will accept her target text as fully representing the source text, and that he will infer speaker meaning based on this assumption. As established above, the $\mathrm{CP}$ and the maxims express the general assumptions that all participants in interaction will intend to communicate in an effective and efficient manner. Mason (2000a:2) asserts that, in this respect, target text producers is no different from other interactants: as a rule, it will be assumed that they will intend to communicate in the same way as other interactants do. Accordingly, Mason (2000a:2) asserts, a target text receiver "will assume, in the absence of evidence to the contrary, that what is communicated is rooted in the source text in some principled way".

Thirdly, the court interpreter may have to consider the possibility of multiple, and different, categories of end receivers. Very often in interaction, a speaker's words may be directed at one specific addressee, but may in fact be intended for another participant. This is especially true of the kind of interaction investigated here, since, throughout the trial, speakers will pay special attention to the kind of impact their utterances may have on those deciding on the outcome of the trial, i.e. the judge and the lay judges, even when these participants are not directly involved in the interaction. The court interpreter is aware of this fact, and therefore two questions arise: (1) When interpreting a particular utterance, will she consider the possibility of multiple end receivers and distinguish between different categories of receivers; and, (2) if so, will she accommodate equally to all categories?

The notion of audience design proposed by Bell (1984) may help provide answers to these questions. Bell (1984) argues that a text producer's style 
may be influenced in different ways and to a varying extent by different receiver groups, and, following Goffman (1981), he distinguishes (1984:158-160) between four categories of receivers, listed here in descending order of potential influence:

- addressees (known and ratified participants who are directly addressed);

- auditors (known and ratified participants but not directly addressed);

- overhearers (known but not ratified participants and not addressed);

- eavesdroppers (whose presence is not known).

Accordingly, a text producer's style will typically be influenced primarily by addressees, to a lesser extent by auditors, to an even lesser extent by overhearers, and not at all by eavesdroppers. So, considering the interaction in this investigation, the audience design of both the source text producer and the court interpreter is as follows:

- addressees ('interrogators'/the court or defendants/ witnesses);

- auditors (all other participants, especially those deciding on the outcome of the trial);

- $\quad$ overhearers (spectators in the courtroom);

Since court records are not verbatim, and since representatives from the media are unable to record dialogues on tape, etc. (cf. Chapter 4, Section 4.3), the interaction is available only to those present in the courtroom during the trial itself, and consequently there can be no category of eavesdroppers.

As regards source texts, the first two categories, addressees and auditors, will exert almost equal influence, because, though designing primarily for addressees, speakers will be particularly attentive to the category of auditors, for the reasons outlined above. The category of overhearers will generally exert only a small degree of influence (during highly spectacular trials with much media coverage, however, this degree may become almost equal to the degree of influence exerted by auditors). 
As regards target texts, the category of addressees will exert most influence, because, though aware of the potential influence of auditors and overhearers on the wording of original utterances, the court interpreter will presumably not be very attentive to either of these groups, since her primary objective is successful interaction (cf. Chapter 1, Section 1.2), rather than the outcome of the trial. In fact, when rendering source texts produced by Danish-speaking participants, she will design exclusively for addressees, i.e. the foreign participant, since she will expect no other category of receivers for target texts produced in the foreign language (unless she is aware that some participants and spectators are familiar with the foreign language). When rendering source texts produced in the foreign language, however, she will be more likely to take the lead of the source text producers: design her target texts primarily for addressees, but be particularly attentive to the category of auditors, and to a minor extent to the category of overhearers. Nevertheless, it is to be assumed that the attention to these latter groups will not be allowed to override the objective of successful interaction. Finally, when, as occasionally happens, an utterance represents a response from a defendant, or a witness, to a question from an 'interrogator', but is clearly directed at the court in general, both the source text producer and the interpreter will design exclusively for the category of addressees (comprising all participants), but to a small extent be attentive to the category of overhearers.

So, returning to the two questions above, the court interpreter will certainly consider multiple end receivers and distinguish between categories of receivers, but, even when determining multiple categories, she will design primarily for the category of addressees.

Having thus considered the implications of the inference process for the court interpreter as a receiver of source texts and a producer of target texts, I shall now discuss, in Sections 7.2 and 7.3, how the court interpreters in this investigation interpreted speaker meaning and conveyed their perception of speaker meaning to end receivers. As explained in the beginning of this chapter, the point of departure for my discussion of interpreter motives is the various categories and subcategories of additions identified in the interpreters' target texts and registered as having either minimal or significant impact on the semantic and/or pragmatic content of the source text. 


\subsection{Interpreter motives for including additions with minimal impact}

As demonstrated in Chapter 6 (Tables 6.1 and 6.2), the category of additions with minimal impact comprised five subcategories: Repetitions $\mathbf{p}_{\mathbf{p}}$,

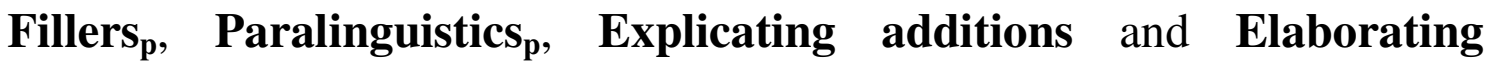
additions. The first three subcategories were judged to have potential

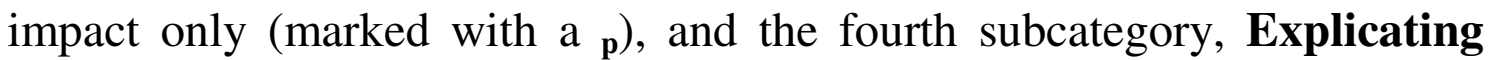
additions, was further divided into three more subcategories: Obviousinformation additions, Connective additions and Additions explicating non-verbal information (the mock trial) or explicating culture-bound information (the authentic trial).

In sections 7.2.1 to 7.2.5, I shall discuss the interpreters' motives for including the additions with minimal impact in their target texts. I shall argue that the subcategories of additions with potential impact may be attributed to the special nature of the interpreting process, rather than to any specific motive on the part of the interpreters, whereas the subcategories of Explicating additions and Elaborating additions were included for a specific purpose, namely that of making speakers' intentions available, or more easily available, to end receivers. Accordingly, I shall argue that the last two subcategories of additions were triggered by the interpreters' instinctive judgments of end receivers' inferencing ability. I shall further argue that this fact, which demonstrates the interpreters' preoccupation with pragmatics, i.e. with building and conveying a mental model of speaker meaning, serves to support the hypotheses presented in Chapter 1 (Section 1.2) of this thesis.

The discussion of interpreter motives will centre on some of the examples presented in Chapter 6 (Sections 6.2.2 and 6.3.2), which have been chosen mainly for their illustrative power. It will not as a rule distinguish between the two kinds of data, since, as explained in Chapter 6 (and illustrated by Tables 6.1 and 6.2), with one exception only, the subcategories of Additions explicating non-verbal information and Additions explicating culture-bound information, the two kinds of data identified the exact same categories and subcategories of additions. 


\subsubsection{Repetitions $s_{p}$}

Additions of this subcategory were judged to have the potential to either decrease (or down-tone) or increase (or emphasize) the force of the original utterance (cf. Chapter 6, Sections 6.2.2.1 and 6.3.2.1). Three facts serve to substantiate the claim that these additions may in fact be attributed to the special nature of the interpreting process:

First of all, the additions merely repeated material which was explicitly expressed in the source text, and which had already been rendered once in the interpreter's target text.

Secondly, as demonstrated by examples 49,50 and 99 , the degree of hesitancy expressed by the additions that potentially decreased the force of the original utterance seemed to lie with the interpreters, since each addition seemed to indicate an interpreter's hesitancy regarding the use of a term in her target text.

Thirdly, the additions which potentially increased the force of the original utterance seemed either to illustrate an interpreter's habit of translation (example 101) or to express a similar uncertainty (example 100) to the one expressed by examples 49, 50 and 99 . The addition in example 100, which potentially increased the force of the original utterance by potentially showing distrust in the defendant's answer, may thus be explained as follows: The prosecutor listed a number of purchases and asked the defendant to confirm whether or not he had made them. The defendant made no audible reply following the prosecutor's first two questions in example 100 but replied yeah following the last question. However, he must be assumed to have provided some indication of an affirmative response, at least to the prosecutor who would presumably not have proceeded otherwise. The interpreter may easily have missed the defendant's indication following her first target text (the one following the prosecutor's first two questions), being seated next to him, rather than facing him, or being busy taking notes, etc., and it is thus a reasonable conclusion that she suspected the possibility that his audible reply was made in response to her first target text only, and that she repeated the prosecutor's third question as a result of this suspicion. 
Furthermore, as regards example 100, when rendering the prosecutor's first utterance, the interpreter omitted his first question and thus only interpreted his second question in that utterance. Possibly she was not aware of her omission, believing perhaps that the question had already been conveyed to the defendant, as well as answered by him, because of the defendant's indication of an affirmative response following that question and/or because the prosecutor proceeded straight away to his second question, which would indicate that he regarded the first question as having been satisfactorily dealt with. Based on personal experience and observation, this happens sometimes in court interpreting, especially in question-answer dialogues (cf. Section 7.2.4.1.4). Technically, however, the interpreter's omission constituted a violation of the principle of Accuracy and Completeness.

\subsubsection{Fillers}

Additions of this subcategory were judged, because of their discourse functions, to have the potential to indicate a particular attitude on the part of the speaker towards the interaction, or part of the interaction, or towards his addressee, or addressees (cf. Chapter 6, Sections 6.2.2.2 and 6.3.2.2). Two facts serve to substantiate the claim that these additions may be attributed to the special nature of the interpreting process:

First of all, the additions registered as Fillers $\mathbf{p}_{\mathbf{p}}$ were identified in renditions in Danish only, and only in the renditions of two interpreters, which may suggest that, in certain situations, these interpreters found the processing of outputs in English more strenuous than the processing of outputs in Danish (their mother tongue).

Secondly, the identified fillers appeared to function as interactional signals. Thus, with a few exceptions only, the added fillers were all identified as starters, that is, as introductory devices meant to help the interpreter start the turn (Stenström 1994:70), which supports the conclusion that the two interpreters who included fillers in their target texts occasionally found the processing of outputs in English particularly strenuous: Stenström (1994:70) explains that some speakers tend to use starters surprisingly often, even though there is no apparent need, since they make a clean, 
rather than a hesitant start. So, it seems that these interpreters needed some kind of takeoff, or felt a need for some kind of linking device. Moreover, the additions which did not function as starters were identified as stalling devices, that is, they were meant to help the interpreter keep the turn, while planning what to say next (Stenström 1994:76), which lends further support to the conclusion that the two interpreters found the processing of outputs in English particularly strenuous. Hence, just like additions with no impact on the semantic and/or pragmatic content of the source text, the filler in example 54 appeared to function as a disguised translational repair (cf. Chapter 6, Section 6.2.1).

In one example (example 53), a starter co-occurred with a change of footing. As explained in Chapter 4 (Section 4.6.1), as per Goffman's (1981:128) definition of footing, a change of footing is a change in a person's relation to a particular utterance to which he has some kind of access, as speaker or hearer, expressed in the way he manages the production or the reception of it. Consequently, since the original utterance in example 53 was a request for clarification of a preceding utterance, which caused a momentary break in the interaction, the change of footing (to rendering the utterance in the third person) could be an indication that the interpreter acknowledged processing problems and accepted responsibility for the break. Still, as mentioned in Chapter 6 (Section 6.2.2.2), the fact that this particular interpreter almost habitually changed footing when translating English source texts into Danish may serve to 'cancel out' an indication that this was her intention.

\subsubsection{Paralinguistics ${ }_{p}$}

Two kinds of paralinguistic features were identified in the data: laughter and audible breathing (cf. Chapter 6, Sections 6.2.2.3 and 6.3.2.3). Like fillers, these additions were judged to have the potential to indicate a particular attitude on the part of the speaker towards the interaction, or part of the interaction, or towards his addressee, or addressees. Discussions of examples 55, 56 and 104 in Chapter 6 will serve to substantiate the claim that the added paralinguistic features may likewise be attributed to the special nature of the interpreting process: 
Examples 55 and 56: These examples illustrate interpreters' inclusion of unilateral laughter which had the potential to 'damage' their neutrality, but which appeared nevertheless to have been spontaneously triggered by something connected with the interpreting process. Thus, as explained in Chapter 6 (Section 6.2.2.3), the interpreter's brief laughter in example 55, which potentially demonstrated a level of intimacy between her and an interactant that constituted a violation of the principle of Impartiality (cf. Chapter 3, Section 3.5.2), appeared to have been spontaneously triggered by something which she considered funny: the simultaneous speech, which occurred when the defence counsel did not wait for the interpretation of the witness' statement before responding to it. This is evidenced by the silent pause and the false start at the beginning of her target text, which occurred immediately after the simultaneous speech and before her brief laughter. As mentioned in Chapter 3 (Section 3.2), simultaneous speech, i.e. a primary speaker and an interpreter speaking at the same time, is not uncommon in the kind of interaction investigated in this thesis and usually occurs because an 'interrogator', who is competent in English, becomes so absorbed in his line of questioning that he momentarily 'forgets' that the defendant, or the witness, is not replying in Danish, or because an 'interrogator', or a defendant, or a witness indicates that he has finished his utterance, but nevertheless proceeds to elaborate on it. However, simultaneous speech will generally cause only minor interruption, as in example 55 .

The interpreter's unilateral laughter in example 56, on the other hand, appeared to have been spontaneously triggered by her perception of the need for tension reduction and face protection which was explicitly expressed in the original question. This addition had the potential to express discomfort on her part at having to ask the question in example 56. Nevertheless, as explained in Chapter 6 (Section 6.2.2.3), there is no reason to assume that there was a specific motive behind the inclusion of her unilateral laughter, since there is no reason to assume that this particular question would have been perceived by the interpreter as requiring additional protection of either the speaker's (the defence counsel's), face or her own face: The need for limiting threats to face was explicitly expressed in the original utterance, and the question merely succeeded a line of potentially more 'dangerous' questions, which also requested details of the same event, the alleged rape, but which did not cause the interpreter to include in her target text features intended to limit threats to face. 
Example 104: This example illustrates the inclusion of the second kind of paralinguistic feature, audible breathing. This feature has the potential to demonstrate annoyance, or exasperation, at having to answer a particular question. However, as explained in Chapter 6 (Section 6.3.2.3), the addition in example 104 was seemingly an expression of the efforts involved in processing the original utterance, since the interpreter appeared to find the processing of this utterance particularly stressful: Not only did she include the paralinguistic feature, but also three voice-filled pauses, one to start off her target text and two to stall while delivering it.

\subsubsection{Explicating additions}

Additions registered as belonging to the subcategory of Explicating additions served to explicate material implicitly present in the context of the source text. These additions seemed to have been triggered by the interpreters' instinctive judgment that implicit meaning had to be made explicit, or partly explicit, if end receivers who were unfamiliar with the context of the interaction (linguistic and/or situational) were to fully infer speaker meaning. Hence my contention that Explicating additions were included for the specific purpose of making speakers' intentions available, or more easily available, to end receivers.

\subsubsection{Obvious-information additions}

As explained in Chapter 6 (Sections 6.2.2.4.1 and 6.3.2.4.1), additions of this subcategory of additions explicitly expressed information classified as obvious by being implicit in the context (linguistic and/or situational), and they thus served to introduce a greater degree of specificity.

Some of the additions of this subcategory explicated information categorized as textually evoked, situationally evoked or inferrable (cf. Chapter 6, Sections 6.2.2.4.1 and 6.3.2.4.1), while others served to repeat, or take up, parts of questions, to explicitly express negation or affirmation inherent in responses, or to complete fragmented source texts. 


\subsection{Additions explicating textually evoked information}

Textually evoked information had been explicitly or implicitly expressed at an earlier stage of the interaction and was therefore implicitly present in the situational context. The information was therefore available to participants, who needed to infer it in order to fully infer speaker meaning. This fact makes for the reasonable conclusion that the additions explicating textually evoked information were included because the interpreters instinctively judged that end receivers would not be able to infer this information without assistance. A discussion of examples 57 and 105 will serve to substantiate this claim:

Example 57: The defendant's utterance represented one of a number of answers to questions meant to establish the kind of relationship that existed between him and his former girlfriend, the witness in the case and the alleged rape victim. He had explained that, since the time when he and his former girlfriend split up, they had seen each other about once a week, for no particular reason, and would meet at her apartment or his apartment. So, seemingly he intended to convey the information that their relationship was not a steady relationship, like that of a couple, but that it was of a more casual nature. His first utterance expressed the textually evoked information: we see each other about once a week (about implicating 'not a routine'). Thus, for speaker meaning in example 57 to be fully available, the textually evoked information had to be available also, since it supported the defendant's claim that they did not meet as a matter of routine. Instinctively judging that the end receiver, the prosecutor, would not be able to re-activate it without assistance, the interpreter explicitly expressed it in her target text. Two factors may have triggered, or supported, her instinctive judgment:

First of all, when the interpreter rendered the defendant's first answer, which expressed the textually evoked information, she omitted about. Apparently, this gave the prosecutor the wrong impression, namely that the relationship referred to was a steady relationship, since the defendant was asked to confirm this impression, as illustrated by example 57. Perceiving (from the prosecutor's question) that the defendant's intention to indicate 'not a routine' had not been made available (though not necessarily 
perceiving why it had not been made available), the interpreter included the textually evoked information for the purpose of remedying this situation.

Secondly, the prosecutor's feed-back item, $h m$, may have indicated to the interpreter that more information was required in order for the defendant's intentions to be available. Moreover, she might have taken the discrepancy between the length of the source text and her target text, if she was aware of it, to provide evidence in support of her perception. As a result, she included the textually evoked information.

So, the inclusion of the textually evoked information may have been triggered by the prosecutor's question, or by the feed-back item, or by both of these factors together. In other words, the perception triggered by one may have served to support the perception triggered by the other.

Based on the subsequent dialogue, the interpreter succeeded in conveying speaker meaning, because the prosecutor apparently perceived the defendant's utterance as conveying the information that the relationship between him and his former girlfriend was of a casual nature only.

Example 105: This example, which is similar to example 57, presents an excerpt from a lengthy answer, which the defendant uttered on his own initiative, and which gave details of his family and career, and which was apparently meant to convey the information that he was a decent, hardworking man, who had always provided for himself and his family, his wife and two children, by which he managed to imply also that he had never previously been involved in illegal activities. However, as regards his career, he had referred to this once before, at a much earlier stage of the interaction, at which time he had stated that he was presently unemployed due to his career as a restaurant manager having ended when the company that he had worked for had gone bankrupt, by which he managed to imply, of course, that he himself was not responsible for bringing an end to his career. The fact that this information, i.e. the textually evoked information, would have to be re-activated for the defendant's intention to be fully available was indicated by his reference to former employers and his use of the past tense: all my old employers,..., that I was working there. Instinctively judging that the end receiver, the defence counsel, would not be able to re-activate this information, possibly because of the length of 
time between the defendant's first utterance referring to his career as a restaurant manager and the utterance in example 105, the interpreter explicitly expressed it.

The defence counsel proceeded by asking the defendant to elaborate on the information provided in example 105, so presumably the interpreter succeeded in conveying speaker meaning.

\subsection{Additions explicating situationally evoked information}

Situationally evoked information was implicitly present in the context of the interaction and represented participants and the situation, which meant that it would not necessarily be available to participants who were not familiar with Danish courtroom procedure. Hence the conclusion that, in example 60, the interpreter included the addition which explicated the identity of the agent in the passive construction, because she instinctively judged that the end receiver, the witness, who was unfamiliar with the context of the interaction, would not be able to infer this information, and thus not able to fully infer speaker meaning.

\subsection{Additions explicating inferrable information}

Inferrable information was implicitly present in the context of the interaction and capable of being inferred by a normal, rational human being from already evoked (implicitly or explicitly introduced) information or from other inferrable information. Like information which was textually or situationally evoked, inferrable information had to be inferred for speaker meaning to be available, or more easily available. So, the additions explicating this information were included when the interpreters instinctively judged that, in order to be available to end receivers who were not familiar with the linguistic and/or situational context, implicit information had to be made explicit, or partly explicit. A discussion of examples 61, 108 and 109 which illustrate defendants' non-observance of Grice's maxims (cf. Chapter 5, Section 5.2.2), of example 63, and of example 112 which illustrates the inclusion of possessive determiners to explicitly express relationships, will serve to substantiate this claim: 
Example 61: Example 61 illustrates an answer generating an implicature and the interpreter's strategy for dealing with the generated meaning: The defendant blatantly flouted the maxim of Relation ('Be relevant') by providing an answer which was seemingly irrelevant to the topic at hand. As explained in Chapter 6 (Section 6.2.2.4.1), the implicature was used to emphasize his firm denial of an alleged fact: that he had picked up a bread knife in the kitchen of the witness' apartment and threatened her with this knife. Thus, by his seemingly irrelevant elaboration on his firm denial, the defendant managed to generate the implicature 'I did not pick up a bread knife in the kitchen and threaten her with it', and also to imply that the fact that he was never in the kitchen ought to prove him innocent. The interpreter's strategy for conveying this implicature was to render the semantic content and explicate part of the implicature (Strategy (5), Chapter 5, Section 5.3.2.5), by explicitly expressing the inferrable information in example 61. Presumably, since the utterance which generated the implicature was clearly linked to the defendant's firm denial (elaborating on the firm denial), and the flout was so obvious, the interpreter instinctively judged that preserving the ambiguity of his utterance, while explicating part of the implicature would be a suitable strategy for making it available, or more easily available, to the end receiver, the prosecutor.

Since the prosecutor did not ask the defendant to verify his intention, the interpreter probably succeeded in conveying the implicature. Presumably, had the prosecutor not been able to infer the implicature, he would have been disinclined to accept the defendant's answer, since it was so obviously ambiguous, but would have asked for verification of the defendant's intention. Besides, the question related to a material piece of evidence.

Example 108: This example illustrates what appears to be a blatant flout of the second maxim of Quantity ('Do not make your contribution more informative than is required'), caused by a clash between that maxim and the second maxim of Quality ('Do not say that for which you lack adequate evidence'): The prosecutor asked the defendant to confirm his purchase of a specific watch, with the use of a specified, and false, credit card. The defendant was not able to confirm the purchase, but instead of merely saying 'no' or 'no, I did not buy that watch', or words to that effect, he provided a long and ambiguous answer, including also information that was 
seemingly superfluous, since it related to purchases that he had not yet been asked to confirm, made with that same credit card.

According to Grice (1975:51-52), a speaker who is faced with a clash between two maxims may signal his dilemma by blatantly flouting one of them (cf. Chapter 5, Section 5.2.3.1.1). In example 108, the defendant may have been facing such a clash: He did not believe that he purchased the watch but, because he did not remember not buying it, he did not have adequate evidence of this fact. Furthermore, he probably assumed that the end receiver, the prosecutor, would not be prepared to accept his statement that he did not purchase the watch, since he had just acknowledged having made other purchases with the use of the same false credit card. Consequently, his answer was meant to signal his dilemma by generating the implicature 'I did not purchase the watch'. The seemingly superfluous information was thus meant to signal his innocence to the prosecutor, while simultaneously illustrating his intentions to co-operate, since by willingly acknowledging purchases he had not yet been asked to confirm, he was able to convey the information that he would willingly have acknowledged purchasing the watch, had he been able to do so.

The interpreter's strategy for dealing with the defendant's ambiguous answer was to render less than the semantic content, while simultaneously explicating part of the implicature (Strategy (6), Chapter 5, Section 5.3.2.6), which preserved the ambiguity of his utterance and at the same time provided clues to the interpretation of his intention. Her choice of strategy thus seems to indicate that she instinctively judged that the defendant's intention would not be available to the prosecutor, unless she explicated part of the implicature. Consequently, she included two pieces of inferrable information in her target text, the first piece, (in backtranslation) I had purchased, explicitly referring to the watch as an item allegedly purchased by the defendant, and the second piece, (in backtranslation) and I believe it must be item number three, expressing the implicit, as well as obvious, conclusion to be inferred from some of the information provided by the defendant.

Apparently, the interpreter's strategy was successful, because the defendant was not asked to verify his intention (at least not straight away), which may indicate that his statement was perceived as providing evidence that the 
watch was not purchased by him. Accordingly, he was next presented with a series of questions relating to the items that he did confirm having purchased with the use of the false credit card.

Interestingly, however, about one minute later the prosecutor returned to the issue of the watch, and now asked the defendant to explain why he believed that he did not purchase it. Once again, he provided a long and ambiguous answer, similar to the one in example 108, i.e. apparently once again intending to generate the implicature 'I did not purchase the watch'. Again, the interpreter adopted the strategy of rendering less than the semantic content, while simultaneously explicating part of the implicature (Strategy (6), Chapter 5, Section 5.3.2.6). Finally, abandoning this line of questioning, the prosecutor proceeded with a series of questions attempting to establish whether the defendant knew the identity of the person who bought the watch, and whether he was prepared to offer this information (cf. the discussion of example 130, Section 7.3.1 below).

Example 109: This example illustrates the defendant's implicit opting out of observing the second maxim of Quality ('Do not say that for which you lack adequate evidence'). As explained in Chapter 5 (Section 5.3.1.1), a defendant may choose to opt out of observing a maxim, when he is unable, or unwilling, to provide the requested information but does not wish to create a false implicature, or appear uncooperative. Thus, in example 109, by implicitly opting out of observing the maxim, the defendant managed to convey the information that he was prepared to inform the prosecutor of the room number, i.e. to co-operate, but also that he was not able to do so, since he did not fully remember it. Instinctively judging, however, that the end receiver (the prosecutor), who was unfamiliar with the linguistic context, would not be able to infer the defendant's intention, the interpreter included the inferrable information in order to make his intention available, or more easily available.

Apparently, the interpreter succeeded in conveying the defendant's intention, because the prosecutor did not ask him to verify it, but proceeded with another line of questioning. Of course, the prosecutor may have proceeded anyway, but, in all probability, had the defendant's answer been perceived as conveying, for example, the opposite intention, i.e. that he did not intend to co-operate, the prosecutor would have asked him to verify this 
in order specifically to draw the court's attention to it. Although, as explained in Chapter 3 (Section 3.1.3) and Chapter 5 (Section 5.3.1.1), a defendant is not obliged to answer questions, or to answer them fully, and, no inference may be drawn from his apparent unwillingness to co-operate, a prosecutor may still be tempted to imply, for tactical reasons, that his apparent unwillingness stems from his intention to mislead the court.

Example 63: Contrary to examples 61, 108 and 109, example 63 does not illustrate the non-observance of one of Grice's maxims. However, the speaker's (the defence counsel's) utterance in this example exhibited a degree of non-explicitness, and consequently the inferrable information (the addition) had to be available in order for speaker meaning to be available also. It is a safe assumption, therefore, that the interpreter explicated the inferrable information in example 63 because she instinctively judged that, despite being implicit in the situational context, the information would not be available to end receivers who were unfamiliar with the context of the interaction.

Presumably, one purpose of asking a general question, that is, a question with a degree of non-explicitness, such as the one in example 63, is to provide an opportunity for multiple interpretations, and in turn to enhance the chances of eliciting affirmative answers. However, by asking such questions, 'interrogators' fail to comply with Section 184 of the Danish Administration of Justice Act which provides that their questioning must be conducted for the purpose of eliciting clear and truthful responses (cf. Chapter 3, Section 3.1.2). Nevertheless, despite Section 184, non-explicit questions are presumably quite common in courtroom interaction (cf. the discussion of examples 92 and 133 in Section 7.3.3 below), though the extent of their frequency is beyond the scope of the present investigation.

Example 112: Finally, example 112 illustrates additions explicating another kind of inferrable information: possessive determiners explicitly expressing relationships which had to be inferred from the situational context. Such additions were not identified in the data from the mock trial, but neither were source texts which did not explicitly express relationships, like the one in example 112. So, presumably, the fact that this defendant did not have English as a mother tongue (cf. Chapter 6, Section 6.3) explains why he did not explicitly express the inferrable information in his 
original utterance. Consequently, it is tempting to conclude that the interpreter included the possessive determiners merely for the purpose of being able to present a grammatically correct target text, fearing perhaps that participants would assume the lack of possessive determiners to be due to faulty interpretation. However, as explained in Chapter 4 (Section 4.6.2), since the interpreters in this investigation were competent and experienced professionals, who did not appear to lack confidence in their own skills and professionalism, attention to assumptions of this kind were presumably not their first priority. Besides, Danish rules of grammar on possessive determiners are less rigid than English rules, so the possessive determiners would not necessarily have had to be included in the Danish target text for it to be grammatically correct. Consequently, I suggest that there is a more reasonable explanation why the interpreter in example 112 included these additions:

The defendant's answer, which was provided in response to a question requesting that he should state what occurred in a particular shop, consisted of four utterances. His first utterance, like his utterance in example 109, illustrated his implicit opting out of observing the second maxim of Quality ('Do not say that for which you lack adequate evidence'), by which he managed to convey the information that he was prepared to offer the required answer, i.e. to co-operate, but that he was not able to do so, since the incident occurred a long time ago. However, since he then proceeded to give the required information in his second, third and fourth utterances, these utterances served to some extent to 'cancel out' his intention to opt out. As a result, he presented an answer which seemingly provided the required information, and thus illustrated his intention to behave in a cooperative manner, but which was also ambiguous at the same time. First of all, he gave a vague description of a place the shop assistants wanted to phone, without indicating why they wanted to phone this place, and, secondly, he did not explicitly express what kind of card he was referring to. Both kinds of information were implicit in the situational context, however, and therefore capable of being inferred. Nevertheless, because of the ambiguity of his answer, the interpreter instinctively judged that the end receiver (the prosecutor) would not be able to infer speaker meaning without assistance. So, in order to make the defendant's intention available, or more easily available to the prosecutor, she included the additions explicitly expressing relationships. 
Presumably, the interpreter succeeded in conveying the defendant's intention, because the prosecutor did not question the defendant's description of the incident, but proceeded with another line of questioning.

\subsection{Additions taking up parts of questions}

Additions which took up, or repeated, parts of questions, were included when, for some reason, a question, or parts of it were not rendered to a defendant, or a witness. As a result of such an omission, the defendant, or the witness, submitted an answer to the original question which would in all probability have been perceived as not constituting the required answer, and thus as indicating their reluctance to co-operate. Consequently, as demonstrated by examples 66 and 113, the interpreters' additions resulted from their instinctive judgment that, unless these additions were included, speakers' intentions would not be fully available to end receivers who were unfamiliar with the context of the interaction.

Example 66: The addition in example 66 may be explained as resulting from the fact that the interpreter's target text substituted a direct question for an indirect question and also omitted some of the material in the source text. As a result, the defendant's affirmative yes in example 66, which constituted the required answer to the direct question in the interpreter's target text, did not constitute the required answer to the original question. So the interpreter instinctively judged that, if the defendant's answer was rendered verbatim, the end receiver (the defence counsel) would perceive it as indicating that the defendant did not intend to conform to the $\mathrm{CP}$ and the maxims. In order for speaker meaning to be fully available, therefore, she included the material which took up parts of the original question.

Apparently, the interpreter succeeded in conveying the defendant's cooperative intention, because the defence counsel did not ask for verification, but proceeded with his line of questioning. Of course, the defence counsel may have proceeded anyway, but if the defendant's intention had not been conveyed, the defence counsel would presumably have asked for verification of it, since he would have wanted the defendant to appear co-operative before the court. 
Example 113: As explained in Chapter 6 (Section 6.3.2.4.1), the addition in example 113 may be explained as resulting from the fact that the prosecutor's question was never interpreted to the defendant, since this was prevented by the defendant's continued speech, which elaborated on his previous response. However, since the defendant's elaboration provided the required answer to the prosecutor's question, the interpreter chose to proceed as if he had received the original question, and thus rendered his answer. But instinctively judging that the prosecutor would perceive the defendant's answer as not necessarily constituting the required answer, since the question was clearly never rendered to him, she included the material which took up parts of the original question in order for speaker meaning to be fully available.

Probably, the interpreter succeeded in conveying speaker meaning, because the prosecutor proceeded with his line of questioning, which may indicate that the defendant's answer was perceived as constituting the required answer.

\subsection{Additions expressing negation or confirmation}

As explained in Chapter 6 (Sections 6.2.2.4.1 and 6.3.2.4.1), these additions explicitly expressed negation or affirmation inherent in the context of a speaker's words, and they thus illustrated the reverse situation to the one in Section 7.2.4.1.4 above. Once again, as demonstrated by examples 68, 114 and 115, the interpreters' additions may be explained as resulting from their instinctive judgment that, unless these additions were included, speaker meaning would not be fully available to end receivers who were unfamiliar with the context of the interaction

Example 68: This example illustrates the witness' response to a question asked by the prosecutor, which in fact consisted of two alternative, as well as interdependent, questions, i.e. the answer to one question depending on the answer to the other question.

The witness answered by repeating parts of the second of these questions, and since she answered only this question, her utterance constituted a blatant flout of the first maxim of Quantity ('Make your contribution as informative as is required'), by which she managed to generate the 
implicature 'it did not happen always', which in fact constituted the required answer to the first question (since they were interdependent). The interpreter's strategy for conveying this implicature was to render the semantic content and explicate part of the implicature (Strategy (5), Chapter 5, Section 5.3.2.5), the negation, instinctively judging that the flout was so blatant that this strategy would be a suitable strategy for making the implicature available, or more easily available, to the end receiver (the prosecutor).

Apparently, since the prosecutor did not ask the witness to verify her intention, but proceeded with another line of questioning, the interpreter succeeded in conveying the implicature. Of course, again, the prosecutor may have proceeded anyway. However, had he not been able to infer the generated meaning, he would presumably have asked the witness to verify her intention, since he might then have perceived her answer as conveying her intention not to behave in a co-operative manner. In all probability, considering that the witness was obliged, as a witness appearing in a court of law, to answer all questions put to her, and to answer them truthfully, her apparent lack of cooperation would have resulted in the suspicion that she in fact intended to mislead the court (cf. Chapter 5, Section 5.3.1.2). The judge, the prosecutor, or the defence counsel would certainly have acted on such suspicion (cf. Chapter 3, Section 3.1.3), especially the defence counsel, seeing that this witness was the alleged victim of rape, cf. Chapter 4, Section 4.1).

Example 114: The addition in this example serves to explicate an implicature. As mentioned in Chapter 6 (Section 6.3.2.4.1), the defendant's answer constituted a blatant flout of the first maxim of Quantity (Make your contribution as informative as is required'), by which he managed to generate the implicature 'no' or 'no it is not correct'. Instinctively judging that the flout was not sufficiently blatant for the implicature, and thus the defendant's co-operative intention, to be fully available to the end receiver (the prosecutor), the interpreter explicated it (Strategy (3), Chapter 5, Section 5.3.2.3).

Since the prosecutor did not ask the defendant to verify his intention, but proceeded with his line of questioning, the interpreter apparently succeeded in conveying the implicature. Again, the prosecutor may have proceeded 
anyway. Still, had the prosecutor not been able to infer the implicature, he would probably have asked the defendant to verify his intention (cf. the discussion of example 109, Section 7.2.4.1.3 above), because he might then have perceived the defendant's answer as possibly conveying his intention to violate the first maxim of Quantity, for the purpose of misleading the court. Presumably, the prosecutor would have been interested in drawing the court's attention to this possibility (cf. Chapter 5, Section 5.3.1.1).

Example 115: In example 115, the interpreter included the affirmative yes in her rendition of the defendant's answer. This example is similar to example 66 above, in the sense that the interpreter's rendition omitted some of the material in the original utterance, which resulted in her substituting a direct question for an indirect question. Because of this omission, the defendant's answer did not quite constitute the required answer. So, once again the interpreter instinctively judged that, if the defendant's answer had been rendered verbatim, the end receiver (the prosecutor) would perceive it as indicating that he did not intend to conform to the CP and the maxims. In order for speaker meaning to be fully available, therefore, she explicated the affirmation inherent in the original utterance.

Apparently, the interpreter succeeded in conveying the defendant's intention to behave in a co-operative manner, because the prosecutor did not ask him to verify it, but proceed with his line of questioning. Of course, again the prosecutor may have proceeded anyway, but, again, had the defendant's answer been perceived as conveying the information that he did not intend to co-operate, the prosecutor would presumably have asked him to verify his intention in order to specifically draw the court's attention to his apparent unwillingness (cf. the discussion of example 114 above, and the discussion of example 109, Section 7.2.4.1.3).

\subsection{Additions completing fragmented source texts}

Finally, some additions served to complete fragmented source texts. As stated in Chapter 4 (Section 4.6.2), the interpreters in this investigation tended to complete all fragmented responses, either by taking up parts of a question, as demonstrated in example 116, or in the manner demonstrated in example 117. As explained in Chapter 4 (Section 4.6.2), in all probability, the interpreters completed such responses because they 
instinctively judged that end receivers who were unfamiliar with the context of the interaction would not be able to fully infer speaker meaning based on these responses. A discussion of examples 116 and 117 will serve to substantiate this claim.

Example 116: As explained in Chapter 6 (Section 6.3.2.4.1), the defendant's fragmented response to the defence counsel's question in example 116 constituted a blatant, and simultaneous, flout of the maxim of Relation ('Be relevant') and of the first maxim of Quantity ('Make your contribution as informative as is required). By blatantly failing to address the defence counsel's question directly, and by simultaneously providing less than the required information, the defendant managed to generate the implicature 'they were not to be returned (for settlement) when I came back', by which he also managed to imply that 'they were for my personal use'. The interpreter's strategy for conveying the implicature was to render the semantic content of the defendant's response, while simultaneously explicating part of the implicature (cf. Strategy (5), Chapter 5, Section 5.3.2.5), completing his fragmented response. Seemingly, the interpreter instinctively judged that the flout was so blatant that preserving the ambiguity of the defendant's utterance, while explicating part of the implicature (completing his fragmented response), would be a suitable strategy for making the implicature available, or more easily available, to the end receiver, the defence counsel. Based on the subsequent dialogue, the interpreter seems to have succeeded in conveying the implicature, because the defence counsel proceeded by asking the defendant to verify it. Example 117: The defendant's utterance in this example explicitly expressed his opting out of observing the first maxim of Quantity ('Make your contribution as informative as is required'), as mentioned in Chapter 6 (Section 6.3.2.4.1). Thus, he clearly indicated that he was not willing to answer the defence counsel's question, which was his right as a defendant (cf. Chapter 3, Section 3.1.3 and Chapter 5, Section 5.3.1.1). There was no obvious reason, therefore, why the interpreter would want to complete his fragmented source text, except for her instinctive judgment that his fragmented utterance would not make his explicit opting out available to the end receiver, the defence counsel.

Apparently, the defendant's intention to opt out of observing the maxim was successfully conveyed to the defence counsel, since he was not asked 
to verify his intention. In all probability, had his utterance been perceived differently, for example as intending to generate the implicature 'I am afraid of this person', or the implicature 'I am not afraid of this person', or as conveying the information that he did not intend to co-operate, the defence counsel (or the prosecutor or the judge) would have asked him to verify his intention. The defence counsel would not have wanted the defendant to appear uncooperative before the court and would presumably have attempted to prevent his utterance from conveying that impression (cf. the discussion of example 66, Section 7.2.4.1.4 above).

\subsubsection{Connective additions}

Like Obvious-information additions, Connective additions introduced a greater degree of specificity by connecting, or linking together, utterances or parts of utterances. All the additions of this subcategory explicitly expressed material categorized as inferrable information (cf. Section 7.2.4.1.3 above), that is, information implicitly present in the context of the interaction and capable of being inferred by a normal, rational human being from already evoked (implicitly or explicitly introduced) information or from other inferrable information. The additions were identified as adverbial links or conjunctions, which, adhering to their grammatical properties, were identified as either co-ordinators or subordinators. The adverbial links explicitly expressed relations of time, addition, result, and cause or reason, and the conjunctions explicitly expressed relations of addition, alternatives, contrast, condition, and result. The relations were implicit in the context of the interaction (linguistic and/or situational) and had to be available to end receivers in order for speaker meaning to be available. Hence, the contention that Connective additions, like Obviousinformation additions, were included because the interpreters' instinctively judged that the inferrable information would not be available to end receivers who were unfamiliar with the context of the interaction.

As explained in Chapter 6 (Section 6.2.2.4.2), in theory at least, a speaker's omission of connectives may constitute a flouting of the maxim of Manner ('Be perspicuous'), generating the implicature that a certain relation exists. So, also in theory, Connective additions served to explicate implicatures, and occurred because, when confronted with these implicatures, the 
interpreters adopted the strategy of interpreting the semantic content and explicating the implicature (Strategy (3), Chapter 5, Section 5.3.2.3).

A discussion of examples 70,73 and 120, which illustrate additions identified as conjunctions, and examples 121 and 124, which illustrate additions identified as adverbial links will serve to substantiate the claim that Connective additions were included in order to make speaker meaning fully available to end receivers who, because they were unfamiliar with the context of the interaction, would not be able to infer the implied relations.

Example 70: Example 70 illustrates the addition of the co-ordinating conjunction and, expressing relations of addition. This inferrable information, the addition, was implicit in the situational context and therefore available to participants. Consequently, there was no reason why the interpreter would include it, were it not for her instinctive judgment that the end receiver (the prosecutor), who was unfamiliar with the linguistic context, would not be able to infer the implied relation, and thus not able to fully infer speaker meaning.

Example 73: This example illustrates the addition of the subordinating conjunction $s a ̊$ (so), which expresses relations of result. By including this subordinator, which introduced the second part of her utterance, the interpreter explicitly expressed that the information in this part expressed the result of the situation referred to in the first part. This inferrable information was implicit in the linguistic context and therefore available to participants. Thus, again, there was no reason why the interpreter would include the inferrable information, were it not for her instinctive judgment that the end receiver (the prosecutor), who was unfamiliar with the linguistic context, would not be able to infer it, and thus not able to fully infer speaker meaning. In this example, though, the interpreter may have been additionally motivated by the fact that, in her target text, she reversed the two parts of the original utterance, whereby the implicit meaning of cause in the second part of original utterance was reversed also. (The opposite meaning of cause is result.) Perhaps, the interpreter judged that her reversal of the two parts would complicate the inferencing of speaker meaning, especially for an end receiver who was unfamiliar with the linguistic context. 
Example 120: This example illustrates the addition of the co-ordinating conjunction but, expressing relations of contrast. This inferrable information, the contrast, was implicit in the linguistic context and thus available to participants. Moreover, this example, like examples 109 and 112 above (cf. Section 7.2.4.1.3), further illustrates the defendant's implicit opting out of the second maxim of Quality ('Do not say that for which you lack adequate evidence'). His utterance was thus meant to convey the information that he intended to behave in a co-operative manner. In other words, he was prepared to provide the required information, i.e. to cooperate, but was not able to do so because he did not fully remember it. Instinctively judging, however, that the inferrable information, the contrast, and thus speaker meaning, i.e. the defendant's opting out, would not be available to the end receiver (the prosecutor), the interpreter included the addition in example 120.

In fact, the defendant continued speaking, elaborating on his answer in example 120, and once again he implicitly opted out of observing the second maxim of Quality. Presumably he feared that his initial answer did not sufficiently demonstrate his intention to behave in a co-operative manner. In any case, since he was never asked to verify his intention, it seems to have been successfully conveyed to the end receiver (the prosecutor), whether by the interpreter's target text in example 120, or by the defendant's subsequent utterance and her rendition of it.

Example 121: Example 121 illustrates the addition of the subordinating conjunction hvis (fordi), expressing positive (open) condition, in combination with the adverbial link så (then), expressing the result of the condition. Thus, as explained in Chapter 6 (Section 6.3.2.4.2), the interpreter explicitly expressed information implicitly present in the linguistic context and therefore available to participants: whether or not the second part of her utterance, introduced by så (then), expressed the required answer, depended on the condition expressed in the first part of her utterance. However, a look at the preceding dialogue, illustrated here by example 136, may provide an explanation why the interpreter chose to explicitly express this inferrable information: 


\section{Example 136:}

QD.10.17-23: $\quad$ ST-P: $\quad \varnothing$ hm hva- hvad ville du få ud af at $\varnothing$ h tage til Danmark og købe i de her falske kreditkort?

FT: $\quad$ erm wha- what would you gain by er going to Denmark and buying in these false credit cards?

TT-I: what should you obtain by going to DrenDenmark, and make purchases on these false er er visa cards?

ST-D: Sorry?

FT: Undskyld?

TT-I: what should you obtain yourself by going to Denmark? er and using these false visa cards?

As illustrated by this example, the question which preceded the defendant's answer in example 121 had to be rendered twice, upon the defendant's request. Following the interpreter's first rendition of it, the defendant responded with a Sorry?, presented with a rising intonation. According to Stenström (1994:108), this would indicate that he was either requesting repetition, or requesting clarification but signalling surprise. So, either he did not hear the question and required its repetition, or he did hear it but wanted to signal surprise at receiving it, presumably because it was not sufficiently explicit for him to perceive what was required of him (or because he was stalling, wanting time to consider his answer). Apparently, the interpreter perceived his response as implying 'your question was not sufficiently explicit', because, when she rendered it the second time, she clearly attempted to make the prosecutor's intention more explicit by including yourself, explicitly expressing the inferrable information that the question concerned only the defendant, that is, it did not refer to his codefendants also. This information was explicitly expressed by the Danish second person pronoun $d u$ in the original question, which refers to only one person, but which, when translated into the English you, may refer to more than one person. Clearly, the interpreter perceived that, since the prosecutor's questions prior to the one in example $136 \mathrm{had}$ referred to the defendant and his two co-defendants, the defendant's request for clarification concerned the issue of who you was meant to refer to. But, of 
course, it may have been the general wording which made him unable (or unwilling) to perceive what was required of him.

The interpreter was not prevented from rendering the prosecutor's question twice, though this meant that she in fact engaged in dialogue with the defendant. But as explained in Chapter 4 of this thesis (Section 4.6.4), the court interpreters in this investigation were generally not prevented from repeating or clarifying questions, upon requests from the foreign participants, nor prevented from asking clarifying questions of these participants. Presumably, in example 121, the Danish participants felt they had sufficient command of English to understand, and monitor, the dialogue, and would be able to intervene, should the interpreter engage in it to a further extent than they were prepared to tolerate.

In any case, the interpreter was apparently correct in interpreting the defendant's Sorry? as a request for clarification, because part of his answer to the prosecutor's question, the second of his three utterances, illustrated by example 121, again requested clarification, and this time explicitly: you mean wha- what would be my reward? Furthermore, since he willingly offered the required information, it would seem that he was generally bewildered (i.e. presumably not intending to stall). Having twice perceived the defendant to be expressing his uncertainty regarding what was required of him in relation to one specific issue, his personal reward, or gain, the interpreter instinctively judged that for speaker meaning to be fully available to the end receiver (the prosecutor), this uncertainty had to be available also. Consequently, she included the addition explicating the fact that whether or not the defendant's first and third utterances provided the required information depended on the condition expressed in his second utterance.

The prosecutor did not respond to the condition in the defendant's utterance, however, but merely proceeded with the line of questioning. Since the condition was explicated, the prosecutor presumably perceived it and would have responded, if required. Consequently, the prosecutor's lack of response may indicate that he perceived the defendant's utterance as having provided the required answer, and for this reason saw no point in commenting on the uncertainty. 
However, focusing on the end receiver, another interesting feature in example 121 should be noted: For some reason, the interpreter translated the defendant's second person pronoun you, presumably referring to one person only, i.e. the prosecutor who had asked the original question, into the Danish second person pronoun plural I (you) (= 'the court') which refers to more than one person. The data do not provide any clues as to why she chose this particular translation of you. Perhaps the defendant indicated non-verbally that he intended his request for the court as such, rather than for only one person, the prosecutor. Or perhaps she merely made a mistake. Or perhaps her translation was triggered by her instinctive perception that, by directing her rendition at the court in general, she would manage to draw further attention to the explicated need for clarification, which would presumably enhance the chance of achieving it: if she managed to convey to the court (i.e. the judge) that the defendant's rights were possibly being infringed, or on the point of being infringed, the court (i.e. the judge) would have to intervene in order to ensure that justice was done (cf. Chapter 3, Section 3.1.3.1). Naturally, this is pure speculation on my part. Nevertheless, since the interpreter was a competent professional and therefore familiar with courtroom procedure and the role of participants, it is not entirely unlikely that she acted in this manner, and for the purpose stated. Consequently, the fact that she directed this particular target text at the court in general certainly deserves mention, not least because it may serve to support my claim regarding her motive for including the adverbial links.

Example 124: This example illustrates the addition of the adverbial link then, expressing time (= 'after that'), by which, as explained in Chapter 6 (Section 6.3.2.4.2), the interpreter explicitly expressed information implicitly present in the linguistic context (evidenced by afterwards): the action described in the defendants second utterance was subsequent to the action in his first utterance. Being inferrable, this information was available to participants. Instinctively judging, however, that the end receiver (the prosecutor), who was unfamiliar with the linguistic and/or situational context, would not be able to infer this information, and thus not able to fully infer speaker meaning, the interpreter included the addition in example 124. 


\subsubsection{Additions explicating non-verbal information}

As explained in Chapter 6 (section 6.2.2.4.3), only one addition was identified as belonging to this subcategory. However, like all other Explicating additions, it was clearly included in order to make speaker meaning available, or more easily available, to the end receiver. Thus, in example 75, when the witness indicated a point on her neck, presumably by pointing to it with her hand or her finger, the interpreter instinctively judged that this non-verbal information would not be available to the end receiver, the prosecutor, and proceeded to explicate it.

\subsubsection{Additions explicating culture-bound information}

Again, only one addition was identified as belonging to this subcategory, and again it was included in order to make speaker meaning available, or more easily available, to the end receiver. Thus, in example 125, the explicated information, i.e. the kind of shop referred to, was implicitly present in the linguistic context of the source text, i.e. in the name of the shop. But instinctively judging that, being unfamiliar with the Danish language, the defendant would not be able to infer this information, the interpreter explicated it.

\subsubsection{Elaborating additions}

The additions of this subcategory served to elaborate on material already rendered once in an interpreter's target text, and, like Obviousinformation additions and Connective additions, they served to introduce a greater degree of specificity.

As mentioned in Chapter 6 (Section 6.2.2.5), by definition, Elaborating additions appeared to function as disguised translational repairs. However, the interesting question is not whether they functioned as such, which they clearly seemed to do, but rather why the interpreters felt that they needed these repairs. Thus, I shall argue, as stated in the beginning of Section 7.2, that these additions, like Explicating additions, were triggered by the interpreters' instinctive judgment concerning end receivers' inferencing ability, and were included for the specific purpose of making speakers' 
intentions available, or more easily available, to end receivers. A discussion of examples 77, 79 and 126 will serve to substantiate this claim.

Example 77: In example 77, the interpreter elaborated on her rendering of serious relationship. The defendant's answer in this example consisted of three utterances. His first utterance provided two pieces of information, the first piece answering the defence counsel's question and the second piece elaborating on the first piece. His second and third utterances further elaborated on this initial information. Seemingly, he intended his answer to convey the information that the reason why he and his former girlfriend, the witness in the case and the alleged victim of rape, had split up was that she wanted more than he was able to offer. Thus, by initially stating that she wanted a real serious relationship, and then elaborating on this answer, he managed to imply that she wanted 'a relationship of a permanent, steady nature, which will lead to marriage, children, etc.', and also to imply 'I was not able to offer her that', which presumably carried the further implication 'I left her, she did not leave me'.

As illustrated by her rendition, the interpreter was clearly having trouble rendering serious relationship. She initially provided a direct translation in Danish: alvorligt forhold. However, instinctively judging that this translation failed to express fully the implicit meaning of serious relationship, and thus speaker meaning, she elaborated by adding varigt forhold (lasting relationship). Clearly, she perceived that this elaboration, or her initial translation in combination with her elaboration, would serve to make the implicit meaning of serious relationship available, or more easily available, to the end receiver (the defence counsel).

Incidentally, the interpreter's target text omitted real, as well as the whole second piece of information in the defendant's first utterance, which was presumably due to her pre-occupation with serious relationship. Apparently, she still managed to convey the defendant's intention, however, because the defence counsel asked him to verify it by asking him to confirm that he moved out, and not the other way round. In all probability, had the interpreter not managed to convey the defendant's intention, the defence counsel would have questioned him further, since the information conveyed by his answer in example 77 presented evidence in 
his defence. Surely, the defence counsel would have wanted this evidence to be fully available to the court.

Example 79: In example 79, the interpreter elaborated on her rendering of samleje (intercourse). Initially, she replaced it by the neutral it, but then elaborated, adding the intercourse. Since the line of questioning had for some time centred on the actual event, the intercourse, or the alleged rape, and the word 'intercourse' had been uttered several times already by both the witness and the interpreter, the meaning of it was implicitly present in the context of the interaction, and therefore available to participants. However, immediately before the prosecutor asked the question in example 79 , the witness had stated that she was very bruised following the intercourse, the alleged rape, and there was thus a possibility that she would perceive it as referring to 'being very bruised' instead of 'intercourse', or even as referring to either. Instinctively judging, therefore, that speaker meaning would not be available to the end receiver (the witness), who was unfamiliar with the linguistic and situational context, the interpreter elaborated on her initial translation.

Example 126: Finally, in example 126, the interpreter elaborated on her rendering of unemployment benefit. The interpreter initially translated the term unemployment benefit into the Danish dagpenge, but this term may refer to two kinds of benefits: 'arbejdsløshedsdagpenge' ('unemployment benefit') or 'sygedagpenge' ('sickness benefits'). Thus, instinctively judging that speaker meaning would not be available to the end receiver (the prosecutor), unless she specified the kind of benefit referred to, the interpreter elaborated on her initial rendition, adding arbejdslфshedsdagpenge (unemployment benefit).

\subsection{Interpreter motives for including additions with significant impact}

The category of additions with significant impact comprised three subcategories: Emphasizing additions, Down-toning additions and Newinformation additions. The additions of these subcategories introduced information which may be categorized as brand-new, that is, introduced either explicitly or implicitly into the interaction for the first time. 
In Sections 7.3.1 to 7.3.3, I shall discuss the interpreters' motives for including these additions in their target texts. As regards Emphasizing additions and Down-toning additions, I shall argue that these subcategories were triggered by the interpreters' instinctive judgment concerning end receivers' ability to spot the presence of implicit information. Thus, rather than being included for the purpose of making implicit information explicit, these additions were included for the purpose of directing an end receiver's attention to the fact that information which was implicitly present in the context of the original utterance had to be inferred (in the case of Emphasizing additions), or had to be verified (in the case of Down-toning additions), in order for speaker meaning to be fully available.

New-information additions, on the other hand, were included because, for some reason, the interpreters selected interpretations of source texts which included this information, either explicitly or implicitly. However, the fact that the interpreters occasionally selected interpretations of speakers' utterances, which did not appear to match what could be derived from the originals, may likewise be explained by reference to their preoccupation with pragmatics, i.e. with building and conveying a mental model of speaker meaning.

Consequently, I shall argue that, just like the subcategories of Explicating additions and Elaborating additions, with minimal impact, all three subcategories of additions with significant impact were triggered by the interpreters' instinctive judgments of end receivers' inferencing ability. Accordingly, I shall further argue that the inclusion of the additions with significant impact in the interpreters' target texts, by further demonstrating their preoccupation with pragmatics, likewise serves to support the hypotheses presented in Chapter 1 (.Section 1.2).

\subsubsection{Emphasizing additions}

As explained in Chapter 6 (Sections 6.2.3.1 and 6.3.3.1), this subcategory of additions served to emphasize, or increase the force of, the utterance, or part of the utterance, in the source text. The emphasis was added by including one or more items which were not present in the source text, 
either explicitly or implicitly, or by stressing one or more items which were not stressed in the source text. A discussion of examples 80, 128 and 130 will serve to substantiate the claim that the additions of this subcategory served to direct the attention of end receivers to the fact that implicit information had to be inferred in order for speaker meaning to be fully available.

Example 80: In example 80, the prosecutor attempted to establish whether the defendant had had anything to drink before arriving at the apartment of the alleged rape victim and witness in the case, his former girlfriend. By the defendant's first answer just beer he managed to imply 'I was not drunk' or 'I was not very drunk', since beer is generally known to contain relatively small amounts of alcohol, by which he further managed to imply 'I am able to remember what happened', or 'I did not act irresponsibly', etc.

However, apparently disinclined to accept the defendant's ambiguous statement, the prosecutor asked for verification of his intention, which he provided in his second answer. This time he managed to imply 'I was not drunk', since regular beer and two would be perceived by most people to indicate 'a small amount of alcohol'. But the prosecutor's request for verification of the defendant's intention may have led the interpreter to perceive that this intention had not been properly conveyed. Thus, by increasing the force of the defendant's second answer, the addition was meant to direct the prosecutor's attention to the fact that information implicitly present in the context of the defendant's answer needed inferencing in order for speaker meaning to be fully available.

The interpreter's strategy may have been successful, because the prosecutor did not question the defendant's intention any further, but proceeded with another line of questioning. Of course, the prosecutor may have proceeded anyway, but, presumably, had he perceived the defendant's second answer as being equally ambiguous, he would again have asked for verification of the defendant's intention.

Example 128: In example 128, the defence counsel attempted to establish whether one of the two co-defendants had told the defendant the number of credit cards that he, the co-defendant, had brought with him to Denmark. The defendant must have provided a non-verbal, negative answer to the 
first question in this example, because the defence counsel's second question asked him to verify that he intended to deny having received this information. Because of the repetition and the change of wording, this second question managed to imply that, despite the defendant's denial, there was a possibility that he had received the information after all. In other words, it managed to convey the information that the defendant's denial was perceived as possibly providing less than the required information, and thus as constituting an intentional violation of the first maxim of Quantity ('Make your contribution as informative as is required) for the purpose of misleading the court. However, the defence counsel cannot have been interested in making the defendant appear uncooperative before the court, so there must have been another reason for her second question, i.e. she intended it to establish a fact in his defence, for example, that he was not responsible after all for some of the purchases allegedly made by him (with the aid of a stolen credit card).

Apparently able to retrieve the information from the defence counsel's second question that he was perceived as possibly providing less than the required information, and apparently wanting to indicate his willingness to behave in a co-operative manner, the defendant provided the required information, as illustrated by example 128 . His answer, which consisted of two utterances, was clearly meant to convey the information that he intended to behave in a co-operative manner. Thus, his first utterance starts with his implicit opting out of observing the second maxim of Quality ('Do not say that for which you lack adequate evidence'), I can't remember, by which he managed to convey the information that he was prepared to offer the required information, but unable to do so, since he did not remember having received it. He then proceeded to acknowledge the possibility implied by the defence counsel, but then repeated his implied intention to opt out, stating once again that he did not remember receiving the information. By repeating this claim, and by further including honestly the second time it was repeated, he managed to imply emphasis, thus emphasizing his intention to opt out. His second utterance, on the other hand, constituted a blatant flout of the maxim of Relation ('Be relevant'), since it failed to address the defence counsel's goal in asking it (to establish a fact in his defence), and also a blatant flout of the first maxim of Quantity ('Make your contribution as informative as is required'), by providing less than the required information. Thus, he managed to generate the 
implicature 'I had no reason to request this information', and also to imply that, since he had no reason to request it, there was no reason why he should have received it, so probably he did not receive it. Consequently, his first utterance both conveyed and emphasized his intention to behave in a co-operative manner, and his second utterance, the implicature, further emphasized this intention, while simultaneously serving to some extent to 'cancel out' his implicit opting out.

When rendering the implicature in the defendant's second utterance, the interpreter selected the strategy of rendering the semantic content and explicating part of the implicature (Strategy (5), Chapter 5, Section 5.3.2.5), namely the inferrable information kort (cards). Apparently, she instinctively judged that this strategy would make the implicature available, or more easily available, to the end receiver, the defence counsel. When rendering the defendant's first utterance, however, she omitted part of the semantic content, but included the addition very likely which served to increase the force of this utterance, almost to the point of eliminating the level of uncertainty in the original. The purpose of this addition was to draw further attention to the implicature: Instinctively judging that, despite having included the inferrable information kort (cards), the flout was not be sufficiently blatant and the generated implicature not sufficiently obvious for it to be apparent to the defence counsel, the interpreter included the addition in example 128 in order to direct attention to the implicature. In other words, she predicted that the apparent contrast between (in backtranslation) very likely and the utterance generating the implicature would alert the defence counsel to the fact that implicit information in the context of the defendant's answer needed inferencing for speaker meaning to be available.

Apparently, the interpreter succeeded in directing attention to the implicature, because the defence counsel proceeded by asking the defendant to verify it (cf. the discussion of example 133 below).

Example 130: This example illustrates emphasis added by stress. Subsequent to the dialogue referred to in example 108 above (cf. Section 7.2.4.1.3), the prosecutor asked a series of questions meant to establish whether the defendant knew the identity of the person who had purchased the watch referred to in example 108, with a specified, false credit card, 
and whether he was prepared to provide this information. The prosecutor's first question requested that the defendant state whether he knew who bought the watch, and, when he firmly denied this possibility, the prosecutor asked him the question in example 130. By this second question, the prosecutor managed to imply that, since the defendant had acknowledged having used this particular card, and had acknowledged having made all other purchases registered to this card (cf. the discussion of example 108), his firm denial had to constitute a lie. In other words, the prosecutor managed to imply that the defendant intended to violate the first maxim of Quality ('Do not say what you believe to be false') for the purpose of misleading the court. Instinctively judging that the defendant would not be able to detect this intention, the interpreter added the emphasis for the purpose of directing his attention to the fact that implicit information in the context of the prosecutor's question needed inferencing in order for speaker meaning to be available.

Apparently, the interpreter did not succeed in directing the defendant's attention to the implicit information in example 130, however, because he merely responded by yes, thus acknowledging only that he had used the card. In other words, he gave no indication of having detected the possible implication of the prosecutor's second question. Presumably, had he been able to fully retrieve speaker meaning, he would have responded differently in order to demonstrate his intention to behave in a co-operative manner. In any case, he continued to deny any specific knowledge of who bought the watch, though he did admit that his wallet, containing the specified, false credit card, had occasionally been in the possession of one particular codefendant, who would thus have had the opportunity to use the card.

\subsubsection{Down-toning additions}

This subcategory of additions served to down-tone, or decrease, the force of the original utterance, or part of the original utterance (cf. Chapter 6, Sections 6.2.3.2 and 6.3.3.2). Down-toning was achieved by including one or more items in the interpreter's target text which were not present, explicitly or implicitly, in the source text. As illustrated by the examples in Chapter 6 (Sections 6.2.3.2 and 6.3.3.2), Down-toning additions appeared to function as hedges. They were included whenever an interpreter was 
unable to select a particular interpretation of an ambiguous utterance as representing the speaker's intention. The additions were thus meant to direct end receivers' attention to the ambiguity of original utterances, and to the fact that implicit information required verification in order for speaker meaning to be available. A discussion of examples 86, 89 and 132 will serve to substantiate this claim.

Example 86: This example illustrates the down-toning of the witness' statement expressing her perception of the defendant's appearance and frame of mind when he arrived at her apartment on the night of the alleged rape. Her statement was provided in response to the prosecutor's general question concerning the events on that particular night, and it consisted of three subsequent utterances, the second and third utterances provided immediately after the interpretation of the previous utterance. Example 86 illustrates her third utterance, which consists of four parts, the first three parts presenting her assumptions concerning the defendant's whereabouts prior to coming to her apartment on the night in question, and the fourth part presenting two pieces of information about his appearance which served as evidence in support of her assumption, almost to the point of eliminating the expressed degree of uncertainty. So, despite initially expressing uncertainty, her utterance was seemingly meant to convey the information that the defendant had indeed been drinking before arriving at her apartment.

However, when rendering the utterance, the interpreter included the adverb maybe in her rendition of the first part of the original utterance, thus increasing the expressed degree of uncertainty in that part, and she omitted one of the pieces of information serving as evidence in support of the assumption in the first part. The total effect was to decrease the force of the original utterance.

Presumably, the interpreter missed one of the two pieces of information about the defendant's whereabouts, and consequently failed to perceive to what extent the assumption concerning the defendant's whereabouts was 'cancelled out'. It thus seems likely that, perceiving that the first three parts of the witness' utterance was meant to convey a degree of uncertainty that was higher on the scale than was actually intended, she perceived the witness to be attempting to mitigate her presented claim concerning the 
defendant's whereabouts, in order to comply with the CP (behave in a cooperative manner) as well as the rules of law (answer the question and answer it truthfully).

In any case, the interpreter perceived two possible interpretations of the witness' utterance, but was unable to select either of them as representing her intention: (1) she intended to convey the information that the defendant had been drunk when arriving at her apartment, or (2) she intended to convey the information that she believed that the defendant had been drunk when arriving at her apartment, but since she did not have sufficient evidence of this fact she needed to mitigate her claim. The interpreter also instinctively judged that the end receiver (the prosecutor) would not be able to perceive both of these interpretations. Consequently, in order to direct his attention to the fact that the witness possibly intended to mitigate her claim and that her intention therefore needed verification, the interpreter included the addition and thus increased the degree of uncertainty expressed in the first part of the witness' utterance. The fact that the interpreter's addition, maybe, also seems to constitute a translational repair (evidenced by her repetition of $h a d$ ), serves to further support this claim, since this fact provides evidence of the significance that she attached to it.

Apparently, the interpreter's strategy was successful, because the prosecutor proceeded by asking the witness to clarify whether she in fact intended to convey the information that the defendant had been drunk.

Example 89: The defence counsel's utterance in this example was spoken during the pre-trial consultation between the defence counsel and the defendant prior to the mock trial. As explained in Chapter 4 (Section 4.1.1), the ethical guidelines stipulating interpreter performance in the courtroom apply in this setting also.

In example 89, the defence counsel was explaining trial procedure to the defendant and his utterance was subsequent to one explaining to the defendant that he would be asked to state whether he would plead guilty or not guilty to the charge. The defence counsel's utterance actually functioned as an indirect request, capable of conveying two kinds of intentions: (1) Considering the defence counsel's familiarity with the case (cf. Chapter 4, Section 4.1), he presumably intended to convey the information that he was aware that the defendant intended to plead not 
guilty, but, since he had been informed of this fact by someone other than the defendant (the case description), he now needed him to confirm it. In other words, he could have replaced his utterance by 'please confirm your intention to plead not guilty', or by a similar utterance. (2) On the other hand, the defence counsel may have intended to convey the information that he was not certain his understanding was correct, and that he needed the defendant to acknowledge whether it was correct or not correct. In that case, he could have replaced his utterance by 'please tell me if my understanding is correct', or by a similar utterance, which would further imply 'please tell me how you plead'.

It is quite conceivable that the interpreter perceived both of these interpretations of the defence counsel's utterance, but that she was unable to select either one as representing his intention. However, instinctively judging that the defendant would not be able to perceive that more than one interpretation of speaker meaning was possible, she included the addition in order to direct the defendant's attention to the fact that verification of the defence counsel's intention was required in order for speaker meaning to be fully available. The defendant did not appear to experience any doubt concerning the defence counsel's intentions, however, because he did not ask for verification but straight away interpreted the question as requesting confirmation of his intention to plead not guilty. Presumably, he assumed that the defence counsel was fully aware of his intention, and therefore not likely to suggest that he intended to plead differently.

Example 132: This example from the data collected at the authentic trial reflects the interesting fact mentioned in Chapter 6 (Section 6.3.3.2) that the Down-toning additions identified in these data occurred in renditions in Danish only. However, further study of this phenomenon amounting to any kind of definite conclusion will require a different kind of data than is available for this investigation, and accordingly no such study will be attempted here. Nevertheless, considering the above contention that Downtoning additions were included when the interpreters were unable, for some reason or another, to select a particular interpretation of a speaker's utterance as representing his intention, it is a fair presumption that this interpreter found the processing of utterances in English more complicated than the processing of utterances in Danish, her mother tongue (cf. section 7.2.2. above). 
In order to explain the addition in the interpreter's rendition of the defendant's answer in example 132, it may be necessary, however, to examine the preceding dialogue, which, incidentally, occurred shortly after the dialogue in example 136 above (cf. Section 7.2.4.2):

\section{Example 137:}

QD.11.3-20: $\quad$ ST-P: førte du regnskab over det?

FT: did you keep an account of this?

TT-I: did you make any calculation or any er statements of of the amounts that you purchased?

ST-D: I, I I wrote, I mean, I I did not but I usually do. at the end of the:. when I finish all the:.

FT: $\quad$ jeg, jeg jeg skrev, altså, det det gjorde jeg ikke men det gør jeg som regel. ved afslutningen af; når jeg er fardig med alle:

TT-I: $\quad \varnothing \mathrm{hm}$, altså, jeg gjorde det ikke men men det gør jeg normalt når jeg er færdig med at $\underline{k ø b e \text { ind. }}$.

Back-translation: erm, I mean, I did not but but I usually do when I have finished shopping.

ST-D: I know approximately. I know approximately.

FT: jeg ved cirka. jeg ved cirka.

TT-I: $\varnothing \mathrm{h}$ men jeg ved cirka hvor meget.

Back-translation: $\quad$ er but I know approximately how much.

ST-P: okay, hvad mener du med normalt, har du gjort det her før?

FT: okay, what do you mean by normally, have you done this before?

TT-I: er what do you mean by normally, have you done this before?

As illustrated by this example, the defendant presented a fragmented and rather hesitant answer to the prosecutor's question regarding whether or not he kept account of the purchases he made. The answer consisted of five 
utterances. The repetitions and the fact that he did not fully complete any of the five utterances clearly indicated that he was having trouble providing the required answer, and accordingly, had his answer been rendered verbatim, it might have been perceived as intending to violate the first maxim of Quantity ('Make your contribution as informative as is required'). However, his answer was not rendered verbatim. Perhaps the interpreter accepted some of the responsibility for the state of his answer, since she had presented him with a rather hesitant rendition of the prosecutor's question, which may or may not have made it difficult for him to perceive fully what was required of him. On the other hand, she might have completed his fragmented response simply to avoid producing a fragmented target text (cf. the discussion of examples 116 and 117, Section 7.2.4.1.6 above).

However, since items were missing in the defendant's utterance, the interpreter had to infer his intention, based on the linguistic context. Presumably, the missing item at the end of his third utterance did not provide any difficulty, since purchases was the logical choice. Similarly at the end of his fourth and fifth utterances (the fifth being a repetition of his fourth utterance), where how much was the logical choice. However, the missing item at the end of his second utterance was another matter, since day and trip both seemed logical choices. However, day would imply that the defendant had intended to keep accounts at the end of every day, whereas trip would imply 'habit', or 'normal procedure', and thus further imply that he had committed a similar offence at least once before. Rather than select a particular item as representing the defendant's intention, therefore, the interpreter preserved the degree of ambiguity in her target text, since it made no explicit mention of either day or trip, but was capable of implying both.

Apparently perceiving the ambiguity and selecting the interpretation that the defendant's utterance was meant to convey that he had committed a similar offence, or offences, before, a fact which required verification, the prosecutor asked the second question in example 137 above (rendered by the interpreter as er what do you mean by normally, have you done this before? Apparently, the defendant perceived the prosecutor's intention, because he presented the answer illustrated by example 132, which, by firmly denying the implication of 'normal procedure', further denied the 
possibility that he had committed a similar offence, or offences, at some earlier time. Furthermore, since his firm denial was followed by a statement which actually served to provide a second answer to the prosecutor's initial question concerning the accounts, it served also to emphasize that answer.

In fact, the defendant's answer in example 132 consisted of three utterances, and it turned out to be just as ambiguous as his first answer. Thus, two interpretations of his first two utterances were available: (1) that he had intended to keep accounts, or (2) that he had merely thought about keeping accounts, i.e. that he had never actually kept them. On the other hand, his third utterance constituted a blatant flout of the first maxim of Quantity (cf. above), by which he managed to generate the implicature 'I did not have an opportunity to keep accounts', and also to imply that this was the reason why he did not keep them. The implicature thus partly cancelled out the second interpretation above, but only partly, since it did not fully eliminate the possibility that the defendant had not reached beyond merely thinking about keeping accounts.

When rendering these three utterances, the interpreter's strategy for rendering the implicature was to interpret the semantic content and explicate the implicature (Strategy (3), Chapter 5, Section 5.3.2.3). However, because all three utterances were ambiguous, the defendant's answer required considerable inferencing in order for his intention to be available. So, perceiving that the implicature only partly eliminated the ambiguity of his two previous utterances, the interpreter instinctively judged that it would have to be explicated in order for speaker meaning to be available, or more easily available, to the end receiver (the prosecutor). Nevertheless, since the implicature only partly eliminated the ambiguity of the defendant's two other utterances, which meant that there were still two possible interpretations of these utterances, she included the addition in example 132. In other words, instinctively judging that the prosecutor would not be able to detect both interpretations, she intended her addition to draw attention to the fact that the defendant's intention needed verification in order for speaker meaning to be fully available.

The prosecutor proceeded by asking whether the defendant had kept receipts from the different purchases, so it seems that he attempted to establish whether the defendant had in fact intended to keep accounts. This 
may indicate that the prosecutor perceived the ambiguity of the defendant's utterance, and thus that the interpreter succeeded in conveying it.

\subsubsection{New-information additions}

As explained earlier (cf. Section 7.3 above), these additions were included because the interpreters selected interpretations of source texts which included this information, either explicitly or implicitly. A discussion of examples 90, 92 and 133 will serve to substantiate the claim that Newinformation additions were likewise linked to the interpreters' preoccupation with pragmatics.

Example 90: This example illustrates the witness' answer to a question from the defence counsel asking her to confirm or deny the defendant's allegation that she had asked him to come to her apartment on the night of the alleged rape, because she wanted to talk to him about some problems she was experiencing at work. As illustrated by example 90, the first part of the witness' utterance was initiated by a firm denial, followed by information which elaborated on this denial, and the second part of her utterance conveyed information which further elaborated on the denial and the elaborating information in the first part. Thus, the witness' firm denial was emphasized by all subsequent information. Moreover, this information constituted a blatant flout of the second maxim of Quantity ('Do not make your contribution more informative than is required'), by which the witness managed to generate the implicature 'he was lying', implying also that the fact that she was experiencing no work-related problems, emphasized by her reference to her impending promotion, ought to prove him a liar. However, the first part of her utterance was ambiguous, because her use of the present continuous tense was capable of implying either 'the present time', or 'generally'. Presumably she intended to imply 'generally', though, because had she intended to imply 'the present time', she would have intended to imply also that the situation used to be the reverse. This would have conveyed the information that the defendant had not been lying after all, which cannot have been her intention.

Apparently, the interpreter perceived the ambiguity of the witness' statement and selected to preserve it by rendering the firm denial, and then 
the subsequent information by rendering the semantic content while explicating part of the implicature (now) (Strategy (5), Chapter 5, Section 5.3.2.5). Thus, it seems that she perceived the witness' use of the present continuous tense to imply 'at the present time', and expressed this information explicitly by including the time adverb now in her rendition of the witness' first utterance (omitting at the moment in her rendition of the second utterance, by mistake, or perhaps because she perceived this information to be implied by I'm in line for).

Interestingly, the defence counsel did not challenge the witness' utterance, nor ask for verification of the implicature, despite the fact that the specification of now may have conveyed the information that his client was lying. Perhaps this was due to the interpreter's addition: the defence counsel may have perceived the addition as effectively eliminating the effect of the implicature, and possibly also as carrying the implication that the witness was untrustworthy.

Example 92: Like example 89 above, this example illustrates a question from the defence counsel during the pre-trial consultation, which occurred prior to the mock trial (cf. Chapter 4, Section 4.1.1). The defence counsel had informed the defendant that he was charged with having used a knife to threaten the alleged victim, and had asked some questions relating to this fact, without specifying the kind of knife referred to or how he had used it. Following this, the defendant was presented with the question in example 92, which requested confirmation of information supplied earlier. Furthermore, by the degree of non-explicitness (cf. example 63, Section 7.2.4.1.3 above), though the information 'that evening' was implicit in the situational context (cf. Chapter 6, Section 6.2.3.3), the question managed to imply 'any kind of knife, e.g. a bread knife, or a carving knife, or a pocket knife, etc.', and 'anywhere, e.g. in your pocket, or in your hand, or in your bag, etc.' However, when rendering it, the interpreter added in your hand, thus explicating the implied information 'anywhere', moving from the general to the specific, but preserving 'any kind of knife'. There was no indication in the context of the interaction at this stage (later, during the trial itself, the witness would explain that the defendant had held the knife in his hand) why the interpreter would select this interpretation of the source text. However, she had seen the case description (cf. Chapter 4, Section 4.1), so she must have been aware that the defendant had allegedly 
fetched a bread knife in the kitchen of the witness' apartment and placed it against her throat, thus presumably holding it in his hand though the case description did not specify this fact. Besides, it is a fair conclusion that an individual who threatens another individual with a knife will hold it in his hand, as opposed to, for example, keep it in his pocket, in order for the threat to be effective. Thus, her addition may be explained as resulting from the degree of non-explicitness in the original question, which left room for her interpretation that the knife was in the defendant's hand based on her knowledge of the alleged events and the general assumption about knives in threatening situations. In any case, since the defendant did not challenge the question, but merely presented a firm denial, the defence counsel, who proceeded with another line of questioning, was apparently unaware that his denial was presented in response to a question carrying this new information.

Example 133: The question in this example occurred immediately after the interaction in example 128 above (cf. Section 7.3.1), and just like the question in example 128, the question in example 133 was one of a series of questions meant to establish events leading up to the defendant's and the two co-defendants trip to Denmark, which they allegedly made in order to make a number of purchases with the use of false credit cards (cf. Chapter 4, Section 4.2). In example 133, the defence counsel asked the defendant to verify the implicature generated by his second utterance in example 128 (cf. the discussion of this example in Section 7.3.1 above), and information conveyed by the implicature, namely that he and his co-defendant had not talked much about the purpose of their trip to Denmark. By the degree of non-explicitness (cf. above), her question was capable of implying that they did not discuss this 'at any time', or 'at a specific time', for example 'before travelling to Denmark', or 'after coming to Denmark'.

Upon the defendant's request, Sorry?, the interpreter had to render the prosecutor's question twice, and just as was the case in example 136 above (cf. Section 7.2.4.2), she was not prevented from doing so (cf. Chapter 4, Section 4.6.4). Apparently, she again perceived the defendant's response to be a request for clarification of the prosecutor's intentions, i.e. as implying 'your question was not sufficiently explicit', because when she rendered the question the second time, she seemingly attempted to make it more explicit, by substituting talk very much about with discuss and about the 
purpose of your travel with what you were going to Denmark to do, thus including the inferrable information to Denmark.

Both of the interpreter's renditions of the original question included the same kind of brand-new information, but it was made more explicit in her second rendition. In other words, both renditions included brand-new information which was capable of implying 'before you left the UK', and thus also 'before travelling to Denmark'. Consequently, the interpreter perceived the defence counsel's question as carrying this specific information, rather than the more general information 'at any time'. Her selection of this interpretation of the prosecutor's intention may be explained by reference to the fact that the defence counsel started this particular line of questioning by requesting information about events prior to the defendant's and the co-defendants' trip to Denmark, and then proceeded to ask questions which by their degree of non-explicitness were capable of implying 'any time', but which did not otherwise indicate that he was no longer referring to a specific time, namely the time before the defendant and his co-defendants left the UK for Denmark. Perhaps, as stated above, the defence counsel intended by the degree of nonexplicitness to leave room for multiple interpretations, attempting in this way to enhance his chances of eliciting an affirmative response from the defendant. In any case, the defendant's answer to the question in example 133 did not refer to the brand-new information, and thus the defence counsel was presumably unaware that the defendant was responding to a question containing this information.

\subsection{Strategies for conveying implicature}

Before concluding this chapter, I shall return once again to the issue of implicature and the court interpreters' strategies for conveying implicatures. In Chapter 5 (Section 5.3.2), I suggested eight strategies that a court interpreter may adopt for conveying implicature. As revealed by the categories and subcategories of additions in Chapter 6 and the discussion in this chapter, the interpreters in this investigation adopted at least three of these strategies for conveying some of the implicatures they encountered. These were (cf. Chapter 5, Section 5.3.2): 
(3) Interpret the semantic content and explicate the implicature.

(5) Interpret the semantic content and explicate part of the implicature.

(6) Interpret part of the semantic content and explicate part of the implicature.

Of course, this investigation did not centre on implicature alone, but on the interpreters' pre-occupation with pragmatics in general. Moreover, I did not systematically register implicatures. I only registered implicatures which occurred in connection with one or more interpreter additions, and then only when these additions were categorized as having either minimal or significant impact. Consequently, the registered number of implicatures was relatively small and therefore not sufficient to provide any definite evidence concerning court interpreters' choice of strategies for conveying them to end receivers. Nevertheless, some interesting facts did emerge:

The interpreters adopted strategies which either explicated all or part of an implicature. Thus, it seems that their choice of strategies was linked to their preoccupation with pragmatics, i.e. the retrievability of speaker meaning. Apparently, the interpreters instinctively judged that flouts are generally not sufficiently blatant for end receivers who are unfamiliar with the linguistic and/or situational context to be able to detect and infer the generated implicatures.

As mentioned in Chapter 5 (Section 5.3.2.9), two of the three strategies, Strategies (3) and (5), together with Strategy (1), were considered the only really plausible strategies, since they did not omit part of the semantic content, but preserved the ambiguity of the original utterance, while, in the case of Strategies (3) and (5), explicating all or part of the implicature. The fact that the interpreters adopted these two strategies may serve to support this claim. Besides, the fact that Strategy (1) was not adopted may be explained by reference to the interpreters' preoccupation with pragmatics, i.e. with ensuring the retrievability of speaker meaning. Presumably, the interpreters did not consider adopting a strategy which fully preserved the ambiguity of the original utterance. 
The third adopted strategy, Strategy (6), as well as Strategies (2) and (4), also seemed plausible, though rather risky, since they involved leaving out parts of the semantic content; interpreters are assumed to avoid adopting strategies which omit semantic content, since the omission could result in the loss of all kinds of valuable information. However, the fact that Strategy (6) was adopted may serve as evidence that, though risky, at least one (and possibly all) of these strategies may after all be plausible. Perhaps the interpreters would want to avoid adopting Strategy (2), though, for the reasons outlined in connection with Strategy (1) above.

Interestingly, Strategy (6) was adopted for conveying a flout of the second maxim of Quantity, which had resulted in a long, ambiguous utterance. Perhaps this indicates that strategies which leave out part of the semantic content tend to be adopted for conveying implicatures generated by lengthy utterances, as opposed to strategies which do not leave out some of this content. On the other hand, an interpreter's omission of part of the semantic content in an utterance as long and ambiguous as the one in example 108 (cf. Section 7.2.4.1.3 above) may have been inadvertent, rather than deliberate.

Finally, as was also pointed out in Chapter 5 (Section 5.3.2.9), the last two of the eight strategies, Strategies (7) and (8), represent such an extreme form of non-compliance with the ethical rules that interpreters are assumed to avoid adopting these strategies altogether. It is hardly surprising, therefore, that I registered neither of these strategies in this investigation.

\subsection{Conclusion}

In this chapter I have discussed the court interpreters' motives for including the identified additions in their renditions of speakers' originals. The discussion revealed that the subcategories of additions with minimal, potential impact may be attributed to the special nature of the interpreting process, rather than to any specific motive on the part of the interpreters. However, the remaining subcategories with minimal impact, the subcategories of Explicating additions and Elaborating additions were included for a specific purpose, namely that of making speakers' intentions available, or more easily available, to end receivers. Consequently, these 
subcategories were triggered by the interpreters' instinctive judgments that end receivers who were unfamiliar with the context of the interaction would not be able to fully infer speaker meaning, unless implicit information was made explicit, or partly explicit.

As regards the subcategories with significant impact, the first two subcategories, the subcategory of Emphasizing additions and the subcategory of Down-toning additions, were included for the purpose of directing an end receiver's attention to the fact that information implicitly present in the context of the original utterance had to be inferred (in the case of Emphasizing additions) or verified (in the case of Down-toning additions) in order for speaker meaning to be fully available. Consequently, the two subcategories of additions were triggered by the interpreters' instinctive judgment that end receivers who were unfamiliar with the context of the interaction would not be able to spot the presence of implicit information, though they would be able to infer it once it was spotted.

Finally, the remaining subcategory of additions with significant impact, the subcategory of New-information additions, was included because the interpreters selected interpretations of source texts which included this information, either explicitly or implicitly. Thus, the presence of this subcategory of additions could not be explained by reference to the interpreters' instinctive judgments concerning end receivers' inferencing ability, or their ability to spot the presence of implicit information. However, the interpreters' motive for including these additions was likewise linked to their preoccupation with pragmatics, i.e. with building and conveying a mental model of speaker meaning to end receivers.

I have also commented in this chapter on the eight strategies for conveying implicature which I suggested in Chapter 5 (Section 5.3.2). As it turned out, the interpreters in this investigation adopted three of the eight strategies available to them. The data were not sufficient to present any clear evidence as to why the interpreters' adopted these strategies. Nevertheless, the choice of strategies indicated that the interpreters instinctively judged that end receivers who were unfamiliar with the context of the interaction would not be able to detect and infer implicatures. 
Thus, it seems plausible that their motive for choosing the three strategies was linked to their preoccupation with pragmatics.

In summation, therefore, this chapter is seen as presenting evidence which supports the hypotheses presented in Chapter 1 . The next chapter, Chapter 8 presents these hypotheses again and concludes on the findings presented in Chapters 6 and 7. 


\section{Conclusion}

This chapter presents a summary of the current investigation and discusses its results, in Section 8.1. Section 8.2 discusses some research perspectives.

\subsection{Research summary and discussion}

The point of departure for the investigation in this thesis was the conflict between the perception of legal systems of the court interpreter as a 'translating machine', simply transferring language products from one language into another, and the observable reality of the interpreting situation. Based on previous research and my own experiences as a practising court interpreter, I hypothesized (1) that the actual behaviour of court interpreters would provide evidence of a preoccupation with pragmatics, i.e. with building a mental model of speaker meaning and with conveying this mental model to end receivers, and (2) that, as a result of this preoccupation, their target texts would contain a variety of additions. In other words, I hypothesized that the primary objective of court interpreters is successful interaction; they are aware that in order for this objective to be achieved, interactants will have to fully understand each other's intentions. The interpreters instinctively judge that providing merely verbatim translations of source texts will not result in such understanding, since end receivers who are unfamiliar with the context of the interaction will not be able to fully infer speaker meaning without assistance. As a result of their instinctive judgment of end receivers' inferencing ability, the interpreters adopt a strategy which will ensure the retrievability of speaker meaning, and one consequence of such a strategy is that their target texts will contain a variety of additions.

By establishing these hypotheses, I further hypothesized that the court interpreters in my investigation would be prepared to violate ethical guidelines, and more specifically the principle of Accuracy and Completeness, which instructs them to deliver absolute verbatim versions of originals. Thus, my hypotheses dispute the view of the Danish legal system, reflected in the guidelines, i.e. that of a 'translating machine'. Consequently, throughout this thesis, I have argued that Danish court 
interpreters are not mere translating devices, but play a much more active role in proceedings than prescribed by the ethical guidelines.

In order to test the hypotheses, I have attempted to answer four specific research questions, namely (1) whether the target texts of the court interpreters in my investigation would include a variety of additions, (2) whether additions identified in their target texts could be categorized, (3) whether established categories would indicate the interpreters' motives for including additions in their target texts, and (4) whether the interpreters' motives, if indicated by the established addition categories, could be linked to a preoccupation with pragmatics on their part.

The first research question was answered by conducting a sourcetext/target-text comparison of consecutively interpreted question-answer dialogues in a courtroom setting. I recorded the dialogues in two trials in Danish district courts, a mock trial and an authentic trial, and then transcribed them for the purpose of analysis. I collected data at the mock trial first, and thus submitted these data to analysis first, but I employed the exact same specified methodology in the analyses of both kinds of data. The source-text/target-text comparison identified a variety of additions in the interpreters' target texts.

I answered the second research question by registering the identified additions according to whether or not they were judged to have an impact on the semantic and/or pragmatic content of the source text. This method established three main categories and various subcategories. Additions which did not add to the semantic and/or pragmatic content of the source text were judged to have no impact. The additions of this category were identified as features typical of normal conversation, and their presence in the interpreters' target texts was presumed to be attributed to the special nature of the interpreting process, requiring fast, almost instantaneous production and understanding in two different languages. Thus, these additions were not considered relevant for the purpose of this investigation, but were identified and categorized purely for elimination purposes.

Additions which added to the semantic and/or pragmatic content were judged to have an impact, and this impact was judged to be either minimal or significant. Thus, additions which explicitly expressed information 
which was implicitly present in the context of the interaction (linguistic and/or situational), or which elaborated on items which had already been rendered once in an interpreter's target text, were judged to have minimal impact; while additions which introduced information categorized as brand-new, i.e. introduced into the interaction for the first time, either explicitly or implicitly, were judged to have significant impact. Finally, some additions were judged to have potential impact only, but this potential impact was judged to be minimal, and consequently these additions were registered as belonging to the category of additions with minimal impact.

Again, since I collected data at the mock trial first, the categories and subcategories were established based on an analysis of these data, but were tested through an analysis of the data from the authentic trial. Generally, the same categories and subcategories of additions were identified in both kinds of data, which served to support the validity of the established categories and subcategories.

The third and fourth research questions were answered by applying H.P. Grice's (1975) theory of conversational implicature, which provides a framework for analysing how hearers infer speakers' intentions, to the investigated interaction. Having examined relevant aspects of Grice's theory, I set up a basic model accounting for conversational implicature in question-answer dialogues in criminal proceedings in Danish district courts, and also presented and discussed eight strategies that court interpreters may be assumed to resort to when confronted with implicature in the speech of a primary speaker. I also discussed the implications of the inference process for court interpreters, applying Bell's (1984) notion of audience design to the investigated interaction, and I concluded that the court interpreters in my investigation could be assumed to design their target texts primarily for addressees. Then, matching Grice's theory and the various assumptions to the established categories and subcategories of additions, I was able to reach certain conclusions regarding the motives of the court interpreters in my investigation for including the identified additions in their target texts. My discussion of motive thus centred on the interpreters' preoccupation with pragmatics.

I did not discuss the court interpreters' motives for including additions with no impact, for the reasons outlined above, but focused on the two other 
main categories. I argued that, with the exception of additions with potential impact which, like additions with no impact, could be attributed to the special nature of the interpreting process, additions with minimal impact were included for the specific purpose of making speakers' intentions available, or more easily available, to end receivers. In other words, these additions were triggered by the interpreters' instinctive judgments concerning the inferencing ability of end receivers who were unfamiliar with the context of the interaction, and they were included in order to make implicit information explicit, or partly explicit.

I further argued that additions with significant impact were included for a similar reason. Thus, I argued that two of the subcategories of additions with significant impact, Emphasizing additions and Down-toning additions, were included for the purpose of directing an end receiver's attention to the fact that information implicitly present in the context of the original utterance had to be inferred (in the case of Emphasizing additions) or verified (in the case of Down-toning additions) in order for speaker meaning to be fully available. Consequently, these two subcategories of additions were likewise triggered by the interpreters' instinctive judgment concerning the inferencing ability of end receivers who were unfamiliar with the context of the interaction. In other words, the interpreters included these additions based on their instinctive judgment that end receivers would not be able to spot the presence of implicit information, though they would be able to infer it once it was spotted. As regards the last subcategory of additions with significant impact, Newinformation additions, I was not able to explain this by reference to the interpreters' instinctive judgment of end receivers' inferencing ability, but I was still able to link the interpreters' motives for including them to their preoccupation with pragmatics.

Consequently, following my discussion of interpreter motives, I was able to conclude that the presence of additions in the target texts of the court interpreters in my investigation could be explained by reference to the interpreters' preoccupation with matching speakers' utterances to relevant aspects of context and with ensuring the retrievability of speaker meaning. Thus, I was able to conclude also that the actual behaviour of the court interpreters provided evidence of a preoccupation with pragmatics, and, in turn, that my findings served to support the hypotheses presented above. 
Further support for my conclusion that the actual behaviour of the court interpreters provided evidence of a preoccupation with pragmatics was presented by the various examples of implicature that I found in the data. I did not systematically register implicatures, since I only registered implicatures that occurred in connection with one or more interpreter additions having either minimal or significant impact. However, the court interpreters adopted strategies for conveying flouts which either explicated, or partly explicated, the generated implicatures. Thus, it seems that their choice of strategy for conveying implicature was likewise triggered by their instinctive judgment concerning the inferencing ability of end receivers who were unfamiliar with the context of the interaction. In fact, three of the available eight strategies were adopted by the interpreters, which may support the plausibility of these strategies.

Finally, three of the four kinds of interpreter behaviour that I observed in the collected data also serve to support my conclusion that the court interpreters were preoccupied with pragmatics: (1) the interpreter who assisted the defendant who did not have English as a mother tongue invariably corrected his grammatical errors, (2) all three interpreters completed fragmented source texts as a rule, and (3) all three interpreters engaged in dialogue with the foreign participants who requested repetition or clarification of source texts in Danish. The three kinds of behaviour demonstrated not only that the interpreters were preoccupied with pragmatics, but also that they were prepared to violate ethical guidelines in order to achieve their objective of successful interaction, seeing that their behaviour constituted a non-compliance with the principle of Accuracy and Completeness.

In conclusion, therefore: The actual behaviour of the court interpreters in the investigation presented in this thesis did indeed show evidence of a preoccupation with pragmatics. The court interpreters did not function as mere translating devices, but participated actively in the process of negotiating meaning in order to reach their primary objective of successful interaction. 


\subsection{Research perspectives}

Evidently, the investigation in this thesis did not provide sufficient evidence to reach generalized conclusions regarding the work of court interpreters. The difficulty of getting access to viable data, an issue wellknown in interpreting research and discussed also in this thesis, prevents investigations leading to any kind of generalized conclusion. Consequently, when investigating dialogue interpreting, i.e. interpreter-mediated communication in face-to-face interaction, researchers such as myself can only aim for evidence of typical patterns of behaviour, and then hope that others will achieve the same or similar evidence, so that one day all the evidence will add up to some kind of generalized conclusion. In this way, researchers, myself included, have profited, and may continue to profit, from building on the findings of previous studies.

When I examined previous studies in dialogue interpreting, including court interpreting, my attention was drawn to the four studies presented and discussed in Chapter 2 of this thesis, whose findings made for the tentative conclusion that the primary objective of court interpreters is successful interaction. I submit that my investigation has strengthened this tentative conclusion to the effect that there is now a strong indication that court interpreters (and dialogue interpreters in other settings, cf. e.g. Wadensjö $1992,1995,1997,1998)$ are in fact active participants in a talk exchange. The objective of successful interaction apparently tends to override attention to official guidelines and/or the perception of primary speakers, even in a controlled and agenda-bound setting such as a court of law.

To what extent court interpreters contribute to the success of the interaction by conveying speaker meaning will have to be an issue for future investigations. I have attempted some tentative conclusions in this thesis, but I have no firm evidence regarding whether or not the interaction would have proceeded differently, had the court interpreters complied fully with ethical guidelines and delivered verbatim translations throughout, plus refrained from complying with participants' requests for repetition or clarification. 
However, based on previous investigations to-date, I conclude that the presence of an interpreter no doubt influences proceedings to some extent (cf. the four studies presented and discussed in Chapter 2). But more issues arise: For example, to what extent, if any, does an interpreter's presence influence the production of source texts? Or to what extent, if any, does her presence influence the role-play of primary speakers? Both questions are relevant and attempts to answer them may provide significant insight into the work of court interpreters.

Naturally, many other issues in court interpreting deserve further study, for example the issues referred to earlier in this thesis, e.g. the negotiation of face, role conflict, and in-group loyalties. In Denmark, for example, authorized interpreters usually share language and culture with court officials, and this may influence their performance as well as defendants' attitudes towards them.

Implicature also deserves further investigation. In this thesis, I have suggested eight strategies that court interpreters may resort to when confronted with implicature in the utterances of primary speakers and suggested that some may be more plausible than others. I have also demonstrated that the court interpreters in my investigation adopted at least three of these strategies for conveying implicature. Further study of how court interpreters, and dialogue interpreters in other settings, deal with floutings may provide firm evidence of the plausibility of these strategies.

Finally, in order for research projects to provide the kind of insights that researchers, including myself, and other interested parties wish for, the difficulty of getting access to data will have to be overcome. I sincerely hope, therefore, that the contents of this thesis will demonstrate to courts that research projects will not necessarily obstruct proceedings or violate the rights of participants, and that this will in turn facilitate more studies of court interpreting in the coming years. 



\section{References}

Adelswärd, V. 1989. Laughter and Dialogue: The Social Significance of Laughter in Institutional Discourse. Nordic Journal of Linguistics, 12, $107-$ 136.

Anderson, B. 1976. Perspectives on the Role of Interpreter. In R.W. Brislin, ed., Translation: Applications and Research. New York: Gardner Press, 208-228.

Baaring, I. 2001. Tolkning - hvor og hvordan. Copenhagen: Samfundslitteratur.

Barik, H.C. 1971. A Description of Various Types of Omissions, Additions and Errors of Translation Encountered in Simultaneous Interpretation. Meta 16(4), 199-210.

Barik, H.C. 1972. Interpreters Talk a lot, Among Other Things. Babel 18(1), 3-10.

Barik, H.C. 1975. Simultaneous Interpretation: Qualitative and Linguistic Data. Language and Speech, 18, 272-294.

Barsky, R. F. 1996. The Interpreter as Intercultural Agent in Convention Refugee Hearings. The Translator, 2(1), 45-63.

Bekendtgфrelse (Regulation) No. 810, 12 September 1994.

Bell, A. 1984. Language style as audience design. Language in Society, 13, 145-204.

Bennett, J. 1981. The Role of Court Interpreting and the Work of Court Interpreters. In R. Roberts, ed., L'interpretation auprès des tribunaux, Ottawa: University of Ottawa Press, 11-18.

Berk-Seligson, S. 1988. The Impact of Politeness in Witness Testimony: The Influence of the Court Interpreter. Multilingua 7(4), 411-39. 
Berk-Seligson, S. 1990a. Bilingual Court Proceedings: The Role of the Court Interpreter. In J.N. Levi \& A.G. Walker, eds., Language in the Judicial Process, New York: Plenum Press, 155-201.

Berk-Seligson, S. 1990b. The Bilingual Courtroom. Chicago: University of Chicago Press.

Bisgaard, O. \& Martinsen, B.R. 2000. Tolkebistand i retssager. In Ugeskrift for Retsvaesen (the Danish weekly law reports), no. 45, 11 November 2000, 577-582.

Blum-Kulka, S. 1986. Shifts of cohesion and coherence in translation. In L. Venuti, ed., The Translation Studies Reader. London/New York: Routledge, 298-313.

Brennan, M. 1999. Signs of Injustice. The Translator, Special Issue, 5(2), 221-246.

Brown, G. \& Yule, G. 1983. Discourse Analysis. Cambridge: Cambridge University Press.

Brown, P. \& Levinson, S.C. 1987. Politeness. Some universals in language usage. Cambridge University Press.

Button, G. \& Lee, J.R.E. 1987. Transcript symbols. In G. Button \& J.R.E. Lee, eds., Talk and Social Interaction. Clevedon/Philadelphia: Multilingual Matters Ltd., 9-17.

Cambridge, J. 1999. Information Loss in Bilingual Medical Interviews through an Untrained Interpreter. The Translator, Special Issue, 5(2), 201219.

Carr, S.E., Roberts, R. P., Dufour, A. \& Steyn, D., eds. 1997. The Critical Link: Interpreters in the Community. Papers from the First International Conference on Interpreting in Legal, Health, and Social Service Settings, Geneva Park, Ontario, Canada. June 1-4, 1995. Amsterdam/Philadelphia: John Benjamins. 
CENT-meddelelse (Notice from the Aliens Division) No. 9 of 24 November 1994. Copenhagen: The National Commissioner of the Danish Police (Rigspolitichefen), E Dept.

Chesterman, A. 1997. Memes of translation: the spread of ideas in translation theory. Amsterdam/Philadelphia: John Benjamins.

Colin, J. \& Morris, R. 1996. Interpreters and the Legal Process. Winchester: Waterside Press.

Dam, H.V. 1995. Tekstkondensering $i$ foredragstolkning. Formel og sproglig analyse på grundlag af spansk-danske tolkninger. Unpublished $\mathrm{PhD}$ Thesis submitted to the Department of Spanish, The Aarhus School of Business.

Dam, H.V. 2001. The manipulation of data: Reflections on data descriptions based on a product-oriented $\mathrm{PhD}$ on interpreting. In D. Gile, H.V. Dam, F. Dubslaff, B. Martinsen \& A. Schjoldager, eds., Getting Started in Interpreting Research. Methodological reflections, personal accounts and advice for beginners. Amsterdam/Philadelphia: John Benjamins, 163-183.

Dam, H.V. \& Schjoldager, A. 1994. "Interpreting as Interaction" by Cecilia Wadensjö. A review article. Hermes, Journal of Linguistics, 12, 1994, $167-$ 182.

Danet, B. 1980. Language in the Legal Process. Law and Society Review, 14(3), 445-564.

Danet, B., Hoffman, K.B., Kermish, N.C., Rafn, J.H. \& Stayman, D.G. 1980. An ethnography of questioning in the courtroom. In R.W. Shuy \& A. Shnukal, eds., Language Use and the Uses of Language. Papers from the Fifth Colloquium on New Ways of Analyzing Variation in English. Washington D.C.: Georgetown University Press, 222-234.

de Jongh, E.M. 1991. Foreign Language Interpreters in the Courtroom: The Case for Linguistic and Cultural Proficiency. The Modern Language Journal, 75(iii), 285-295. 
de Jongh, E.M. 1992. An Introduction to Court Interpreting. Theory \& Practice. Lanharn, MD: University Press of America.

Dübeck, I. 1994. Introduktion til Dansk Ret. Nomos Verlagsgesellschaft, Baden-Baden.

Du Bois, J.W. 1991. Transcription design principles for spoken discourse research. Pragmatics, 1(1), 71-106.

Edwards, J.A. \& Lampert, M.D., eds. 1993. Talking Data: Transcription and Coding in Discourse Research. Hillsdale, NJ: Lawrence Erlbaum Associates.

Englund Dimitrova, B. 1997. Degree of Interpreter Responsibility in the Interaction Process in Community Interpreting. In S.E. Carr, R. Roberts, A. Dufour \& D. Steyn, eds., The Critical Link: Interpreters in the Community. Amsterdam/Philadelphia: John Benjamins, 147-164.

Erickson, B., Lind, E.A., Johnson, B.C. \& O'Barr, W.M. 1978. Speech Style and Impression Formation in a Court Setting: The Effects of "Powerful" and "Powerless" Speech. Journal of Experimental Psychology, $14,226-279$.

Fenton, S. 1997. The Role of the Interpreter in the Adversarial Courtroom. In S.E. Carr, R. Roberts, A. Dufour \& D. Steyn, eds., The Critical Link: Interpreters in the Community. Amsterdam/Philadelphia: John Benjamins, 29-34.

Forvaltningslov (Public Administration Act) No 571 of 19 December 1985, as amended by Section 2 of Act No. 347 of 6 June 1991 and the EC Judgments Convention No. 11006 of 14 June 1991.

Fowler, Y. 1997. The Courtroom Interpreter. Paragon and Intruder? In S.E. Carr, R. Roberts, A. Dufour \& D. Steyn, eds., The Critical Link: Interpreters in the Community. Amsterdam/Philadelphia: John Benjamins, 191-200. 
Gile, D. 1995. Interpretation Research: A New Impetus? Hermes: Journal of Linguistics, 14, 15-29.

Gile, D. 2000. Issues in Interdisciplinary Research into Conference Interpreting. In B. Englund Dimitrova \& K. Hylstam, eds., Language Processing and Simultaneous Interpreting. Amsterdam/Philadelphia: John Benjamins, 89-106.

Gile, D., H.V. Dam, F. Dubslaff, B. Martinsen \& A. Schjoldager, eds. 2001. Getting Started in Interpreting Research. Methodological reflections, personal accounts and advice for beginners. Amsterdam/Philadelphia: John Benjamins.

Goffman, E. 1981. Forms of Talk. Basil Blackwell.

Gonzales, R.D., Vasquez, V.F. \& Mikkelson, H. 1991. Fundamentals of Court Interpretation. Theory, Policy, and Practice. Durham, North Carolina: Carolina Academic Press.

Green, G.M. 1996. Pragmatics and Natural Language Understanding. Mahwah, NJ: Lawrence Erlbaum Associates.

Grice, H.P. 1971. Meaning. In D.D. Steinberg \& L.A. Jakobovits, eds., Semantics. An interdisciplinary reader in philosophy, linguistics and psychology. Cambridge University Press, 53-59.

Grice, H.P. 1975. Logic and Conversation. In P. Cole and J.L. Morgan, eds., Syntax and Semantics 3: Speech Acts. New York: Academic Press, 41-58.

Grice, H.P. 1978. Further Notes on Logic and Conversation. In P. Cole, ed., Syntax and Semantics 9: Pragmatics. New York: Academic Press, 113127.

Grice, P. 1981. Presupposition and Conversational Implicature. In P. Cole, ed., Radical Pragmatics. New York: Academic Press, 183-198.

Grice, P. 1989. Studies in the Way of Words. Harvard University Press. 
Hale, S. 1996. Pragmatic considerations in court interpreting. Australian Review of Applied Linguistics, 19(1), 61-72.

Hale, S. 1997a. The Interpreter on Trial. Pragmatics in Court Interpreting. In S.E. Carr, R. Roberts, A. Dufour \& D. Steyn, eds., The Critical Link: Interpreters in the Community. Amsterdam and Philadelphia: John Benjamins, 201-211.

Hale, S. 1997b. The Treatment of Register Variation in Court Interpreting. The Translator 3(1), 39-54.

Hale, S. 1999. Interpreters' treatment of discourse markers in courtroom questions. Forensic Linguistics, 6(1), 57-82.

Hale, S. 2001. How are Courtroom Questions Interpreted? An Analysis of Spanish Interpreters' Practices. In I. Mason, ed., Triadic Exchanges. Studies in Dialogue Interpreting. Manchester: St. Jerome, pp. 21-50.

Halliday, M.A.K. \& Hasan, R. 1976. Cohesion in English. Longman.

Harris, B. 1981. Observations on a Cause Célèbre: Court Interpreting at the Lischka Trial. In R. Roberts, ed., L'interpretation auprès des tribunaux, Ottawa: University of Ottawa Press, 189-201.

Harris, B. \& Sherwood, B. 1978. Translating as an Innate Skill. In D. Gerver \& H.W. Sinaico, eds., Language Interpretation and Communication. New York/London: Plenum Press, 155-170.

Hatim, B. \& Mason, I. 1990. Discourse and the Translator. London/New York: Longman.

Heritage, J. \& Atkinson, M. 1984. Introduction. In M. Atkinson \& J. Heritage, eds., Structures of Social Action. Studies in Conversation Analysis. Cambridge University Press, 1-15.

Historier fra en politistation, TV2, 2000. 
Instruks for Tolke (Instructions for Interpreters), November 1994. Copenhagen: The National Commissioner of the Danish Police (Rigspolitichefen), E Dept.

Jacobsen, B. 1998. Court interpreting in Denmark - the role of court interpreters in Danish courtrooms. In Proceedings from CIATI Translation, Interpretation and Culture in the Age of Globalization, Sao Paulo - Brasil, 11-14 May 1998, 137-143.

Jacobsen, B. 1999. Court Interpreting in Denmark - A Critical Perspective. In Proceedings. Fourth International Forum and First European Congress on Court Interpreting and Legal Translation "Language is a Human Right”, Graz, Austria, 6-8 November 1998, 56-63.

Jacobsen, B. 2000. Additions in court interpreting. In Proceedings from the First Forli Conference on Interpreting Studies, Interpreting in the $21^{\text {st }}$ Century, Challenges and Opportunities, Forli, Italy, 9-11 November 2000. In press.

Jacobsen, B. 2001. Pragmatics in court interpreting: Additions. In Proceedings. Critical Link 3: Interpreting in the Community: the Complexity of the Profession, Montreal, Quebec, Canada, 22-26 May 2001. In press.

Jacobsen, B. 2002a. Conversational implicature and court interpreting. Paper delivered at EU High Level Scientific Conference series: "Textology and Translation”, Prague, Czech Republic, 14-16 March 2002.

Jacobsen, B. 2002b. Court interpreting and pragmatic meaning. Paper delivered at Sixth International Forum on Legal Translation and Court Interpreting "Legal Translators and Court Interpreters: Rights, Duties and Needs”, Paris, France, 12-14 June 2002.

Jansen, P. 1995. The Role of the Interpreter in Dutch Courtroom Interaction: the Impact of the Situation on Translational Norms. In P. Jansen, ed., Selected Papers of the CERA Research Seminars in Translation Studies 1992-1993. Katholieke Universiteit Leuven, 133-155. 
Kadric, M. 2000. Interpreting in the Austrian Courtroom. In R.P. Roberts, S.E. Carr, D. Abraham \& A. Dufour, eds., Critical Link 2: Interpreters in the Community, Vancouver, BC, Canada, 19-23 May 1998, 153-164.

Katschinka, 1. \& Springer, Ch. 1999. Proceedings. Fourth International Forum and First European Congress on Court Interpreting and Legal Translation, "Language is a Human Right", Graz, Austria, 6-8 November 1998.

Keith, H. 1984. Liaison Interpreting - an Exercise in Linguistic Interaction. In W. Wills \& G. Thome, eds., Die Theorie des Übersetzens und ihr Aufschlusswert für die Übersetzungs- und Dolmetschdidaktik, Tubingen: Gunter Narr Verlag, 308-317.

Kelly, A. M. 2000. Cultural Parameters for Interpreters in the Courtroom. In R.P. Roberts, S.E. Carr, D. Abraham \& A. Dufour, eds., Critical Link 2: Interpreters in the Community, Vancouver, BC, Canada, 19-23 May 1998, 131-148.

Knapp-Potthoff, A. \& Knapp, K. 1987. The man (or woman) in the middle: Discoursal aspects of non-professional interpreting. In K. Knapp, W. Enninger \& A. Knapp-Potthoff, eds., Analyzing Intercultural Communication. Mouton de Gruyter, pp. 181-211.

Kruglov, A. 1999. Police Interpreting: Politeness and Sociocultural Context. The Translator, Special Issue, 5(2), 285-302.

Kundgфrelse (Proclamation) I No. 11, 12 January 1994.

Lang, R. 1976. Interpreters in Local Courts in Papua New Guinea. In W.M. O'Barr \& J.F. O'Barr, eds., Language and Politics. The Hague: Mouton, 327-365.

Lang, R. 1978. Behavioral Aspects of Liaison Interpreters in Papua New Guinea: Some Preliminary Observations. In D. Gerver \& H.W. Sinaico, eds., Language Interpretation and Communication. New York/London: Plenum, 231-244. 
Leech, G.N. 1985. Principles of Pragmatics. London/New York: Longman.

Leech, G. \& Svartvik, J. 1994. A Communicative Grammar of English. London/New York: Longman.

Levi, J.N. \& Walker, A.G. 1990. Language in the Judicial Process. New York/London: Plenum Press.

Levinson, S.C. 1983. Pragmatics. Cambridge: Cambridge University Press.

Lind, E.A., Erickson, B.E., Conley, J. \& O'Barr, W.M. 1978. Social Attributions and Conversation Style in Trial Testimony. Journal of Personality and Social Psychology, 36(12), 1558-1567.

Lovbekendtgфrelse (Consolidation Act) No. 181, 25 March 1988, as amended by Section 15 of Act No. 936 of 27 December 1991, Section 10 of Act No. 377 of 22 May 1996, Section 16 of Act No. 386 of 22 May 1996, and Section 4 of Act No. 227 of 21 April 1999.

Luchjenbroers, J. 1997. 'In Your Own Words ...': Questions and answers in a Supreme Court trial. In Journal of Pragmatics, 27, 477-503.

Madsen, K. L. 1997. Tolkens rolle i retssalen - med fokus på straffesager Unpublished MA Thesis submitted to the Department of English, The Aarhus School of Business.

Martinsen, B. 2000. Public service interpreting: Challenges and how to meet them. In Proceedings from the First Forli Conference on Interpreting Studies, Interpreting in the $21^{\text {st }}$ Century, Challenges and Opportunities, Forli, Italy, 9-11 November 2000. In press.

Mason, I., ed., 1999a. Dialogue Interpreting. The Translator, Special Issue, $5(2)$.

Mason, I. 1999b. Introduction, The Translator, Special Issue, 5(2), 147160. 
Mason, I. 2000a. Audience Design in Translating. The Translator, 6(1), 122.

Mason, I. 2000b. Models and Methods in Dialogue Interpreting Research. In M. Olohan, ed., Intercultural Faultlines. Research Models in Translation Studies I. Textual and Cognitive Aspects. Manchester: St. Jerome Publishing.

Mason, I., ed., 2001. Triadic Exchanges. Studies in Dialogue Interpreting. Manchester: St. Jerome Publishing.

Mason, I. \& Stewart, M. 2001. Interactional Pragmatics, Face and the Dialogue Interpreter. In I. Mason, ed., Triadic Exchanges. Studies in Dialogue Interpreting. Manchester: St. Jerome, pp. 51-70.

Mikkelson, H. 1998. Towards a redefinition of the role of the court interpreter. Interpreting, 3(1), 21-45.

Mikkelson, H. 2000. Introduction to Court Interpreting. Manchester: St. Jerome Publishing.

Morris, R. 1989a. The Impact of Court Interpretation on Legal Proceedings. Unpublished MA Thesis submitted to the Hebrew University of Jerusalem.

Morris, R. 1989b. Court Interpretation: the Trial of Ivan John Demjanjuk. A Case Study. The Interpreters' Newsletter 2, 27-37.

Morris, R. 1993a. Images of the Interpreter: A Study of LanguageSwitching in the Legal Process. Unpublished PhD Thesis submitted to the Department of Law, Lancaster University.

Morris, R. 1993b. The Interlingual Interpreter - Cypher or Intelligent Participant? International Journal for the Semiotics of Law, VI(18), 271291.

Morris, R. 1995. The Moral Dilemma of Court Interpreting. The Translator, 1(1), 25-46. 
Morris, R. 1999. The Face of Justice: Historical Aspects of Court Interpreting. Interpreting, 4(1), 97-123.

Myers, G. 1999. Interaction in writing: principles and problems. In C.N. Candlin \& K. Hyland, eds., Writing: Texts, Processes and Practices, 40-61. London/New York: Longman.

Nida, E.A. 1964. Towards a Science of Translating with Special Reference to Principles and Procedures Involved in Bible Translating. Leiden: E.J. Brill.

O'Barr, W.M. 1982. Linguistic Evidence. Language, Power and Strategy in the Courtroom. New York: Academic Press.

Ochs, E. 1979. Transcription as Theory. In E. Ochs \& B.B. Schieffelin, eds., Developmental Pragmatics. New York: Academic Press, 43-72.

O'Connell, D.C. \& Kowal, S. 1990. Some sources of error in the transcription of real time in spoken discourse. The Georgetown Journal of Languages \& Linguistics, 1(4), 453-466.

O'Connell, D.C. \& Kowal, S. 1994. Some Current Transcription Systems for Spoken Discourse: A Critical Analysis. Pragmatics 4(1), 81-107.

O'Connell, D.C. \& Kowal, S. 1995. Transcription Systems for Spoken Discourse. In J. Verschueren, J.O. Östman \& J. Blommaert, eds., Handbook of Pragmatics, Manual. Amsterdam/Philadelphia: John Benjamins, 646-656.

O'Connell, D.C. \& Kowal, S. 1999. Transcription and the Issue of Standardization. Journal of Psycholinguistic Research, 28(2), 103-120.

Pöchhacker, F. 1995a. "Those Who Do...”: A Profile of Research(ers) in Interpreting. Target, Special Issue, 7(1), 47-64.

Pöchhacker, F. 1995b. Writings and Research on Interpreting: A Bibliographical Analysis. The Interpreter's Newsletter, 6, 17-31. 
Pöchhacker, F. 1999. 'Getting Organized': The Evolution of Community Interpreting. Interpreting 4(1), 125-140.

Pöchhacker, F. \& Kadric, M. 1999. The Hospital Cleaner as Healthcare Interpreter: A Case Study. The Translator, Special Issue, 5(2), 161-178.

Pöchhacker, F. \& Shlesinger, M. 2002. The Interpreting Studies Reader. London and New York: Routledge.

Politiken, 9 April 1999. Thulefanger svakkede sin sag.

Prince, E. 1981. Toward a Taxonomy of Given - New Information. In P. Cole, ed., Radical Pragmatics. New York: Academic Press, 223-255.

Pym, A. 1999. "Nicole Slapped Michelle": Interpreters and Theories of Interpreting at the O.J. Simpson Trial. The Translator, Special Issue, 5(2), 265-283.

Quirk, R., Greenbaum, S., Leech, G. \& Svartvik, J. 1979. A Grammar of Contemporary English. London: Longman.

Reddy, M. 1979. The Conduit Metaphor: A Case of Frame Conflict in our Language about Language. In A. Ortony, ed., Metaphor and Thought. Cambridge: Cambridge University Press, 284-324.

Retsplejeloven (The Danish Administration of Justice Act). Most recently amended version is that of 14 September 2001.

Roberts, R.P., ed. 1981. L'interpretation auprès des tribunaux. Ottawa: University of Ottawa Press.

Roberts, R.P. 1997. Community Interpreting Today and Tomorrow. In S.E. Carr, R. Roberts, A. Dufour \& D. Steyn, eds., The Critical Link: Interpreters in the Community. Amsterdam/Philadelphia: John Benjamins, 7-26. 
Roberts, R.P., Carr, S.E., Abraham, D. \& Dufour, A. eds. 2000. The Critical Link 2: Interpreters in the Community. Selected Papers from The Second International Conference on Interpreting in Legal, Health and Social Service Settings, Vancouver, BC, Canada, 19-23 May 1998. Amsterdam/Philadelphia: John Benjamins.

Roy, C.B. 1993. A sociolinguistic analysis of the interpreter's role in simultaneous talk in interpreted interaction. Multilingua, 12(4), 341-363.

Roy, C.B. 1996. An interactional sociolinguistic analysis of turn-taking in an interpreted event. Interpreting, 1(1), 39-67.

Roy, C.B. 2000. Interpreting as a Discourse Process. New York: Oxford University Press.

Sadock, J.M. 1978. On Testing for Conversational Implicature. In P. Cole, ed., Syntax and Semantics 9: Pragmatics. New York: Academic Press, 113127.

Schiffrin, D. 1988. Discourse markers. Cambridge: Cambridge University Press.

Schiffrin, D. 1994. Approaches to Discourse. Oxford: Blackwell Publishers.

Schjoldager, A.G. 1996. Simultaneous Interpreting: Empirical Investigation into Target-text/Source-text Relations. Unpublished $\mathrm{PhD}$ Thesis submitted to the Department of English, The Aarhus School of Business.

Schjoldager, A. 2001. Reflective summary of a dissertation on simultaneous interpreting. In D. Gile, H.V. Dam, F. Dubslaff, B. Martinsen \& A. Schjoldager, eds., Getting Started in Interpreting Research. Methodological reflections, personal accounts and advice for beginners. Amsterdam/Philadelphia: John Benjamins, 221-232. 
Schweda Nicholson, N. \& Martinsen, B. 1997. Court Interpretation in Denmark. In S.E. Carr, R. Roberts, A. Dufour \& D. Steyn, eds., The Critical Link: Interpreters in the Community. Amsterdam/Philadelphia: John Benjamins, 259-270.

Setton, R. 2002. Meaning assembly in simultaneous interpretation. In F. Pöchhacker \& M. Shlesinger, eds., The Interpreting Studies Reader. London and New York: Routledge, 178-202.

Shlesinger, M. 1989. Extending the Theory of Translation to Interpretation. Norms as a Case in Point. Target, 1(1), 111-115.

Shlesinger, M. 1991. Interpreter Latitude vs. Due Process: Simultaneous and Consecutive Interpretation in Multilingual Trials. In S. TikkonenCondit (ed.), Empirical Research in Translation and Intercultural Studies. Tübingen: Gunter Narr, 147-155.

Sperber, D. \& Wilson, D. 1981. Irony and the use-mention distinction. In P. Cole, ed., Radical Pragmatics. New York: Academic Press, 295-318.

Sperber, D. \& Wilson, D. 1986. Relevance. Communication and Cognition. Oxford: Basil Blackwell.

Straffeloven (The Danish Penal Code). Most recently amended version is that of 14 September 2001.

Stenström, A.-B. 1994. An Introduction to Spoken Interaction. London/New York: Longman.

Stygall, G. 1994. Trial Language. Differential Discourse Processing and Discursive Formation. Amsterdam/Philadelphia: John Benjamins.

Sørensen, K. 1991. English and Danish Contrasted. A Guide for Translators. Munksgaards Sprogserie.

Tebble, H. 1999. The Tenor of Consultant Physicians: Implications for Medical Interpreting. The Translator, Special Issue, 5(2), 179-200. 
The 1950 European Convention on Human Rights.

Thomas, J. 1995. Meaning in Interaction: An Introduction to Pragmatics. London/New York: Longman.

Vestre Landsrets dom (Judgement of the High Court), Western Division), 5 September 1996

Vestre Landsrets dom (Judgement of the High Court, Western Division), 26 August 1997.

Wadensjö, C. 1992. Interpreting as Interaction: On Dialogue Interpreting in Immigration Hearings and Medical Encounters. Dissertation. Department of Communication Studies, University of Linköping.

Wadensjö, C. 1995. Dialogue Interpreting and the Distribution of Responsibility. Hermes: Journal of Linguistics, 14, 111-129.

Wadensjö, C. 1997. Recycled Information as a Questioning Strategy: Pitfalls in Interpreter-Mediated Talk. In S.E. Carr, R. Roberts, A. Dufour \& D. Steyn, eds., The Critical Link: Interpreters in the Community. Amsterdam/Philadelphia: Benjamins, 35-52.

Wadensjö, C. 1998. Interpreting as Interaction. Longman.

Wales, K. 1989. A Dictionary of Stylistics. London/New York: Longman.

Wande, E. 1994. Translating Machine or Creator? On Finnish-Swedish Community Interpreting in Sweden. Hermes: Journal of Linguistics, 12, 109-126.

Wilson, D. \& Sperber, D. 1981. On Grice's Theory of Conversation. In P. Werth, ed., Conversation and Discourse. London: Croom Helm, 155-177.

Yule, G. 1996. Pragmatics. Oxford University Press. 
